\title{
PROPOSTA METODOLÓGICA PARA IDENTIFICAÇÃO, CLASSIFICAÇÃO E MINIMIZAÇÃO DAS INCERTEZAS EM ESTUDOS DE RISCOS
}

\author{
Tese apresentada à Escola \\ Politécnica da Universidade de \\ São Paulo para obtenção do \\ Título de Doutor em Engenharia
}




\title{
WAGNER JOSÉ GOMES PEREIRA
}

\section{PROPOSTA METODOLÓGICA PARA IDENTIFICAÇÃO, CLASSIFICAÇÃO E MINIMIZAÇÃO DAS INCERTEZAS EM ESTUDOS DE RISCOS}

\author{
Tese apresentada à Escola Politécnica \\ da Universidade de São Paulo para \\ obtenção do Título de Doutor em \\ Engenharia \\ Área de Concentração: \\ Engenharia Naval \\ Orientador: \\ Prof.Titular \\ Hernani L. Brinati
}


Este exemplar foi revisado e alterado em relação à versão original, sob responsabilidade única do autor e com a anuência de seu orientador.

São Paulo, de setembro de 2010.

Assinatura do autor

Assinatura do orientador

FICHA CATALOGRÁFICA

Pereira, Wagner José Gomes

Proposta metodológica para identificação, classificação e minimização das incertezas em estudos de riscos / W.J.G.

Pereira. -- ed.rev. -- São Paulo, 2010.

$169 \mathrm{p}$.

Tese (Doutorado) - Escola Politécnica da Universidade de São Paulo. Departamento de Engenharia Naval e Oceânica.

1. Análise de risco 2. Incertezas 3. Proposta metodológica I. Universidade de São Paulo. Escola Politécnica. Departamento de Engenharia Naval e Oceânica II. t. 


\section{AGRADECIMENTOS}

Ao meu orientador Professor Hernani pelas diretrizes seguras e permanente incentivo.

A funcionária Lania da Pós Graduação do departamento de Engenharia naval da USP pelo apoio inestimável.

A todos que colaboraram direta ou indiretamente, na execução deste trabalho. 


\section{RESUMO}

A identificação das incertezas envolvidas no processo de estudo, possibilita que a tomada de decisão seja realizada de forma clara e científica - Abrahamsson (2001). Será feito um estudo crítico das diversas etapas envolvidas nos estudos de risco e confiabilidade, buscando identificar as incertezas envolvidas, descobrir a sua natureza e estabelecer formas adequadas de trata-las. Vários aspectos de incertezas serão discutidos. Qual o papel das incertezas no processo de tomada de decisão? Que etapas do processo de análise de risco produzirão incertezas? Quais os tipos de incertezas existentes? Como os órgãos de normalização estão tratando o problema de incerteza? Por final será apresentada uma proposta metodológica que auxilie na minimização das incertezas e que facilite, no futuro próximo possível a criação de normas que melhorem o grau de exatidão nos estudos de riscos e de alguma forma os Estudos relacionados com Análise de Risco possam melhorar em qualidade.

Palavras-chave: Análise de risco. 


\begin{abstract}
S
The identification of the uncertainties involved in the study, enables the decisionmaking is carried out in a clear and scientific - Abrahamsson (2001). There will be a critical study of the various steps involved in studies of risk and reliability, identifying the uncertainties involved, discover the nature and stablish appropriate ways to treat them. Several aspects of uncertainties will be discussed. What is the role of uncertainties in the process of decision making? What stages of risk analysis will produce uncertainties? What types of uncertainty? As the standardization bodies are addressing the problem of uncertainty? By the end will be presented a methodology to assist in reducing the uncertainties and to facilitate in the near future it possible to create standards to improve the degree of accuracy in studies of risks and somehow the studies related to Risk Analysis to improve quality.
\end{abstract}

Keywords: Risk analysis. 


\section{LISTA DE FIGURAS}

Fig. 1.1 Discrepâncias entre curvas de isso risco

Pág. 04

Diferentes abordagens utilizada pelos 7 grupos extraída de

Fig. 1.2 lauridsen et al. (2001 b)

Pág. 05

Variação dos resultados da avaliação de consequências das

Fig. 1.3 diferentes canários. Retirada de Lauridsen et al. (2001 b) Pág. 07

Discrepância no risco social calculado por diferentes estudiosos (baseado em dados fictícios de população). Retirado de lauridsen et

Fig. 1.4 al. (2001 a)

Seis níveis de complexidade na caracterização do risco, Paté

Fig.1.5 Cornell 1996

Esquema das fontes de incertezas e sua propagação Abrahamsson

Fig. $1.6 \quad 2000$

Representação de em intervalo de curvas probabilísticas para

Fig. 3.1 $\min =2, \operatorname{Max}=3$ e média=2,5 (adaptada de Tucker e Ferson )

Relação entre a freguência do julgamento e o número atual de

Fig. 5.1 mortes ( extraída de slovic, Fischoff e Lichtensteis, 1892)

Características das fontes de perigos e estratégias de gerenciamento

Fig. $6.1 \quad$ ( Rasmussen 1997 )

Pág. 08

Pág. 14

Pág. 16

Pág. 41

Pág 57

Fig. 7.1 Propagação pala incerteza pelo modelo. IAEA (1989)

Pág. 71

Pág.81

Fig. 7.2 Fluxograma do algoritmo (adaptado de GROMKOVIC,2001) Pág.84

Fig. 7.3 Exemplo de operações aritméticas

Curvas probabilísticas para uma distribuição normal de média

Pág.87

variando no intervalo $(0.5 ; 06)$ e desvio padrão no intervalo

Fig. $7.4 \quad(0.05 ; 0.1)$, (Adaptada de Tucker e Ferson )

Curvas probabilísticas para uma distribuição; caso A - média mais próxima do mínimo, $\mathrm{B}$ media no meio do intervalo,C - mais

Fig. 7.5 próxima do máximo ( Adaptada de Tucker e Ferson)

Curvas probabilísticas para uma distribuição onde se conhece a mediana e os valores máximos e mínimos, no caso do exemplo A a mediana esta mais próxima do mínimo, em $\mathrm{B}$ esta no meio do intervalo e em $\mathrm{C}$ esta mais próxima do máximo e em $\mathrm{D}$ temos a

Fig 7.6 representação em percents ( Adaptada de Tucker e Ferson)

Curvas probabilísticas para uma distribuição onde se conhece a moda e s valores máximos e mínimos, no caso do exemplo A a moda esta mais próxima do mínimo, em $\mathrm{B}$ está no meio do intervalo e em $\mathrm{C}$ esta mais próxima do máximo ( Adaptada de

Fig 7.7 Tucker e Ferson )

Pag. 88

Pág. 89

Curvas probabilísticas para o intervalo de confiança de 95\% Kolmorogov-smirnov, para modelos empíricos de distribuição baseado nos valores $(0.2,0.5,0.6,0.7,0.75, \mathrm{e} 0.8)$ ( Adaptada de

Fig. 7.8 Tucker e Ferson )

Pág.92

Fig. 7.9 Curvas probabilísticas A,B ,C e D Pág.92

Fig. 7.10 Soma de curvas probabilísticas ( Adaptada de Tucker e Ferson ) Pag.93 


\section{LISTA DE TABELAS}

Freguências de eventos de um mesmo cenário (eventos/ano).

Tab.1.1 Extraída de lauridsen et al.(2001 b)

Pag. 06

Sub-Classes da incerteza do modelo UF3 (Adaptado de

Tab. 4.1 COWI,1996a)

Pag. 61

Sub-Classes da incerteza do modelo UF3, análise completa

Tab. 4.2 (Adaptado de COWI,1996a)

Pag. 63

Comparação entre metodos de montecarlo e curvas probalisticas

Tab. 7.1 (Adaptada de Tucker e Ferson )

Tempo relatico de execução das diversas metodologias

Tab. 7.2 propostas( adaptado de ferson et al 1999 e abhraassom, 2001 )

Pag. 114

Tab. 8.1 Tabela de correlação

Condições meteorologicas contempladas ( retirado do commitee for

Tab. 10.1 prevention of disasters, 1999)

Pag. 119

Pag. 139

Tab.10.3 Coeficientes de dispersao extraidos de CCPS (2000)

Pag. 161

Tab. 10.4 Valores da constante na formula PROBIT

Pag. 163

Tab. 10.5 Expecificação dos parametros incertos

Pag. 163

Tab.10.6 Probabilidade para as condições meteorológicas ( hipóteses )

Pag. 165

Tab. 10.7 Probabilidade para cada uma das condições de vento ( Hipoteses )

Pag. 167

Tab. 10.8 Concentração para a abordagem holandesa

Pag. 167

Tab. 10.9 Os intervalos adotados para as variaveis incertas

Pag. 168

Tab.10.10 Concentração resultante na abordagem intervalar

Pag. 168

Tab 10.11 Variaveis fuzzy

Pag. 169

Pag. 169

Representação das variaveis incetteza como distrivuição de

Tab 10.12 probabilidades

Pag. 171

Tab10.13 Variaveis de incertezas e suas distribuições

Pag. 173 
São apresentadas as três variaveis de entrada e uma hipotética exposição a uma contaminante; Concentration - concentração, Intake rate - taxa de ingestão , Body weight - massa corporal e exposure - nível de exposição de acordo com as normas

Fig. 7.11 internacionais (Adaptada de Tucker e Ferson )

Pág.94

Fig. 8.1 Exemplos de diagramas de dispersão

Pág.94

Fig. 8.2 Equação de regressão linear

Pág.111

Fig. 8.3 Diagrama de dispersão

Pág.111

Fig. 10.1 Representação gráfica do exemplo.

Pág. 130

Fig. 10.2 ( M2)

Pág. 138

Fig. 10.3 Concentração media para diferentes condições meteorológicas

Pág.139

Fig. 10.4 Resultados obtidos para diferentes condições meteorológicas

Pág. 140

Fig. 10.5 Curvas probabilísticas para a velocidade do vento na condição D

Pág.141

Fig. 10.6 Concentração para diversas condições meteorológicas

Pág.142

Fig. 10.7 Concentração media para as condições meteorológicas D

Pág.143

Fig. 10.8 Risco individual

Pág.144

Fig 10.9 Ranqueamento usando Spearman

Pág.145

Fig10.10 Ranqueamento usando coeficiente de regressão parcial

Pág. 145

Fig10.11 Ranqueamento usando coeficiente de correlação

Pág. 146 


\section{CAPÍTULO 1}

\section{INTRODUÇÃO}

\subsection{Identificação do problema}

Em um estudo de Abrahamssom (Abrahamssom, 2001) publicado no verão de 2002 onde foram ouvidos 20 analistas de riscos. $O$ fato mais intrigante foi a diversidade significativa nas abordagens, métodos e hipóteses aplicadas nas análises. Um dos problemas que surge, nas práticas de tomada de decisão, onde as situações analisadas são baseadas em diferentes métodos, modelos e hipóteses básicas, é a dificuldade de compará-las. A falta de regras bem definidas na análise, torna difícil verificar e reproduzir o experimento, por alguém que não participou do trabalho, o que dificulta a revisão e avaliação do mesmo.

O problema do conhecimento e do tratamento da incerteza é o elemento central para a qualidade e aplicação prática da Análise de Risco ï AR. Em estudo de risco, uma inestimável gama de incertezas é introduzida ao longo do processo e o impacto destas incertezas precisa ser conhecido.

Nos últimos anos, tem havido uma crescente aceitação dos estudos de riscos. Estes estudos são realizados em diversas áreas da engenharia, nos mais variados projetos. Pode-se dividir os objetivos dos estudos de riscos em: riscos à integridade humana, riscos econômicos ou riscos ambientais. Diferentes estudiosos podem enfocar um mesmo problema e obter diferentes resultados. Percebe-se que, apesar da crescente necessidade de estudos de riscos, pouco se abordou, até agora, sobre o grau de incerteza envolvido nestes estudos. A diversidade de resultados, em geral, ocorre devido às diferentes metodologias que são adotadas ou ainda do grau de precisão exigido. A outra questão que vem ganhando em importância é a dificuldade de caracterizar e medir as incertezas envolvidas em um estudo de risco. Há bem pouco tempo apenas alguns estudiosos se preocupavam em definir, classificar e estudar as incertezas envolvidas em seu estudo de risco. E, muito menos, havia a preocupação em verificar como se dava a propagação de incerteza ao longo do estudo. Outro ponto que deve ser ressaltado é a necessidade de classificar de forma ponderada as incertezas e, assim, poder diminuir potenciais fontes que contribuem, de forma mais significativa, para a incerteza global.

Muitos estudos foram realizados nos últimos 20 anos avaliando o impacto das incertezas na Análise de Risco. Entre os anos de 1988 e 2001 o JOINT RESEARCH CENTER e o Riso National Laboratory coordenaram um projeto que serviu como pilar para uma série de 
questionamentos e estudos posteriores. Basicamente o projeto consistia em tentar, de alguma forma, identificar e dimensionar as incertezas envolvidas em análise de risco. Foi estabelecido um cenário real que deveria ser analisado por um determinado número de especialistas. As fases a serem cumpridas pelos especialistas eram: uma fase documental, três fases de trabalho e uma fase de avaliação e disseminação. As fases de trabalho compreendem uma de análise qualitativa, uma de análise quantitativa e outra de estudos de casos. Durante a fase documental os especialistas visitavam a instalação a ser estudada, familiarizandoï se assim com a natureza da planta e com os processos relacionados a ela; muitas questões eram formuladas pelos especialistas em risco e respondidas pelos especialistas na planta.

Participaram da organização do projeto as seguintes instituições:

DET NORSKE VERITAS LIMITED. UK

INERIS. FR

HEALTH AND SAFETY EXECUTIVE UK

NCSR DEMOKRITOS Systems safety and Risk Assessment, GR

TNO, Dept of Industrial Safety. NL

UNIVERSITÁ DI BORGONHA, DICMA.IT

VTT Automation . FI

THE JOINT RESEARCH CENTER. ISPRA ${ }^{1}$

RISO NATIONAL LABORATORY. DK

Foi proposto a sete grupos, de diferentes países europeus, o estudo de um r̃sistema de estocagem e utilidades com Amôniaò A planta a ser estudada é parte de um largo complexo industrial que serve para a produção de fertilizantes a base de amônia. Por razões de simplicidade foi limitado o escopo do estudo somente às seções relacionadas à produção e estocagem de amônia. A planta possui tanto estocagem de baixa pressão com estocagem refrigerada. A amônia é acondicionada em tanques por um sistema de linhas de tubulação (ñpipelineô) que transfere ao setor de produção. A planta é dividida em cinco partes:

Estocagem criogênica de amônia

Terminal de carga e descarga para os navios

Terminal e linhas de alimentação (ñpipelineô)

Estocagem de amônia em baixa pressão

Carga e descarga para caminhões.

O objetivo deste estudo era determinar o estado da arte neste tipo de análise e estimar o grau de incerteza nos estudos de riscos. Durante a parte de avaliação documental os pesquisadores puderam visitar as instalações e fazer perguntas aos especialistas na planta.

1 Institute for Prospective Technological Studies (IPTS) é um dos sete institutos que compõem o European Commission's Joint Research Centre (JRC). 
Após a fase documental as questões mais controvertidas eram discutidas por e-mail, e a mesma informação era enviada a todos os grupos.

Com isso pode-se passar para a fase seguinte de análise qualitativa. Nesta fase cada grupo pôde utilizar a metodologia que julgasse mais eficiente para identificar os perigos e classificá-los de forma adequada para as fases seguintes. Percebe-se, logo de início, que cada grupo utilizou a metodologia que julgou mais adequada, e observou-se que houve discrepância não só nas metodologias usadas (Master Logic Diagram, HAZOP, SWIFT, HAZSCAN, HCA, etc) como também nos perigos julgados mais importantes e na própria classificação ponderada dos mesmos. Posteriormente, na Análise Quantitativa o estudo foi concentrado na avaliação do risco individual (definido como a probabilidade de fatalidade para uma pessoa, em um período de 24 horas, em uma específica posição nas localidades da planta, em caso de acidente na mesma). Outra preocupação, desta fase de análise quantitativa, consistia no cálculo do risco social expresso como rã freqüência que um dado número de fatalidades irá ocorrerò $A$ comparação dos resultados revelou significante variação.

As diferenças podem ser vistas na figura 1.1, que apresenta as curvas de iso-risco (linhas que unem os pontos com o mesmo grau de risco) individual de $10^{-5} \mathrm{ano}^{-1}$. A linha que delimita a menor área representa o menor resultado obtido, ou seja, uma posição menos conservadora, e a que delimita maior área o maior resultado obtido, ou seja uma posição mais conservadora. Portanto, há uma clara discrepância entre os valores obtidos, por grupos diferentes, apesar de ambos terem usado as mesmas informações. Fonte : Assessment of Uncertainties in Risk Analysis of Chemical Establishments Risø-R-1344(EN) 


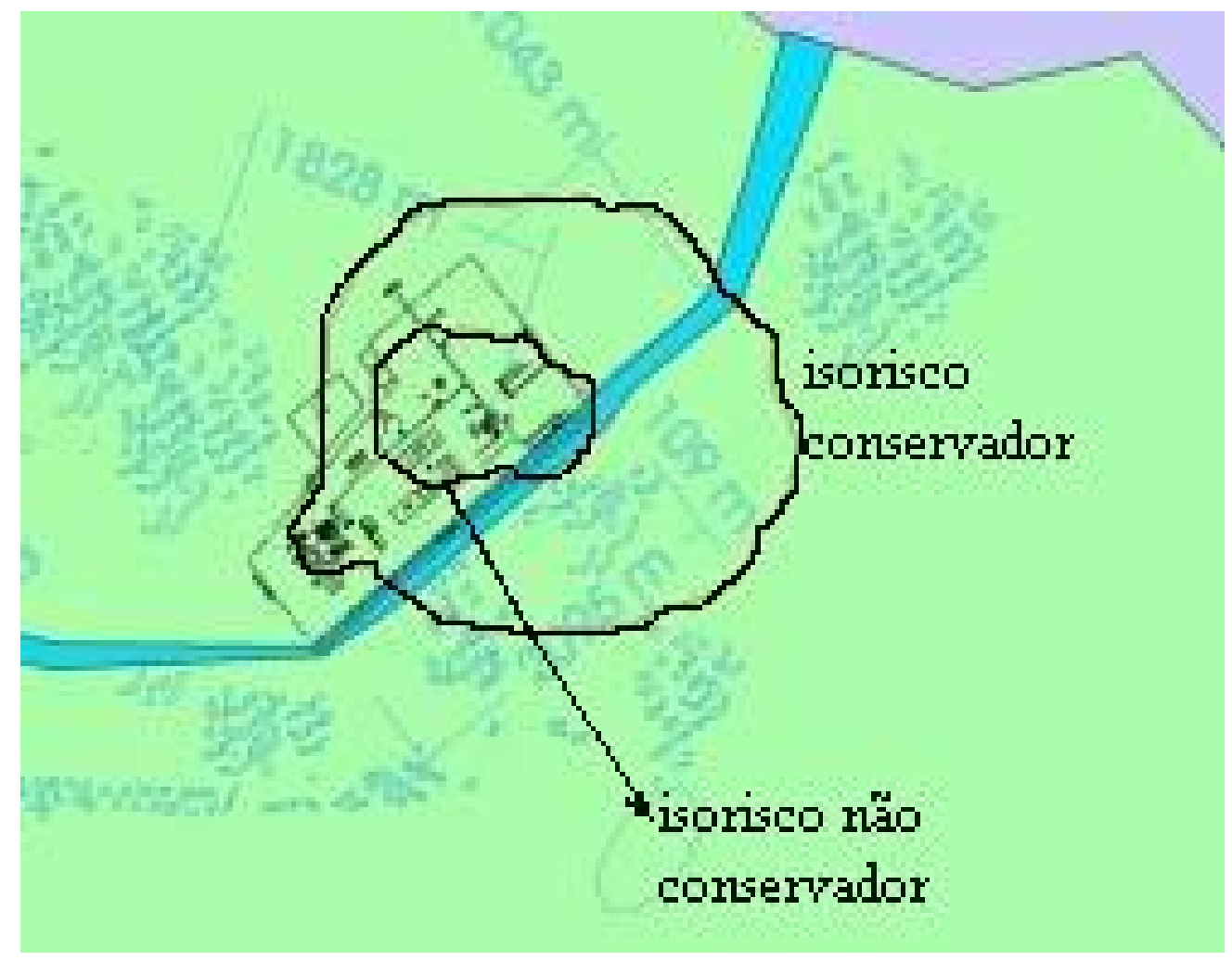

Figura 1.1 Discrepâncias entre curvas de isorisco

Para avaliação de freqüência de eventos perigosos, os métodos mais usados pelos diversos grupos foram estruturas lógicas como árvore de eventos e árvore de falhas. Além de divergência na interpretação do sistema que apresentou falha, observou-se também que a própria estrutura lógica da árvore de falhas apresentou diferenças para cada grupo. Quanto aos tipos de abordagens utilizadas, pode-se extrair pela figura abaixo, que a maior parte dos grupos optou pela abordagem probabilística, enquanto que o grupo 6 utilizou uma abordagem determinística. Na figura 1.2 é apresentado um esquema das diferentes abordagens utilizadas pelos grupos. 


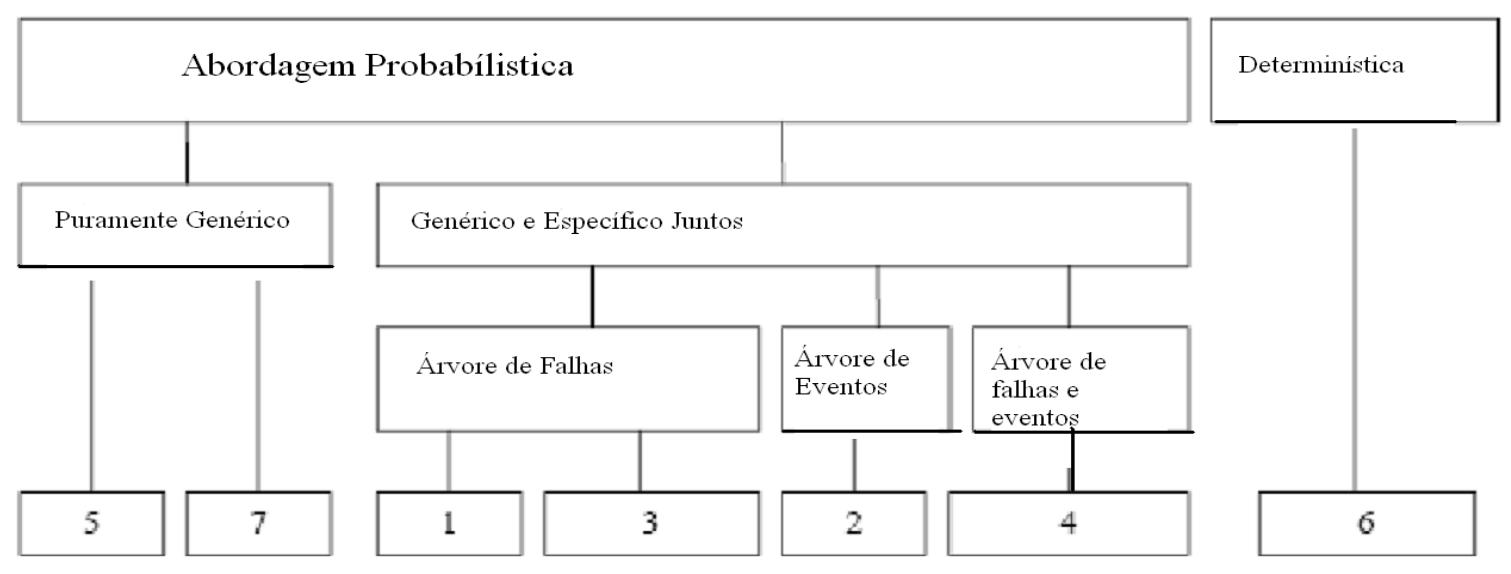

Figura 1.2 Diferentes abordagens utilizada pelos 7 grupos. Extraída de Lauridsen et al. (2001 b).

Eram sete equipes que analisaram 11 cenários. Dentre estes cenários pode-se destacar: Cenário 1-Vazamento de amônia de uma longa linha de 8 polegadas conectada a uma bomba contendo amônia pressurizada; Cenário 3ï ruptura ou desconexão entre um navio de transporte de amônia e o sistema de descarga refrigerado; Cenário 4- Ruptura no encaixe de uma bomba de 10 polegadas etc. Os resultados deste estudo mostram a variabilidade das estimativas de riscos entre os diversos grupos. Observou-se que existe um espalhamento não só dos resultados finais de risco individual e social, como também existe significativa variação entre as diversas estimativas de freqüência de eventos e de conseqüências utilizadas no decorrer do estudo. 
Tabela 1.1.Freqüências de eventos de um mesmo cenário (eventos/ano). Extraída de Lauridsen et al. (2001 b).

\begin{tabular}{|c|c|c|c|c|c|c|c|}
\hline $\begin{array}{l}\text { eve } \\
\text { ntos }\end{array}$ & gupo 1 & gupo 2 & gupo 3 & gupo 4 & gupo 5 & gruipo ? & variaçăo \\
\hline 1 & $9.010^{-7}$ & $1.010^{-6}$ & $1.410^{3}$ & $9.010^{-7}$ & $1.010^{-6}$ & $1.810^{-7}$ & $1.810^{-7}-1.410^{-5}$ \\
\hline 2 & $1.010^{-5}$ & $3.010^{-6}$ & $1.410^{-5}$ & $9.010^{-7}$ & $7.310^{-7}$ & $4.610^{-6}$ & $7.310^{-7}-1.410^{-5}$ \\
\hline 3 & $4.810^{-4}$ & $4.810^{-6}$ & $8.010^{-5}$ & $5.010^{-3}$ & $5.410^{-5}$ & $1.310^{-5}$ & $4.810^{-6}-8.010^{-3}$ \\
\hline 4 & $1.010^{-6}$ & 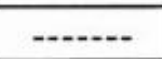 & $4.610^{-6}$ & $9.010^{-7}$ & $8.010^{-7}$ & $1.810^{-6}$ & $8.010^{-7}-4.610^{-6}$ \\
\hline 5 & $2.810^{-7}$ & $6.410^{-10}$ & $5.710^{-3}$ & --.-. & $2.310^{-6}$ & $4.910^{-6}$ & $6.410^{-10}-5.710^{-5}$ \\
\hline 6 & $5.010^{-7}$ & $1.010^{-\gamma}$ & $4.010^{-8}$ & -..... & $5.010^{-8}$ & $5.010^{-7}$ & $1.010^{-8}-5.010^{-7}$ \\
\hline 7 & $6.010^{-6}$ & $1.010^{-6}$ & $5.010^{-6}$ & $9.010^{-7}$ & $4.010^{-1}$ & $4.010^{-7}$ & $4.010^{-7}-6.010^{-6}$ \\
\hline 8 & $1.010^{-6}$ & $5.010^{-7}$ & $1.010^{-6}$ & $4.510^{-7}$ & $1.310^{-5}$ & $4.010^{-7}$ & $4.510^{-7}-1.310^{-5}$ \\
\hline 9 & $3.010^{-6}$ & $3.410^{-7}$ & $1.510^{-5}$ & $9.010^{-7}$ & $2.210^{-6}$ & $8.010^{-7}$ & $3.410^{-7}-1.510^{-5}$ \\
\hline 10 & $2.410^{-6}$ & $1.510^{-7}$ & $2.110^{-3}$ & $2.710^{6}$ & $6.010^{-6}$ & $5.010^{-7}$ & $1.510^{-7}-2.110^{-3}$ \\
\hline 11 & $5.510^{-9}$ & $1.510^{-9}$ & $1.210^{-7}$ & $1.210^{-7}$ & $4.710^{-6}$ & $1.410^{-8}$ & $1.510^{-9}-4.710^{-6}$ \\
\hline
\end{tabular}

A tabela 1.1 mostra que os desvios em alguns cenários são de diversas ordens de magnitude. $O$ espalhamento dos resultados, obviamente, interfere na estimativa do risco final (o Grupo 6, por exemplo, não apresenta estimativas de freqüências, já que trabalha com uma abordagem determinística). Maiores informações dos principais métodos de cálculo de freqüências usados pelos diferentes estudiosos podem ser obtidas em Lauridsen et al. (2001b).

A figura 1.3 apresenta os resultados das análises de conseqüências. Em cada coluna estão indicados os valores de distância máxima, mínima e média da curva de isorisco para a concentração de 6200 ppm (LC50) para os diversos grupos. Deve-se observar que o espalhamento dos valores é significativo 


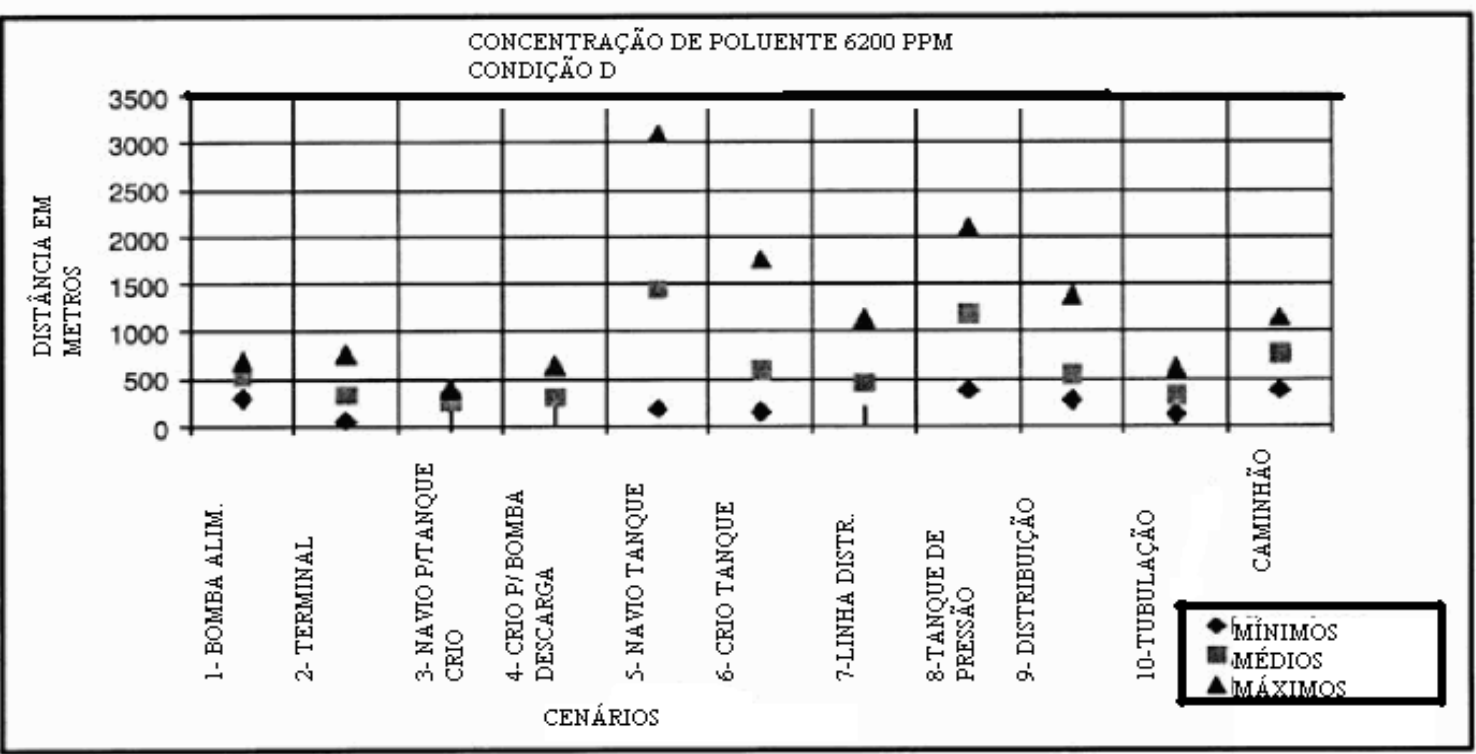

Figura 1.3. Variação dos resultados da avaliação de conseqüências dos diferentes cenários. Retirada de Lauridsen et al. (2001 b).

A Figura 1.4 mostra variação dos resultados da avaliação de conseqüências de diferentes cenários. Mínimo, Máximo e Média para concentração final de 6200 ppm (LC50). Ou seja, a comparação dos resultados (risco social, que será definido posteriormente na forma de curva do tipo F-N) esses resultados são baseados nos cenários identificados e julgados aceitáveis para serem incluídos na análise por diferentes estudiosos. De novo pode-se observar um considerável espalhamento. 


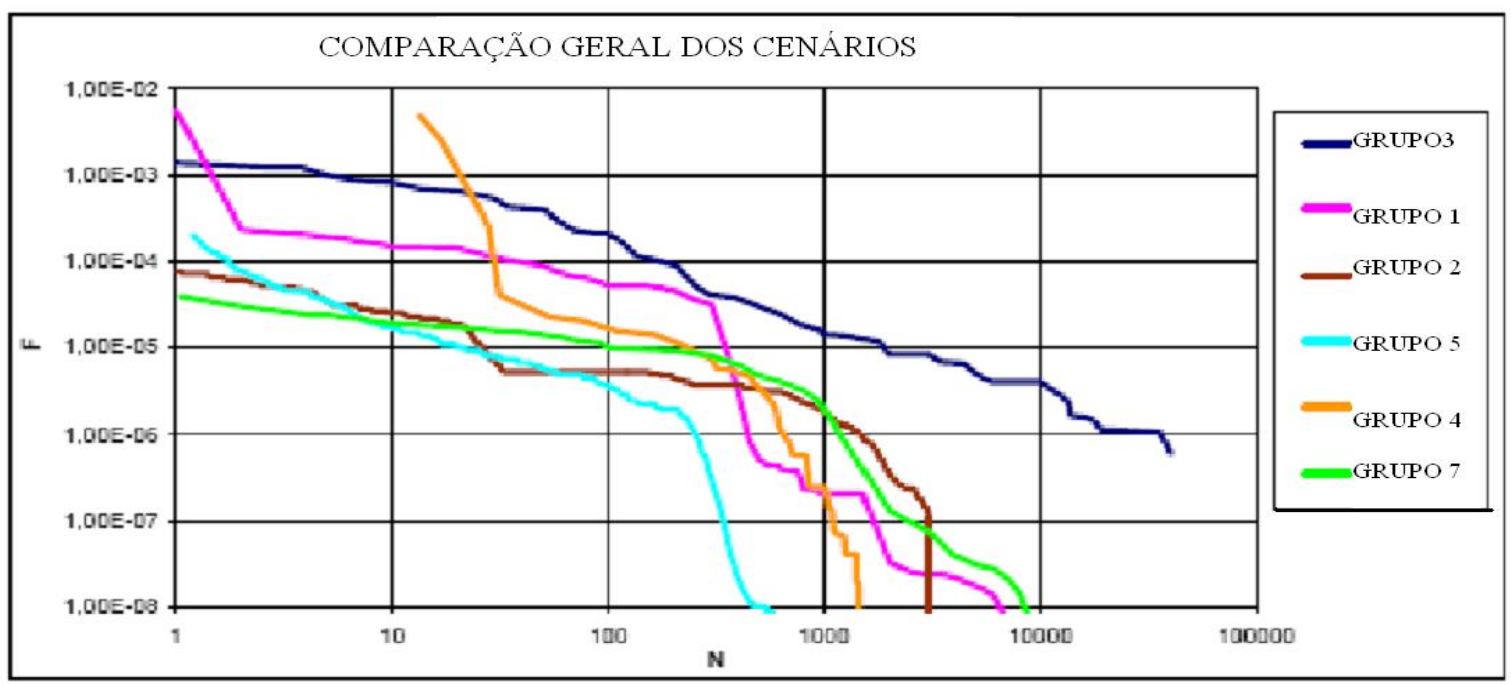

Figura 1.4. Discrepância no risco social calculado por diferentes estudiosos (baseado em dados fictícios de população). Retirado de Lauridsen et al. (2001 a).

\subsection{Objetivo}

A proposta inicial desta tese é criar uma base de conceitos que produza material para futuros esforços de padronização (criação de procedimentos bem definidos) e normatização (estabelecimento normativo de regras mínimas para o estudo) em estudos de riscos e confiabilidade, mais especificamente na caracterização das incertezas. Isto permite estabelecer uma nova metodologia para determinar o grau de credibilidade em um estudo de risco. A identificação das incertezas, envolvidas no processo a ser estudado, permite que a tomada de decisão seja realizada de forma clara e científica - Abrahamsson (2001).

Procura-se apresentar nesta tese um sumário dos tipos de incertezas que podem ser introduzidas em uma AR (Análise de Risco) e propor uma forma de tratamento para as mesmas.

É importante ter uma abordagem crítica das diversas etapas envolvidas nos estudos de risco e confiabilidade, buscando identificar as incertezas envolvidas, descobrir a sua natureza e estabelecer formas adequadas de tratá-las. Vários aspectos de incertezas serão discutidos. Algumas perguntas devem ser respondidas, tais como: Como definir o papel das incertezas no processo de tomada de decisão? Que etapas do processo de análise de risco podem gerar incertezas? Quais os tipos de incertezas existentes? Há necessidade de separar os diferentes tipos de incertezas quando se realiza análise de risco? Como os órgãos de 
normatização estão tratando o problema de incerteza? É possível criar normas que melhorem o grau de exatidão nos estudos de riscos?

Atualmente existe uma tendência em utilizar regulamentações e certificações baseadas em riscos em áreas de complexidade tecnológica. O uso da $A R$ (Análise de Risco) é o fundamento para uma análise racional de decisão e está crescendo em inúmeras áreas, como a indústria aeroespacial, indústria nuclear, estruturas marítimas, etc, Berg \& Kafka (1997).

Diversos autores na literatura especializada de análise de risco já se manifestaram que a AR está associada a uma variedade de incertezas em sua formulação: Morgan et al (1990), Amendola et al (1998), Van Asselt (1999) e Paté-Cornell (1996). Os sistemas analisados com a AR são, em geral, complexos com diversas fontes iniciadoras de acidentes. Soma-se a isto o fato de que estes sistemas geralmente são dinâmicos, com pouca ou nenhuma história estatística de acidentes, tornando o tratamento da incerteza um desafio, Abrahamsson (2000). Em Amendola et all (1998) pode-se extrair que a AR é uma importante ferramenta usada em processos de tomada de decisão e, por isto, deve, na medida do possível, possuir alto grau de precisão. Assim, fica clara a importância do estudo das incertezas inerentes ao próprio processo de tomada de decisão, como se pode concluir do trecho retirado de Amendola ñAs QRA is used as an input in many decisions related to the control of major accident hazards and the need for accuracy in the result increases, the adequate management of these uncertainties gains increased importanceò Ou seja, a Análise de Risco (AR) é usada como entrada em processos de tomada de decisão e para controle de inúmeros incidentes perigosos e assim necessita que seja feita com acurácia, e exige um adequado gerenciamento das incertezas envolvidas.

Os principais pontos que deveriam ser explorados em estudos relacionados à área de risco são:

a) A IMPORTÂNCIA DO ESTUDO. O papel dos estudos de risco e confiabilidade. Mostrar os diferentes objetivos do estudo, dando ênfase à importância das tolerâncias no processo de tomada de decisão. Abordar problemas relacionados às estimativas e à falta de normatização e de critérios em risco e confiabilidade (ALARP etc.). Normatização em diversos países, normas internacionais.

b) A NATUREZA DAS INCERTEZAS. Discutir sobre a natureza das incertezas: fontes (falta de conhecimento teórico, monitoramento inadequado, erros em exemplos e erros analíticos, modelos que não correspondem à realidade, aleatoriedade do modelo). Distinção entre Erro e Incerteza.

c) AS INCERTEZAS NAS FASES DO ESTUDO DE RISCO. Discutir as incertezas não só em relação às fontes, como também mostrar os tipos de incertezas existentes em diversas fases dos estudos de risco e confiabilidade. Incertezas nas diversas etapas; identificação de riscos (HAZID, HAZOP, ENVID) incertezas nas árvores de falhas e eventos, incertezas na análise de riscos, incertezas no cálculo final do risco. 
d) AS INCERTEZAS NOS MODELOS. Como deve ser tratada a incerteza no modelo. Como a incerteza afeta o modelo, abordar as incertezas naturais nos modelos, a aleatoriedade da natureza, as incertezas provenientes da falta de conhecimento do modelo ou do fenômeno, as incertezas pelos erros de medidas.

e) AS INCERTEZAS NOS BANCOS DE DADOS. Abordar as incertezas de dados, a qualidade dos dados, as origens dos dados, a completude dos dados, a coerência dos dados, a validade dos dados, a aderência dos dados ao modelo, como tratar os dados, como medir a incerteza nos dados, Análise qualitativa de dados. Análise probabilística clássica dos dados.

f) MODELAMENTO DA INCERTEZA/MÉTODOS PROBABILÍSTICOS. A PROPAGAÇÃO DA INCERTEZA. Análise freqüentista e bayesiana.

g) Técnicas para analisar os efeitos e propagação de incertezas. Análise de sensibilidade. Incerteza probabilística, métodos analíticos (propagação de variância, serie de Taylor, aproximação de primeira ordem,) métodos numéricos, monte Carlo, hipercubo latino

h) MODELAMENTO DA INCERTEZA/ MÉTODOS NÃO PROBABILÍSTICOS. Conjuntos Nebulosos (Fuzzy sets) aritmética nebulosa (fuzzy arithimetics), teoria possibilísta. Métodos alternativos, regressão simples, regressão múltipla. Comparação entre os axiomas de probabilidade e possibilidade. Comparação de avaliação de confiabilidade de componentes usando métodos probabilísticos e possibilísticos. Comparação de métodos probabilísticos e Fuzzy em projetos baseados em confiabilidade.

i) OS ESPECIALISTAS E AS INCERTEZAS. Os julgamentos dos especialistas ante as incertezas, as incertezas relacionados ao julgamento humano.

j) MÉTODOS PARA classificação ponderada DAS INCERTEZAS PARAMÉTRICAS. Métodos numéricos, Coeficientes de correlação, coeficientes parciais de correlação, análise de regressão.

A AR (análise de risco) traz consigo uma grande quantidade de incertezas, que inevitavelmente, são introduzidas durante o processo.

Passou a existir uma crescente preocupação, nos últimos anos, no estudo dos riscos. Percebeu-se que apesar da crescente necessidade de estudos de riscos, pouco se abordou, até agora, sobre o grau de incerteza envolvido nestes mesmos estudos. Diversos estudiosos podem enfocar um mesmo problema de forma semelhante e mesmo assim obter diferentes soluções. Muitas vezes isto ocorre devido às diferentes metodologias que podem ser adotadas em um estudo de risco ou ainda ao grau de precisão exigido por cada estudo. Outro ponto importante a ser considerado é a caracterização e medida das incertezas envolvidas em um estudo de risco.

Esta tese tem como proposta estabelecer um paradigma para uma reflexão sobre as incertezas envolvidas em estudos de risco; para isto serão utilizados conceitos empregados em 
outros países, onde a abordagem do problema está mais amadurecida. Na verdade, ainda não há um consenso internacional de como poder ser feito este estudo. Porém, percebe-se nitidamente a necessidade de se realizar de forma mais consistente, em nosso País, o estudo das incertezas em Análise de Risco. São os seguintes os objetivos a serem alcançados:

1. Estabelecer uma reflexão sobre as incertezas existentes em estudos de Risco;

2- Ressaltar a importância de caracterizar e conhecer a natureza das incertezas envolvidas;

3- Apresentar formas para representação destas incertezas;

4- Estabelecer uma padronização para a caracterização e representação das incertezas;

5- Normatizar conceitos e procedimentos que reduzam o grau de incerteza do Estudo;

6- Provocar uma reflexão sobre a subjetividade dos analistas em seus estudos;

7- Estabelecer uma metodologia para tratamento da incerteza paramétrica e no modelo.

Apresenta-se, a seguir, algumas considerações que justificam o propósito de desenvolver estes objetivos específicos.

Os dados usados em diversos tipos de AR são, algumas vezes, fontes de incertezas significativas. Geralmente em AR são utilizados dados históricos coletados no sistema ou em sistemas similares ao que se deseja analisar. Parte destas incertezas é originada da falta de aderência entre o sistema real e o sistema referência. Elas ainda podem ser originadas pela carência de dados, causada pela inexistência de modelos similares. As incertezas produzem um estudo de conseqüências deficientes, em diversas áreas, muito importantes, tais como indústrias nucleares, plantas químicas e transporte de produtos perigosos. Existem inúmeros métodos estatísticos que podem ser usados para extrair ou extrapolar os dados. O uso destes métodos pode e deve ser aceito, porém, é importante que sejam citados com clareza não só o método utilizado, como também a extrapolação utilizada. Abrahanssom (2000) afirma que os dados devem ser analisados no contexto histórico em que foram produzidos, e conclui que, é sempre necessária uma análise crítica das fontes de dados. Com relação ao modelo ressaltase que, muitas vezes, é impossível criar um modelo perfeito que represente a realidade. Devese ter a certeza que o modelo representa a realidade nas situações específicas a serem estudadas. Não seria assim exagero afirmar que o uso de modelos sempre introduz subjetividades.

Percebeu-se em diversos países que o processo de estudo de risco deve possuir maior rigor científico e, como conseqüência, as diversas incertezas envolvidas precisam ser melhores previstas. Uma correta quantificação das incertezas do próprio processo de estudo de risco deve ser um objetivo a ser alcançado, já que estes erros dificultam a análise das conseqüências e a sua correta mensuração. 
Uma importante conceituação que será utilizada nesta tese é a divisão dos diversos processos utilizados em uma análise de risco em grupos que permitam posteriormente a classificação e tratamento associados a estes processos.

Os processos relacionados a estudos de riscos podem ser divididos conforme a sua natureza em processos matemáticos ou racionais; qualitativos ou por especialistas e estatísticos ou banco de dados.

Processos matemáticos ou racionais são os processos relacionados aos cálculos numéricos quer sejam eles analíticos, determinísticos ou probabilísticos. Estudando as incertezas relacionadas a estes processos estamos determinando as incertezas numéricas, como foram abordadas nos capítulos 7 e 8 . As incertezas numéricas estão presentes em todas as atividades que demandam algum de cálculo matemático ou avaliação numérica.

Processos qualitativos ou que derivam de conhecimento de especialistas. A análise de risco, como qualquer produto da mente humana, incorpora todos os defeitos e virtudes que 0 ser humano pode gerar. Por isso, atualmente crescem em importância os estudos dos mecanismos psicológicos utilizados pelo homem no processo de tomada de decisão. Muitos métodos estruturais podem ser usados para compreender melhor a informação baseada na opinião de vários especialistas, Morgan \& Henrion (1990). Segundo os estudos de Amos Tversky e Daniel Kahnemann (1974), as heurísticas segundo eles são o meio pelos quais os agentes encontram soluções ótimas, levando em consideração os custos para tomar decisões plenamente racionais, uma vez que é da natureza humana a existência de restrições ao exercício da plena e ilimitada racionalidade. Os vieses cognitivos são erros sistemáticos de julgamento, ou melhor, são erros mentais causados por simplificação da estratégia de processamento da informação, que ocasionam muitas vezes uma distorção na maneira como os indivíduos percebem a realidade. Determinar as incertezas relacionadas as estes processos é fundamental.

Os processos estatísticos são os processos que derivam de tarefas relacionadas à aquisição, pesquisa, manipulação em banco de dados. Os bancos de dados, conforme a origem, podem ser: Bibliográficos, quando obtidos de uma fonte secundária como um manual, livro, publicação científica ou qualquer outra fonte literária; Banco de Dados de Entrevista quando é originário de entrevistas com pessoas relacionadas aos fatos; Banco de dados de Pesquisa de Campo, quando já originários de pesquisa e análise por observação direta em Campo; e Banco de Dados Laboratoriais quando derivam de Pesquisa realizada em Laboratório ou sob condições controladas que simulam a Pesquisa em Campo aberto.

\subsection{Revisão bibliográfica}

Como já foi escrito acima, nos últimos vinte anos tem aumentado em todo o mundo a preocupação em estabelecer critérios mais rígidos para quantificar a precisão de Estudos de Riscos. Diversos trabalhos foram publicados notadamente 
na Suécia, Dinamarca, Holanda, Inglaterra, Noruega, e Estados Unidos. A seguir são apresentados alguns autores que servirão de referências para o estudo.

A doutora Elisabeth Paté-Cornell do Departament of Management Science and Engineering da Stanford University vem, ao longo dos anos, tentando estabelecer metodologias para o aumento da credibilidade do estudo de Risco, notadamente na área de Análise Probabilística de Risco. Ela estabeleceu seis níveis de quantificação no tratamento da incerteza em análise de risco. No esquema da figura 1.5, Paté-Cornell (1996) é apresentada, a título ilustrativo, a forma como a autora tem tratado este assunto. Nesta figura pode-se ver a tentativa da autora em classificar os níveis de quantificação para o tratamento da incerteza. $O$ nível 0 consiste na identificação do perigo, o nível 1 consiste na identificação do pior caso, o nível 2) consiste em definir o nível superior que seria aceitável, o nível 3 é a melhor estimativa do valor central, o nível 4 consiste uma análise probabilística de risco, o nível 5) é a determinação das incertezas do processo de análise de risco. 


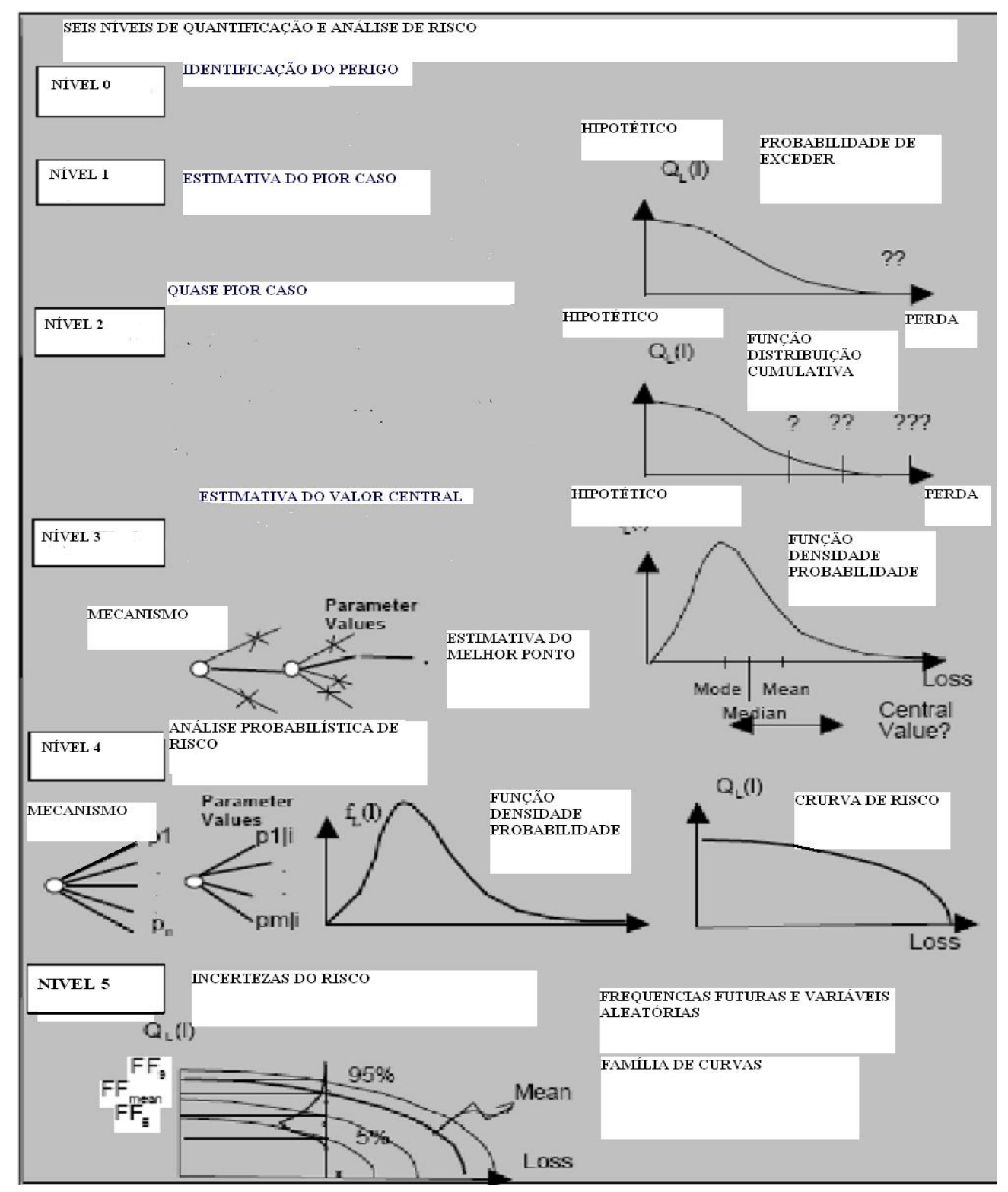

Figura 1.5 Seis níveis de complexidade na caracterização do risco, Paté-Cornell 1996

Em muitos casos é importante, para um dado problema, apenas uma resposta binária do tipo ñsimòou m̃ãoò. Esta resposta simples pode estar associada, por exemplo, à simples constatação do perigo. Isto geralmente ocorre em estudos básicos, primários ou de natureza preliminar, como forma de orientar estudos posteriores mais exatos. A este nível a autora chamou de NíVEL ZERO. O primeiro nível consiste em uma abordagem do tipo pior caso, por exemplo, ñ máximo de vítimas envolvidas em um específico eventoò $O$ segundo nível consiste em r̃uase pior casoò descrita como a m̃máxima probabilidade de um evento ou máxima credibilidade de ocorrer um terremotoò $O$ terceiro nível consiste em melhor 
estimativa ou em inglês ñbest estimativesô, ou seja, qual a mais crível estimativa da probabilidade ou perdas em de um acidente. O quarto nível é chamado de análise de risco probabilística de primeira ordem ou freqüências de eventos futuros; por exemplo, ñqual a probabilidade de exceder um dado nível de perda para diferentes graus de falhas em um sistema com mitigaçãoô. O quinto consiste na análise probabilística de segunda ordem, baseada na representação completa e separação epistêmica ou, como diz a própria autora, consiste na determinação das incertezas envolvidas no próprio estudo de análise de risco.

Em uma primeira abordagem, a simples identificação do perigo é suficiente, se o perigo é perfeitamente definido e a solução é simples e rápida ou se os efeitos catastróficos potenciais são muito pequenos com pouco custo associado ao fracasso. Uma análise qualitativa que inclui métodos simples como matriz de riscos: em um eixo, a probabilidade (alta, média ou baixa), e no outro eixo, as conseqüências (alta, média ou baixa) de eventos indesejados. Esta abordagem é suficiente quando não há necessidade de um tratamento numérico.

Uma segunda abordagem (análise de pior caso) é geralmente suficiente quando o pior caso é perfeitamente definido ou claro, e especialmente se há uma solução razoável para este caso. Outra abordagem possível é a de ou quase pior caso (ñplausible upper boundsò) que representa uma associação entre a distribuição de probabilidades e a distribuição de conseqüências (ou perdas). O problema de políticas baseadas nestes conceitos é que não se sabe previamente qual o nível que irá solucionar um dado problema.

A autora aplica a sua metodologia em diversas áreas, como risco de anestesia em hospitais, análise de risco de terremoto na baia de São Francisco, risco de acidente no ônibus espacial etc. Suas obras são:

Paté-Cornell, M.E., Uncertainty in risk analysis: Six levels of treatment. Reliability Engineering and System Safety 54, Elsevier Science limited, Northern Ireland, 1996.

Paté-Cornell, M.E., Priorities in Risk Management: Human and Organizational Factors as External Events and a Maritime Illustration. Proceedings of the $4^{\text {th }}$ International Conference on Probabilistic Safety Assessment and Management, PSAM 4, Edited by Mosleh, A. \& Bari, R.A., New York, 1998.

Outra referência importante é Marcus Abrahamssom do Department of Fire Safety Engineering da Lund University, Suécia. No mesmo caminho da professora Patê-Cornell e a partir de suas premissas, Abrahamssom faz um estudo abrangente das incertezas envolvidas no Estudo de Risco. Com uma visão notadamente probabilística, ele estabelece um índice que mede o grau de exatidão do estudo de risco em função de diversas fontes de incertezas existentes nos modelos, nos bancos de dados e na opinião de um especialista. Posteriormente ele disserta sobre os métodos para o tratamento das incertezas como analíticos, numéricos. 


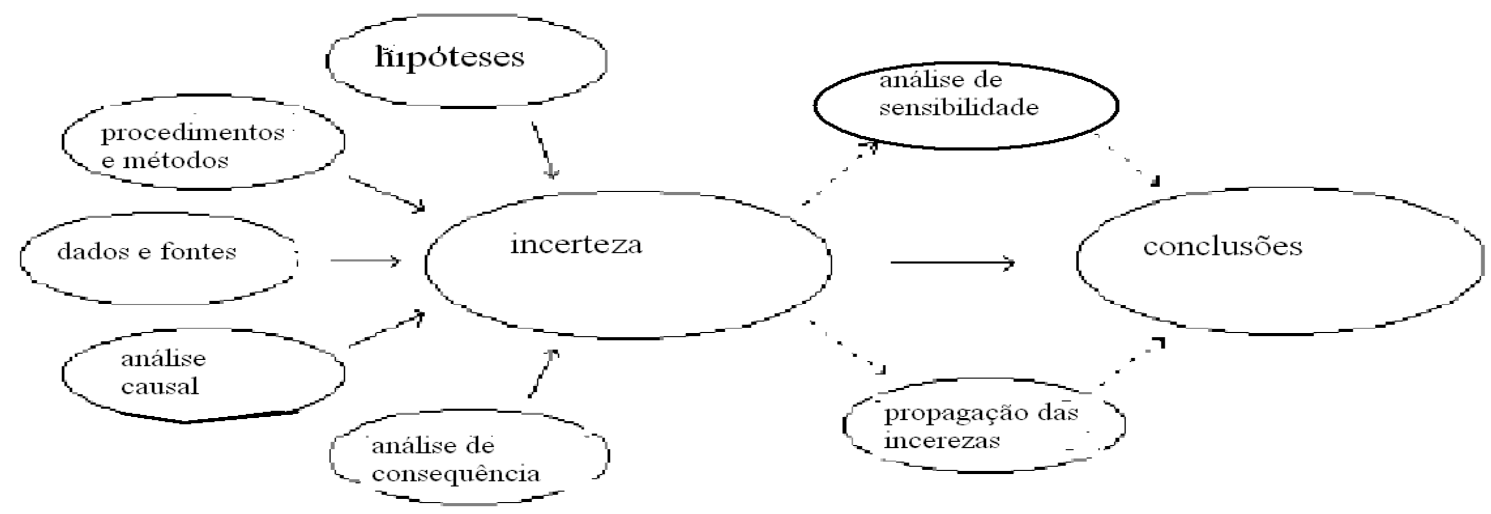

Figura 1.6 Esquema das fontes de incertezas e sua propagação Abrahamsson 2000

$\mathrm{Na}$ figura 1.6 pode-se ver um tipo de abordagem para identificar e tratar as incertezas em estudos de riscos. Diferentes partes do estudo de risco podem gerar incertezas; isto pode ser visto pela parte esquerda da figura que simboliza as diferentes etapas envolvidas em estudos de riscos tais como:

Dados/Fontes ou r̃DATA/SOURCESòque é o processo de obtenção de dados, como taxa de freqüência de falhas etc, pode ser uma fonte inicial de incerteza;

Análise de causas ou ñCAUSAL ANALYSISò é a busca pelos elementos iniciadores dos processos perigosos e também a busca pela origem das falhas;

Análise de conseqüências ou ñCONSEQUENCE ANALYSISò que consiste nas hipóteses de possíveis conseqüências;

Escolha dos Métodos e procedimentos ou r̃PROCEDURE \& METHODSò é o processo de estudo dos procedimentos e métodos a serem usados na análise de risco;

Premissas Gerais ou ñASSUMPTIONSò é o nome dado ao conjunto de hipóteses gerais utilizadas pelo estudioso.

$\mathrm{Na}$ parte mais a direita da figura estão representados os dois principais métodos de tratamento de incertezas que são: propagação de incertezas (UNCERTAINTY PROPAGATION) e análise de sensibilidade (SENSITIVITY ANALYSIS).

Alguns trabalhos de Abrahamsson são:

Abrahamsson, M., Treatment of Uncertainty in Risk Based Regulations and Standards for Risk Analysis. Report 3116, Department of Fire Safety Engineering, Lund University, Lund, 2000. 
Abrahamsson, M., Behandling av osäkerheter i riskanalyser ï Studie av befintliga analyser. Department of Fire Safety Engineering, Lund University, Lund, to be published. (In Swedish).

Abrahamsson, M., Johansson, H., \& Magnusson, S.E., Methods for treatment of uncertainty in quantitative risk analysis. Safety, Risk and Reliability ï Trends in Engineering, Conference report, IABSE, Zürich, 2001.

Abrahamsson, M., \& Magnusson, S.E., Treatment of uncertainties in quantitative risk analysis. Foresight and Precaution, Cottham, Harvey, Pape \& Tait (eds.), Balkema, Rotterdam, 2000.

Saccomannno et all (1990) mostram que diferentes estimativas de taxas de acidentes e probabilidades de vazamentos podem resultar em uma grande variação da estimativa de risco. O seu principal estudo é

Saccomanno, F.F. \& Bakir, O. Analysis of Risk Uncertainty for the Transport of Hazardous Materials. Transportation of Dangerous Goods: Assessing the Risks. Institute for Risk Reseach, University of Waterloo, Ontario, Canada, 1991.

Parry (1998) também discute o efeito da análise das incertezas no processo de tomada de decisão. O objetivo foi determinar se havia ou não confiança nos resultados e como isso podia influenciar o processo de tomada de decisão. Pode-se extrair do seu trabalho que a caracterização das incertezas é dependente das hipóteses e critérios utilizados pelo analista que é a parte subjetiva do estudo de risco. O trabalho de Parry a ser estudado é:

Parry, G.W. Uncertainty in PRA and its Implications for Use in Risk-Informed DecisionMaking. Proceedings of the 4th International Conference on Probabilistic Safety Assessment and Management, PSAM 4, Edited by Mosleh, A. \& Bari, R.A., New York, USA, 1998.

Rowe (1994) decompõe a incerteza em 4 classes: temporal, estrutural, i.e. incerteza devido à complexidade, métrica i.e. incerteza na medição e tradicional i.e. incerteza em explicar os resultados incertos. Este estudo é encontrado na obra abaixo:

Rowe, W.D. Understanding Uncertainty, Risk Analysis, Vol 14, No 5, Plenum Press, New York, USA, 1994.

Outro autor de enorme importância no estudo das incertezas em estudos de riscos é Amendola. Ele é extremamente preocupado no estudo das incertezas envolvidas em análises de risco ambientais notadamente na emissão de poluentes gasosos ou líquidos no meio ambiente. Amendola realizou inúmeros estudos que buscavam mostrar a fragilidade das abordagens em estudos de riscos. Fez inúmeros estudos para a Agência Ambiental Americana- EPA. Nestes estudos Amendola apresenta a necessidade de normatização de estudos de riscos visando melhorar a exatidão dos resultados apresentados. Algumas obras são: 
Amendola et al Uncertainties in chemical risk assessment: Results of a European benchmark exercise. Journal of Hazardous Materials, 29. Elsevier Science Publishers B.V, Amsterdam, 1992;

Amendola, A \& Christou, M. How Lessons learned from Benchmark Exercises Can Improve the Quality of Risk Studies. Proceedings of the 4th International Conference on Probabilistic Safety Assessment and Management, PSAM 4, Edited by Mosleh, A. \& Bari, R.A., New York, USA, 1998.

Por fim, pode-se destacar ainda mais uma referência que foi estudada: ñAn Introductory Guide to Uncertainty analysis in Environmental and Health Risk Assessmentò do Environmental Restoration Program, de autoria de F.O Hoffman e J.S Hammonds.

Os principais procedimentos técnicos consolidados e os órgãos responsáveis estão relacionados abaixo:

U.S. Environmental Protection Agency: Policy for use of Probabilistic Analysis in Risk Assessment and Guiding Principles for Monte Carlo Analysis, EPA/630/R-97/001, EPA 1997

CPR, Committee for the Prevention of Disasters, Methods for the calculation of damage, r̃Green bookò Voorburg: Ministry of social affairs and employment, 1990

CPR, Committee for the Prevention of Disasters, Methods for determining and processing probabilities, ז̃Red bookò The Hague: SDU, 1997a.

CPR, Committee for the Prevention of Disasters, Methods for the calculation of physical effects, ñyellow bookò The Hague: SDU, 1997b.

USNRC: An Approach for Using Probabilistic Risk Assessment in Risk-Informed Decisions on Plant-Specific Changes to the Licensing Basis, Regulatory Guide 1.174, U.S. Nuclear Regulatory Commission, 1998

USNRC: Use of Probabilistic Risk Assessment Methods in Nuclear Activities: Final Policy Statement, Federal Register, Vol. 60, p. 42622 (60 FR 42622), August 16, 1995.

Amendola A. \& Papadakis G.A. (Editors) Guidance on the preparation of a safety report to meet the requirements of Council Directive 96/82/EC (SEVESO II), JRC European Commission, 1997.

\section{As principais Normas Internacionais são:}

Norwegian Standard NS 5814: Requirements for risk analyses, Norwegian Standardisation Association, 1991;

DS-Information DS/INF 85: Risk Analyses, requirements and terminology, Danish Standards Association, 1993;

European Standard EN 1050:1996: Safety of machinery - Principles for risk assessment, European Committee for Standardisation, 1996; 
IEC International standard $\mathrm{nr}$ 60300-3-9: Dependability management- Part 3: Application guide- Section 9: Risk analysis of technological systems, International Electrotechnical Commission, 1995;

British Standard BS 8444: Risk management, Part 3 Guide to analysis of technological systems - application guide, British Standards Institution, 1996;

Australian/New Zealand Standard AS/NZS 3931: Risk analysis of technological systems - application guide, Standards Australia, Standards New Zealand, 1998;

Australian/New Zealand Standard AS/NZS 4360: Risk Management, Standards Australia, Standards New Zealand, 1995;

Canadian Standard CAN/CSA-Q850-97: Risk management: Guideline for DecisionMakers, Canadian Standards Association, 1997.

A Análise de Risco (AR) é usada como uma base teórica para o processo de tomada de decisão. Quando é realizada uma Análise de Risco (AR) uma grande quantidade de incertezas, inevitavelmente, são introduzidas e estas incertezas precisam ser tratadas.

O comum é dividir os objetivos dos estudos de riscos em: riscos a integridade humana, riscos econômicos ou riscos ambientais. Percebeu-se que apesar da crescente necessidade de estudos de riscos, pouco se abordava sobre o grau de incerteza envolvido nestes estudos. Diversos estudiosos podem enfocar um mesmo problema e obter diferentes soluções. Muitas vezes isto ocorre devido às diferentes metodologias que podem ser adotadas ou ainda ao grau de precisão exigido. Soma-se a isto a dificuldade de caracterizar e medir as incertezas envolvidas em um estudo de risco. Uma pergunta precisa ser respondida: óPode-se confiar

\section{em um estudo de risco?ô}

Observa-se que em diversos estudos de riscos, busca-se um resultado, um ñúmeroò que caracterize o maior ou menor grau de risco envolvido (o que é comumente chamado pela sigla de ALARP- ñAs low as possibleòou ñ menor possívelòem português). Muitas vezes este múmeroò é despido de um significado mais preciso. Na verdade os resultados numéricos, obtidos por diferentes estudiosos, apresentam, por vezes, valores completamente inconsistentes ou ainda divergentes entre si. Estas divergências são causadas por diferentes dados usados como referência, ou ainda por hipóteses simplificadoras ou modelos inadequados.

Foi observado em diversos estudos de risco e confiabilidade que são efetuados que apesar de possuírem o mesmo objeto de estudo, apresentam resultados dissonantes. Se não bastasse a divergência de resultados, muitas vezes os resultados são apresentados sob a forma de simples algarismos (por exemplo, risco individual do projeto, calculado por um analista A é igual a 0,00003, enquanto para o mesmo projeto o cálculo do analista B apresenta risco de 0,000567), sem nenhuma consideração adicional, tornando difícil compreender a verdadeira essência por trás dos números. Serão apresentados no capítulo 9 exemplos de como as incertezas podem influenciar o estudo de risco e a avaliação de suas conseqüências. 


\subsection{Estruturação da tese}

No capítulo 2 é descrito o papel da AR. São apresentados os diferentes objetivos da AR. No capítulo 3 é apresentada uma discussão sobre as diversas classes de incertezas e uma visão dos diversos tipos de incertezas em diferentes tipos de estudos de AR. São descritos diferentes métodos de representar a incerteza nos parâmetros e variáveis usadas nos modelos de risco.

O capítulo 4 aborda o tratamento da modelagem da incerteza, com ênfase na confiabilidade dos modelos de predição. Um dos maiores desafios da análise quantitativa de risco (QRA) é a persistente falta de dados, isto pode ser contornado com o uso de especialistas que fornecem estimativas quantificadas do desconhecimento necessário. No capítulo 5 são apresentadas diversas abordagens utilizadas por especialistas no processo de tomada de decisão, ou seja, como ocorre o processo de criação das heurísticas pela mente humana e os vieses que podem ser gerados a partir das hipóteses aceitas. O capítulo é concluído com a apresentação de três diferentes abordagens para a agregação de opinião de especialistas.

O capítulo 6 contém uma breve introdução de como diferentes tipos de dados de experiências (acidentes) são usados em diferentes estágios da QRA. São ainda definidos alguns requisitos básicos que um banco de dados deve apresentar para ser usado em análise de risco. No capítulo 7 são apresentados diferentes métodos para a abordagem da incerteza, ressaltando os tipos de informações necessárias para cada método. Neste capítulo será estudado o processo de propagação da incerteza e suas conseqüências.

No capítulo 8 aborda-se o processo de classificação ponderada das incertezas paramétricas e alternativas para diminuição da incerteza geral. No capítulo 9 é apresentada a metodologia propriamente dita com a sugestão de passos a serem seguidos em um estudo de risco de forma a minimizar as incertezas relacionadas a estes estudos. No capítulo 10 é apresentado um problema simples onde é testada a metodologia, no que concerne as incertezas numéricas, e são testados os métodos dos capítulos 7 e 8 . No capítulo 11 são apresentados aspectos relacionados ao esforço de normatização internacional e uma idéia de como se encontra este aspecto específico no Brasil. No capítulo 12 é apresentada a conclusão final com reflexões para trabalhos futuros.

\subsection{Considerações finais}

Neste capítulo mostrou-se que apesar de se utilizar, muitas vezes de metodologias bem, estruturadas e pré-concebidas, existe uma diversidade de resultados possíveis para um dado estudo de Risco. Tal preocupação passou a ser crescente nos últimos anos e tentativas de tornar os estudos mais aceitáveis foram feitas. Esta tese é mais uma tentativa de dar maior credibilidade ao estudos de Riscos focando justamente nos seu r̃calcanhar de Aquilesò as incertezas presentes no mesmo. 


\section{CAPÍTULO 2}

\section{A ANÁLISE DE RISCO}

\subsection{Considerações preliminares.}

Inicialmente surge a necessidade de formalizar a definição de Estudo de Risco ou Análise de Risco. Conforme Kumamoto, ao se buscar a definição de risco no dicionário encontra-se a definição de risco como uma ñpossibilidade de perda ou lesão a pessoas e propriedadesò Segundo ele, se engenheiros escrevessem dicionários, trocariam a palavra possibilidade por probabilidade. De uma forma geral, um estudo de risco se resume basicamente à busca de um risco individual e um risco coletivo. Por esta abordagem mais clássica teria assim a análise de risco etapas pré concebidas como definição de sistemas, análise preliminar de perigos, identificação da sequência de acidentes, análise de conseqüências. Porém, este mesmo autor relata a dificuldade de definir de forma precisa 0 conceito de risco e enumera outras técnicas que, de certa forma, não se enquadram de forma perfeita nas etapas, como FMEA, análise de criticalidade, ñhazard studyò análise de causas e consequências. Após mais de duas décadas desta versão do livro de Kumamoto, percebe-se, a um leitor atento de Estudos de Risco, uma maior diversificação dos estudos de Riscos, desde estudos determinísticos, onde etapas tradicionais são suprimidas ou juntadas, até técnicas diversas das já expressadas anteriormente. Por exemplo, Lauridsen(2001) emprega o termo Análise de Risco para um estudo determinístico em que não se chega, em nenhum momento, a probabilidades e/ou fatalidades. Os estudos que se baseiam na metodologia de Smith para as consequências ao longo da vida útil de uma plataforma de petróleo, publicados pela Mineral Management Service (MMS), responsável pela normatização para a instalação de plataformas de petróleo, não se enquadram nas etapas rígidas citadas em Kumamoto. Em diversos estudos observa-se uma abrangência maior da denominação Análise de Risco; o próprio Kumamoto percebeu esta diversidade e apesar de se concentrar em uma formatação mais clássica, em nenhum momento, ele se volta contra eventuais opiniões em contrário, como se pode ver na página referente à análise de criticalidade, página 34 da edição de 1991. Além disto, deve-se perceber que os conceitos usados em Kumamoto são conceitos que se aplicavam de forma, quase perfeita, aos estudos da época. Hoje, porém, observam-se diversos estudos na área de explosões, fogo, análise financeira, Hidrologia, etc que se apossam desta denominação de análise de risco, mesmo não seguindo as etapas clássicas fundamentadas por Kumamoto. 
A definição de Análise Risco nesta tese é de um estudo estruturado de forma a prever as consequências danosas e, se possível, mensurá-las de forma adequada; é um conceito um pouco mais amplo que o conceito clássico usado por Kumamoto e assim contém este.

Em alguns casos em que as incertezas envolvidas são muito pequenas, a abordagem determinística, relacionando a entrada à saída, é suficiente. Este é o caso, por exemplo, do estudo sobre o alcance de um ñet fireòresultante de um furo de diâmetro bem definido em um r̃aiserò de diâmetro conhecido e submetido a uma pressão constante. No caso particular citado, não há qualquer motivação para utilização de técnicas de análise de risco, uma vez que os resultados são perfeitamente previsíveis (Ganoulis, 1994).

Entretanto, há casos em que o sistema, por exemplo, um sistema hídrico, é alimentado por dados incertos, com variáveis espacial e temporalmente incertas. As incertezas presentes na avaliação dos futuros resultados fazem com que estes não mais podem ser considerados determinísticos. As incertezas têm um importante papel em sistemas que apresentam múltiplas entradas com diversas fontes iniciadoras de eventos perigosos e a técnica apropriada para lidar com o problema consiste na análise de risco.

Segundo Vieira (1997) a análise de risco compreende duas etapas seqüenciadas:

1. A qualificação ou identificação dos riscos - esta fase diz respeito ao levantamento das incertezas existentes, dos riscos associados, suas causas e formas de ocorrência.

2. A quantificação ou avaliação dos riscos ï esta fase materializa em números as probabilidades ou possibilidades de ocorrência de eventos indesejáveis ou falhas de projetos, bem como quantifica, sempre que necessário e exeqüível, as conseqüências destes eventos.

O gerenciamento dos riscos, por sua vez, diz respeito ao comportamento dos tomadores de decisão, através da análise sistêmica, seleção de alternativas, e minimização dos riscos envolvidos.

Atualmente, busca-se uma abordagem mais completa, que não se limita ao estudo do risco ou análise quantitativa do risco, outras etapas são introduzidas e compreendem:

1-ANÁLISE DE RISCO

2-ESTUDO DAS INCERTEZAS

3-QUANTIFICAÇÃO DOS RISCOS

4-GERENCIAMENTO DOS RISCOS

Pode-se concluir que, embora o objetivo principal da análise de risco seja conhecer o potencial perigo de um sistema, isto só será possível se as incertezas tiverem sido identificadas e os riscos quantificados a priori. No caso da análise das incertezas, novas metodologias passaram a ser usadas na literatura: a de abordagem probabilística, na qual a Simulação de Monte Carlo está incluída, e a fundamentada na teoria r̂́uzzyòou teoria dos conjuntos difusos. 
Para um estudo aprofundado das incertezas numéricas existentes na avaliação de risco, para se conhecer os efeitos causados pelas incertezas, é preciso se concentrar em pelo menos três etapas: análise de sensibilidade, propagação de incertezas e classificação ponderada das incertezas.

Quando as fontes de incertezas são identificadas e as incertezas, propriamente ditas, classificadas o processo de estudo fica bem mais simplificado. Porém, há que se ter em mente que a total determinação das incertezas é uma tarefa quase impossível. Não se pode ter a pretensão de apresentar um rol exaustivo de toda a literatura existente na área, já que o estudo das incertezas, nos mais variados campos científicos, tem recebido crescente atenção nas últimas décadas, resultando em inúmeras publicações sobre o assunto. Busca-se, na verdade, delinear o estudo das incertezas de uma maneira clara e didática, indo do geral ao específico, na tentativa de sintetizar o estado da arte das incertezas.

A Análise de Risco é aqui descrita como um processo estruturado para identificar e analisar as contribuições mais importantes no risco total em uma atividade da vida humana, do meio ambiente ou alguma outra parte vulnerável da sociedade. O processo de Análise de Risco, segundo a abordagem clássica de Kumamoto, ocorre por meio de diversas etapas.

Anteriormente foi formalizado o conceito de Análise de Risco utilizado nesta tese. Em um conceito mais conservador e conhecido de análise de risco (AR) (Kumamoto, 1991), em que um estudo de Risco consiste em algumas etapas pré- definidas, pode-se utilizar estas diversas etapas para a detecção das incertezas. A partir do conhecimento das diversas fases da análise de risco, pode-se extrair as potenciais fontes de incertezas e, como conseqüência, pode-se conhecer o impacto dos vários tipos de incertezas nas diferentes etapas do processo.

\subsection{Contribuição para o risco.}

Como já dito anteriormente, a AR é um processo estruturado que utiliza ferramentas que permitem um conhecimento do processo a ser estudado. Kumamoto ao contrário do que muitos acreditam não condicionou o estudo de risco a Etapas pré concebidas, ele apenas exemplificou desta forma visando viabilizar uma metodologia mais clara. Hoje em dia, o problema da avaliação de risco é normalmente abordado segundo duas perspectivas: Avaliação Qualitativa e Avaliação Quantitativa. O objetivo consiste em analisar o risco qualitativamente e ou quantitativamente e estimar a possível redução de danos, ou perdas, devida à implementação de diferentes medidas de segurança. Recentemente Ludin et al ( 2003) classificaram os métodos de avaliação em qualitativos, semi quantitativos e quantitativos. Por seu lado, Marchand cita também três métodos, um qualitativo, outro quantitativo e um terceiro que designou de sistemática ou racional ( rrationalised systematic approachô). Larson 2003, denomina como métodos de análise de risco (risco de incêndio ï ñmethods for fire risk analysisô) e os classifica em - Regulamentos e óchecklistsô Métodos Semi-Quantitativos ( $\tilde{n}$ Ranking methodsô) e Métodos quantitativos. Como a terminologia 
empregada varia com o contexto da sua utilização, ela pode gerar confusão, pela falta de uniformização nos diversos campos de aplicações.

Em síntese, estão disponíveis os seguintes procedimentos:

I) Qualitativos, que envolvem métodos narrativos ou descritivos - regulamentos e listas de checagem (checklists), e - árvores lógicas (no seu aspecto qualitativo);

II) Quantitativos, que incluem diversas variantes: métodos semii quantitativos; métodos de esquemas de pontos; métodos analíticos ou estatísticos; árvores lógicas: - de eventos, de tipos de falha - efeitos, de falhas (ou êxitos), de decisões (causa - efeito), de decisões (efeito causa); métodos estatísticos; e modelos matemáticos ï determinísticos ou estocásticos

São apresentados, a seguir, de forma simplificada, alguns dos métodos disponíveis, enquadrados segundo a classificação acima:

\subsection{AR para decisões de risco}

A fase da decisão é primordial e é o principal componente da gestão do risco. A ausência de decisão constitui um perigo tão grande, ou maior, que tomar a decisão errada. $A$ decisão deve ser baseada em diferentes alternativas, conseqüências e respectivas probabilidades. Na gestão do risco, o risco final deve ser composto com os valores relativos aos riscos associados a diferentes opções, que deverão ser integrados em metodologias de decisão, em conjunto com outros condicionantes, como, por exemplo, custos ambientais ou até mesmo sociais. O processo de decisão tem dois momentos e objetivos distintos:

- a decisão associada diretamente à apreciação de um risco (aceitação, não aceitação);

- a decisão de selecionar e de hierarquizar medidas de controle ou de mitigação;

Sabe-se que na tomada de uma decisão, que envolve riscos públicos relevantes, interferem também as dimensões subjetiva, ambiental, econômica e social. Os critérios de decisão deverão, então, considerar os indicadores econômicos (custos e benefícios) e os princípios éticos e jurídicos (direito do risco), que possibilitem, ao avaliador, uma compreensão das diversas vertente, as quais podem ultrapassar o domínio estrito de uma decisão fria ou meramente técnico-econômico e podem se situar na esfera do social ou até mesmo da esfera política. Todas as atividades que se desenvolvem no âmbito de uma gestão do risco exigem sentido de responsabilidade profissional ética (deontológica), mas o processo de decisão, relacionado a medidas associadas a alterações ou à manutenção de riscos individuais ou públicos, envolve um nível maior de responsabilidade, ético-moral, social e legal. A fundamentação da decisão associada a uma comunicação adequada permite que a mesma seja interpretada de um modo consistente. A comunicação e a fundamentação é primordial na construção da percepção individual ou social do risco e também no controle e mitigação do risco.

A partir da apreciação e avaliação do risco, o processo de decisão deverá desencadear o controle e mitigação do risco através da seleção de medidas ou ações que conduzam à 
manutenção do risco a valor residual ou aceitável ou ainda à diminuição desse valor. Estas medidas podem ser agrupadas segundo o objetivo pretendido: medidas de prevenção, de mitigação e medidas de resposta a crises.

As medidas de prevenção são as medidas que têm por objetivo manter ou diminuir a probabilidade de ocorrência de um acidente, um evento, de um cenário (e.g. um sistema de observação das possíveis causas de acidentes, ou de monitoração de um sistema, ou a realização de medidas reforço de segurança). Estas medidas incidem, assim, na cadeia de probabilidades condicionadas que está associada ao cenário que pode ser uma ocorrência agressiva ou perigosa (ñhazardousò), possibilitando que a probabilidade total resultante diminua ou que não aumente.

As medidas de mitigação agrupam as ações que tenham o propósito de diminuir os efeitos negativos ou prejudiciais como: diminuição de número de vítimas humanas, de prejuízos financeiros, econômicos, sociais ou ambientais. Incidem na cadeia de probabilidades das conseqüências ou dos prejuízos condicionados a um valor esperado das conseqüências, no caso de ocorrer um determinado acidente ou evento perigoso (e.g. um sistema de alerta e aviso ou um plano de emergência ou de evacuação).

Por exemplo, na engenharia civil as medidas de prevenção e de mitigação podem ser estruturais (envolvendo obras físicas) ou não estruturais (envolvendo a elaboração de planos de contingência ou de resposta, zoneamentos de riscos).

Um tipo especial de medidas de mitigação são aquelas associadas às atividades relacionadas a uma emergência, durante ou imediatamente após um acidente. São medidas extraordinárias que têm por objetivo diminuir as conseqüências de um acidente ou de uma catástrofe e possibilitar uma rápida recuperação. As medidas de planejamento de emergência são específicas para a situação em causa e resultam da avaliação do risco.

\subsection{Introdução de incertezas em diferentes estágios de AR.}

Será feita agora uma pequena abordagem dos diferentes caminhos pelos quais as incertezas podem ser introduzidas nos diversos estágios de AR.

As etapas do AR, na visão clássica de Kumamoto são:

-Definição do escopo e objetivos.

-Identificação de perigos, definição dos possíveis cenários de acidentes.

-Valoração de eventos e efeitos das conseqüências.

-Estimativa da freqüência dos acidentes em potencial.

- Estimativa do risco.

$\mathrm{Na}$ fase de definição de escopos e objetivos, são feitas as considerações iniciais sobre o trabalho a ser desenvolvido. Nesta fase são definidos os limites, parâmetros e fronteiras do estudo. Trata-se da parte introdutória, onde o definidor do problema (que é o cliente que encomendou o estudo ao analista) traça um esboço da situação e esclarece o resultado que 
deseja. Nesta fase, pode-se tudo, pode-se inclusive considerar que não são introduzidas incertezas. O definidor pode não saber esclarecer o problema, mas a partir do momento que o faz, tem-se o nascedouro, ou seja, o ponto inicial de todo o processo.

\subsubsection{Estágio da identificação.}

A fase da identificação inclui a descrição do sistema, com a identificação dos eventos inicializadores e cenários. Nesta fase o objetivo é produzir uma lista compreensiva dos eventos inicializadores, com a identificação de prioridades entre eles, e termina com tomada de decisão.

Algumas perguntas precisam ser respondidas tais como: será que todos os cenários podem ser identificados? ; qual a possibilidade de uma análise errada não permitir estimar todas as situações perigosas? Métodos estruturados costumam ser usados para identificar os cenários perigosos tais como: Estudo de Perigos e Operabilidade (ñ HazOp-Hazard and Operability Studyô, análise ñwath-ifô ( causa /conseqüência) e Análise de Modos de Falhas e Efeitos (AMFE ou FMEA em inglês).

\section{Árvores de falhas}

Esta técnica surgiu em 1962, com o objetivo de verificar a confiabilidade de projetos, e têm sido amplamente utilizada em diversas áreas, como na indústria nuclear e na indústria química. A árvore de falhas é uma técnica amplamente empregada na análise de risco, porque permite a obtenção de resultados qualitativos e quantitativos. Será abordada rapidamente a sua aplicação qualitativa.

A técnica consiste em um processo dedutivo baseado na Álgebra de Boole, que permite determinar a sequência de acontecimentos, que são estudados em função dos acontecimentos não desejados (falhas) e dos eventos que são subjacentes. Assim, podem ser avaliados, de forma qualitativa, os mais diversos acontecimentos, desde os menos prováveis até os mais prováveis, dado que requerem a ocorrência simultânea de numerosas causas.

Pode-se decompor simultaneamente um acontecimento complexo denominado de acontecimento de TOPO em acontecimentos intermediários até chegar aos acontecimentos básicos. Na técnica da árvore de falhas importa destacar duas fases bem diferenciadas: a primeira consiste na elaboração da árvore e a segunda na análise dos resultados e no seu tratamento.

\section{Elaboração da árvore de falhas}

Nesta fase importa integrar toda a informação sobre o funcionamento de operação da instalação e em especial o acontecimento em estudo. 
Pode-se numerar as portas lógicas da árvore no sentido de facilitar a sua identificação. Acontecimentos não desenvolvidos.

Existem acontecimentos no processo de decomposição da árvore de falhas que são interrompidos, muitas vezes por falta de informação, ou ainda por não se considerar necessário. São representados mediante um trapézio.

\section{Simbologia utilizada na árvore de falhas}

O primeiro passo consiste em identificar o acontecimento m̃ão desejadoòque deverá ocupar o TOPO da estrutura gráfica representativa da árvore. Da definição clara e precisa deste acontecimento de topo depende todo o desenvolvimento da árvore.

A partir deste acontecimento de topo estabelecem-se de forma sistemática todas as causas imediatas que contribuem para a sua ocorrência definindo-se assim os acontecimentos intermediários unidos através de portas lógicas. O processo de decomposição de um acontecimento intermediário repete-se sucessivas vezes até que se atinjam os acontecimentos básicos componentes da árvore.

\section{Árvore de Eventos como método de análise de risco}

Por exemplo, em um método de engenharia de segurança contra incêndio baseado na análise de risco, efetua-se necessariamente a quantificação do nível de segurança. Este método pode utilizar a técnica de árvore de acontecimentos que combina o cálculo do desenvolvimento do acidente (no caso incêndio) com um modelo de evacuação aplicável a cada cenário. $O$ processo completo do projeto de segurança contra incêndio consistiria em cinco passos: revisão qualitativa do projeto, Análise de Risco, avaliação do risco, análise de sensibilidade e otimização. A revisão qualitativa do projeto seria utilizada com o objetivo de sublinhar as entradas ou aspectos relacionados com a segurança contra incêndio de uma forma sistemática. Na revisão junta-se toda a informação necessária para a realização no processo de análise de risco. O risco é por final calculado e avaliado assim como é analisada e avaliada a eficácia das diferentes estratégias de segurança contra incêndio. A análise de sensibilidade tem o objetivo de identificar vantagens e desvantagens (pontos fracos e fortes) de cada uma das medidas utilizadas no projeto de segurança incêndio. Eventualmente existirá a possibilidade de otimizar as medidas adotadas de segurança contra incêndio no sentido de encontrar as medidas que melhor se adaptam a um edifício específico.

\subsubsection{Estimativa de freqüência}

Existem diversas formas de estimar o número de ocorrências ou a freqüência de eventos. Um exemplo de método para a medição de risco de certa atividade, em termos de 
número de acidentes, é chamado de índice de mortalidade por acidentes, conhecido pela sigla FAR $^{2}$ (ñfatal accident rateo). Os valores diferem em função das diversas atividades, por exemplo, os riscos relacionados à indústria química são estimados de $F A R=$, em que metade é atribuível a acidentes de trabalho normais e a outra metade devido aos riscos químicos. Por isso não é aceitável um valor estimado de risco, devido ao funcionamento de uma instalação química, superior a $F A R=2$. Isto no que se refere aos trabalhadores; quanto ao público este valor ainda deverá ser inferior.

Outros índices utilizados para determinar o risco de uma determinada atividade são a Taxa de Freqüência e a Taxa de Gravidade, definidos abaixo.

Taxa de Freqüência $=\left(\right.$ Número de acidentes com îbaixaờNúmero de horas de trabalho) $\times 10^{6}$ Taxa de Gravidade $=\left(\right.$ Número de dias Perdidos $/$ Número de horas de trabalho) $\times 10^{3}$

Considere-se o caso de uma indústria química, em que o objetivo de segurança para uma instalação é de $F A R=2$. No caso de uma instalação de risco médio, onde há pelo menos 5 acidentes significativos, isto implica que para cada acidente deve-se atribuir um FAR $=0,4$ que deve ser calculado com base na exposição do grupo de maior risco e não na população constituída pelo conjunto de todos os trabalhadores.

Pode-se, converter os valores FAR em índices de acidentes, mais populares na representação dos perfis de risco.

De uma forma geral, os métodos de quantificação baseados somente em probabilidade são hoje considerados insuficientes para uma efetiva gestão dos riscos, eles não levam em consideração a gravidade do acidente, pois estes parâmetros não consideram as conseqüências decorrentes de cada acidente. Apesar de desejável, os cálculos das conseqüências de um acidente encontram hoje ainda grandes dificuldades de objetivação.

Qual o efeito de uma eventual emissão de um produto inflamável armazenado a baixa temperatura em um tanque de armazenagem onde se verificou uma ruptura? Os modelos para resolução deste problema são muito complexos e envolvem um grande número de parâmetros. Só com base em modelos computacionais e em equipes multidisciplinares podem ser obtidas soluções aproximadas aceitáveis.

\subsubsection{Estimativa das conseqüências}

\section{Determinação da Gravidade}

De uma forma geral, a estimativa da gravidade é realizada apartir do conhecimento prévio do analista que, observando casos semelhantes, passa de forma lógica a projetar a sequência de acontecimentos e, assim, concluir o desfecho dos eventos. Obviamente, a metodologia utilizada para determinar a conseqüência dos acidentes depende da natureza do

O FAR é calculado através do número de acidentes mortais em $10^{8}$ horas de trabalho, o que equivale à vida de trabalho de 1000 pessoas (1000 pessoas x 55 anos x 1800 horas ). 
processo a ser estudado. A seguir serão apresentados alguns métodos para quantificação da gravidade de um acidente no caso de ocorrer uma fuga de gás combustível dando lugar a uma nuvem explosiva. A sobre pressão causada pela explosão, que constitui a gravidade potencial de destruição, pode ser estimada usando o método de TNT equivalente (TNT-Trinitrotolueno). A emissão máxima estimada a considerar é a equivalente a todo o conteúdo existente dentro do maior reservatório ou conjunto de reservatório.

Existem diversos outros métodos para resolver o problema acima, e a escolha deverá ocorrer por razões objetivas e subjetivas do analista.

O objetivo nesta seção não é discorrer sobre todos os métodos e assim esgotar o assunto; a intenção é exemplificar e demonstrar como, de uma forma geral, ocorre o processo de escolha da metodologia a ser utilizada.

\subsubsection{Estimativa do risco}

A expressão rãvaliação de riscosò é empregada ao estudo do potencial de risco, cuja finalidade é estimar, quantitativamente, as freqüências de ocorrência e também as suas conseqüências; para a avaliação podem ser utilizadas técnicas experimentais e/ou modelos matemáticos.

O público alvo em um estudo de risco é variado, já que a avaliação dos riscos pode ser efetuada tanto para as pessoas que trabalham ou simplesmente frequentam a área. $O$ estudo pode ainda ser usado, por exemplo, para uma instalação industrial, ou ainda sob a forma de riscos ocupacionais, como para a comunidade vizinha às instalações industriais. $\mathrm{Na}$ avaliação de risco as freqüências de ocorrência podem ser determinadas pela técnica de Análise de Árvore de Falhas e as conseqüências podem ser determinadas pela técnica de Análise de Conseqüências. O potencial de risco calculado é uma média expressa em função do Risco Social e do Risco Individual em fatalidades/ ano, e pode ser calculado tanto para a comunidade vizinha à instalação industrial, como para os funcionários da instalação. Finalmente, a taxa de acidentes fatais (TAF) também pode ser estimada para a mesma instalação.

\section{Risco individual}

O nível de Risco Individual médio é calculado pela divisão do valor do Risco Social médio pelo número de pessoas (população) expostas ao perigo e, assim com chances de vir a ser vítima fatal de um potencial acidente industrial ocorrido dentro dos limites da instalação. $O$ Risco Individual significa a freqüência esperada, de que um indivíduo situado em uma determinada posição geográfica possa sofrer um certo nível de dano, que pode representar a sua morte ou um ferimento. Concluindo, o Risco Individual médio é definido pela seguinte expressão:

RISCO INDIVIDUAL MÉDIO = RISCO SOCIAL MÉDIO/POPULACAO EXPOSTA 
$\underline{\text { Risco coletivo }}$

O Risco Coletivo ou Social Médio representa o valor de risco de fatalidade a que está sujeita a comunidade (população) nas proximidades da instalação ocasionada por acidentes industriais, são exemplos destes acidentes explosão, incêndio e emissão tóxica que podem ser causados por falha na instalação e que tenham seus efeitos danosos projetados além dos limites divisórios da instalação em estudo. Portanto, a expressão do Risco Social Médio é a seguinte:

Risco Social Médio = Freqüência de ocorrência $x$ número de perdas

\section{Critérios para o risco aceitável.}

Finalizando, a última etapa da análise de riscos consiste em verificar se o risco calculado é aceitável ou não. Por exemplo, em termos sociais é aceitável que a atividade perigosa gere, em contrapartida, benefícios que contrabalancem os potenciais danos que podem ser causados.

$\mathrm{Na}$ Europa, mais precisamente em Portugal (dados de 1986), o risco de morte para os utilizadores de transporte rodoviários é $2,63 \times 10^{-4}$ mortes/ano. Este número, por si só, não tem muito significado. Seria mais significativo se fosse comparado com algum outro valor; assim se for mencionado que na Europa tal risco é de $1,49 \times 10^{-4}$ mortes/ano, pode-se efetivamente comparar os dois. Mas será ainda assim aceitável este valor?

O parâmetro, em si, nada informa sobre a gravidade dos acidentes onde ocorreram as vitimas, ou as possíveis causas. Para um leigo, 100 acidentes, com uma única vítima por acidente, têm um significado bem diferente de 100 vitimas num só acidente. No entanto, em termos probabilísticos é a mesma coisa.

Assim, pode-se concluir que a gravidade é um fator que deve ser buscado e por isso a sua importância na análise de risco, mas só por si este valor, também não dá a dimensão do risco. É necessário conjugar a sua importância com a freqüência estimada.

\subsubsection{Gestão do risco}

Existem basicamente duas estratégias para gestão do risco remanescente, quando ele for inaceitável: investir em prevenção, suprimindo as causas do perigo e diminuindo, deste modo, a probabilidade de acidentes, ou investir em proteção para minorar as conseqüências 
decorrentes da eclosão de um acidente. Neste caso diminui-se o parâmetro r̃gravidadeò Para maiores detalhes observar a Norma ABNT 2005.

Para se ter uma idéia melhor sobre a dificuldade de se estabelecer parâmetros consistentes e científicos que possam embasar a tomada de decisão, coloca-se a questão básica: E qual deve então ser o risco máximo para o público? É geralmente aceitável que o valor deve ser 100 vezes inferior à ordem de grandeza do risco de morte por causas naturais que é aproximadamente $10^{-5}$ por pessoa/ano ${ }^{3}$.

\subsection{Considerações finais}

Neste capítulo foram explorados os conceitos de análise de risco e suas etapas. Deve ficar claro que para esta tese o conceito de análise risco é mais amplo, sendo um estudo estruturado de forma a prever as consequências danosas e se possível mensurá-las de forma adequada. Neste ponto o estudo não segue de modo rígido às formas pré concebidas em Kumamoto. Assim, quando a metodologia é apresentada nos capítulos finais, deve-se observar que a sua formulação é ampla de forma a abrigar a diversidade de conceitos de risco utilizados na atualidade.

3 Em um ano de 8760 horas daria um FAR $=0.11$, o que corresponde a uma diminuição de $0,1 \%$ na esperança de vida de um cidadão de 30 anos. 


\section{CAPÍTULO 3}

\section{INCERTEZAS}

\subsection{Introdução às incertezas}

O mundo está repleto de incertezas. As incertezas podem advir de uma informação incompleta ou de discordâncias entre diferentes fontes da informação. Podem surgir de uma imprecisão lingüística, ou podem se referir a uma variabilidade natural. Mesmo no caso de uma informação aparentemente completa, as incertezas podem estar presentes devido às simplificações ou aproximações para tornar os modelos mais tratáveis matematicamente. As incertezas podem ser acerca do que se gosta, sobre que atitude tomar, sobre o que irá acontecer. Pode-se estar incerto até sobre o grau da própria incerteza.

Apesar de tudo, o homem aprendeu, inconscientemente, a conviver com as incertezas do dia-a-dia, desenvolvendo diferentes critérios e preferências para definir regras de decisões para as suas atitudes, tais como ouvir previsões de tempo, escolher entre viajar de avião ou carro, ou escolher uma dada trajetória para o trabalho.

Logicamente, as incertezas não se limitam a atuar na vida privada de cada um. Elas estão presentes nas pequenas e grandes decisões, nas situações individuais e nas que envolvem toda a sociedade. Entretanto, continuou-se lidando com as incertezas, por muitos anos, de forma amadorística. De acordo com Bernstein (1997), somente há alguns anos se começou a ter, em termos internacionais, um interesse em se compreender, quantificar e administrar as mais diversas situações de risco, transformando o futuro incerto - de ameaça ï em oportunidade. O autor traduz muito bem, esta transição, ao afirmar que ća idéia revolucionária que define a fronteira entre os tempos modernos e o passado é o domínio do risco: a noção de que o futuro é mais do que um capricho dos deuses e de que homens e mulheres não são passíveis ante a natureza. Até os seres humanos descobrirem como transpor esta fronteira, o futuro era um espelho do passado ou o domínio obscuro de oráculos e adivinhos que detinham o monopólio sobre o conhecimento.ô

Como bem assinalou Arrow (1992), ó nosso conhecimento do funcionamento das coisas, na sociedade ou na natureza, vem a reboque de nuvens de imprecisões. Grandes males têm se seguido a uma crença de certezaô, o que significa que, a administração do risco obrigatoriamente deverá ser precedida pela identificação e pelo estudo aprofundado das incertezas inerentes ao processo em estudo. É importante se conhecer o tamanho do seu desconhecimento. 
De acordo com Ermoliev (1993), a incerteza é uma característica presente em qualquer estudo voltado para o futuro e a tendência na tomada de decisão sob incerteza é adiar a decisão até que as incertezas sejam esclarecidas, o que, logicamente, nem sempre é possível.

Como ressalta Canter (1996), são quatro as atitudes que se pode ter em um cenário de incertezas: ignorá-las inteiramente (uma ação pouco prudente a se tomar); tentar evitá-las, através de medidas mitigadoras (o que diminui os impactos negativos de eventos incertos, mas não acaba com a fonte dos riscos); tentar reduzi-las através de aprofundamento da pesquisa e conhecimento, com a coleta de mais dados e informações durante a fase de planejamento (algumas incertezas são diminuídas, outras não podem ser eliminadas) e, finalmente, incorporar os riscos e as incertezas ao processo em estudo.

\subsubsection{Definição de incerteza}

O conceito de incerteza é de difícil definição, englobando diversas conceituações. A variedade de fontes de incertezas gera, com certeza, sérias confusões. Diversos são os significados atribuídos aos verbetes áncertezaô e áncertoô nos vários dicionários da língua portuguesa. No dicionário Aurélio, por exemplo, podem-se extrair vários significados para a palavra áncertoà não certo, indeterminado, impreciso, duvidoso, aleatório, ambíguo, vago, inconstante e variável. O substantivo áncertezaô deriva dos conceitos acima descritos e pode ser sintetizado como óo estado (ou qualidade) de estar incertoô

Conforme Kundzewicz (1995), não há consenso acerca do real significado do termo áncertezaô, ele vem agregando em torno de si os mais diversos significados e conotações, que variam de acordo com a formação de quem que o conceitua, e que, nas mais variadas vezes, não são consistentes com seu significado comum.

Uma possível definição é adotar o conceito de áncertezaô proposto por Vieira (1997), que afirma, no sentido mais amplo, ćas incertezas são as fontes geradoras dos riscosô

\subsubsection{Tipos de incertezas}

É importante diferenciar, de forma clara, os diversos tipos e fontes de incertezas, uma vez que os mesmos necessitam ser tratados de diferentes formas. Vários autores na literatura têm analisado diversos tipos de incerteza e relacionado várias distinções, tais como subjetivas e objetivas, secundárias e primárias, tecnológicas e naturais. As mais variadas classificações de tipos de incerteza podem ser encontradas em Morgan \& Henrion (1993).

Bernier (1987) fez distinção entre as incertezas naturais, devidas à aleatoriedade dos processos naturais, e as incertezas tecnológicas, as quais envolvem erros de amostragem e de adequabilidade do modelo adotado.

Beck (1987) examinou detalhadamente as incertezas na estrutura do modelo, na estimativa dos parâmetros e a propagação dos erros nas estimativas. 
Conforme Kundzewicz (1995), os hidrólogos, de uma forma geral, afirmam que já dominam as incertezas há bastante tempo. E pondera que esta afirmação deve ser considerada verdadeira ao se reconhecer que eles sempre foram obrigados a lidar com as incertezas e, com isso, desenvolveram ferramentas para trabalhar com elas. Por exemplo, a determinação da máxima cheia em trinta anos é um exemplo. Mas surge a pergunta: Qual é o grau de incerteza destes números? Ou ainda, pode-se confiar nas estimativas de confiabilidade?

Diversas são as tentativas de identificar os mais variados tipos de incertezas no campo dos Recursos Hídricos e da Hidrologia, Plate e Duckstein (1987). Eles as classificaram em incertezas hidrológicas, incertezas na amostragem e incertezas na função densidade de probabilidade. Identificaram a existência ainda das incertezas hidráulicas, as incertezas no modelo (equações empíricas)

Klir (1989) relacionou a incerteza com a complexidade: Assim, ao reduzir a complexidade, a incerteza aumenta. Segundo ele, a incerteza estaria relacionada à informação, sendo reduzida à medida que mais dados são obtidos, que pode ser conseguido pela informação direta e a realização de experimentos.

Ganoulis (1995), que atua na mesma área de Plate e Duckstein (1987), adota classificação semelhante a eles, agrupando as incertezas em quatro categorias: incertezas hidrológicas, hidráulicas, econômicas (variações nos custos e preços) e incertezas estruturais.

Segundo Ganoulis (1995), as incertezas, de uma forma genérica, podem ser divididas em dois grandes grupos: incertezas naturais (ou aleatórias) e incertezas epistêmicas. As incertezas naturais (ou aleatórias) são inerentes ao processo e não podem ser diminuídas com a utilização de modelo mais sofisticado ou com a coleta de dados adicionais. As incertezas epistêmicas podem ser divididas ainda nos seguintes tipos: incertezas nos dados ï relacionadas aos métodos de amostragem, erros de medição ou nos métodos de análise dos dados; incerteza do modelo ï relacionada a modelos matemáticos inadequados ou erro na estimativa dos parâmetros; e ainda incertezas operacionais - relacionadas à construção, operação e manutenção de obras de engenharia. Ao contrário das incertezas naturais, as epistêmicas podem ser reduzidas por uma melhor coleta de informações ou ainda pelo aperfeiçoamento do modelo matemático.

Frey (1998) dividiu as incertezas no modelo, definidas por Ganoulis (1994) anteriormente em duas categorias: incertezas no modelo matemático e incertezas nas estimativas dos parâmetros. Para Frey, as estruturas matemáticas utilizadas para representar os fenômenos e cenários são uma das principais fontes de incertezas. Isto ocorre porque, como os modelos são apenas uma representação simplificada do fenômeno, há limites em sua aplicabilidade, ou seja, os limites de aplicação do modelo podem estar incompletos ou incorretos. Com relação às incertezas na estimativa dos parâmetros, o autor segue a metodologia proposta por Morgan \& Henrion (1993), que as separam em incertezas nas quantidades medidas empiricamente (por exemplo, medidas de concentração de poluentes), 
nas constantes utilizadas por convenções (constante de Plank, velocidade da luz, etc), nas variáveis de decisão, nos valores dos parâmetros e ainda nos parâmetros associados ao modelo utilizado.

Ainda abordando a modelagem matemática de sistemas hidrológicos pode-se relacionar outros, como Vincens et al. (1975), que propuseram uma nova metodologia e classificam as incertezas inerentes a estes estudos em três tipos: incertezas do Tipo I desconhecimento do verdadeiro modelo que rege o processo natural; incertezas do Tipo II incompleta avaliação dos parâmetros dos modelos matemáticos e incertezas do Tipo III ï as inerentes aos processos naturais.

Incertezas do Tipo I - As incertezas do Tipo I são de avaliação difícil, uma vez que todo modelo é, por si mesmo, uma simplificação da realidade. Em geral, os fenômenos naturais apresentam comportamento tão complexo que os modelos matemáticos detalhados não conseguem reproduzir, com exatidão, os processos naturais. De acordo com Morgan \& Henrion (1993), ñodo modelo é, definitivamente, falsoà já que mesmo quando o modelo é o resultado de boas aproximações de um sistema natural, em particular, ele nunca será completamente exato. Eles afirmam ainda que, mesmo que se possa determinar que um modelo é melhor que outro - na precisão de suas previsões, não se pode afirmar que ele é o mais provável. Conclui que, desta forma, não se pode atribuir probabilidades a modelos.

Incertezas do Tipo II - Mesmo que a complexidade dos fenômenos possa ser fielmente reproduzida por um modelo, ainda se coloca uma questão. Será que os parâmetros da população, tais como média rө variânciarobtidos a partir de amostras relativamente pequenas ï uma única série histórica disponível ï representam os parâmetros da população? Ou eles vão conter uma grande dose de incerteza? Costuma-se admitir, em estudos, que séries de 30 anos de dados permitem a obtenção de resultados com a precisão aceitável. Campos (1997) adverte que a validade desta assertiva depende da variabilidade do fenômeno em análise ${ }^{4}$.

As incertezas do Tipo III - São aquelas inerentes aos processos naturais, e não podem ser reduzidas pelo uso de um modelo mais sofisticado ou pela coleta de mais informações. Elas não podem mudar e, assim, deve-se conhecê-las e incorporá-las ao planejamento.

\footnotetext{
Considerando que se 30 anos de dados sejam suficientes para um estudo de vazões no Nordeste dos Estados Unidos, o qual apresenta, em termos médios, um CVdef ( Coeficiente de Variação da Vazão dos defluídos) da ordem de 0,25 , para que se cometa o mesmo erro em um rio do Nordeste Brasileiro, ou na Austrália, que apresentam CVdef próximos a 1,2, seria necessária uma série de medições de 690 anos
} 


\subsection{CLASSES DE INCERTEZAS}

A forma tradicional de dividir as classes de incertezas é apresentada por (Parry 1998): Incerteza Paramétrica, Incerteza no Modelo e Incerteza na sua Completude.

Incerteza Paramétrica é introduzida quando os valores dos parâmetros usados não são bem definidos, e geralmente apresentados sobre a forma de distribuição de probabilidades. Incerteza no Modelo advém do fato que qualquer modelo conceitual ou matemático inevitavelmente é uma simplificação da realidade. O último tipo advém do fato que nem todas as incertezas envolvidas em uma AR são conhecidas; seria assim uma grande classe que abrangeria todas as incertezas que não podem ser caracterizadas nas duas classes anteriores.

Diversos tipos de incertezas podem gerar diferentes métodos de abordagem. Outro aspecto é a possibilidade de redução da incerteza; na medida em que se conhece a natureza da incerteza, fica mais fácil tentar diminuí-la ou mitigá-la. Sabendo quais são as fontes de incertezas envolvidas na análise pode-se avaliar a acurácia do estudo, seus pontos fortes e fracos. Diferentes tipos de incertezas geram diferentes formas de tratamento, assim deve-se empregar um dado método para um tipo de incerteza e outro completamente diferente para uma incerteza que apresente características diversas.

\subsubsection{Incerteza epistêmica vs incerteza aleatória}

As incertezas de natureza aleatória e epistêmica são os dois principais tipos de incertezas: de um lado tem-se a aleatória, estocástica, e do outro a epistêmica ou incerteza do conhecimento.O principal instrumento utilizado para analisar a incerteza aleatória é o conceito matemático de probabilidades (Patê-Cornell-1996). Como a incerteza epistêmica advém da falta de conhecimento subjetivo, da ignorância ou da ambigüidade, para lidar com ela é necessário melhorar ou aumentar o conhecimento.

A questão principal que surge é se é importante descobrir qual a origem da incerteza. Outra questão que se coloca é se é realmente necessário identificar e separar os diversos tipos de incertezas. Winkler( 1996) considera que as respostas as estas questões são respectivamente: sim e não.

Como já mencionado anteriormente, o melhor método para quantificar a incerteza é o probabilístico que será abordado no capítulo 7. Basicamente há duas escolas, a Bayesiana e a freqüentista, a diferença entre as duas escolas será abordada posteriormente.

A chamada incerteza aleatória possui diversos nomes na literatura: variabilidade, vagueza, estocástica e incerteza irredutível. Esta incerteza representa, de uma forma simples, a aleatoriedade da natureza. Por outro lado, a incerteza epistêmica tem nomes tais como ambigüidade, ignorância, falta de conhecimento base, incerteza redutível ou subjetiva. A incerteza epistêmica é relacionada, como já mencionado anteriormente, à falta de conhecimento a respeito do fenômeno. Diferentes técnicas para minimizar este tipo de 
incerteza, que está relacionada basicamente à utilização de conhecimento de especialistas, são apresentadas no capítulo 5. Para maiores detalhes veja em Hofer (1996) que ilustra os diferentes tipos de incertezas.

Deve-se atentar que somente a incerteza baseada no conhecimento pode ser reduzida. A incerteza estocástica é por definição irredutível. Outra importante diferença é que as incertezas de natureza estocástica podem cancelar-se entre si, por exemplo, pode-se ter uma variável de entrada que possui uma correlação positiva com a saída, enquanto outra variável de entrada apresenta uma correlação negativa, logo elas podem eventualmente se anular. Mas para a falta de conhecimento isto não é possível.

\subsection{Métodos para representar a incerteza}

A forma mais comum de representar a incerteza que pode ser quantificada, seja ela epistêmica ou estocástica, está na utilização de distribuição de probabilidades. Como já descrito, há duas formas de interpretar o conceito de probabilidade a freqüentista e a bayesiana. A freqüentista define probabilidade como um limite de freqüência enquanto a bayesiana define a probabilidade como um grau de confiança. Devido à dificuldade de estabelecer valores para o conhecimento epistêmico, a utilização do conceito freqüentista nem sempre é possível. Uma análise freqüentista somente é valida se for possível identificar variáveis independentes ${ }^{5}$; por isso em alguns casos a interpretação bayesiana se torna necessária.

Durante os últimos anos, tem se observado uma grande discussão sobre se os processos de raciocínio humano possuem alguma correlação com os procedimentos normativos; isto tem sido bastante debatido em periódicos de renome ${ }^{6}$. Este debate teórico vem acontecendo principalmente em duas áreas de pesquisa: raciocínio dedutivo e raciocínio sobre probabilidades condicionais ${ }^{7}$. Tal debate tem relação com o modo como a informação é representada na mente humana e assim, com a natureza dos processos utilizados para se raciocinar e julgar com base em tais modos de representação. Concluindo, Kahneman e Tversky acreditam que as pessoas representam a informação em termos de exemplos individuais e, por conseguinte, julgam através de processos de raciocínio também baseados em exemplos individuais (abordagem dos vieses ou heurísticas). Em linha oposta, Cosmides, Gigerenzer e outros propuseram que os seres humanos representam a informação com base

\footnotetext{
${ }^{5}$ Ou seja um exemplo de independentes e identicamente distribuídas observações de um fenômeno de interesse.

${ }^{6}$ Como o ñCognition, Journal of Memory and Language ,ò Psychological Reiewò , ñBehavioral and Brain Sciencesò e ñJournal of Experimental Psychology:Generalò

7 Neste contexto,de um lado tem-se Kahneman e Tversky e seus associados (Ex.:Kahneman,Slovic,\&Tversky,1982; Kahneman \&Tversky,1972,1973,1996)e,do outro,Gigerenzer e seus associados (Ex.:Gigerenzer,1996; Gigerenzer \&Hoffrage,1995),junto com Cosmides e seus associados (Ex.:Cosmides \&Tooby,1996)
} 
em freqüências populacionais, assim o raciocínio e julgamento desses últimos também são baseados em freqüências populacionais (abordagem freqüentista). Desta forma, enquanto que para Cosmides e Gigerenzer a probabilidade se refere exclusivamente a eventos de freqüências populacionais, para Kahneman e Tversky a probabilidade se refere, antes de tudo, a eventos únicos (expressando, assim, o nível de confiança subjetivo) ${ }^{8}$.

\subsubsection{O Raciocínio probabilista}

Tradicionalmente, estuda-se o raciocínio probabilista relacionando-o com as teorias matemáticas da probabilidade. No início do desenvolvimento deste ramo da matemática, na segunda metade do século XVII e do século XVIII, havia uma forte correlação entre a probabilidade e uma abordagem mais intuitiva dos problemas. Assim as intuições de quem lidava com tarefas que requeriam a avaliação de acontecimentos incertos (apostas, jogos de azar etc.) eram consideradas como fontes confiáveis dos cálculos formais de probabilidade. $O$ físico, matemático e astrônomo francês Pierre-Simon de Laplace (1749-1827) teve papel relevante no desenvolvimento deste tipo de raciocínio. Laplace foi responsável direto pela primeira teoria da probabilidade (Ex.:Teoria analítica da probabilidade,1812). Ele desenvolveu esta teoria através da criação de um conjunto de técnicas de cálculo (funções geradoras) em um conjunto de hipóteses que forneceram autonomia à definição de probabilidade. Na obra Ensaio Filosófico sobre a Probabilidade (1814), que se tornou depois a introdução das últimas edições da Teoria Analítica, Laplace, de forma crítica, aborda os problemas que se originam a partir da utilização da teoria probabilista no estudo dos fenômenos naturais.

$\mathrm{Na}$ verdade, inúmeros psicólogos têm considerado o cálculo da probabilidade como a forma ideal de avaliar o elemento subjetivo, ou seja, as intuições ao invés de ser considerado apenas o resultado da formalização de julgamento intuitivo em condições de incertezas. É de Laplace o ponto de vista ñpsicológicoòde que a teoria da probabilidade pode ser definida como simplesmente o senso comum reduzido a cálculo. Isto gera como conseqüência que os cálculos probabilísticos espontâneos passaram a serem considerados errados, já que parecem divergir dos produzidos a partir da utilização de regras probabilísticas normativas. Em um período caracterizado pelo ideal determinista, o recurso a critérios probabilísticos criou, de fato, inúmeros problemas que Laplace $^{9}$ procurou superar recorrendo a uma inteligência r̃mnicompreensivaò Ao invés de ser considerado como o resultado da formalização de julgamento intuitivo em condições de incertezas, o cálculo de probabilidade tem sido considerado por muitos psicólogos como uma forma ideal de avaliar as intuições.

\footnotetext{
${ }^{8}$ De um determinado indivíduo acerca da verificação de um determinado evento.

${ }^{9}$ Laplace procurou superar recorrendo a uma inteligência ñomnicompreensiva ò, a única capaz de ter certezas absolutas ou seja ñGiven ... an intelligence which could comprehend all the forces by which nature is animated and the respective situation of the beings who compose it -an intelligence sufficiently vast to submit these data to analysis ...nothing would be uncertain and the future as the past,would be present to its eyes. (Laplace, 1814,p.4)
} 
Conseqüentemente, os cálculos probabilísticos espontâneos têm sido considerados errados, na maioria dos casos, exatamente porque parecem divergir daqueles produzidos a partir da aplicação das regras probabilísticas normativas.

O raciocínio de tipo probabilista diz respeito ao raciocínio indutivo, visto que este último tipo de raciocínio requer competências de tipo probabilista, como a capacidade de avaliar a variabilidade e a numerosidade de uma amostra a respeito da qual a inferência é realizada.

\section{O Teorema Bayesiano}

O Raciocino bayesiano está associado à capacidade de se estimar a probabilidade de um evento a partir de dois tipos de conhecimentos: não apenas o que se sabe sobre um evento antes que ele se verifique, mas também novas informações que podem ser obtidas em seguida; isto constitui um dos princípios estatísticos de base da teoria. O princípio formulado pelo matemático e reverendo inglês Thomas Bayes (1702-1761) permite o cálculo da probabilidade de uma hipótese fundamentando-se na probabilidade a priori e de novas evidências relevantes.

Para tornar este princípio mais claro, considere-se o problema concreto abaixo ï o problema da doença ï apresentado em duas partes: Parte A: A ocorrência da doença $X$ é 1/1000. Um teste é usado para detectar se uma pessoa tem a doença $X$. Cada vez que o teste é aplicado em uma pessoa que tem a doença, o resultado do teste deve ser positivo. Parte B: Em algumas vezes, o teste, porém apresenta um resultado positivo quando é realizado em uma pessoa que é completamente saudável. Isto ocorre em $5 \%$ de todas as pessoas que são perfeitamente saudáveis e apresentam um resultado positivo para a doença. Pergunta: Qual é a chance de uma pessoa que teve o resultado positivo ter, de fato, a doença, assumindo que você não sabe de nada sobre os sintomas e sinais da pessoa?

A partir desta informação inicial, é possível se computar a probabilidade a posteriori, a partir do teorema bayesiano da probabilidade, de ser um sujeito realmente doente, visto que ele foi diagnosticado como doente. Em outras palavras, é necessário avaliar a estimativa inicial da probabilidade de um indivíduo ter uma doença, tendo como base o resultado do teste, considerando-se ao mesmo tempo a precisão deste teste em diagnosticar a doença. Assim, o cálculo da probabilidade a posteriori (o indivíduo ter realmente a doença que the foi diagnosticada) é o resultado da razão entre duas estimativas de probabilidade:

A partir deste cálculo, é possível responder à questão. Qual é a chance de uma pessoa que teve o resultado positivo, de fato, ter a doença, assumindo que você não sabe de nada sobre os sintomas e sinais da pessoa ${ }^{10}$.

\footnotetext{
${ }^{10}$ Se a probabilidade a priori deste indivíduo ser doente era de $0,001(1 / 1000)$ e, em seguida, após submetido a um teste, ter sido diagnosticado positivamente, a probabilidade a posteriori de ser realmente doente é de 0,19627 . Em termos de frequiência, 1, em um total de 50,95 indivíduos que são testados como positivos,tem a doença; e expressado como uma freqüência relativa, pode-se dizer que entre todas as pessoas diagnosticadas como doentes, somente $1,9627 \%$ é,de fato, doente.
} 
Esta descrição semi-intuitiva do teorema de Bayes pode ser representada mais formalmente. Entretanto, antes de retornar ao teorema, é importante introduzir a rãbordagem dos vieses e das heurísticasò Esta abordagem argumenta que as pessoas ao invés de utilizarem os procedimentos computacionais do teorema bayesiano para solucionar problemas do tipo acima descrito, geralmente são incapazes de fazê-lo,utilizando, ao contrário,uma ampla variedade de atalhos não normativos e inadequados de tipo informal ao tomar decisões

\subsubsection{Representação em intervalos}

A representação em intervalos é muito útil em situações em que se possui a absoluta certeza sobre os limites a distribuição das variáveis e se tem pouco conhecimento adicional. Em um exemplo simples, supondo que um golfista fez dois buracos nas três primeiras etapas de um campo de golfe com o total de 18 buracos, pode-se, perguntar quantos buracos 0 golfista pode acertar ao percorrer todas as etapas do campo de golfe. Como se pode ver, há poucas informações, que são o total de buracos no campo e o desempenho inicial do golfista. A resposta correta estaria em um intervalo que vai de 2 até 17 ou seja $[2,17]$.

Pode-se, assim, representar a incerteza de um resultado a partir da incerteza das variáveis de entrada com a utilização desta forma de representação, que possibilita inclusive operações aritméticas ou algébricas.

\subsubsection{Representação em famílias de curvas probabilísticas}

A incerteza em um escalar pode ser representada em intervalos. Em alguns casos um par de curvas probabilísticas pode ser usado para representar uma incerteza em uma dada distribuição de probabilidades (Ferson 1996,1998,1999). As famílias de curvas probabilísticas podem ser representadas de forma paramétrica onde a incerteza é representada por um parâmetro, como pode ser visto na curva na figura 3.1, onde um dado parâmetro $X$ é uma distribuição log-normal com média variando no intervalo $[2,5 ; 3]$ e desvio padrão $[0,8 ; 1]$. É também possível construir família de curvas probabilísticas de uma forma mais livre, onde o ñshapeòda curva não é perfeitamente definido; neste caso a curva deve respeitar as condições mínimas definidas pelos dados empíricos. Por exemplo, para o parâmetro $\mathrm{Y}$ os únicos dados disponíveis são máximo 3, mínimo 2 e média 2,5, nada mais é sabido a respeito do ñ shapeòda curva. Na figura abaixo pode-se ver a região onde a curva poderia passar. As incertezas podem ser derivadas de exemplos de dados de entrada, conhecimento sobre média e variância, conhecimento sobre mínimo, máximo ou moda (Ferson et all 1999). 


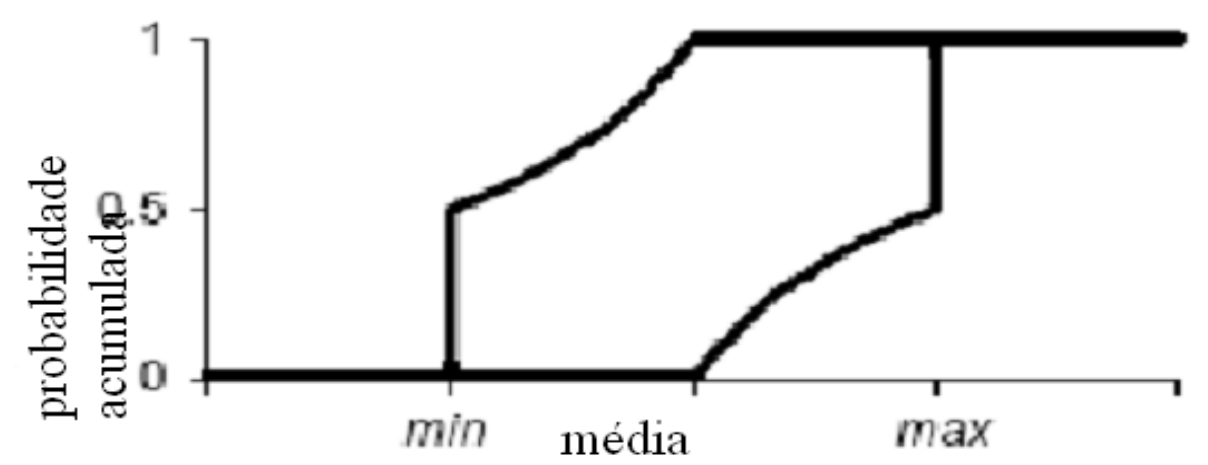

Figura 3.1 Representação de em intervalo de curvas probabilísticas para min=2, Max=3 e média=2,5 ( Adaptada de Tucker e Ferson)

Representações de operações aritméticas envolvendo família de curvas probabilísticas, ou outros exemplos, podem ser vistas Ferson 1996, 1999.

\subsubsection{Representação "fuzzy"}

Foi Lofti A. Zadeh que, em 1965 na Universidade da Califórnia, criou o que se chama hoje de lógica "fuzzy". Basicamente a Lógica "fuzzy" permite representar valores lógicos intermediários entre Verdadeiro e Falso, possibilita ainda o tratamento de atributos imprecisos, como preço (alto, baixo, médio), velocidade (rápido, lento, normal), comprimento (pequeno, médio, grande, extra-grande), fortuna (muito, razoável, pouco) etc. A lógica "fuzzy" combina inteligência artificial, lógica polivalente, redes neurais e teoria das probabilidades, o seu objetivo é representar o modo humano de pensar e se expressar.

A teoria na lógica "fuzzy" está fundamentada na existência de conjuntos, chamados conjuntos nebulosos. Por exemplo, na teoria clássica dos conjuntos, um elemento do universo é considerado pertencente ou não a um dado conjunto, não existindo dúvidas quanto e em qual das situações isso ocorre. Por outro lado na teoria dos conjuntos nebulosos, temos um grau de pertinência de cada elemento a um determinado conjunto que pode variar de 0 a 1 . Por exemplo, com que grau de precisão pode-se afirmar que uma determinada pessoa pertence ou não ao conjunto "das pessoas altas"?

O número de conjuntos que se associa a uma variável está diretamente relacionado com o grau de precisão com que se lida com a variável. Por exemplo, considerando a variável "comprimento", pode-se considerar 3 conjuntos (o conjunto das "coisas" pequenas, das médias e das grandes), e para um maior grau de precisão, 5 conjuntos (muito pequenas, pequenas, médias, grandes, muito grandes). Pode-se classificar um valor, quanto à variável comprimento, estabelecendo graus de associação para um conjunto considerado. Pode-se classificar um 
terreno, quanto ao seu comprimento, como sendo 0,8 grande, 0,2 média e 0,0 pequena. $\mathrm{A}$ lógica "fuzzy" trabalha com os valores do intervalo [0, 1].

Os valores das variáveis-na lógica "fuzzy" são descritos lingüisticamente (pequeno, frio, alto, perto etc.). A lingüística da lógica é estruturada em alguns elementos como modificadores de predicado, estimadores. Os modificadores de predicado (pouco, muito pouco, muito, mais ou menos, bastante etc.) e estimadores (vários, poucos, em torno de, cerca de etc.), juntamente com o uso de expressões lingüísticas para traduzir probabilidades (provável, improvável etc.), são interpretadas como números "fuzzy" que permite a sua manipulação aritmética.

No cotidiano são usadas palavras tais como: grande, raramente, pouco, muito, grande, pequeno. Nestas situações têm-se uma certa vagueza e não podem ser precisamente descritas. Por exemplo:

Ela é muito alta.

O salário é pouco.

O bolo deve permanecer no forno até ficar no ponto.

$\mathrm{Na}$ verdade seria difícil expressar estes termos pela matemática de conjuntos clássicos (sim e não). Na lógica "fuzzy" consegue-se um método mais adequado, mais consistente de lidar com a incerteza;

\subsection{Considerações finais}

Neste capítulo foram apresentadas as diversas formas, como na literatura, é feita a classificação das incertezas; em uma etapa futura será apresentada a metodologia utilizada nesta tese para classificar as diversas incertezas existentes. 


\section{CAPÍTULO 4}

\section{USO DE MODELOS EM ANÁLISE DE RISCO}

\subsection{Considerações iniciais}

O uso de modelos, sejam conceituais ou matemáticos, para representar a realidade é muito comum em estudos de análise de risco. A criação de um modelo perfeito que represente, em todas as suas singularidades, um dado fenômeno é uma tarefa impossível; na verdade um modelo que imite a realidade em todos os detalhes implicaria, muitas vezes, em algo não exeqüível computacionalmente, mesmo para fenômenos mais facilmente modeláveis como o de eventos determinísticos. Mesmo nestes casos, o equacionamento proposto para representar o fenômeno é uma simplificação da realidade. Uma boa técnica de construção de modelos consiste em representar as características mais significativas do fenômeno a ser observado. Por exemplo, para se modelar o movimento de um corpo no espaço, poder-se-ia utilizar um modelo complexo que representasse desde um movimento a velocidades baixas (bem menor que a velocidade da luz, $v<<c$ ), até velocidades próximas a da luz; para isto utilizar-se-ia 0 modelo proposto por Einstein. Porém, este modelo não seria adequado ou útil no caso do movimento de uma bola de futebol, já que as variações na massa e no espaço tempo seriam desprezíveis e só complicariam a execução do modelo.

Como escreveu Katherine Laskey, em suas notas do curso de verão em Inteligência Artificial: ñTodos os modelos estão errados, mas possuem a sua utilidadeò(Laskey,1994). Para um modelo se tornar útil para um dado estudo, deve-se minimizar as incertezas relacionadas com seus aspectos mais relevantes para aquele estudo. Muitas vezes, porém, não há um modelo específico para uma situação ou muitas vezes não é possível construir um modelo que represente o fenômeno em sua plenitude. Todos os modelos carregam consigo certa carga de subjetividade que é trazida pelo estudioso ou especialista. Esta carga de subjetividade está associada às experiências do especialista, às suas convicções pessoais. Modelos empíricos são dependentes das condições do experimento e do isolamento dos elementos que interferem com o fenômeno, mas não fazem parte dele. Assim, conclui-se que de alguma forma todos os modelos apresentam imperfeições. Identificar e quantificar estas imperfeições são as tarefas a que se propõe o presente capítulo 


\subsection{Confiabilidade dos modelos de predição}

Nesta fase são analisados alguns fatores que podem influenciar a confiabilidade dos modelos. Os modelos são desenvolvidos a partir de um conjunto de etapas que facilitam a sua construção. As etapas que afetam a confiabilidade dos modelos são:

-Especificação do problema (cenário)

-Formulação conceitual do modelo

-Formulação do modelo computacional

-Estimação dos parâmetros

-Cálculo e documentação de resultados.

\subsubsection{Especificação do problema}

A especificação do problema é a fase inicial e de suma importância. Para uma correta especificação do problema deve-se possuir, em primeiro lugar, um profundo conhecimento das características do problema: quais os fenômenos relacionados ao problema, quais os fatores mais importantes, suas causas e conseqüências. Deve-se buscar elementos que possibilitem, no futuro, uma formulação determinística ou probabilística, que represente o problema. Uma boa observação da realidade proporciona uma correta especificação do problema. É importante que o estudioso esteja o mais familiarizado possível com o problema.

\subsubsection{Formulação conceitual e computacional do problema}

O modelo conceitual é muito útil e precisa ser construído, já que é a expressão do problema em uma linguagem humana. Os processos, trajetórias, variáveis e as interações entre as variáveis precisam ser bem definidos. Nem todos os processos e mecanismos precisam ser considerados para análise do fenômeno. Obviamente, em situações práticas, geralmente relacionadas à baixa qualidade de dados, torna-se virtualmente impossível incluir todos os processos e mecanismos imaginados no modelo conceitual.

O modelo computacional é gerado por equações e parâmetros obtidos a partir de simulações ou ainda por meio de dados bibliográficos ou históricos. Os modelos computacionais são usados para obter resultados quantitativos; eles não dependem de laboratório ou de simulações experimentais que utilizam modelos físicos. Os resultados quantitativos precisam ser validados; para isto critérios de validação, de comparação e verificação devem ser definidos com a finalidade de testar e confirmar o modelo. Basicamente, testar um modelo computacional consiste em comparar o resultado do modelo com algum resultado que se conhece previamente. 


\subsubsection{Especificação dos parâmetros}

A especificação dos parâmetros está relacionada à realização de experimentos que permitam o conhecimento de valores relacionados a um fenômeno. Muitas vezes os parâmetros relacionados a um dado modelo não podem ser usados em um modelo fisicamente semelhante $^{11}$. $\mathrm{Na}$ determinação dos parâmetros de modelos muitas incertezas estão associadas, seja pelo julgamento subjetivo do estudioso, seja pelo caráter determinístico ou probabilístico do modelo.

\subsubsection{Cálculo, apresentação e documentação}

Algumas das principais fontes de incertezas estão associadas à documentação e cálculo dos resultados (IAEA 1989). Os resultados devem ser expressos de forma clara com a indicação das condições em que foram obtidos permitindo, assim, que possam ser comprovados e validados por outros especialistas. A fonte de incerteza associada ao modelo deve ser minimizada e conhecida para evitar que a realização do trabalho não fique comprometida em sua etapa final.

\subsection{Tratamento da incerteza do modelo.}

Nesta seção são avaliadas formas de conhecer e minimizar as incertezas associadas aos modelos. As incertezas nos modelos devem ser vistas sob diversos aspectos: aquela introduzida pelos dados adotados nos modelos e a gerada pelo julgamento do especialista.

De acordo com Brown \& Heuvelink ${ }^{12}$ (1998), as incertezas introduzidas em modelos são, muitas vezes, geradas por medidas de campo ou laboratoriais. Assim, para ser especificado um dado parâmetro do modelo muitas vezes se faz uso de dados colhidos de forma empírica. Porém, os autores alegam que nem sempre é possível obter uma quantidade grande de medidas. Em outras ocasiões a observação que vem do fenômeno a ser modelado é limitada por questões de espaço e tempo. Isto provoca a necessidade de interpolação nos dados, o que gera uma incerteza denominada por eles de ñncerteza de interpolaçãoò $A$ incerteza na medida pode ser minimizada através do uso de dados mais acurados, ou de testes laboratoriais com instrumentos de medidas mais precisos, ou ainda por repetidas medidas com o mesmo instrumento, visando determinar o erro associado ao instrumento de medida e determinando uma possível curva de distribuição.

No caso especifico de fluxo de água no solo, Brown \& Heuvelink 1998, sugerem que, para ter uma boa medida do fluxo, a melhor abordagem consiste em dividir o solo que compõe

\footnotetext{
${ }^{11}$ Por exemplo, se um modelo é usado de forma eficiente para uma faixa de temperatura entre 20 e 30 Graus Celsius, este modelo pode não se comportar de foma adequada em um fenômeno semelhante mas em um evento onde a faixa de temperatura varia entre 25 e 40 Graus Celsius

12 Que se dedicaram ao estudo das incertezas associadas ao fluxo de água no solo.
} 
o campo a ser estudado em pequenos pedaços de solo que apresentem características homogêneas (Volts \& Webster, 1990). Muitas vezes, porém isto não é possível ou não é adequado já que as variáveis associadas ao solo variam no espaço e no tempo. Para resolver este problema os autores sugerem o uso de técnicas estatísticas e de geoestatísticas que podem não apresentar o valor mais preciso, mas permitem trabalhar com o mais provável. Isto pode ser aplicado em problemas diversos do usado pelos autores.

Para se obter uma boa estimativa dos parâmetros de modelos utiliza-se o julgamento de rexpertsò já que muitos dados precisam ser processados e interpretados por pessoas. Por vezes, para se ter valores mais precisos dos dados, a única ferramenta disponível é o julgamento de um especialista que, assim, se torna essencial. O chamado ñexpert elicitationò formaliza o processo de se estimar os parâmetros a partir do julgamento de especialistas (Cooke 1991; Kaplan 1992). Este processo é utilizado em diversos estudos relacionados a riscos ambientais (Morgan et al 2001). Modelos probabilísticos são largamente influenciados por processos subjetivos já que as opiniões humanas possuem uma variação probabilística própria. Isto pode ser associado ao fato de que sempre algum pessimismo ou otimismo é atribuído ao estudo (Morgan \& Henrion 1990). A incerteza é uma construção inerentemente social, principalmente se o estudo é realizado de forma livre sem a utilização de controles rígidos que possibilitariam balizar a opinião do r̃expertò

Modelos são inerentemente imperfeitos porque eles abstraem e simplificam situações reais ou processos que muitas vezes são imperfeitamente conhecidos ou interpretados. $O$ estudo do modelo assim permite prever o seu desempenho e sua habilidade para explicar e interpretar um fenômeno ( Beven , 2001).

\subsubsection{Componentes da incerteza em modelos}

A incerteza em modelos pode ser estrutural (incerteza conceitual ou lógica), incerteza nos parâmetros do modelo ou ainda a incerteza na solução do modelo (Addiscott et al, 1995). Por exemplo, de acordo com Brown \& Heuvelink (1998), um modelo hidrológico do solo poderia ignorar o fluxo macroporo ( isto é, o fluxo que ocorre em um nível superior ao dos poros do solo); neste caso têm-se uma incerteza estrutural que está associada à lógica da construção do modelo. Pode ainda haver dúvida sobre o valor da condutividade hidrológica do solo (incerteza paramétrica). E, finalmente, este modelo pode ser resolvido usando um conjunto de equações diferenciais parciais (incerteza na solução).

Incertezas no modelo estrutural podem ter como origem a falta de conhecimento sobre o processo real e seu funcionamento ou, ainda, a crença de que o modelo intencionalmente abstrai e simplifica o processo conhecido. Alguns autores alegam que a incerteza nos parâmetros não é necessariamente incerteza, porque não se refere a valores reais e sim a valores empíricos que se ajustam a fenômenos específicos, Brown \& Heuvelink (1998). Por 
exemplo, variando o coeficiente de friccional de um modelo, pode-se permitir que o mesmo seja aplicado a diferentes tipos de superfícies.

Incerteza é a expressão da confiabilidade sobre o r̃conhecidoò tanto o individual como o coletivo, sendo por isto possuidora de certa carga de subjetividade. Diferentes pessoas podem ter diferentes conclusões sobre a incerteza em algo. Estas conclusões são baseadas na sua experiência pessoal e na sua visão sobre os fatos analisados que, em contrapartida, é influenciada pela quantidade de informações disponíveis, Cooke (1991). Esta tendência de avaliação da incerteza não tem nenhuma relação com o mundo real ou o comportamento do sistema, mas mesmo assim o julgamento sobre a incerteza pode ser influenciado de forma indireta pelo meio ambiente. Por exemplo, de acordo com Brown \& Heuvelink(1998), o meio ambiente pode parecer mais ou menos complexo, dependendo do conhecimento que o julgador tem sobre o sistema a ser analisado. Isto se manifesta nas simplificações ${ }^{13}$ : Para o autor, a incerteza difere de ignorância porque a ignorância está associada à falta ou vazio do conhecimento que é associado ao nosso conhecimento imperfeito Smithson (1989), Heuvelink, (1998).

\subsubsection{Representação da incerteza com distribuição de probabilidades}

A determinação exata da realidade é impossível, já que mesmo em processos determinísticos existe uma distorção entre a realidade e a nossa percepção da mesma. Assim, se não se pode determinar um valor exato, pode-se pelo menos determinar as fronteiras ou ainda a tendência que pode apresentar. A distribuição de probabilidades é uma forma conveniente e muito útil para representar variáveis que possuem uma variação natural. $A$ distribuição de probabilidades é uma curva que pode apresentar diversas formas em função de determinados parâmetros. Um destes parâmetros é a variância, que é um indicador da magnitude média da incerteza. Outro elemento que precisa ser especificado é o domínio do modelo probabilístico. O domínio é importante para a determinação dos parâmetros de um modelo. O domínio do modelo probabilístico inclui um conjunto de condições que descreve, às vezes, em que o modelo se tornou válido e os locais ou áreas onde foi aplicável. Um segundo grupo de condições que governam a aplicação de um modelo probabilístico deve incluir ainda o padrão das incertezas no tempo e o padrão das incertezas no espaço, a relação entre a grandeza da incerteza e a magnitude da variável medida e ainda qualquer restrição ao tamanho e padrão imposto por outras variáveis.

\footnotetext{
${ }^{13} \mathrm{Em}$ sua obra o autor cita o seguinte exemplo : As simplificações podem ocorrem em diversos ocasiões como : O evento pode ser tão variável para ser capturado (taxa de infiltração do solo mediterrâneo); pode ainda ser vasto e interconectado para ser observado o tempo todo ou ainda muito pequeno para ser observado em escalas práticas, ou tão opaco para ser observado (condutividade hidráulica) ou, finalmente, pode-se não ter capacidade de observar ( que ocorre no que eles chamam de ñsoil matrix over large areasò)
} 
A correlação entre as diversas variáveis que compõem o modelo deve ser analisada com bastante cuidado, já que, além de fornecer informações importantes sobre a dependência entre elas, permite também que se conheça com mais precisão o efeito que a incerteza em uma variável pode provocar em outra ou no resultado final. O padrão das incertezas no tempo e no espaço sofre influência da correlação das variáveis nestes dois meios. Similarmente, quando se trabalha com diversas variáveis, o erro de correlação ou r̃cross correlationò permite também identificar o tipo de relação que existe entre as variáveis (p.e, os valores extremos de uma variável podem coincidir com os valores extremos de outra variável de forma positiva ou negativa $)^{14}$.

\subsubsection{Validação do modelo.}

A validação do modelo consiste em verificar se as previsões fornecidas são compatíveis com as observações realizadas na situação real. Neste caso os dados experimentais são comparados com dados reais e assim são verificados os parâmetros do modelo e sua adequação com a realidade. Um bom exemplo foi o estudo sistemático de fenômenos ambientais promovido na Europa por uma série de instituições no ñHarmonisation within Atmospheric Dispersion Modelling for Regulatory Purposesò Este estudo foi lançado em 1991 para promover o aumento da cooperação e da padronização em modelos de dispersão atmosférica, com propósito de regulação (Olsen, 2001). Após algumas conferências e workshops foi concluído o Tíit de validação de um modeloà que é um ñpacoteò com três conjuntos de dados experimentais que são acompanhados por um software de avaliação de modelo de dispersão. Informações complementares podem ser obtidas em www.dmu.dk/AtmosphericEnvironment/harmoni.htm (2002-02-05).

Uma regra geral em validação de modelos é que nunca é possível utilizar um modelo em todas as situações; deve-se determinar o intervalo de validade do modelo. Outro problema consiste em que nem sempre se pode verificar de forma ampla a utilidade de um modelo, já que o modelo não possui as limitações físicas do mundo real; assim, uma situação fática qualquer, referente ao processo que está sendo modelado, pode não ser verificada, mas pode ser modelada ${ }^{15}$.

\subsubsection{Tratamento da incerteza em uma situação prática}

\footnotetext{
14 Por exemplo, de acordo com Brown \& Heuvelink 1998, as concentrações de Cadmio e Zinco em um solo poluído são extremamente correlacionadas e, por conseqüência, associadas, facilitando o estudo e a determinação dos valores.

15 Para saber mais sobre métodos de avaliação de modelos pode-se ver em COWI (1996c) ou em ñModel Evaluation Group (1994)ò. Para práticas de validação de modelos veja em Hanna et al (1991).
} 
Como visto anteriormente, a incerteza em modelos é uma das maiores fontes de incertezas em um processo de AR. Apesar disto, há poucos trabalhos acadêmicos sobre o estudo da incerteza em modelos. Em um estudo de Abrahamssom,2000, procurou-se observar a importância que os pesquisadores dão ao estudo dos modelos. Mais especificamente o autor abordou a relação entre as incertezas nos modelos e a importância dada a elas pelos pesquisadores. Neste estudo, pode-se observar que dificilmente os estudiosos abordam de forma explícita as incertezas que vêem dos modelos. Em muitos destes estudos, em que diversos modelos são estudados, nenhuma observação é feita com relação ao modelo e suas incertezas intrínsecas e extrínsecas.

Em contrapartida, é um desafio, nos trabalhos analisados, extrair regras gerais para o tratamento de incerteza em modelos e como o modelo pode satisfazer a todas as situações de ordem prática a que são submetidos. Um princípio que pode ser estabelecido é que, em algumas situações, uma discussão qualitativa é suficiente, porém em outras situações uma análise mais sofisticada se faz necessária. A partir do que já se estudou a respeito de avaliação da incerteza de modelos, é possível traçar três abordagens clássicas para quantificar a incerteza em modelos em um estudo de risco.

A primeira delas é conhecida como ñinhas mestras de abordagem com utilização de metodologia holandesaò estabelecida pelo órgão responsável na Holanda pelo controle e normatização na área de risco ${ }^{16}$. A sua principal característica é estabelecer quais modelos devem ser usados em situações específicas e em diferentes estágios da análise de risco. Assim, o estudioso pode utilizar vários modelos determinísticos prévios (que são definidos de forma rígida) que são disponibilizados pelo Comitê. A definição de qual o modelo deve ser usado dependerá da situação fática em estudo.

Outro método de abordagem, que é denominada de semiquantitativa, procura classificar o modelo de acordo com características pré-concebidas. Este método é apresentado em publicação dinamarquesa de 1996, denominada COWI ${ }^{17}$. Esta Norma dinamarquesa estabelece uma série de paradigmas que podem ser usados para estabelecer o grau de confiança no modelo; ela se baseia em três características: relevância, validade e variabilidade natural. A relevância se refere a como um modelo cobre uma situação específica; a validade analisa o processo de validação do modelo, ou seja, a aderência entre o modelo e a situação real; a variabilidade lida com a variabilidade natural do modelo.

Considerando estas três subclasses, é feita uma avaliação semiquantitativa do modelo por meio de uma tabela, que o classifica de acordo com o grau que é atribuído a cada uma das subclasses. Assim, é efetuada uma operação matemática com os diferentes graus que o modelo pode apresentar para cada característica.

\footnotetext{
${ }^{16}$ Trata-se do Committee for the Prevention of Disasters, no estudo denominado Guidelines for Quantitative Risk Assessment CPRI8E ñPurple bookò.

${ }_{17}$ Em dinamarquês Usikkerhedsbeskrivelse $i$ kvantitative risikoanalyser $\mathrm{Ï} \mathrm{vejledning.}$
} 
Os valores obtidos a partir da tabelas são utilizados para o cálculo final da incerteza. A tabela 4.1 apresenta uma classificação de incerteza do modelo em função de suas características de relevância, validade e variabilidade.

Assim um modelo pode ser avaliado pelo seu analista como de relevância igual a 11 (baixa relevância, ou seja, o modelo não cobre exatamente a situação, por se tratar de uma aproximação do modelo ideal; por exemplo, o modelo que simula a emissão de jatos de fogo em rraisersò petrolíferos), com validade 3 ( valor baixo causado por poucas simulações, ou verificações de aderência entre o modelo e o processo real) e com variabilidade igual a 1 ( baixa variabilidade, ou seja é um processo da natureza bem definido e com leis bem determinadas, com alta previsibilidade; por exemplo, o movimento de uma esfera metálica em uma superfície lisa) . O símbolo $\mathrm{UF}_{\mathrm{i}}$ define o grau de confiabilidade do modelo segundo cada uma das características: $\mathrm{i}=1$ para a relevância, $\mathrm{i}=2$ para a validade $\mathrm{e} \mathrm{i}=3$ para a variabilidade.

Tabela 4.1 Sub-Classes da Incerteza do Modelo UF $_{\mathrm{i}}$ (Adaptado de COWl, 1996a)

\begin{tabular}{|l|l|l|l|}
\hline & $\begin{array}{l}\text { Pequena Incerteza } \\
1<\mathrm{UF}_{i}<2\end{array}$ & $\begin{array}{l}\text { Média Incerteza } \\
2<\mathrm{UF}_{i}<10\end{array}$ & $\begin{array}{l}\text { Grande Incerteza } \\
10<\mathrm{UF}_{\mathrm{i}}\end{array}$ \\
\hline Relevância UF & Alta & Média & Baixa \\
\hline Validade $\mathrm{UF}_{2}$ & Alta & Média & Baixa \\
\hline Variabilidade $\mathrm{UF}_{3}$ & Baixa & Média & Alta \\
\hline
\end{tabular}

A classificação irá obviamente depender do analista ou especialista no modelo

A incerteza total do modelo, UF, pode ser calculada pela fórmula abaixo, em função do grau de incerteza das diferentes características: relevância, validade e variabilidade. Como são usadas somente três características, o valor de m̃òé igual a três.

$$
U F=\exp \left(\sum_{i=1}^{n}\left(\ln U F_{i}\right)^{2}\right)^{\frac{1}{2}}
$$

Porém, poderia ser adotada uma forma mais precisa e complexa para o cálculo da incerteza no modelo, atribuindo outras características, além das três já indicadas. Este caso é apresentado na tabela 4.2, e será melhor explicado no capítulo 7; ele também foi extraído de uma versão mais completa de COWI ( 1996a). Esta abordagem, de quantificar a incerteza em modelos, adotado pelos holandeses, foi iniciada a partir de um esforço dos dinamarqueses de normatizar as linhas mestras para o tratamento da incerteza, e começou com a publicação do ñDescription of uncertainty in quantitative Risk Analysis in Oil/Gás industryò na Dinamarca em 1994, em conjunto com inúmeros participantes, COWI ( 1996 a-d). O projeto foi finalizado em 
1996 e quatro artigos foram publicados. O Guia tratou a incerteza em 3 diferentes níveis de análise: nenhuma descrição da incerteza, pouco grau de incerteza e grande grau de incerteza. Para cada um destes níveis há uma descrição de como tratar e como apresentar o tipo de incerteza de forma adequada.

Uma forma mais completa de definir a confiabilidade dos modelos foi proposta no ano seguinte pela publicação dinamarquesa COWI, como apresentado na tabela 4.2. Desta vez, ao invés das características básicas: relevância, variabilidade e validade, são propostas outras características mais complexas que facilitam o seu uso pelo analista.

Uma terceira e última abordagem seria usar diferentes modelos ao mesmo tempo (ou seja, em paralelo), de forma a poder avaliar como eles se diferenciam entre e si e, assim, tentar estabelecer uma maior credibilidade dos resultados. Trata-se na verdade de uma forma empírica e prática de comparar diferentes modelos e concluir qual é mais adequado para cada processo. Esta última metodologia é mais adequada em modelos mais simples que podem ser facilmente simulados em laboratório ou, em último caso, simulados computacionalmente.

A compreensão sobre as limitações e eventuais erros do modelo permite ao analista um conhecimento mais completo de todo o processo e, em conseqüência, uma avaliação de risco mais precisa.

Tabela 4.2 Sub-Classes da Incerteza do Modelo UF, análise completa (Adaptado de COWI, 1996a)

\begin{tabular}{|c|c|c|c|}
\hline & $\begin{array}{l}\text { Pequena incerteza } \\
1<U F i<2\end{array}$ & $\begin{array}{l}\text { Incerteza Média } \\
2<\mathrm{UFi}<10\end{array}$ & $\begin{array}{l}\text { Grande Incerteza } \\
\mathrm{UFi}<10\end{array}$ \\
\hline $\begin{array}{lr}\text { Experiência } & \text { do } \\
\text { analista } & \text { e } \\
\text { Competência } & \end{array}$ & $\begin{array}{l}\text { Vasta. O analista e } \\
\text { qualificado e possui } \\
\text { experiência }\end{array}$ & $\begin{array}{l}\text { Razoável. O } \\
\text { analista é capaz } \\
\text { de estimar a } \\
\text { grande maioria } \\
\text { das incertezas } \\
\text { envolvidas }\end{array}$ & $\begin{array}{l}\text { Pequeno. O analista pode } \\
\text { apenas especificar a } \\
\text { incerteza envolvida em } \\
\text { algumas variáveis }\end{array}$ \\
\hline $\begin{array}{l}\text { Conhecimento } \\
\text { anterior e condições } \\
\text { do projeto }\end{array}$ & Vasto & Razoável & Pequeno \\
\hline $\begin{array}{l}\text { Tempo disponível e } \\
\text { recursos }\end{array}$ & Suficiente & Razoável & Não suficiente \\
\hline $\begin{array}{l}\text { Conhecimento } \\
\text { Geral na área } \\
\text { específica }\end{array}$ & $\begin{array}{lr}\text { Vasto. A área } \\
\text { específica } \\
\text { conhecimento é bem } \\
\text { conhecida. Há um } \\
\text { consenso } & \text { dos } \\
\text { especialistas } & \\
\end{array}$ & $\begin{array}{l}\text { Há alguma falta } \\
\text { de conhecimento } \\
\text { ou não } \\
\text { concordância dos } \\
\text { analistas }\end{array}$ & $\begin{array}{l}\text { Há uma substancial falta } \\
\text { de conhecimento }\end{array}$ \\
\hline
\end{tabular}




\subsection{Considerações finais.}

Neste capítulo são apresentadas considerações sobre os modelos e suas incertezas Estas incertezas serão tratadas nesta tese como pertencentes a um dos grupos na classificação que é apresentada no capítulo 9. Posteriormente a identificação e classificação têm-se a etapa seguinte, que consiste no tratamento e minimização das incertezas. 


\section{CAPÍTULO 5}

\section{O JULGAMENTO DE ESPECIALISTAS EM ANÁLISE DE RISCO}

\subsection{Discussão geral}

Este capítulo tem como objetivo mostrar que o processo de tomada de decisão, com base em julgamento de especialistas, carrega consigo diversas imperfeições, que muitas vezes independem da boa vontade ou do profundo conhecimento específico do analista. Trata-se na verdade de um processo subjetivo inerente a qualquer processo cognitivo experimentado pela mente humana. A análise de risco, como qualquer produto da mente humana, incorpora todos os defeitos e virtudes que o ser humano pode gerar. Por esta razão, atualmente crescem em importância os estudos dos mecanismos psicológicos utilizados pelo homem no processo de tomada de decisão. Serão apresentados alguns métodos para entender e agregar informações de especialistas. Muitos métodos estruturais podem ser usados para compreender melhor a informação baseada na opinião de vários especialistas. Morgan \& Henrion (1990) estudaram com profundidade estes mecanismos e são os autores mais referenciados na literatura para tratar a incerteza que deriva do erro subjetivo dos especialistas.

Outra discussão necessária é avaliar o comportamento mental humano e a criação de heurísticas e vieses na resolução de problemas. Segundo os estudos de Amos Tversky e Daniel Kahnemann (1974), heurísticas ${ }^{18}$ são atalhos mentais que tornam mais leve a carga cognitiva de tomar decisões, mas que podem conduzir a vieses no processo de decisão. As heurísticas, segundo eles, são o meio pelos quais os agentes encontram soluções ótimas, levando em consideração os custos para tomar decisões plenamente racionais, uma vez que é da natureza humana a existência de restrições ao exercício da plena e ilimitada racionalidade. Os vieses cognitivos são erros sistemáticos de julgamento, ou melhor, são erros mentais causados por simplificação da estratégia de processamento da informação, que ocasionam muitas vezes uma distorção na maneira como os indivíduos percebem a realidade.

\footnotetext{
${ }^{18}$ Os autores, descrevem três heurísticas utilizadas no processo de tomada de decisão em situações de incerteza: (a) heurística da representatividade, usualmente empregada quando as pessoas são questionadas a estimar a probabilidade de ocorrência de um objeto ou evento A, pertencente a uma classe ou processo B; (b) heurística da disponibilidade para exemplos ou cenários, é freqüentemente utilizada quando as pessoas são questionadas a calcular a freqüência de uma classe ou a plausibilidade de um desenvolvimento particular e; (c) Ajustamento ou ancoragem, é utilizada em previsões numéricas quando um valor serve de parâmetro para uma estimativa (Tversky e Kahneman, 1974, p. 1131). A seguir as heurísticas serão apresentadas detalhadamente. .
} 


\subsection{Protocolo de avaliação por especialistas}

Um primeiro conceito que deve ser compreendido é que não há uma estrutura simples que garanta o sucesso de um estudo, mesmo que ele seja conduzido por um grupo de especialistas de alto renome. O primeiro problema que surge é como deve ser a composição do grupo que irá analisar um dado processo ou um dado fenômeno. Para uma dada situação, diferentes metodologias podem ser usadas para selecionar e compor o grupo de especialistas que irá estudar o problema. Um método simplificado de representação de uma metodologia é apresentado por Clemen (1996); abaixo são reproduzidos os passos sugeridos.

1. Avaliação inicial, i.e. Identificação e descrição das variáveis que eventualmente podem necessitar de um especialista para sua especificação ou mensuração. Isto pode ser feito usando conhecimentos dos eventos anteriores a partir da literatura científica ou ainda poderia vir do conhecimento de especialistas.

2. Identificação e recrutamento de especialistas: possivelmente pode-se solicitar ajuda de associações profissionais.

3. Manter os Especialistas Motivados: alguns cientistas são relutantes em participar de certos exercícios porque temem que suas opiniões não estejam cientificamente corretas. Entretanto, algumas variáveis que requerem avaliação de especialistas não podem ser determinadas usando métodos tradicionais e científicos. Nestes casos as decisões precisam ser feitas usando a melhor informação disponível principalmente quando não há alternativas realistas.

4. Estrutura e decomposição: i.e. os especialistas devem contribuir para um melhor entendimento das relações causais e estatísticas entre as diferentes variáveis que compõem o estudo. Por exemplo, uma determinada distribuição de probabilidade de uma variável de entrada pode ser condicionada a distribuição de outra variável de entrada e, por conseqüência, permitir estabelecer algumas conclusões preliminares sobre o estudo que está sendo realizado. 5. Treinamento para avaliação de probabilidades: explicação dos princípios básicos da avaliação e de heurísticas conhecidas e vieses relacionados com tais exercícios.

6. Elicitação e verificação de probabilidades: processo real de avaliação das variáveis desconhecidas pelo especialista, sempre sob a orientação de um indivíduo treinado no processo de elicitação.

7. Agregação de diferentes opiniões de especialistas.

Maiores informações podem ser obtidas em Clemen (1996) and ñAttributes of a Good Assessment Protocolòou ainda Morgan \& Henrion (1990). 


\subsection{Processo subjetivo de avaliação}

Daniel Kahneman e Amos Tversky, dois psicólogos de Israel que emigraram para a América do Norte, argumentam que, enquanto disciplinas formais ï como a Lógica e a Matemática ï fornecem procedimentos computacionais normativos para se chegar à solução de vários tipos de problemas, o raciocínio comum tem pouco ou nenhum acesso a tais procedimentos e depende, ao invés disso, de uma série de heurísticas não-lógicas. O conceito de heurística foi introduzido por Simon $(1957,1982)$, em suas explorações sobre os limites do raciocínio dos seres humanos, para indicar algumas estratégias ao mesmo tempo econômicas/parcimoniosas, econômicas/eficazes, mas não sistemáticas de resolução dos problemas. Tais heurísticas ou estratégias de pensamento são procedimentos não sistemáticos de tipo informal, aproximações práticas, ou então apenas estratégias gerais, mas não os algoritmos exatos fornecidos pelas teorias normativas. De fato, enquanto a ativação de uma heurística pode levar à solução correta de um problema, sua aplicação não garante necessariamente que esta solução seja sempre alcançada. É possível que, em outros casos, esta mesma heurística seja capaz de produzir resultados diferentes daqueles obtidos através da aplicação das regras matemáticas. Estes resultados diferentes consistem geralmente em erros sistemáticos.

\subsubsection{A abordagem por meio de vieses e heurísticas.}

De acordo com Tversky e Kahneman (1974), as pessoas utilizam um limitado número de princípios heurísticos (atalhos mentais) e vieses cognitivos, os quais minimizam a difícil tarefa de estimar as probabilidades e calcular valores em operações de julgamento. Ressaltam que, por mais que essas heurísticas e vieses sejam úteis por vezes, direcionam os indivíduos a cometerem erros sistemáticos e graves no processo de tomada de decisão. Como Kahneman e Riepe (1998, p. 53) afirmam: ñnvestidores que são propensos a estas heurísticas e vieses cognitivos, correm mais riscos que não reconhecem, experimentam resultados que não podem antecipar, serão propensos a negociações não justificadas e podem acabar culpando a si mesmos ou outros por maus resultadosò

Entre as heurísticas propostas por Kahneman e Tversky (1982), Tversky e Kahneman $(1973,1982)$ estão a representatividade (julgamentos influenciados pelo o que é típico), disponibilidade (julgamentos baseados no que é mais facilmente relembrado), prototipicidade ou controle (julgamentos que se fundamentam em modelos prototípicos), ancoragem (julgamentos que se baseiam no que vem primeiro).

A estratégia geral de Kahneman e Tversky tem sido a de apresentar problemas de raciocínio, para os quais um juízo normativo pode ser definido, e para os quais respostas que correspondam a tal juízo são raras. De acordo com a teoria, esses rerros sistemáticosòï que 
podem decorrer da ativação tanto de vieses como de uma ou mais heurísticas (ou atalhos) ${ }^{19}$ representam, portanto, a diferença entre o desempenho real e o normativamente correto.

\subsubsection{Disponibilidade}

Uma das mais importantes heurísticas sugeridas por Kahneman e Tversky é a da disponibilidade. Em um experimento realizado por estes dois pesquisadores (Tversky \& Kahneman, 1973), solicitava-se que os participantes avaliassem a probabilidade ou freqüência de uma determinada letra do alfabeto ( $K, L, N, R$ ou $V$ ) se encontrar no começo de uma palavra, comparando com a probabilidade, por exemplo, da mesma letra se encontrar na terceira posição. Apesar das cinco consoantes serem mais freqüentes na terceira posição, 2/3 dos participantes do estudo julgavam que a primeira posição era mais provável para a maioria das letras. ${ }^{20}$ Isto se deve ao fato de que as pessoas fundamentam suas estimativas na disponibilidade relativa de palavras destes dois tipos, i.e., na facilidade de relembrar palavras que possuem a letra solicitada respectivamente na primeira e na terceira posição. Por exemplo, faz sentido pressupor ser mais fácil relembrar palavras que possuem a letra r̃ò na primeira posição (Ex.:r̃uaò), comparativamente com palavras que possuem a mesma letra na terceira posição (Ex.:ĩcaraò). Conseqüentemente, se as estimativas são baseadas na probabilidade gerada pela disponibilidade relativa destas palavras, as estimativas serão erradas em todos aqueles casos ou eventos nos quais as freqüências reais são diferentes daquelas que podem ser calculadas, exatamente, de acordo com a disponibilidade.

A Figura 5.1 apresenta um outro exemplo, com os resultados do julgamento feito pelos participantes do estudo sobre as causas de morte comparados com as causas efetivas da morte por ano.

\footnotetext{
${ }^{19}$ Para Kahneman e Tversky as heurísticas cognitivas podem estar tanto conexas com a especificidade da informação particular (Tversky \& Kahneman,1980),como associadas à ausência de causalidade (Kahneman \& Tversky,1980).Entre outros fatores explicativos do fenômeno observado podem ser citados a saliência (Nisbett \&Borgida,1975)e a pertinência (Bar-Hillel,1983)

${ }^{20}$ Para uma discussão mais aprofundada neste tópico ver também Lopes e Oden (1991)e Sedlmeier,Hertwig e Gigerenzer (1998).
} 


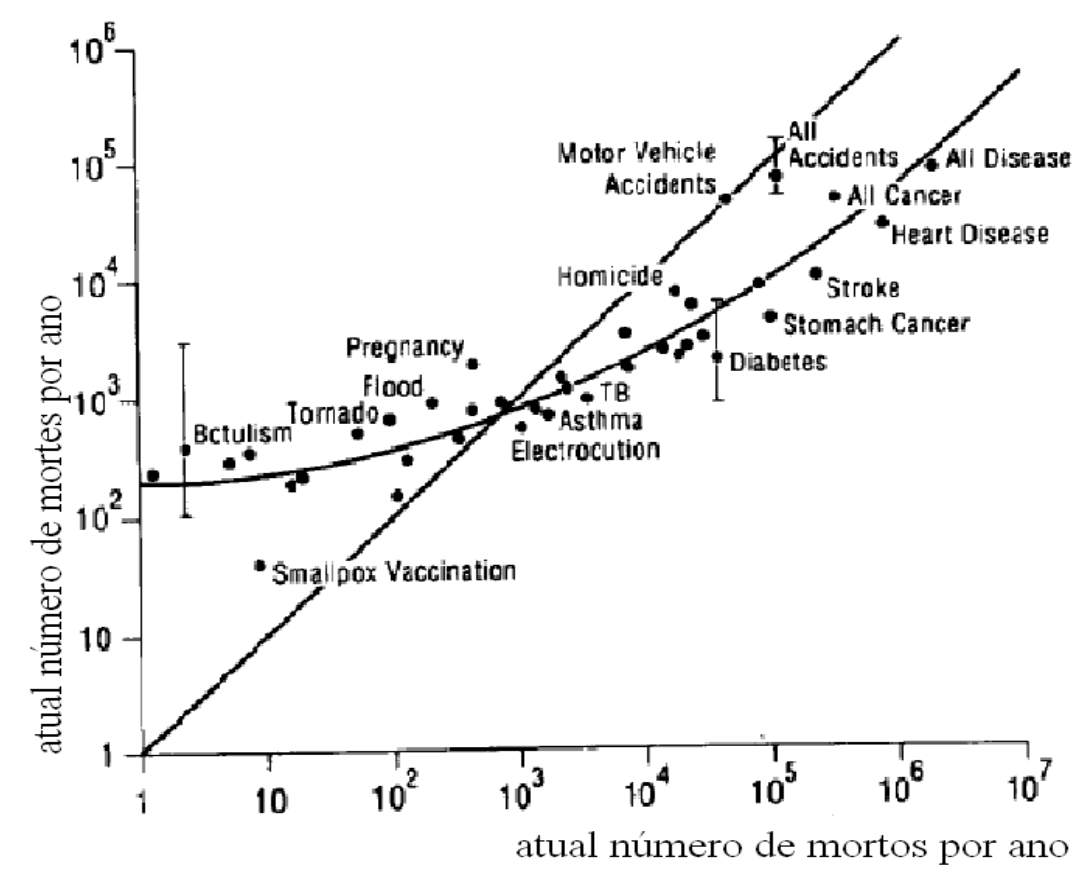

Figura 5.1 Relação entre a freqüência do julgamento e o número atual de mortes (extraída de Slovic, Fischoff e Lichtenstein, 1982)

No eixo das abscissas é apresentado o número real de mortes/ano e no eixo das ordenadas a estimativa de mortes/ano.

Para a análise da figura, deve-se observar que se o julgamento e a freqüência atual são iguais, o dado estará na linha reta. Os pontos, e a curva traçada, representam a média da resposta. No caso de botulismo e diabetes foram traçadas as retas percentis de $25 \%$ e $75 \%$.

Outras aplicações da heurística da disponibilidade podem ser observadas também em julgamentos que dizem respeito a eventos mais realistas do que o acima descrito, sobre a freqüência relativa das palavras. Tversky e Kahneman (1973) verificaram que uma classe de indivíduos que podem ser relembrados com mais facilidade (Ex.: personagens famosas do mundo cinematográfico ou da música) era avaliada como mais numerosa do que uma classe do mesmo tamanho, mas contendo elementos menos fáceis de relembrar. Nesta mesma ótica, apontam os resultados de outros estudos, como o de Brown e Siegler $(1992,1993)$ na estimação de parâmetros demográficos, como o tamanho da população de um país, e o estudo de Lichenstein,Slovic, Fishhoff e Layman (1978) sobre a tendência das pessoas em exagerar a freqüência de algumas causas específicas de morte, apresentadas na figura 5.1. Por exemplo, no estudo de Lichtenstein e colaboradores, verificou-se que as causas de morte que são mais facilmente relembradas, por serem mais divulgadas pelos meios de comunicação, devido a sua natureza mais espetacular e violenta, são superestimadas em relação à sua freqüência real (Ex.: mortes decorrentes de acidentes de avião, furacões). Ao contrário, outras causas de morte menos noticiadas, visto que são mais comuns e, por conseguinte, menos interessantes, 
são menos disponíveis e conseqüentemente subestimadas (Ex.: mortes decorrentes de cirrose hepática ou diabete).Todos estes estudos têm levado os pesquisadores a apontar que a heurística da disponibilidade é uma das mais largamente empregadas assunções em tomadas de decisão ñone of he most widely shared assumptions in the decision making as well as in social judgment research ò(Schwartz \&cols., 1991,p.195).

De acordo com Kahneman e Tversky, as evidências acima apresentadas apontam para o fato de que, nos casos em que é difícil relembrar todos os elementos de uma categoria em que precisa ser computada a freqüência relativa ou absoluta, as estimativas dos indivíduos, se apoiam na facilidade ou maior disponibilidade de acesso a exemplos significativos de tal categoria.

A abordagem teórica dos vieses e das heurísticas de Kahneman e Tversky, e todo o programa de investigação realizado para corroborar esta posição teórica, têm sido submetidos a um exame crítico, e veementemente questionados duramente nos últimos anos por uma série de pesquisadores (Ex.:Cohen,1981,1986;Cosmides\&Tooby,1996;Fiedler,1988;Gigerenzer,1991a,1991b,1996;Gig erenzer\&Hoffrage,1995;Gigerenzer,Todd\&ABC Research Group,1999). Eles argumentam que as leis da teoria da probabilidade podem ser compreendidas mais facilmente quando as estimativas de eventos incertos são solicitadas em termos de freqüências. Em outras palavras, seria mais fácil calcular probabilidades relativas a freqüências do que a eventos únicos ou singulares e, conseqüentemente, seria necessário fornecer informações freqüentistas para poder se obter julgamentos de probabilidade ñbayesianamenteòcorretos.

Por exemplo, os julgamentos de probabilidade que um determinado evento ocorra podem depender da ativação de uma heurística como a da r̃̃lisponibilidadeò que leva a pessoa julgar como mais prováveis os eventos que são mais facilmente relembrados.

Um dos primeiros problemas experimentais que levou ao debate é o problema do táxi ${ }^{21}$. Kahneman e Tversky (1982) argumentaram que a solução normativamente correta de um problema deste tipo consiste em computar a probabilidade a posteriori ${ }^{22}$, tendo como base a informação específica ${ }^{23}$, i.e.,a proporção de casos ñverdadeiro-positivosò e f̃also-positivosò de identificação de um táxi como da cor certa, e da informação relativa à probabilidade de base. Assim, para estes autores, o procedimento computacional normativo para resolver este problema é fornecido pelo Teorema de Bayes, através do qual se pode calcular a probabilidade a posteriori de que um evento $A$ (azul =o táxi é azul) ocorra,dado que um evento $B$

\footnotetext{
${ }^{21}$ O qual se apresenta da seguinte forma: Duas empresas de táxi operam numa dada cidade: a Táxi Azul e a Táxi Verde. 85\% dos táxis na cidade são verdes, enquanto que os $15 \%$ restantes são azuis.Um táxi se envolveu em uma batida e seu motorista fugiu durante a noite.Mais tarde, uma testemunha identificou o táxi como sendo azul.o tribunal examinou a capacidade da testemunha de distinguir entre os táxis verdes e azuis sob as condições noturnas de visibilidade. Foi constatado, que a testemunha identificou cada cor corretamente em $80 \%$ das vezes e confundiu as duas cores em $20 \%$ das vezes. Quais são as chances de que o táxi criminoso tenha sido azul, como a testemunha relatou?

${ }^{22}$ De que o táxi seja efetivamente azul

${ }^{23}$ Isto é a proporção de casos ñverdadeiro-positivosò e ñfalso-positivosò de identificação de um táxi como azul, e da informação relativa à probabilidade de base
} 
independente ${ }^{24}$ (r̃azul ò= testemunha diz que o táxi é azul) também tenha ocorrido. Neste caso, tem-se:

$P(A \mid B)=P(A)^{*} P(B \mid A) /\left[P(A)^{*} P(B \mid A)+P(N a ̃ o A)^{*} P(B \mid N a ̃ o A)\right]$, onde:

ó $\quad P(A \mid B)$ é a probabilidade que o táxi seja azul, dado que a testemunha disse que ele é azul ï probabilidade a posteriori;

$P(A)$ é a probabilidade que um táxi seja azul ï probabilidade a priori $(0,15)^{25}$;

$\mathrm{P}(\mathrm{B} \mid \mathrm{A})$ é a probabilidade que a testemunha diga que o táxi é azul, dado que o táxi é de fato azul $(0,80)^{26}$;

$P(N a ̃ o A)$ é a probabilidade de um táxi ser verde $(0,85)$

$\mathrm{P}(\mathrm{B} \mid$ Não $\mathrm{A})$ é a probabilidade que a testemunha diga que o táxi é azul, dado que o táxi é de fato verde $(0,20)$.

Assim, a fórmula calcula a razão entre a probabilidade dos táxis azuis que seriam identificados corretamente pela testemunha, e a soma da probabilidade dos táxis azuis que seriam identificados corretamente, e da probabilidade dos táxis verdes identificados incorretamente como azuis, i.e., pela probabilidade total que um táxi seja identificado como azul, incluindo as identificações corretas e incorretas.

No exemplo, o evento ñáxi identificado pela testemunha como azulò enquanto azul e verde (sem aspas) indicam as cores reais dos táxis ï e os valores fornecidos no enunciado do problema. Ou seja, com base nos dados disponíveis, ao contrário do que afirmado pela testemunha, existe uma chance de cerca de $41 \%$ dos táxis envolvidos no acidente serem azuis; fato que decorre do maior número de táxis verdes circulantes na cidade. Em termos freqüentistas, é possível afirmar que, em um total de 29 táxis identificados como azuis (independentemente dos mesmos terem sido identificados corretamente ou não), 12 de fato, são azuis e 17, de fato, são verdes. Assim somente $41 \%$ serão efetivamente azuis.

Acontece que tal resposta quase nunca é encontrada nos estudos relatados na literatura. Ao invés disso, a resposta modal, normalmente apresentada por $40-50 \%$ dos sujeitos, é $80 \%$, que coincide com a r̃atendibilidadeòda testemunha, i.e., com a capacidade de identificar corretamente como azul um táxi azul, ou melhor, a probabilidade da testemunha

\footnotetext{
${ }^{24}$ Eventos não-relacionados, que podem ou não ocorrer conjuntamente. Ser motorista de ônibus e gostar de algodão-doce,por exemplo,são eventos independentes.Já ser motorista de ônibus e ser cobrador não são independentes,pois há uma influência de um para com o outro (não se pode ser ambos ao mesmo tempo).

${ }^{25}$ No contexto de problemas de probabilidade condicional, também é conhecida como probabilidade de base ou primária,taxa básica,frequiência populacional ou base rate

${ }^{26}$ Os eventos Não A são todos os eventos que, juntos com A,representam a totalidade dos eventos dependentes possíveis.No exemplo do ônibus,se A for ñser motorista ò,então Não A incluiria ñser cobrador òe ñser passageiro ò

(ñalgodão-doce ònão entra em consideração por ser um evento independente)

Probabilidade a posteriori de A,dado que B

Probabilidade de B,dado que A tenha ocorrido

Probabilidade de B, dado que Não A tenha
} 
fazer uma identificação correta. Não se considera, assim, o número de táxis em circulação (isto é, na avaliação da probabilidade a posteriori, não se considera a probabilidade de base ou primária ï base rate ï que corresponde ao percentual de táxis azuis e verdes em circulação) (Ex.:Bar- Hillel,1980; Birnbaum \& Mellors,1983; Hammerton,1973; Kahneman \& cols.,1982; Kahneman \& Tversky,1973; Lyon \& Slovic,1976). Apenas uma pequena minoria de sujeitos costuma dar uma resposta que aparenta ser claramente influenciada pelas p̃probabilidades de base ou primária (base-rates) dos táxis verdes e azuis ï resultado este denominado como a ñalácia da probabilidade de baseò (base rate fallacy or base-rate neglect: falta de consideração da probabilidade de base). Aparentemente, essas conclusões não dependem do conteúdo específico do problema do táxi, tendo em vista que já foram replicadas em problemas que se referem, por exemplo, ao diagnóstico dado por um mecânico de automóveis (Birnbaum \& Mellors, 1983) ou à identificação de indivíduos com uma dada doença a partir de um teste médico (Heller, Saltzstein \& Caspe,1992).

As respostas apresentadas ao problema dos táxis são consistentes com o uso de heurísticas dessa natureza, porque os sujeitos parecem se concentrar na informação individualizante, excluindo a informação que foi dada sobre as freqüências populacionais. Esta é uma tendência de resposta que seria de se esperar a partir de heurísticas individualizantes, tais como a representatividade ou a dependência de um protótipo.

Abrahamssom denomina esta heurística como r̃availabilityò (disponibilidade). O conceito de r̃availabilityòse preocupa como o fenômeno que ocorre quando indagadas sobre a estimativa do tamanho de uma classe (i.e. o número de mortes devido a fogo residencial em um ano), as pessoas fazem as estimativas em função de elementos subjetivos relacionados ao grau de conhecimento do problema; assim, quando não conhecem algo, as pessoas tendem a desprezar o seu valor.

A Heurística de disponibilidade tem demonstrado exercer considerável impacto nas diferentes percepções de risco. Isto foi visto anteriormente em estudo de Slovic, Fischoff e Lichtenstein (1982), em que se solicita que um grande número de pessoas leigas estime a probabilidade de morte por várias causas diversas. A resposta padrão tende a superestimar muito o risco de causas de mortes bem conhecidas, como botulismo e tornados, quando comparadas com causas pouco conhecidas, como câncer estomacal ou infecção no coração.

A utilização da heurística da disponibilidade pode levar à ocorrência de alguns viéses cognitivos, que são:

- Viés decorrente da recuperabilidade de exemplos - avaliação do tamanho de uma classe pela facilidade de recuperação, devido à ocorrência de um número maior de exemplos.

- Viés da imaginibilidade - avaliação da possibilidade de ocorrência de eventos que não estão armazenados na memória através da geração de respostas baseadas em determinadas regras. 


\subsubsection{Representatividade}

Kahneman e Tversky (1972) afirmam que a heurística da representatividade é empregada pelas pessoas quando estimam a probabilidade de um evento incerto nos casos em que: (a) ele é similar ou representativo da população de que se origina; (b) se o grau reflete os aspectos proeminentes do processo pelo qual é gerado (tal como o acaso). O uso da heurística da representatividade ocorre quando não se consegue entender o conceito de estimativas básicas - a prevalência de um evento ou de uma característica dentro de sua população de eventos ou de características (Zindel, 2008). Zindel afirma que outro motivo é a insensibilidade ao tamanho da amostra já que, de acordo com Kahneman e Tversky(1972), acredita-se erroneamente que pequenas amostras de eventos, pessoas, etc, assemelham-se em todos os aspectos, à população inteira da qual a amostra é extraída. Subestima-se a probabilidade de que as características de uma pequena amostra de uma população representem inadequadamente as de toda a população. Também há uma tendência em se utilizar a heurística da representatividade quando se está muito consciente da evidência casuística baseada em uma amostra muito pequena da população (Kahneman e Tversky, 1974, p.1124).

A utilização da heurística da representatividade pode levar a ocorrência de alguns viéses cognitivos, tais como:

Insensibilidade à probabilidade dos resultados anteriores - tendência a ignorar as probabilidades de resultados anteriores ou a freqüência de estimativas básicas de resultados;

Insensibilidade ao tamanho da amostra - dificuldade em avaliar a probabilidade de obter um determinado resultado em uma amostra específica de uma população;

Concepção errônea de acaso - expectativa de que uma seqüência de dados gerados por um processo aleatório represente as características essenciais do processo, mesmo que a seqüência do evento seja demasiadamente pequena para que seja estatisticamente válida. Nesse caso, o acaso é percebido como um processo de autocorreção, no qual um desvio, em uma determinada direção, induz ao desvio na direção oposta para restaurar o equilíbrio. Considere-se o problema de Linda como exemplificação da heurística da representatividade (julgamentos influenciados pelo que é típico). Em um determinado estudo, Tversky e Kahneman $(1982,1983)$ apresentaram aos participantes uma rápida descrição de uma jovem chamada Linda. Este estudo pode ser lido em r̂́Sobre o Debate Freqüentista Versus Probabilista: Sorte de Toloò É feita uma síntese do texto de Antonio Roazzi, Universidade Federal de Pernambuco e David P. Oßrien do Baruch College and the Graduate Center of the City University of New York e Maria da Graça B. B. Dias Universidade Federal de Pernambuco, que extraíram suas idéias e exemplos de Tversky e Kahneman (1982,1983):

Linda tem 31 anos, não é casada, é extrovertida e brilhante. É formada em filosofia e quando era estudante universitária era bastante engajada politicamente e participava de muitas manifestações antinucleares. 
Em seguida, apresentavam-se oito sentenças relativas às atividades de Linda e perguntava-se qual das sentenças descritivas de Linda mais provavelmente dizia a verdade a respeito da mesma. Mais especificamente, o sujeito devia ordenar as sentenças do nível mais provável para o nível menos provável. Abaixo são apresentadas três destas sentenças que o sujeito tinha que ordenar:

1. Descrição A: r̃Linda é uma bancáriaò

2. Descrição B: ñinda é uma feministaò

3. Descrição $A$ e B: ñ Linda é uma bancária e uma feministaò

A maioria dos sujeitos escolhia a sentença 3 como mais provável do que as outras duas, embora a teoria da probabilidade canônica de eventos conjuntos afirme que a probabilidade de um conjunto isolado é sempre maior ou igual à probabilidade daquele conjunto em interseção com um outro ${ }^{27}$. Mais especificamente, aproximadamente $90 \%$ dos sujeitos consideravam a sentença 1 (Descrição A) Linda é uma bancária como menos provável do que a sentença 3 (Descrição A e B) Linda é uma bancária e uma feminista. Desta forma, os julgamentos dos indivíduos violam o principio estatístico e lógico de inclusão de classes, possibilitando a ocorrência do erro ou falácia de conjunção (conjunction fallacy), isto é, uma avaliação da probabilidade de dois eventos conjuntos superiores à probabilidade de eventos isolados. Segundo Tversky e Kahneman (1982), isso é uma evidência do uso de uma T̃eurística da representatividadeò já que a idéia ou imagem geral de uma jovem que é uma feminista é mais representativa do que a idéia ou imagem de uma jovem que é uma bancária. Assim, ao se comparar a descrição Linda é uma bancária e uma feminista ( $A$ e B), como menos provável, visto que menos específica, com a descrição Linda é uma bancária (A), a descrição r̃A e Bòacaba sendo avaliada como mais provável do que a descrição r̃a ơ $^{8}$, visto que o traço r̃ser feminista òrepresenta adequadamente tudo o que se sabe sobre Linda, e, por isso, é mais representativo sobre ela. Assim, a heurística da representatividade de um evento pode levar as pessoas a uma avaliação errada da probabilidade de um evento ocorrer. O problema de Linda é bem conhecido na literatura da área.

Considere-se um outro problema, o dos engenheiros/ advogados, elaborado por Kahneman e Tversky (1973). Neste problema, pede-se também ao sujeito para calcular a probabilidade a posteriori da ocorrência de um determinado evento que, apesar de ser bem menos complexo do que o problema do táxi ou da doença ï anteriormente apresentados ï parece, da mesma forma, produzir, em geral, respostas erradas peculiares.

Um grupo de psicólogos analisou a personalidade de 70 engenheiros e 30 advogados (experimento 1); em um segundo experimento os engenheiros eram 30 e os advogados 70 ). $A$

\footnotetext{
${ }^{27}$ Considerando $\mathrm{A}$ e $\mathrm{B}$ como eventos,a probabilidade $(\mathrm{P}) \mathrm{de} \mathrm{A}$ ou $\mathrm{B}$ ocorrer é sempre maior ou igual à probabilidade de ocorrerem A e B ao mesmo tempo:P(A e B) $\square \mathrm{P}$ (A)ou $\mathrm{P}$ (B).Este princípio estatístico pode ser visto como uma forma específica do princípio lógico de inclusão de classes,de acordo com o qual um conjunto é sempre superior a/ou igual a soma de cada uma de suas partes

${ }^{28}$ A possibilidade de que, neste caso em particular, a representatividade pode ser culturalmente específica é de pouca importância para fins da presente discussão
} 
partir desta análise, os psicólogos elaboraram fichas descritivas de cada uma das 100 pessoas entrevistadas. Do total destas fichas, são extraídas, ao acaso, cinco. Qual a probabilidade desta ficha pertencer a uma das duas categorias profissionais? (Esta probabilidade era avaliada em uma escala que variava de 0 a 100).

Um exemplo de ficha extraída é apresentado a seguir:

João tem 45 anos, é casado e tem quatro filhos. Tende a ser bastante conservador e é muito cuidadoso e ambicioso. Não possui qualquer interesse na área política e social e passa a maioria do seu tempo livre em atividades como fazer pequenos consertos, passear de barco à vela e se entreter em jogos matemáticos.

Para resolver este problema, é necessário considerar que a probabilidade de base de que um indivíduo escolhido ao acaso, a partir da amostra, seja um engenheiro é muito diferente nas duas condições ( $70 \%$ na condição 1, e 30\% na condição 2). Entretanto, apesar da diferença na probabilidade de base, a maioria dos indivíduos não apresentava julgamentos de probabilidades diferentes nas duas condições. Geralmente, estimavam uma mesma probabilidade $і ̈$ que João fosse um engenheiro nas duas condições; mesmo quando os engenheiros eram menos (30\%), julgavam como mais provável que a ficha escolhida fosse de um engenheiro. Considerando este problema, e o julgamento do ponto de vista estatístico, pode-se afirmar que os sujeitos entrevistados não consideravam a probabilidade de base e focalizavam a atenção para fornecer o julgamento probabilista nos dados relativos às fichas descritivas fornecidas pelo entrevistador. Por outro lado, quando se solicitava ao sujeito julgar a probabilidade de um indivíduo qualquer, escolhido ao acaso entre os dois grupos de profissionais, sem a apresentação da ficha descritiva, ser um engenheiro, eles, ao responderem, consideravam a probabilidade de base, isto é, seus julgamentos se diferenciavam em função do número relativo de engenheiros iniciais (70 ou 30).

Para Tversky e Kahneman esta tendência em não considerar a probabilidade de base $e$, conseqüentemente, fornecer respostas erradas, opostas àquelas que manifestam a tendência ao assim denominado r̃̃onservadorismoò corresponde a uma super avaliação da probabilidade de base. Isto é determinado pela heurística da r̃epresentatividadeò (Tversky \& Kahneman,1982). Através deste termo, como se pode inferir, define-se a relação de similaridade entre um indivíduo ñXòe a classe ñZò̀ qual pertence, ou entre uma amostra ñAòe a população îPòda qual é retirada. É neste ponto que, para estes pesquisadores, a heurística da representatividade impede um julgamento probabilista estatisticamente válido. Ao se julgar algo como representativo, isto é, que possui características típicas da classe à qual pertence, o julgamento sobre a probabilidade de que este algo pertença de fato à classe considerada será influenciado pelo grau de representatividade atribuída que, do ponto de vista estatístico, não é relevante; e ao mesmo tempo, deixarão de ser consideradas outras variáveis estatisticamente relevantes, como a probabilidade de base. No exemplo de João, ocorre exatamente o que foi descrito acima; visto que os traços que o definem parecem muito representativos do 
engenheiro típico, os entrevistados estarão mais propensos em considerá-lo um provável engenheiro independentemente de qualquer consideração da probabilidade de base.

Isto não significa que o grau de representatividade de algo em relação a uma classe não possa ser, em determinados casos, um bom índice para o julgamento da probabilidade de que o indivíduo pertença àquela própria classe. Geralmente, é mais provável que seja extraído, a partir de uma determinada população, um indivíduo com um alto nível de representatividade, em detrimento de um com um baixo nível de representatividade. Esta consideração não contrasta com o conceito de heurística, visto que uma heurística pode levar a uma rápida e correta solução de alguns tipos de problemas.

Representatividade é o fenômeno relacionado com as probabilidades condicionais. A Heurística REPRESENTATIVIDADE tem importantes implicações (em termos de vieses) quando um indivíduo é perguntado para estimar a probabilidade condicional $p(A / B)$ de que um evento $A$ irá ocorrer dado que um evento $B$ tinha ocorrido. Experimentos mostram que quando se faz julgamentos, as pessoas tendem a buscar um grau de similaridade de eventos entre $A$ e B (Coke, 1991; Tversky and Kahneman 1982b). Em adição, a heurística representatividade tende a influenciar as pessoas a ignorar os efeitos causados pelo tamanho do exemplo ${ }^{29}$.

\subsubsection{Outros tipos de heurísticas}

Além da disponibilidade e da representatividade, são usadas outras heurísticas no processo de julgamento; algumas delas são expostas a seguir.

\section{A) Ancoragem}

Um fenômeno conhecido, quando pessoas são solicitadas a estimar o valor de uma variável desconhecida, é que elas tendem a fixar o valor inicial e assim ajustar o seu valor. Este fenômeno é chamado de ancoragem e o problema com essa heurística é que freqüentemente 0 ajuste que as pessoas fazem é insuficiente. Em um experimento de Tversky e Kahneman (1982 a), indivíduos eram solicitados a estimar a porcentagem de nações da AFRICA que são membros da Organização das Nações Unidas. Um número entre 1 e 100 era gerado, girando uma roda (na presença de pessoas). A média estimada de porcentagem de países africanos incluídos na ONU era 25, para um grupo em que a ancoragem era 10, e 45 para um grupo em que a ancoragem era 65 .

\footnotetext{
${ }^{29}$ Um exemplo de Tversky e Kahneman ( 1982c) ilustra este efeito: ñUma certa cidade é servida por 2 hospitais . No maior hospital nascem cerca de 45 bebes por dia e no menor hospital nascem 15 bebes por dia; como sabemos $50 \%$ dos bebes são homens . Entretanto a exata porcentagem varia de dia a dia . Algumas vezes poderia ser maior que 50\% e outras menor. Por um período de 1 ano, cada hospital registrou os dias onde o número de nascimento de meninos foi superior a $60 \%$. Qual o hospital que você acredita que registrou maior número de dias? 95 pessoas responderam esta pergunta, 21 optaram pelo maior e 21 pelo menor e 53 acham que ambos os hospitais registraram o mesmo número de dias. Naturalmente, é mais provável que no menor hospital ocorra um valor de $60 \%$ de meninos em um dado dia.
} 
Talvez o mais relevante na ancoragem do julgamento de especialistas (ou elicitation estimação de especialistas) ocorre quando os indivíduos são solicitados a estimar 5\% e 95\% fractis $^{30}$ de uma distribuição. Neste caso, eles parecem fixar o valor central de uma distribuição e então ajustam para obter o fractil de interesse.

B) Controle

Uma possível fonte de distorção na avaliação de probabilidades ocorre quando um indivíduo tende a pensar que, por possuir controle sobre um evento secundário, isto pode influenciar o evento principal.

Um exemplo disto está em Cooke (1991), que apresenta um experimento com um grupo de carregadores no Estado de Nova York. É dada a um grupo de 26 carregadores a oportunidade para comprar um bilhete de loteria por 1 dólar. O prêmio a ser pago, de 50 dólares, será dado ao ganhador que tiver o número correspondente ao bilhete retirado de uma urna. Para alguns dos participantes foi dada a oportunidade de escolher o número que quisesse. Para um segundo grupo o número era escolhido pelo pesquisador e dado ao participante. Ao final era perguntado aos participantes dos dois grupos se alguém gostaria de vender o seu bilhete mesmo achando que poderia ganhar. No grupo que pode escolher 0 número do bilhete o preço médio de revenda foi de 8,67 dólares, enquanto que no grupo que não teve a oportunidade de escolher o preço médio de revenda foi de 1,96 dólares. Ou seja, há uma tendência das pessoas em valorizar o seu processo decisório mesmo quando o processo independe da escolha feita pelo indivíduo; assim o indivíduo tem a falsa impressão que domina a seqüência de eventos, que na verdade se tratam de eventos aleatórios.

\section{C) Superconfiança e calibração}

Um exaustivo estudo de superconfiança no julgamento de especialistas foi realizado por Zindel na Universidade Federal de Santa Catarina. Segundo Zindel, alguns estudos demonstram que o excesso de confiança geralmente aumenta em tarefas de difícil julgamento (Fischhoff, Slovic e Lichtenstein, 1977; Koriat; Lichtenstein; Fischhoff, 1980; Lichtenstein e Fischhoff, 1977, 1980; Phillips e Wright, 1977). Lichtenstein e Fischhoff (1977) descobriram que o excesso de confiança para questões difíceis tornava-se baixa confiança para questões fáceis, quando a dificuldade era definida pelo número de questões corretas. Dessa forma, os indivíduos apresentavam excesso de confiança para questões difíceis e baixa confiança para questões fáceis (Lichtenstein, 1982). Esse efeito denominando hard-easy effect, r̃ocorre quando o grau de excesso de confiança aumenta com a dificuldade das questões, onde a dificuldade é medida pela porcentagem de respostas corretasò (Gigerenzer, Hoffrage e Kleinbölting, 1991, p. 506).

\footnotetext{
${ }^{30} \mathrm{O}$ fractil $\mathrm{k} \%$ de uma distribuição contínua de uma variável $\mathrm{X}$ é o menor valor $\mathrm{xk}$ que $\mathrm{p}(\mathrm{X}<\mathrm{xk})>\mathrm{k} / 100$
} 
Alguns experimentos demonstram que os indivíduos apresentam baixa confiança quando são solicitados a estabelecer o quão confiantes estão em que suas respostas estejam corretas como um todo, em um conjunto de itens. O experimento realizado por May (1991) consistia em solicitar aos indivíduos depois de concluído o teste que eles estimassem quantas questões eles tinham acertado (estimativas da freqüência). Quando os sujeitos foram questionados através deste procedimento, eles subestimaram o número de respostas que haviam acertado. May (1991) argumenta que tal fato demonstra baixa confiança no conhecimento, não excesso de confiança no julgamento, como demonstrado por curvas de calibração.

Resultados similares também foram encontrados por Gigerenzer, Hoffrage e Kleinbölting (1991) que também descobriram que, quando as pessoas foram solicitadas a estimar os acertos e a confiança para um conjunto de respostas, ocorreu boa calibração.

D) Quadro geral de vieses e heuristicas

Reunindo as diversas as heurísticas apresentadas, destacam-se alguns vieses de decisão oriundos do seu uso, segundo Andrade et al. (2007), que são apresentadas no estudo apresentado por Macedo e Fontes junto UFRural/RJ. A Tabela 5.X sintetiza estes pontos. 


\begin{tabular}{|c|c|}
\hline Viés & Descrição \\
\hline Falta de Sensibilidade às Proporções da Base & $\begin{array}{l}\text { este viés se refere à situação em que o individuo tende a ignorar dados e fatos relevantes } \\
\text { passando a considerar informaçoes irrelevantes ao processo decisório. }\end{array}$ \\
\hline Falta de Sensibilidade ao tamanho da amostra & $\begin{array}{l}\text { este ocorre quando o individuo ignora o tamanho da amostra; critica para uma avaliação } \\
\text { estatistica rigorosa, crucial para a decisão. }\end{array}$ \\
\hline Concepções Errôneas do acaso & $\begin{array}{l}\text { referência ao fato de que as pessoas ignoram a independência de eventos múltiplos aleatórios, } \\
\text { em vista de procurarem eventos que se pareçam mais aleatórios, fazendo uso errado da } \\
\text { intuição e da heurística da representatividade decidindo por determinados de }\end{array}$ \\
\hline A Falácia da Conjuntução & $\begin{array}{l}\text { refere a uma das leis qualitativas mais simples e fundamentais da probabilidade, caso em que } \\
\text { um subconjunto não pode ser mais provável do que um conjunto maior que inclui totalmente } \\
\text { o primeiro. A conjunção será julgada mais provável do que um componente i }\end{array}$ \\
\hline $\begin{array}{l}\text { Decisões Afetadas pelo Enquadramento das } \\
\text { Escollhas }\end{array}$ & $\begin{array}{l}\text { este viés reflete, com maior incidência, sobre a soma dos resultados de todas as escollhas } \\
\text { indesejáveis predominando sobre a soma de todas as escollhas desejaveis, isto é, o } \\
\text { enquadramento do problema é combinado em duas partes, tendo como resultado uma reve }\end{array}$ \\
\hline $\begin{array}{l}\text { Decisões Afetadas pelo Enquadramento do } \\
\text { Resultados }\end{array}$ & $\begin{array}{l}\text { aqui a localização do referencial é construída para se determinar que uma decisão está } \\
\text { enquadrada positivamente ou negativamente, afetando a preferência do risco resultante do } \\
\text { tomador de decisão. }\end{array}$ \\
\hline $\begin{array}{l}\text { Decisões Afetadas pela Pseudocerteza } \\
\text { Pseudo-incerteza Enquadradas nas Escollhas }\end{array}$ & $\begin{array}{l}\text { relacionado ao fato dos indivíduos darem menor peso a eventos de alta probabilidade, mas } \\
\text { ponderarem adequadamente eventos que são certos. Aqui, a inconsistência de julgamento } \\
\text { observada, pela facilidade de manipulação da percepção de certeza, originando }\end{array}$ \\
\hline $\begin{array}{l}\text { Enquadramento do Pagamento de Prêmio } \\
\text { versus a Aceitação de Perdas Certas }\end{array}$ & $\begin{array}{l}\text { neste viés se verifica que as pessoas estão mais propensas a aceitarem uma perda certa se tal } \\
\text { for vista como o prêmio de um sequro do que se encarada como um prejuizo financeiro. }\end{array}$ \\
\hline
\end{tabular}

Tabela 5.1 Quadro Geral de Vieses e Heurísticas (Extraída de Macedo e Fontes)

\subsection{Diferentes abordagens para agregar a opinião de especialistas}

As dificuldades, naturalmente, crescem quando os especialistas discordam sobre um problema em questão, inclusive em casos em que eles tenham acesso aos mesmos dados iniciais, Existem muitos caminhos para resolver um problema, alguns mais apropriados que outros.

Até mesmo especialistas tendem a subestimar as incertezas. Segundo Patê-Cornell (1996), ños métodos mais prováveis de fornecer um razoável grau de objetividade são aqueles que focam na construção de um conjunto de hipóteses e na avaliação das mesmas, com base 
em todas as evidências científicasò. Isso requer um processo que se inicia com o ñgatheringòlevantamento de todos dados disponíveis, quando avaliando e agregando probabilidades relevantes em uma forma ordenada e lógica.

Os três clássicos caminhos para agregar a opinião de especialistas como descritos por Patê-Cornell (1996) são apresentados a seguir:

ABORDAGEM ANALÍTICA ï quando cada especialista fornece a sua distribuição de probabilidades; quando alguém (o tomador de decisão) cria uma função distribuição combinada, por exemplo, distribuindo pesos nas avaliações dos especialistas.

ABORDAGEM ITERATIVA (teoria Delphi) - quando diferentes avaliações provenientes de diferentes especialistas são analisadas e posteriormente reenviadas aos especialistas e é dada a possibilidade para eles revisarem a sua opinião, com base no que os outros especialistas informam. O processo é repetido até que os valores convirjam, isto geralmente avança rápido se, juntamente com a opinião, for informada a forma como os resultados foram obtidos.

ABORDAGEM INTERATIVA - quando especialistas são questionados e debatem e explicam como avaliaram. Os especialistas têm a chance de mudar de opinião sobre o problema.

Para obter mais informações sobre os métodos que buscam agregar informações de diversos analistas pode-se consultar MORGAN \& HENRION (1990). Mas, muitas vezes a agregação da opinião de especialistas não é desejada.

\subsection{Metodologia delphi}

A metodologia delphi, disseminada no início dos anos 50 pela óRand Corporationô tinha por objetivo original desenvolver procedimentos para aprimorar o uso de especialistas na previsão tecnológica (Webler Et All, 1991; Kuespert, Estes, 1976; Mitchel, 1992; Wright, 1994; Wright, 1989; Sáfadi, 2001), buscando um consenso de suas opiniões. Em síntese, é um método para estruturar processos de comunicação coletiva, permitindo que um grupo de indivíduos lide com um problema complexo.

Há, nesse método, a despeito de possíveis variações em sua aplicação, três premissas básicas. Como se pretende reunir as idéias de especialistas, mas evitar que haja influência prévia das idéias de uns sobre os outros e também o constrangimento de eventuais mudanças futuras de opinião, busca-se garantir o anonimato dos respondentes.

A segunda premissa é a representação estatística dos resultados de cada rodada de questões. Quando as respostas da primeira rodada forem apresentadas e tabuladas, o ideal é que sejam feitas representações estatísticas de modo a possibilitar, para a segunda rodada, uma melhor visualização por parte dos respondentes, de qual a sua posição perante o grupo. Adicionalmente, a representação estatística oferece ao organizador dos debates a 
possibilidade de acompanhar o processo de criação do consenso entre os especialistas, objetivo central da técnica.

Por fim, já mencionado acima, o método delphi implica a realimentação ï ñfeedbackôde respostas do grupo para reavaliação nas rodadas subseqüentes. Tanto as respostas fechadas quanto as abertas devem ser tabuladas e reenviadas, anonimamente, aos respondentes, para que suas visões possam ser aprofundadas.

O método delphi possui características muito peculiares na visão de diversos autores. Assim, pode-se afirmar que esse método é especialmente recomendável quando não se dispõe de dados quantitativos, ou quando estes não podem ser projetados para o futuro com segurança, em face de expectativa de mudanças estruturais nos fatores determinantes das tendências futuras, ou seja, quando há rupturas ou descontinuidades no ambiente ou no assunto específico que se pretende estudar.

De igual maneira, sua estrutura básica é bastante simples. Um questionário interativo circula repetidas vezes por um grupo de peritos em busca da formação de consenso entre os participantes. Na primeira rodada, os especialistas recebem um questionário, preparado por uma equipe de coordenação, e a eles é solicitado responder individualmente todas as questões. As respostas das questões quantitativas são tabuladas, recebendo um tratamento estatístico simples, definindo-se a mediana e os quartis, e os resultados são devolvidos aos participantes na rodada seguinte. Quando há justificativas e opiniões qualitativas associadas a previsões quantitativas, a coordenação busca relacionar os argumentos às projeções quantitativas correspondentes. A cada nova rodada, as perguntas são repetidas e os participantes devem reavaliar suas respostas à luz das respostas numéricas e das justificativas dadas pelos demais respondentes na rodada anterior. São solicitadas novas previsões com justificativas, particularmente se estas previsões divergirem das respostas centrais do grupo.

Esse processo é repetido por sucessivas rodadas do questionário até que a divergência de opiniões entre especialistas tenha se reduzido a um nível satisfatório, e a resposta da última rodada é considerada como a previsão do grupo para o cenário em questão.

\section{A técnica Delphi e seu uso atual}

A técnica original foi estendida para incorporar a busca de idéias e estratégias para a proposição de políticas organizacionais mais gerais. Essa nova versão não se caracteriza tanto como instrumento de previsão, mas sim como técnica de apoio à decisão e à definição de políticas e passou a ser conhecida como Policy Delphi - Delphi de Políticas (WEBLER et all, 1991).

O horizonte do tempo pode ser fixado em uma data futura, mas o processo considera proposições e opiniões sobre políticas alternativas referentes a uma dada questão, independente de sua localização temporal. 
Limitações e riscos do Método Delphi

Apesar de todas as suas vantagens, o uso incorreto da técnica pode gerar graves problemas aos organizadores (WRIGHT, 1989). Em primeiro lugar, há a possibilidade de forçar o consenso indevidamente, pois os respondentes, se não corretamente orientados, podem acreditar que o objetivo é consenso, custe o que custar, e sentir-se-ão forçados a tal. Além disso, cumpre destacar a dificuldade de redigir um questionário sem ambigüidades e não viesado sobre tendências futuras. Como os dados são, muitas vezes, intuídos pelos organizadores, podem trazer implícitos pontos de vista, que nortearão indevidamente o debate.

A demora excessiva para a realização do processo completo, especialmente no caso de envio do questionário via correio, é outro inconveniente da técnica. Sucessivas rodadas, envolvendo especialistas de fora da instituição, sem uma remuneração ou contrato, freqüentemente implicam na desistência não anunciada de alguns participantes, sendo comum que, entre a primeira e a última rodadas, o abandono gire em torno de $50 \%$ dos participantes originais.

\subsection{Considerações finais}

A análise do processo cognitivo humano e o conhecimento dos mecanismos dos vieses e heurísticas servirá de base para a identificação e tratamento das incertezas de natureza subjetivas que estão relacionadas ao julgamento de especialistas, que será melhor tratado posteriormente. 


\section{CAPÍTULO 6}

\section{USO DE BANCO DE DADOS EM ANÁLISE RISCOS}

\subsection{Considerações gerais}

Acidentes, bem como outros tipos de ocorrências que envolvem experiências humanas, são registrados em alguma espécie de banco de dados e estes têm um papel significativo e relevante na identificação dos perigos e na análise de risco.

Inicialmente, deve-se entender a importância da utilização de banco de dados na análise de risco. Qualquer experiente analista de risco utiliza-se desta ferramenta em seu estudo. Em grande parte isto se deve à necessidade de obter informações sobre equipamentos e taxas de acidentes e número de ocorrência de eventuais falhas em uma escala tempo.

Esta busca por dados ocorre, em grande parte, pela complexidade dos projetos que envolvem situações e equipamentos cujos dados não são perfeitamente conhecidos. Por exemplo, considere-se o problema de determinar o número de ocorrências/ano de acidentes causados por objetos em plataforma de petróleo, em período noturno, na Região do Golfo do México. Como se pode observar, trata-se de um evento muito específico e mesmo com uma busca cuidadosa e exaustiva dificilmente conseguir-se-ia obter um resultado exato. Poder-seia, por exemplo, obter o número de incidentes relacionados com a queda de objetos durante 0 dia na região do Mar do Norte (OREDA 2005). Poder-se-ia, ainda, fazer uma estimativa, calculando o número de pessoas que transitam por metro quadrado na plataforma no período noturno (para isto, é necessário saber quantos funcionários circulam em cada região da plataforma no período ou turno de trabalho), que é um valor extremamente aleatório. Talvez fosse possível obter uma média que representasse um valor aproximado, porém, este valor sofreria influências do horário e do local onde o trabalhador se encontrasse. Além disto, o Mar do Norte é muito mais agitado que a Costa Brasileira ou o Golfo do México (mesmo com a eventual possibilidade de ocorrência de furacões ou tempestades tropicais). Outra questão diz respeito ao projeto da plataforma que pode ser semelhante ao da plataforma da qual foram extraídos os dados, seja por similaridade do arranjo, seja pelo número de seções ou elementos estruturais.

Desta forma, percebe-se de forma clara que, em estudos de risco, o uso de banco de dados é muito importante; porém, sem o devido cuidado, inúmeros erros são introduzidos nestes estudos. Pela importância dos bancos de dados, nos estudos de riscos, cuidados especiais devem ser observados. Ao longo deste capítulo serão apresentadas algumas considerações para minimizar as incertezas no uso de banco de dados em análise de risco. 
Muitos estudiosos têm se preocupado com a correta utilização dos dados. Davidsson et al (1999) apresentam um estudo em que representam as características das diversas fontes de perigos e as diversas estratégias de gerenciamento de risco, explicitando a necessidade do estudioso ser criterioso na introdução de dados retirados de outros estudos ou banco de dados. Rasmussem $(1994,1997)$ aborda a mesma questão e cita o estudo anterior de Davidsson. É possível, de acordo com os autores, estabelecer distinção entre os diversos tipos de banco de dados conforme a estratégia e o problema a ser estudado.

A figura 6.1 apresenta a divisão apresentada em diversos tipos de bancos de dados, de acordo com a freqüência de acidentes (eixo vertical) e a magnitude das perdas com o acidente (eixo horizontal). Percebe-se que os acidentes mais freqüentes são, em contrapartida, os menos perigosos e ao contrário, os menos freqüentes produzem maiores perdas. As estratégias de gerenciamento destes perigos são descritas a seguir.

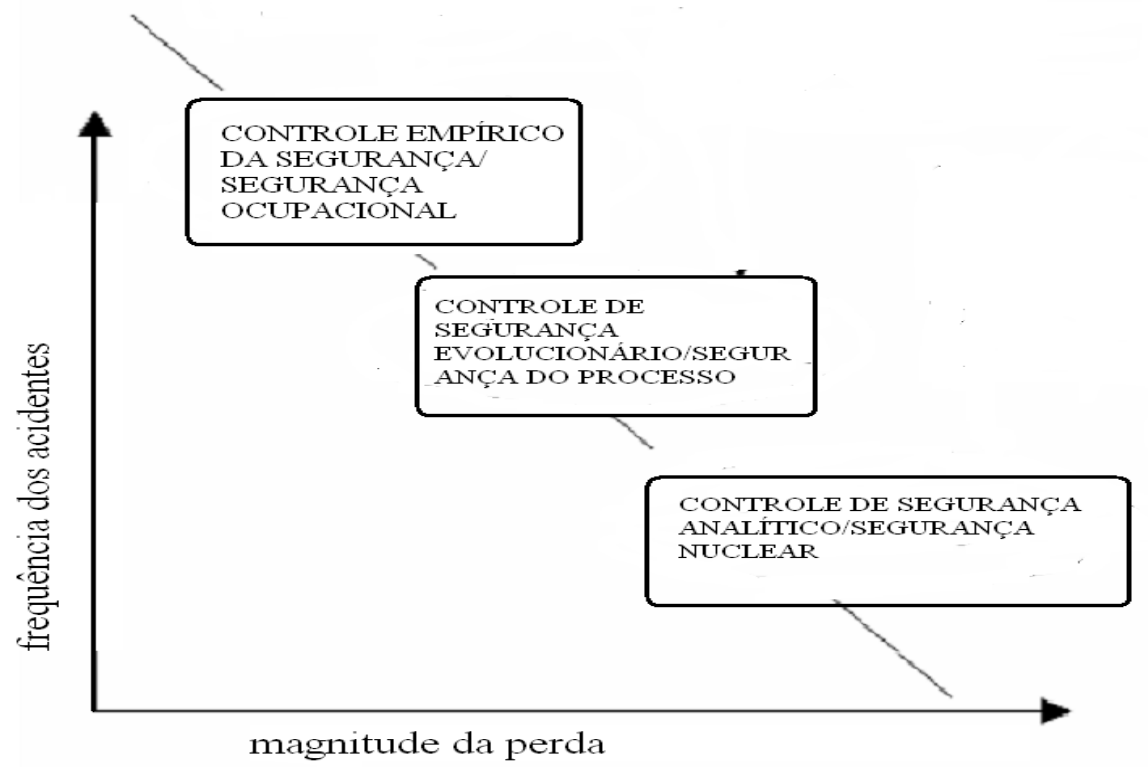

Figura 6.1 Características das fontes de perigos e estratégias de gerenciamento (Rasmussen 1997),

A categoria I - Estratégia de Segurança Empírica (ñempirical safety strategy ò)- é geralmente aplicada quando se lida com um complexo conjunto de fontes perigosas com alta freqüência de acidentes, mas usualmente com potencial de conseqüências relativamente pequenas. Os bancos de dados de experiências anteriores são usados principalmente em análises estatísticas, análise de tendências ou identificação de perigo.

A categoria II - Estratégia de Segurança Evolucionária (ñevolutionary safety strategyò) é freqüentemente aplicada em processos industriais e setores de transporte. Os perigos são 
caracterizados pela baixa taxa de freqüência, mas com a possibilidade de conseqüência substancialmente danosa. A Análise de Risco é uma ferramenta comum nestes casos. Nesta categoria utiliza-se freqüentemente de banco de dados de experiências anteriores com a finalidade de identificar as fontes de perigos e seqüência de eventos danosos para a estimativa de conseqüência.

A categoria III - Estratégia de Segurança Analítica (ñanalytical safety strategyò) - é caracterizada por fontes perigosas com baixa taxa de acidentes, mas com enorme potencial de conseqüências catastróficas, por exemplo, acidente em uma planta nuclear. Os bancos de dados, nestes casos, são usados freqüentemente como entrada em avaliação de eventos iniciais e confiabilidade das barreiras de segurança.

\subsection{Uso de dados em diversas etapas da análise de riscos}

Sabe-se que incertezas são introduzidas em diferentes estágios da $A R$, como já descrito anteriormente. Agora especificamente será abordada a utilização de banco de dados nos diferentes estágios de Análise de Risco.

A fase inicial de uma AR consiste na identificação do problema. A utilização de uma metodologia de identificação estruturada, como HAZOP ou FMEA, com o uso de banco de dados em conjunto, produz bons resultados na identificação de perigos. $O$ emprego eficiente destes instrumentos permite a identificação dos cenários e origens dos acidentes. A identificação errada dos incidentes pode causar inúmeros problemas ou até mesmo a invalidação do estudo.

\subsubsection{Identificação de acidentes}

Existem diversos bancos de dados úteis para identificação de acidentes que estão relacionados abaixo.

MHIDAS (Major Hazard Incident Data Service) ou Serviço de dados sobre Incidentes mais perigosos, é mantido pela instiuição inglesa AEA techonology com a supervisão da HSE ( Health and safety Executive), Grã Bretanha. Este banco de dados relata aproximadamente 7000 incidentes com substâncias perigosas, como vazamentos ocorridos em uma planta industrial, durante o transporte ou durante a estocagem. Alguns casos especiais de eventos, como material radioativo são omitidos neste banco de dados. Toda a informação colhida na MHIDAS é obtida de fontes públicas de dados confiáveis, incluindo aproximadamente 30 periódicos de natureza científica, bem como de empresas envolvidas nos eventos.

FACTS é mantido pela DUTCH RESEARCH ORGANIZATION (TNO). O banco de dados teve sua origem a partir de 1980 e contém informações de mais de 16.000 acidentes ou incidentes industriais, ocorridos desde 1900 até os dias de hoje. Aproximadamente 700 novos 
eventos são relatados por ano e outros 500 eventos são atualizados quando uma nova informação se torna disponível.

As informações que compõem o banco de dados do FACTS são coletadas via simpósios e periódicos focados em risco industrial, gerenciamento de risco e prevenção de desastres. Outra importante fonte são companhias (autoridades, organizações) ligadas à prevenção de acidentes e serviços de resgates. Este banco não contém dados populacionais ou de operações que poderiam ser usados para estimar freqüências falhas. O banco de dados FACTS é disponibilizado pela TNO em diversas mídias como Cd ROM ou papel.

O ñACCIDENT DATABASEò ou Banco de Dados de Acidentes é um banco de dados mantido pelo Institute Of Chemical Engineers, Estados Unidos da América ñ O banco contém informações de mais de 8.000 acidentes e incidentes. Todas as informações deste banco são geradas por companhias que trabalham com substâncias perigosas ou processos que apresentem algum risco. Aproximadamente 3.000 eventos são baseados em publicações internacionais que disponibilizam os seus dados.

MARS (Major Accident Reporting System) ou Sistema de Informação de Grandes Acidentes é um banco de dados misto. Grande parte das informações sobre o MARS é extraída do MAHB (Major Accidente Hazards Bureau), na web-page http://mahbsrv.jrv.it/ActivitiesWhatlsMARS.html. O MARS fornece um conjunto de informações sobre os acidentes ocorridos nos países membros da União Européia de acordo com as diretivas de 450 maiores acidentes.

Dois tipos de informações são fornecidos: o óshort reportò é o caso de notificação imediata de acidente; o r̃full reportôpara o caso de acidentes extensamente investigados, com a análise mais profunda das causas, a evolução do acidente e as suas conseqüências.

O ñshort reportò fornece informação essencial relacionada ao acidente; em um texto livre de formatação deve conter:
a- o tipo de acidente
b- substâncias diretamente envolvidas
c- fonte inicial do acidente
d- causas indireta
e- efeitos indiretos
f- medidas tomadas em caráter emergencial
g- lições aprendidas com o incidente

O ñfull reportò é mais analítico e envolve mais trabalho na preparação. Enquanto no anterior o texto é livre na narração dos fatos relacionados ao acidente, neste há uma estrutura definida, com dados da forma mais completa possível, como listada abaixo:
a- o tipo de acidente
b- indústria onde ocorreu
c- atividade desenvolvida
d- componentes diretamente envolvidos
e- sistemas ecológicos afetados 
g- medidas urgentes adotadas

\subsubsection{Banco de dados para falhas frequentes}

Os bancos de dados de acidentes apresentados anteriormente focam na descrição de possíveis causas e, em geral, no curso de eventos que são desencadeados pelos acidentes ou na proximidade dos acidentes.

Adicionalmente, neste tipo de documento de cenários de acidentes encontra-se ainda um banco de dados de freqüência de falhas que podem conter informações e dados que permitem o cálculo de diferentes valores de confiabilidade de equipamentos.

\section{OREDA}

Oreda- Offshore Reliability Data - é um projeto de colaboração entre diversas empresas (entre elas, BP Exploration Operating Company Ltda e Philips Petroleum Company Norway), que tem como objetivo produzir um banco de dados de equipamentos usados na industria de óleo e gás Offshore, principalmente da Grã Bretanha e Noruega, no Mar do Norte.

O Oreda contém informações com descrição qualitativa e quantitativa de taxas de falhas de sistemas de processos, sistemas de segurança, sistemas elétricos, sistemas de socorro, sistemas de carregamento e de manobra de cargas. A descrição qualitativa contém informações das unidades do sistema, suas funções e aplicações, o ambiente em que são operadas as unidades, causas possíveis de falhas etc. Os dados de confiabilidade incluem ainda taxas de falhas e tempos de reparos.

THE GUIDELINES FOR PROCESS EQUIPAMENT RELIABILITY DATA WITH DATA TABLES (CCPS,1989) - Guia para cálculo de Confiabilidade em equipamentos com dados e tabelas - é disponibilizado pelo Center for Chemical Process Safety (CCPS) e pelo American Institute of Chemical Engineers ( AIChE). O principal propósito desta publicação é proporcionar ao engenheiro ou analista dados de taxas de falhas e informações sobre diversos recursos necessários ao estudo de confiabilidade. São apresentadas taxas de falhas de uma variedade de equipamentos comuns em processos químicos industriais como bombas, compressores, chaves e transmissores etc. Os dados são caracterizados como falhas nos equipamentos por 1.000.000 horas de operação ou taxa de falhas por 1000 acionamentos de forma ininterrupta.

\subsubsection{Conseqüências}

Para estimativa de conseqüências, grande parte da análise é feita de forma teórica ou determinística, ou ainda de forma empírica, com base em modelos fenomenológicos físicos. Em situações em que é possível ocorrer acidentes, muitas vezes, experiências ou relatos 
anteriores, que caracterizam o desencadeamento do fenômeno, se tornam úteis para estimar as conseqüências.

Uma abordagem mais precisa necessita de um sistema de dados que inclua a descrição detalhada e objetiva dos efeitos e dos danos causados pelo acidente e, se possível, do mecanismo avariado; além disto, informações sobre eventos subseqüentes podem ser úteis.

\subsection{Requisitos básicos para aceitabilidade de dados em análise de riscos}

Os requisitos para que um banco de dados possa ser usado em AR podem variar consideravelmente, dependendo de uma série de fatores, como o objetivo da AR ou o estágio da análise. Em alguns estágios em que a análise de risco é muito específica, informações detalhadas seriam muito úteis, mas em outros estágios é mais importante dispor de informações gerais e abrangentes. É extremamente difícil conseguir dados que representem todas as situações possíveis e possam cobrir todas as hipóteses de forma simultânea. Entretanto, alguns requisitos básicos e comuns, para o uso em todas as fases, foram propostos por Davidsson et al 1999. São eles: acessibilidade, facilidade de uso, confiabilidade (rastreabilidade das informações), relevância (com respeito a análise objetiva), cobertura e atualização regular.

A utilização de Banco de Dados em AR é importante em diversas fases, como cálculo de freqüência de falhas, conseqüências e efeitos. Quando são utilizadas informações de um específico banco de dados é importante se conhecer o critério de registro do banco de dados, ou seja, o porquê do dado estar ali? É importante, se possível, saber se algum dado foi deliberadamente omitido do banco de dados, por exemplo, em casos de acidentes onde as conseqüências não são perfeitamente conhecidas ou ainda quando se trata de área geográfica limitada.

\subsection{Considerações finais}

A correta obtenção dos dados é importante para aumentar o grau de previsibilidade de qualquer estudo. Em estudos de riscos não é diferente. O correto tratamento dos bancos de dados permite diminuir e tratar as incertezas envolvidas no processo de aquisição de conhecimento a partir de banco de dados. No capítulo 9 as incertezas relacionadas aos bancos de dados terão um tratamento especial na metodologia proposta. 


\section{CAPÍTULO 7}

\section{MÉTODOS PARA DETERMINAÇÃO DA PROPAGAÇÃO DE INCERTEZAS}

\subsection{Considerações gerais}

Neste capítulo são apresentados os métodos de propagação e análise de incerteza. Posteriormente, os conceitos serão usados em um exemplo, onde se pode delinear o emprego destes métodos para determinação das incertezas existentes em processos de análise de risco. Qualquer estudioso do assunto tem a seu alcance uma diversidade de métodos de análise da incerteza e de sua propagação. Logo, nada justifica a realização de estudos desprovidos da quantificação da incerteza envolvida e de seus efeitos.

Admite-se que será empregada uma bateria de modelos e que, se possam identificar as incertezas nestes modelos. Tentar-se-á identificar o impacto da incerteza nos parâmetros de entrada que podem ter efeito sobre as saídas. Existem 3 grandes grupos de técnicas que podem ser aplicadas:

Análise de Sensibilidade - metodologia que avalia os efeitos das variações nos parâmetros de entrada sobre a saída;

Propagação de Incertezas - metodologia que estuda o processo de transmissão da incerteza das variáveis de entrada para as variáveis de saída;

Medidas Relevantes ou Classificação Ponderada de Incertezas - métodos que permitem calcular a contribuição relativa da incerteza da variável de entrada sobre a incerteza da variável de saída.

Os dois primeiros grupos serão discutidos neste capítulo, com ênfase na propagação da incerteza, com a revisão de métodos que permitem medir o efeito da incerteza nos parâmetros de entrada sobre os resultados. Uma abundância de métodos está disponível na literatura; somente os de uso mais freqüente serão discutidos aqui. O terceiro grupo, medidas relevantes, será explicado no capítulo 8 e destina-se basicamente a fornecer uma idéia da contribuição relativa na variável de saída provocada por uma incerteza na variável de entrada. O importante é saber que, em um primeiro momento, a incerteza global do modelo pode ser reduzida na medida em que se identificam as suas fontes e posteriormente, em um segundo momento, atua-se de forma seletiva visando interferir sobre as variáveis que mais contribuem nas incertezas.

Muitos dos modelos normalmente usados em AR são programas computacionais. Nestes casos costuma-se usar ANÁLISE DE REGRESSÃO e MÉTODOS DE RESPOSTA SUPERFICIAL para produzir expressões analíticas baseadas em poucas variáveis de entrada 
que, mesmo assim, conseguem representar modelos computacionais mais complexos. Maiores detalhes de como representar os modelos de resposta superficial com informação explícita, e de como criar Métodos de Resposta Superficial, podem ser obtidos em Frantzich (1990) e Ang et al (1975).

Quando se usa MÉTODOS DE RESPOSTA SUPERFICIAL, é imperativo ter certeza que as variáveis usadas nos métodos são relevantes e importantes para o comportamento do modelo. Por isto elas exigem um estudo mais cuidadoso, já que contribuem de forma mais significativa para a Incerteza global. Outro cuidado que se deve ter é verificar se o modelo está sendo usado dentro do raio definido pela análise de regressão. Pode-se notar que a geração ou criação da Equação de Resposta Superficial pode introduzir uma nova classe de incertezas no modelo. Para maiores detalhes veja Morgan \& Henrion (1998).

A Análise de Sensibilidade é freqüentemente usada para identificar quais parâmetros devem ser incluídos em uma analise de incerteza, em estudos de propagação, e a importância das mesmas.

\subsection{Métodos de resposta superficial}

Muitos dos métodos de propagação de incerteza descritos na literatura requerem expressões analíticas. Além disto, em sua grande maioria, exigem o emprego de computadores para a sua solução.

Em diversas áreas de pesquisa, por exemplo, Agronomia, Biologia, Engenharia, os pesquisadores se deparam freqüentemente com a dificuldade em relacionar o efeito de variáveis quantitativas (fatores) sobre uma ou mais variáveis-respostas. Na maioria das vezes, o relacionamento desejado entre fatores e resposta é aquele que determina uma combinação dos níveis dos fatores que dão uma resposta ótima. Atualmente, tem-se dado ênfase ao uso da metodologia de superfície de resposta para estudar esse tipo de relacionamento.

A metodologia de superfície de resposta é essencialmente um conjunto de técnicas estatísticas usadas em pesquisas, com a o objetivo de otimizar uma função ou aumentar conhecimento sobre a natureza de certos fenômenos. É composta por planejamento e análise de experimentos, em que se procura relacionar respostas com os níveis de fatores quantitativos que afetam essas respostas (Box e Draper, 1987). O relacionamento entre respostas e níveis de fatores procura atingir, entre outros, um dos seguintes objetivos: estabelecer uma descrição de como uma resposta é afetada por um número de fatores em alguma região de interesse; estudar e explorar a relação entre várias respostas; localizar e explorar a vizinhança de resposta máxima ou mínima. A aplicação dessa metodologia foi realizada inicialmente na indústria química e seus fundamentos foram formalizados por Box e Wilson (1951). 


\subsection{Análise de sensibilidade}

A Análise de Sensibilidade permite identificar a importância das variáveis em um dado modelo, isto é, quais as variáveis que possuem maior impacto na resposta do modelo $\mathrm{A}$ Análise de Sensibilidade é freqüentemente utilizada numa espécie de ñwhat ifò ou seja, mudase o valor de uma variável, enquanto as outras são mantidas constantes, em seu valor nominal, avaliando, assim, o impacto relativo de cada mudança na resposta do modelo. Neste sentido, Análise de Sensibilidade pode ser usada como um método simples de avaliar a importância das variáveis, e conseqüentemente de suas incertezas. Entretanto, um sério problema está associado ao uso da Análise de Sensibilidade, ou seja, a dificuldade de se trabalhar com variáveis que possuem diferentes unidades de medida. Isto se torna ainda mais difícil quando as variáveis de saída possuem unidades diferentes; neste caso, é necessário efetuar algumas alterações que será abordado no capítulo seguinte.

Na verdade, Análise de Sensibilidade é utilizada geralmente para saber que variáveis devem ser incluídas no estudo das incertezas, ou seja, se uma variável é ou não importante ou ainda se é necessário incluí-la em um estudo de análise de incertezas.

\subsection{Análise probabilistica de incerteza}

A seguir são apresentados alguns métodos probabilísticos, que são usados em estudos de propagação de risco. A apresentação dos métodos não é exaustiva e outros métodos podem ser usados; para isto pode-se consultar Morgan \& Henrion (1990). Os métodos probabilísticos são os mais usados para análise de incertezas em muitas áreas de risco, talvez, porque eles têm fundamentos firmes e por terem sido usados ao longo de muito tempo.

Uma forma muito aplicada aos conceitos de incerteza é uso de distribuição probabilística para descrever a incerteza. Como pode ser visto na figura 7.1, a propagação de variáveis $f_{1}, f_{2}, f_{3}$ (representadas pelas respectivas funções densidades probabilidades FPD) pode ser estabelecida por uma função resposta que associe as diversas funções apresentadas anteriormente $\left(f_{1}, f_{2}, f_{3}\right)$. Isto pode ser feito com um conhecimento básico de teoria de probabilidade e estatísticas - Vose ( 2000 ), Morgan e Henrion (1990). 


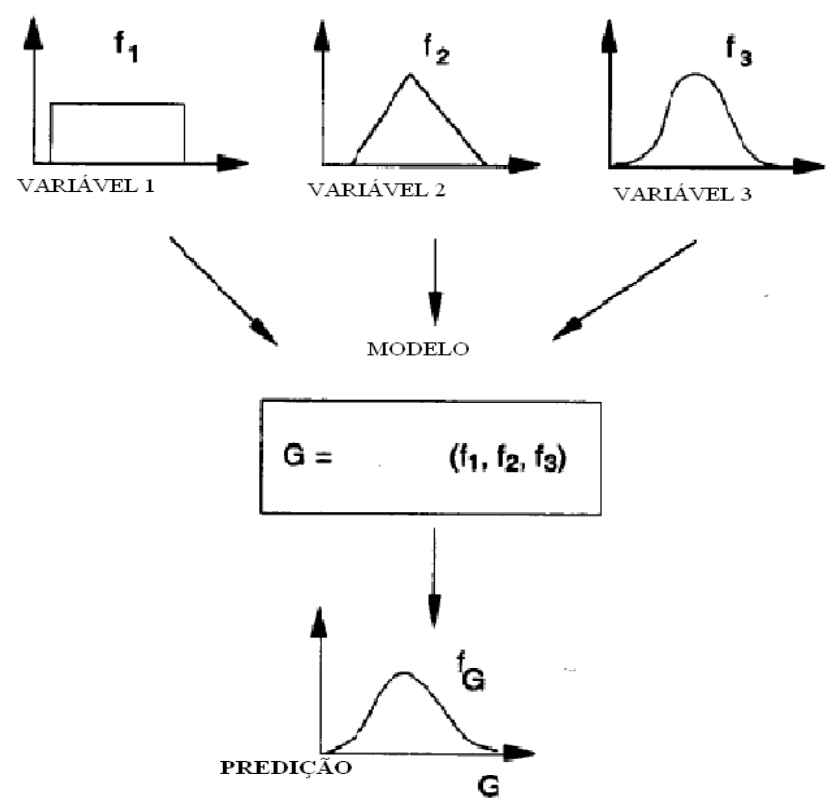

Figura 7.1 Propagação de incerteza pelo modelo, extraído de IAEA (1989)

\subsubsection{Métodos analíticos}

Os métodos analíticos são muito empregados em propagação de incerteza. Isto se deve, em parte, à grande evolução dos métodos computacionais, aliada a maior capacidade de cálculo de computadores. Desta maneira, modelos computacionais, que antes eram muitos complexos para as simulações, agora são facilmente manipulados; assim, pode-se representar com maior fidedignidade a situação real.

\subsubsection{Método por amostragem (sampling method)}

Com o grande desenvolvimento dos computadores pessoais, métodos numéricos para análise de incerteza, passaram a permitir o uso mais completo de distribuição de probabilidades para descrever os parâmetros de incerteza. São apresentados, a seguir, dois destes procedimentos - MONTECARLO e HIPERCUBO LATINO.

\section{Método de monte carlo}

O método de Monte Carlo consiste na simulação do valor futuro de variáveis que compõem um modelo. Esta metodologia deve ser empregada com cuidado, principalmente devido ao alto custo computacional da implementação e processamento. Mesmo assim, vem sendo cada vez mais utilizada, não somente no gerenciamento de risco, mas em diversas 
outras áreas. Sua crescente popularidade se dá, principalmente, pela liberdade na modelagem do problema (passando de "soluções exatas de problemas aproximados" para "soluções aproximadas de problemas exatos"), avaliação de perguntas do tipo "e se?" (permitindo a avaliação de mudanças de cenários ou conseqüências de decisões) e avaliação de problemas em que o conhecimento das variáveis envolvidas é parcial.

Para uma elucidação das possibilidades da utilização de Monte Carlo como instrumento para estudar as incertezas, torna-se interessante visualizar como Hromkovic (2001), um dos especialistas no assunto, aborda as diversas possibilidades que este método proporciona. O propósito desta tese não é esgotar o assunto referente à Monte Carlo, por isso aconselha-se a consulta a Hromkovic (2001).

Hipercubo latino (latin hypercube)

Em 1979, McKay, Beckman e Conover sugeriram uma nova técnica de redução de variância baseada no forte controle do processo de amostragem, o Hipercubo Latino. $\mathrm{O}$ fundamento da técnica é a estratificação da distribuição amostral em estratos de igual probabilidade de ocorrência e o sorteio aleatório de um valor em cada um deles.

Contemporaneamente e independentemente dos estudos do Hipercubo Latino, uma abordagem alternativa para a simulação de Monte Carlo foi desenvolvida por Saliby (1980), a Amostragem Descritiva. Nesta abordagem, rompe-se completamente a seleção aleatória da amostra, baseando-se em uma seleção determinística de valores (pontos centrais dos mesmos estratos utilizados no Hipercubo Latino) e uma posterior permutação destes, (Malleta B.,2005).

Diferentemente das primeiras técnicas de redução de variância, o Hipercubo Latino e a Amostragem Descritiva apresentam resultados significativamente superiores à Amostragem Aleatória Simples em diversos estudos (Marins, Santos E Saliby, 2003; Araújo, 2001). Apesar da proximidade das técnicas, Moreira (2001) e Saliby (1997) mostraram que a Amostragem Descritiva é um aperfeiçoamento do Hipercubo Latino tanto na eficiência estatística quanto na eficiência computacional.

O Hipercubo latino consiste na estratificação da distribuição acumulada de probabilidade das variáveis de entrada da simulação em $n$ partes de igual probabilidade. Em seguida, escolhe-se aleatoriamente um valor dentro de cada estrato. A amostra hipercúbica é composta por estes valores permutados aleatoriamente. A fórmula usada para a geração dos valores hipercúbicos, a serem depois permutados, é:

$$
x h_{i}=F^{-1}\left(i i \text { Rand }_{i}\right) / n \quad i=1, \ldots . ., n
$$

em que:

xhié o valor que compõe a amostra hipercúbica;

n é o tamanho da amostra; 
$\mathrm{F}^{-1}$ é a inversa da função de distribuição acumulada;

Randi é um número aleatório entre 0 e 1.

\subsection{Matemática intervalar}

A matemática intervalar surgiu no final da década de 50 com Ramon E. Moore visando dar suporte a problemas que lidam com a incerteza. Os números, representados como intervalos, servem como controladores da propagação do erro, pois garantem que a resposta correta de determinado problema pertence ao intervalo obtido. Desse modo, pode-se afirmar que sua utilização consiste no controle rigoroso da propagação dos erros dos dados e parâmetros iniciais ao longo do processo computacional provocada por sucessivos erros de arredondamentos e/ou truncamentos.

O conceito de Intervalo Aritmético oferece uma tarefa computacional inexpressiva, e logicamente consistente, que é usado, muitas vezes, para representar as incertezas. A matemática intervalar pode ser usada no estudo da propagação de incertezas a partir dos parâmetros de entrada. Esta metodologia tem sido empregada ao longo das últimas décadas por exemplo, Dwyer (1951), Moore (1966,1979), e ainda Alefeld \& Herzberger (1983). Considerem-se 2 variáveis $X$ e $Y$, com intervalos $\left[x_{l}, x_{u}\right]$ e $\left[y_{1}, y_{u}\right]$, respectivamente onde $x_{l}$ é menor ou igual a $x_{u}$ e $y_{l}$ é menor ou igual a $y_{u}$. As operações mais comuns são:

$$
\begin{aligned}
& \mathrm{X}+\mathrm{Y}=\left[\mathrm{x}_{\mathrm{l}}+\mathrm{y}_{\mathrm{i}}, \mathrm{x}_{\mathrm{u}}+\mathrm{y}_{\mathrm{u}}\right] \\
& \mathrm{X}-\mathrm{Y}=\left[\mathrm{x}_{\mathrm{l}}-\mathrm{y}_{\mathrm{i}}, \mathrm{x}_{\mathrm{u}}-\mathrm{y}_{\mathrm{u}}\right] \\
& X \cdot Y=\left[\min \left(x_{l} y_{l}, x_{l} y_{u}, x_{u} y_{l}, x_{u} y_{u}\right), \max \left(x_{l} y_{l}, x_{l} y_{u}, x_{u} y_{l}, x_{u} y_{u}\right)\right] \\
& X / Y=\left[\min \left(x_{l} / y_{l}, x_{l} / y_{u}, x_{u} / y_{l}, x_{u} / y_{u}\right), \max \left(x_{l} / y_{l}, x_{l} / y_{u}, x_{u} / y_{l}, x_{u} / y_{u}\right)\right] ; 0 \notin\left[y_{l}, y_{u}\right] \text { (7.5) }
\end{aligned}
$$

Pode-se visualizar na Figura 7.2 um exemplo simples, extraído de Ferson et al 1999. Supondo que se saiba que o valor de A está entre 2 e 4 , e o valor de B está entre - 1 e 3, usase a seguinte representação: $A=[2,4]$ e $\quad B=[-1,3]$. É fácil ver, intuitivamente, que a soma de $A$ e $B$ está entre 1 e 7 ou no intervalo [1,7], e a diferença entre $A$ e $B, A-B=[-1,5]$.O produto $A x B$ deve ficar no intervalo $[-4,12]$. 

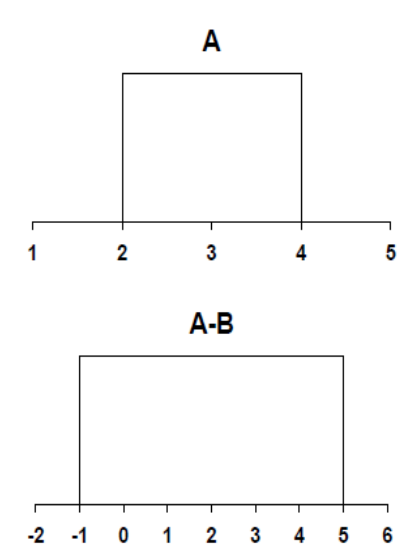
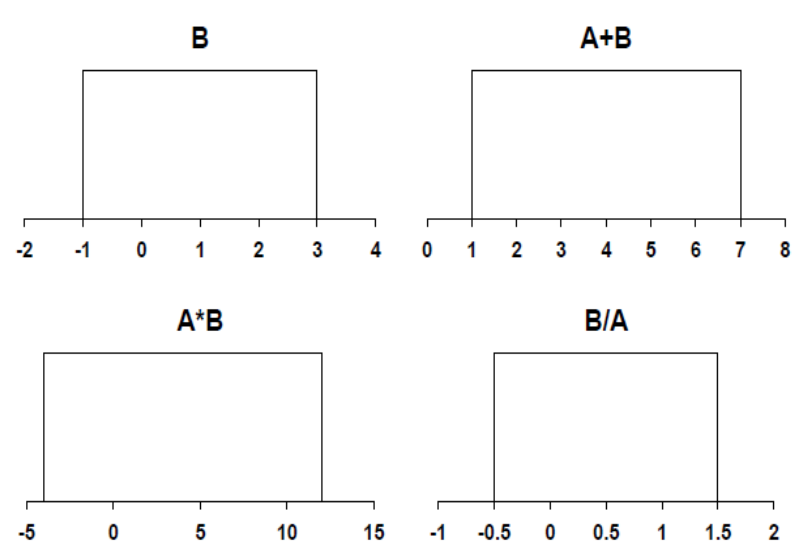

Figura 7.2 Exemplo de operações aritméticas intervalares

A aritmética intervalar é uma aritmética definida em conjuntos de intervalos de números reais, ao contrário da aritmética convencional, que é definida apenas no conjunto de números reais. A primeira abordagem de aritmética intervalar ocorreu com Burkill (1924). Young (1931) realizou um novo estudo a respeito do assunto e mais tarde Sunaga (1958) concretizou o uso da aritmética intervalar. $O$ desenvolvimento moderno da aritmética intervalar, com um enfoque global, começou com a dissertação de doutorado de Moore (1962). Desde então, vários artigos e numerosos livros têm abordado este assunto. Congressos, encontros, softwares e grupos de discussão vêm contribuindo para o aumento do interesse e da importância deste tema.

A modelagem de eventos físicos através de técnicas computacionais possui uma grande limitação em termos da contabilidade dos parâmetros utilizados. Os dados utilizados na realização da modelagem de qualquer evento físico são obtidos, via de regra, por medições. Estes dados apresentam intrinsecamente um erro, quer seja por falha humana (erro de leitura), quer seja por deficiência mecânica nos próprios instrumentos (erro do instrumento). Por outro lado, a representação numérica utilizada nos computadores digitais nem sempre permite que os números sejam armazenados com exatidão, U. Kulisch, (1999). Isto pode gerar erros de arredondamento e/ou truncamento, tanto na modelagem quanto na execução dos cálculos numéricos.

Devido, principalmente a estes fatores, a modelagem de eventos físicos só permite que resultados aproximados sejam obtidos. Em alguns casos, ocorrem aproximações bastante pobres, o que torna necessária a execução de tarefas auxiliares, de modo que se possa analisar os erros associados ao problema. Este tipo de análise, além de exigir um considerável esforço computacional, não é uma tarefa simples de ser operacionalizada.

A maior parte dos problemas científicos envolve incerteza em parâmetros ou dados inexatos. Uma maneira simples de representar e executar operações em informações inexatas é utilizar a aritmética intervalar, também chamada de análise intervalar. Neste contexto, uma incerteza em um dado real pode ser representada por um intervalo de números reais, que presumivelmente contém o valor desconhecido r̃exatoòdo número em questão. Desta maneira, 
a incerteza fica envolvida pelo tamanho do intervalo e não há necessidade de nenhuma distribuição de probabilidade para representá-la, simplificando assim o trabalho de operações e análises.

\subsubsection{Análise do pior caso}

A Matemática Intervalar é o método apropriado para fazer um estudo do pior caso. Ela é, na verdade, uma ferramenta simples que permite ao analista fazer uma avaliação conservadora e segura de um processo. Ela pode ser empregada em estudos de processos que envolvam derramamento de substâncias tóxicas, que possam causar concentração de substâncias cancerosas no ar, e assim estimar as conseqüências mais severas.

\subsubsection{Cuidados com a matemática intervalar}

A matemática intervalar consiste, na verdade, em uma adaptação do emprego de operações aritméticas para lidar com medidas determinísticas incertas. Isto é facilmente visto, principalmente quando o mesmo parâmetro é usado mais de uma vez em uma equação. Por exemplo, na equação abaixo:

$X-X=\left[X_{a}, X_{b}\right]-\left[X_{a}, X_{b}\right]=\left[X_{a}-X_{b} ; X_{a}-X_{b}\right]$ que é diferente de zero, para situações onde $X_{a}$ é diferente de $X_{b}$, isto é o intervalo é não nulo.

Uma das leis básicas dos números reais é a chamada distribuitividade dos números reais. Essencialmente isto significa que $X(Y+Z)=X Y+X Z$. Pode-se, facilmente, demonstrar que a lei distributiva não cabe no caso de números colocados na forma intervalar, quando se considera números negativos; ela porém é válida quando os números são positivos. Para qualquer tipo de intervalo o valor obtido em $X(Y+Z)$ está contido em $X Y+X Z$.

$$
\begin{aligned}
& 0 \in X-X \\
& X(Y+Z) \subseteq X Y+X Z
\end{aligned}
$$

\subsection{Abordagem por curvas probabilísticas}

De acordo com Tucker e Ferson (1993) em ñ Probability bounds analysis in environmental risk assessmentsô, a análise por curvas probabilísticas combina teoria de probabilidades com matemática intervalar para produzir estruturas denominadas ñprobability boxesô ou óp-boxesò estruturas estas que permitem estudar e analisar a propagação de incertezas. Este tipo de abordagem em estudo de incertezas, principalmente quando empregada em análise de risco, passou a ter nos últimos anos uma importância muito grande, principalmente em estudos ambientais.

Algumas considerações a esse respeito podem ser encontradas nas diretrizes da EPA, principalmente no EPÄ̈s Gindance for Probabilistic Risk Assessments at Suferfund sites (EPA 
2001). Nesta referência (seções 1.2.4 e 3.4.1) encontram-se diversas considerações sobre a correta formalização da incerteza que está contida em uma distribuição e como deve ser representada ${ }^{31}$.

A idéia de fronteiras em análise probabilísticas remonta às considerações históricas de George Bole (1854) e Halpern (1888) que, usando a noção de intervalos fronteiriços para a probabilidade Chebyshev (1874), descreveu que as fronteiras em uma distribuição onde somente a média, a variância das variáveis são definidas, e de Markov ( 1886), que usou mesmo raciocínio quando somente a média é conhecida. Frechet (1935) descobriu como podem ser feitos cálculos com estimativas incertas das probabilidades sem assumir a independência das funções. Nos dias atuais Walley e Fine 1986, Lovi 1986, Mand e Owings 1988, Walley 1991, Tessen 1992, Smith 1995, Kyburq 1998 revisaram a história das probabilidades intervalares e traçaram uma abordagem mais consistente.

O emprego a Curvas Probabilísticas em Análise de Risco se deve a Golwasser et al (2000), Donald e Ferson (1997), Spencer et al(1999,2001), Regan et al (2002,2002b).

Basicamente a teoria aborda três diferentes problemas: Modelos Parametrizados, Modelos não parametrizados e Modelos Empíricos

\subsubsection{Modelos parametrizados}

Modelos Parametrizados são aqueles em que não se sabe o exato valor dos parâmetros da distribuição, mas se sabe qual o tipo de distribuição. Assim, pode-se ter uma distribuição tipo Lognormal, em que a média varie no intervalo entre dois valores e o desvio padrão varie em outro intervalo definido.

Os modelos são ditos parametrizados quando se conhece previamente a que família de curvas pertence a distribuição de probabilidades que representa o fenômeno, porém não se tem certeza sobre parâmetros que identificam a curva, como a média ou desvio padrão. A família de curvas pode ser determinada pelo conhecimento do fenômeno que é apresentado; por exemplo, populações humanas costumam apresentar uma distribuição normal de características físicas, tais como altura e peso.

Um exemplo de modelo parametrizado, que pode ser representado usando a técnica de família de curvas probabilísticas, é apresentado a seguir. Sabe-se, de início, que a distribuição é uma curva normal de média variando no intervalo $[0,5 ; 0,6]$ e desvio padrão variando no intervalo $[0,05 ; 0,1]$. Na verdade, a utilização de família de curvas permite que o usuário preencha um certo nível de incerteza paramétrica ou conceitual com algum tipo de informação que possa ser processada e trabalhada de forma matemática. A figura 7.3 apresenta o exemplo de uma curva normal com a variação intervalar acima.

\footnotetext{
${ }^{31} \mathrm{Na}$ verdade, este tipo de idéia é bem mais antigo e remonta aos processos de combinação dos modelos padrões de análise intervalar ( Moore 1996, Neumaier, 1990) e à teoria clássica de probabilidade (Feller, 1968 e 1971).
} 


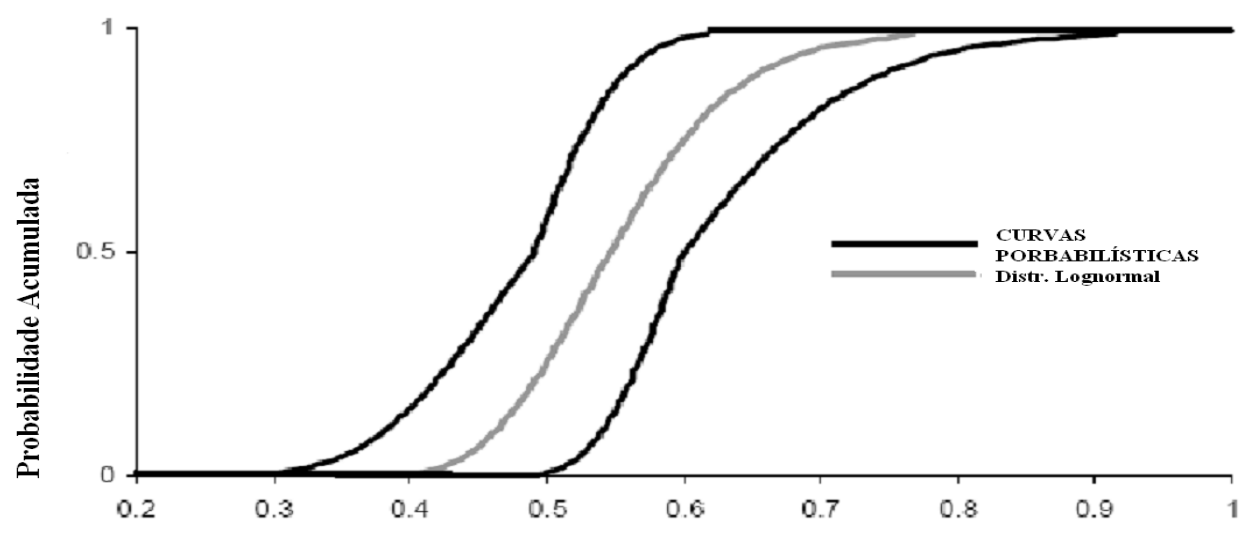

Figura 7.3 Curvas probabilísticas para uma distribuição normal com média e desvio padrão intervalares ( Adaptada de Tucker e Ferson).

\subsubsection{Modelos não parametrizados}

Modelos não parametrizados são modelos para os quais não se conhece a distribuição exata, ou em que esta não pode ser determinada, principalmente porque as informações empíricas são muito vagas. Um exemplo é o caso de se conhecer somente informações limitadas de uma dada variável, que representa uma característica do fenômeno, como seus valores mínimo e máximo e a média. Estes dados, muitas vezes, são a única informação segura que se dispõe, mas mesmo com esta pouca informação pode-se ter uma idéia da área probabilística que representa o fenômeno. Na Figura 7.4 pode-se observar que, no caso de se ter somente o mínimo, o máximo e a média, pode-se traçar limites que possibilitam uma representação. Para um caso arbitrário de $x$ pertencente ao intervalo [Min; Max], o valor de ñò da CDF (função de distribuição acumulada) em $x$, representa a probabilidade de um valor estar à esquerda de ñò Assim, de acordo com Tucker, 2003, pode-se escrever:

$$
\mathrm{Px}+(1-\mathrm{p}) \text { Max }=\text { média }, \text { que gera } \mathrm{p}=(\text { Max-média }) /(\text { Max }-\mathrm{x})
$$

A representação da curva cumulativa de probabilidade é apresentada abaixo para três situações: média próxima do valor de mínimo, média centrada e média próxima do valor de máximo 

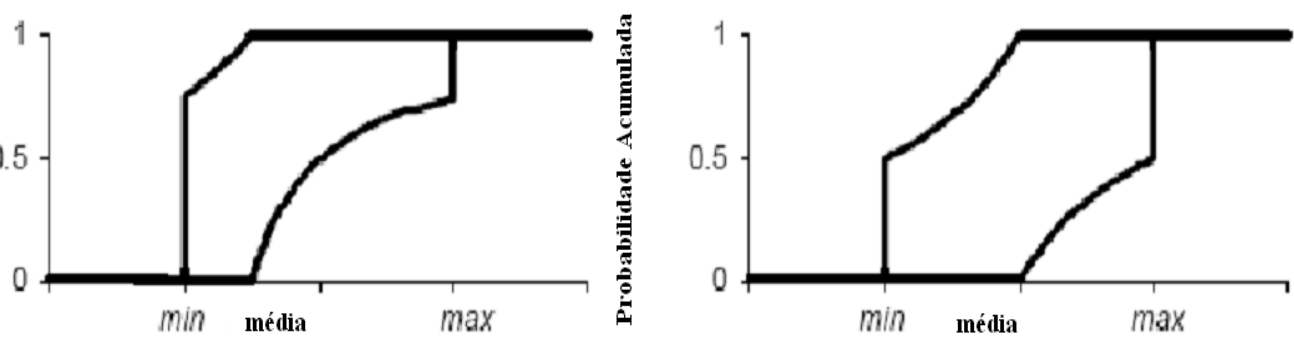

A

$x$

$\mathrm{B}$

$x$

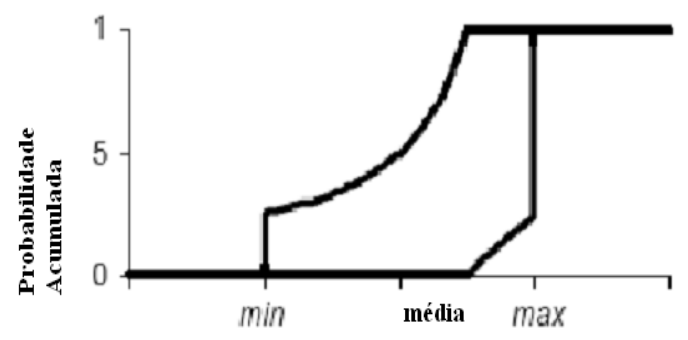

C

$x$

Figura 7.4 Curvas probabilísticas de distribuição; caso A - média mais próxima do mínimo, B média no meio do intervalo, C - mais próxima do máximo ( Adaptada de Tucker e Ferson)

Em outros casos de modelos não parametrizados as informações disponíveis são o máximo o mínimo e a mediana. A curva de distribuição de probabilidades acumulada passa a apresentar as formas indicadas na Figura 7.5. Mais uma vez são apresentadas três curvas, a primeira para o caso da mediana estar próxima ao mínimo, a segunda para a mediana próximo a centro do intervalo e a terceira para a media próxima ao máximo, uma quarta curva é apresentada para o caso de se conhecer não só a mediana como os percentis de $25 \%$ e $75 \%$. 


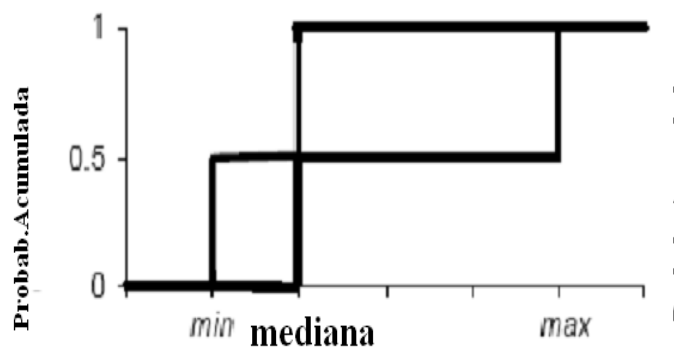

A

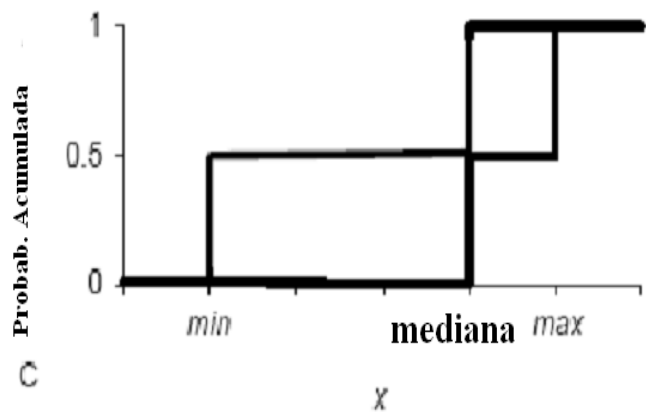

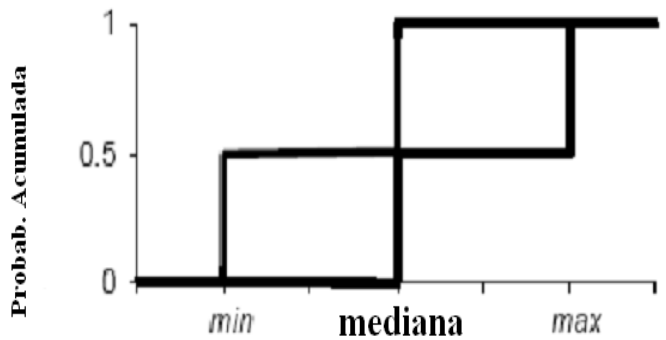

B

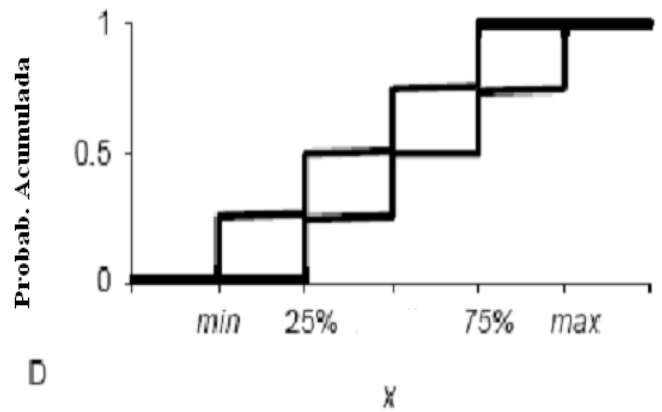

Figura 7.5 Curvas probabilísticas para uma distribuição onde se conhece a médiana e os valores máximos e mínimos, no caso do exemplo A a médiana está mais próxima do mínimo, em $B$ está no meio do intervalo e em $C$ está mais próxima do máximo e em $D$ temos a representação em percentis (Adaptada de Tucker e Ferson)

Outra situação possível é quando se dispõe da moda, neste caso as curvas de distribuição de probabilidade acumulado podem apresentar as formas abaixo 


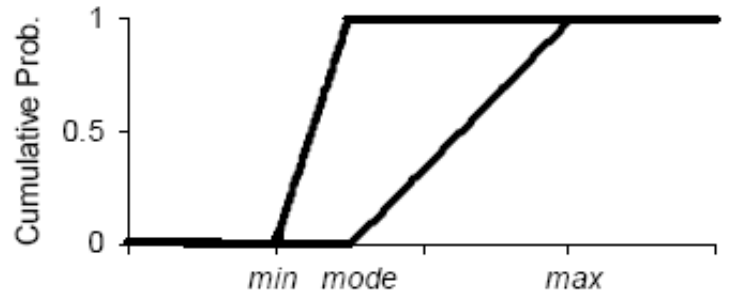

A

$x$

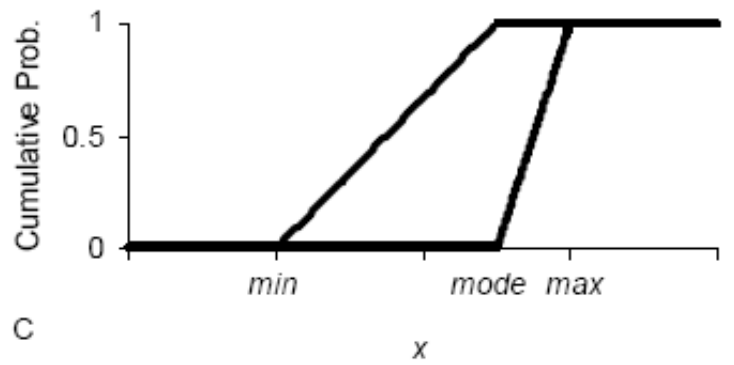

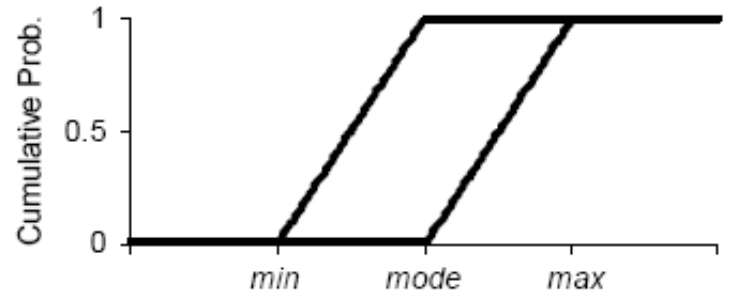

B

Figura 7.6 Curvas probabilísticas para uma distribuição onde se conhece a moda e os valores máximos e mínimos, no caso do exemplo A a moda está mais próxima do mínimo, em B está no meio do intervalo e em C está mais próxima do máximo ( Adaptada de Tucker e Ferson)

\subsubsection{Modelos Empíricos}

Os modelos empíricos são aqueles onde se dispõe de uma série de valores que a variável pode apresentar. Utilizam-se os limites de confiabilidade de Kolmorogov e Smirnov (Sokal e Rohlf (1994)) para a construção das curvas. Este modelo requer que o analista especifique o intervalo e o nível de confiabilidade. Para um caso hipotético onde se sabe que a variável apresenta os valores $(0,2$ 0,5 0,6 0,7 0,75 e 0,8), distribuídos entre 0 e 1, pode-se ver na curva da Figura 7.7 a sua representação. 


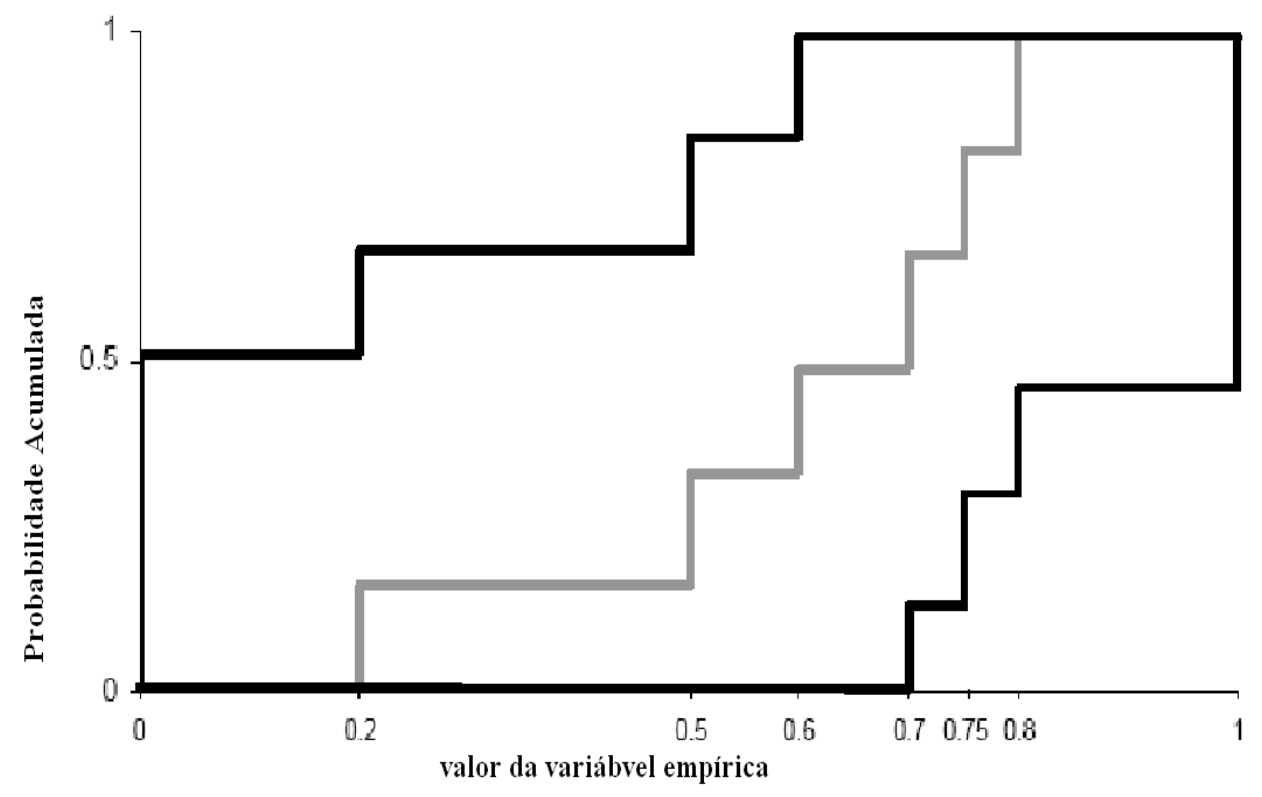

Figura 7.7 Curvas probabilísticas para um intervalo de confiança de $95 \%$ Kolmorogov-Smirnov, para modelo empírico de distribuição (Adaptada de Tucker e Ferson)

Williamson e Dows (1990) introduziram métodos numéricos explícitos para trabalhar computacionalmente as curvas, permitindo a sua adição, subtração, multiplicação e divisão. 0 algoritmo foi implementado em software (Ferson e Long,1995; Ferson et al,1997; Ferson 2002) e posteriormente foi estendido para logaritmos, raiz quadrada e convoluções, por Berleant e Goodman e seus colegas (1993;1996); Berleant e Cheng, 1998; Berleant e Gooodman Strauss,1998). Este algoritmo é usado no exemplo prático apresentado a seguir, extraído de Tucker e Ferson.

Este exemplo demonstra, de forma simples, o resultado de uma operação entre diversas curvas probabilísticas. O resultado da convolução entre quatro curvas probabilísticas (Figura 7.8) é mostrado na Figura 7.9 extraída de Tucker e Ferson. Na figura 7.8, são apresentadas: a curva $A$, que é uma curva Lognormal de média $[0,5 ; 0,6]$ e variância $[0,05$; 0,1 ]; a curva $B$, que é uma curva onde se sabe o mínimo e máximo e a moda, no caso 0, 0,4 e 0,3 respectivamente; a curva $C$, que é extraída de dados empíricos que são $(0,2 ; 0,5 ; 0,6 ; 0,7 ; 0,75$ e 0,8); e a curva $D$, que é uma distribuição uniforme. 

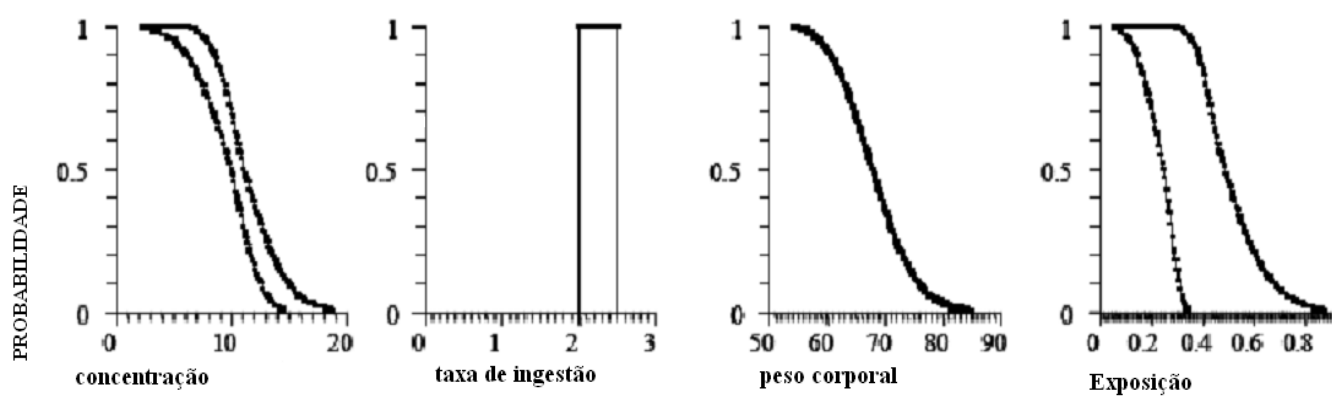

Figura 7.8 Curvas probabilísticas A, B, C e D

Nas Figuras 7.8 e 7.9 pode-se observar o resultado da soma das distribuições especificadas na figura acima em que alinha em cinza mostra aplicação de Monte Carlo e as curvas em negrito a aplicação de curvas probabilísticas. A distribuição soma de $A+B+C+D$ utilizando Monte Carlo é apresentada em linha mais fraca em cor cinza na figura 7.9, enquanto que o resultado usando as curvas probabilísticas é apresentado na área representada pelas curvas mais grossas em negrito.

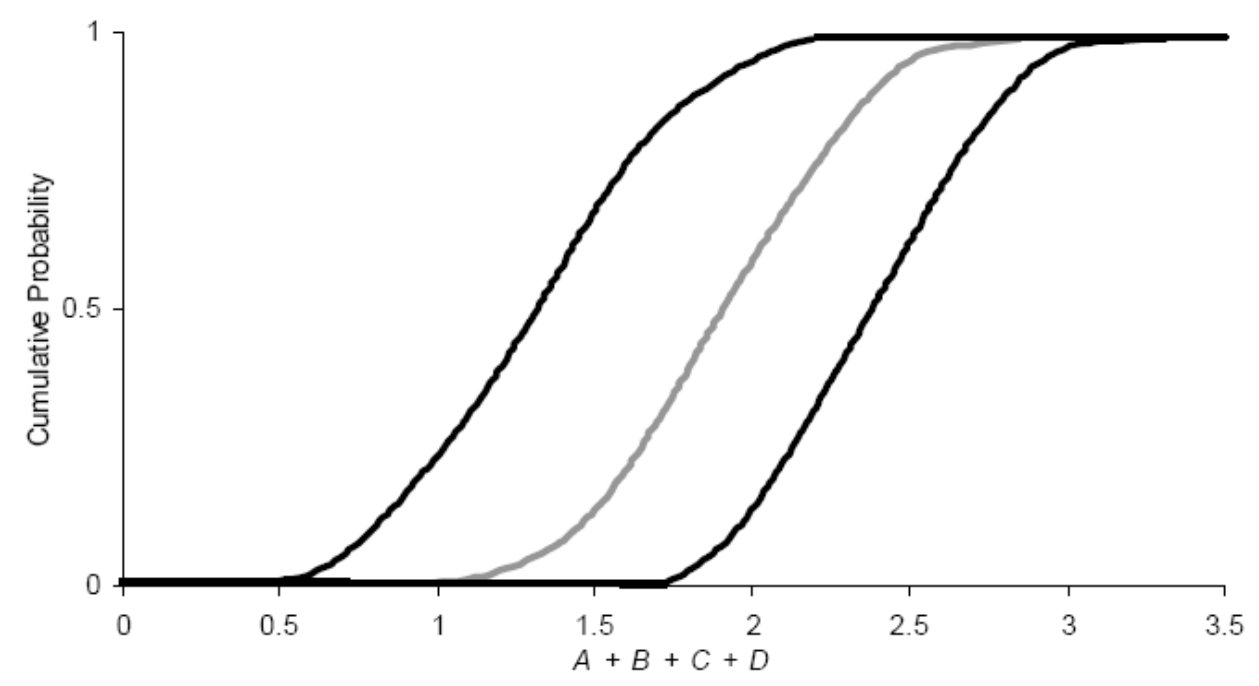

Figura 7.9 Soma de curvas probabilísticas ( Adaptada de Tucker e Ferson)

Um exemplo prático do uso de modelos empíricos, que envolve o cálculo da quantidade de substância tóxica consumida por um ser humano, é apresentado na Figura 7.10. Este cálculo é muito usado em risco ambiental para se determinar o grau de risco envolvido em caso de exposição a substâncias tóxicas. Sabe-se que:

Exposição=Concentração $\times$ Taxa de ingestão/Peso corporal 

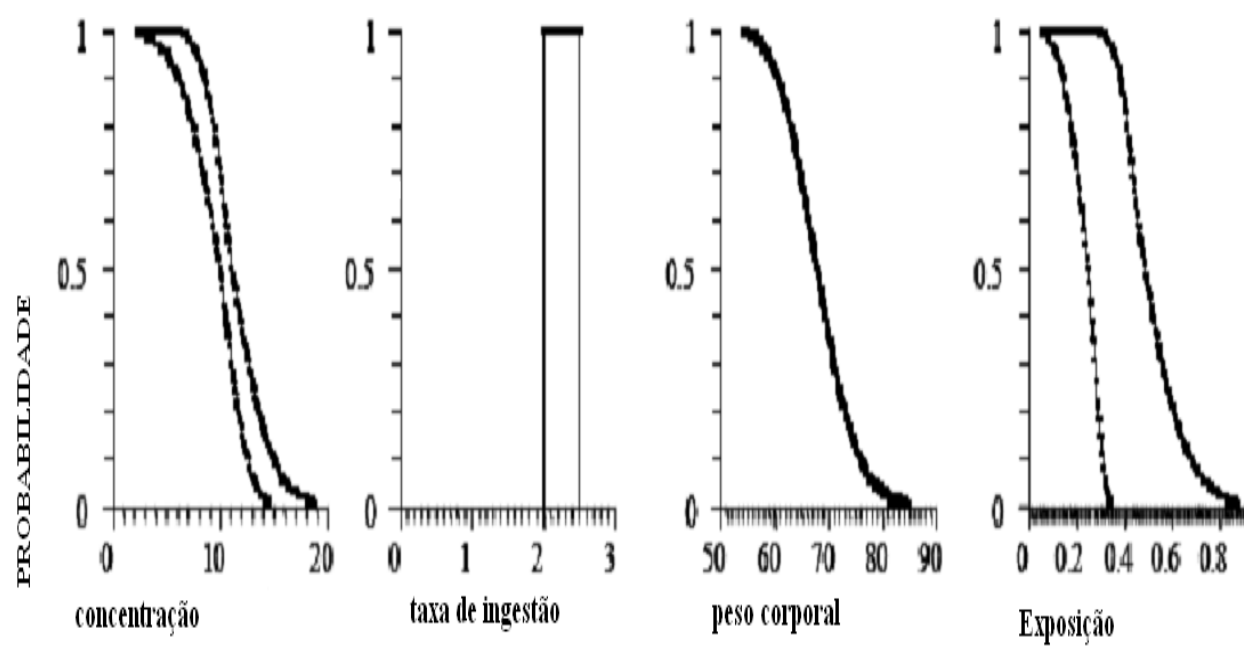

Figura 7.10 Curvas das variáveis de entrada e da variável de saída ( Extraída de Tucker e Ferson)

Para se conceituar a incerteza envolvida em processos de Curvas Probabilísticas devem-se considerar os seguintes pontos: a incerteza envolvida nos valores dos parâmetros de uma específica distribuição de probabilidades é referente à incerteza sobre os limites de variabilidade; e a incerteza referente à forma da distribuição, com os parâmetros bem definidos, é referente à incerteza sobre o formato ou ñshapeòda curva. Por outro lado, uma junção destas duas incertezas leva a uma classe maior de incerteza onde pouco se sabe do formato e do real valor dos parâmetros que é por alguns a chamado de caso de incerteza da variabilidade.

7.6.4 Breve comparação entre Montecarlo e analise por curvas probabilísticas

Uma comparação entre as estas duas abordagens pode ser sintetizada na Tabela 7.1, em que são listadas as suas características mais relevantes. 
Tabela 7.1 Comparação entre métodos de Montecarlo e Curvas probabilísticas (Adaptada de Tucker e Ferson)

\begin{tabular}{|c|c|c|}
\hline $\begin{array}{c}\text { CONHECIMENTO } \\
\text { EMPIRICO }\end{array}$ & MONTECARLO & $\begin{array}{c}\text { CURVAS } \\
\text { PROBABILÍSTICAS }\end{array}$ \\
\hline $\begin{array}{l}\text { O intervalo de variação da } \\
\text { variável }\end{array}$ & Assume distribuição uniforme & Assume intervalo \\
\hline $\begin{array}{l}\text { Alguns limites sobre a } \\
\text { variável aleatória }\end{array}$ & $\begin{array}{l}\text { Seleciona a distribuição com } \\
\text { maior relação de uma classe } \\
\text { de distribuição }\end{array}$ & $\begin{array}{l}\text { Forma um envelope ao } \\
\text { longo da classe de } \\
\text { distribuição dentro dos } \\
\text { limites }\end{array}$ \\
\hline $\begin{array}{l}\text { Incerteza sobre a família de } \\
\text { distribuição e tipo }\end{array}$ & $\begin{array}{l}\text { Repete a análise com outras } \\
\text { possíveis distribuições }\end{array}$ & $\begin{array}{l}\text { Forma uma distribuição } \\
\text { de possíveis formatos }\end{array}$ \\
\hline Exemplos numéricos & $\begin{array}{l}\text { Forma uma função distribuição } \\
\text { empírica }\end{array}$ & $\begin{array}{l}\text { Usa Kolmorogov- } \\
\text { Smirnov intervalos de } \\
\text { confiança }\end{array}$ \\
\hline $\begin{array}{l}\text { A variável acompanha uma } \\
\text { distribuição marginal }\end{array}$ & distribuição & $\begin{array}{l}\text { Usa uma distribuição } \\
\text { particular }\end{array}$ \\
\hline Incerteza medida & $\begin{array}{l}\text { Ignora a incerteza ou executa } \\
\text { análise de sensibilidade }\end{array}$ & $\begin{array}{l}\text { Expressa um intervalo e } \\
\text { incorpora a incerteza a } \\
\text { análise }\end{array}$ \\
\hline Não detectado & $\begin{array}{l}\text { Reporta não detectado com } \\
\text { um valor equivalente a metade } \\
\text { do grau de precisão }\end{array}$ & $\begin{array}{l}\text { Reporta não detectável } \\
\text { com um dado intervalo }\end{array}$ \\
\hline Independência das variáveis & ndependência & Assume independência \\
\hline Magnitude da correlação & lação & $\begin{array}{l}\text { Simula correlação a } \\
\text { partir de um valor } \\
\text { conhecido }\end{array}$ \\
\hline $\begin{array}{l}\text { Conhecido somente o sinal } \\
\text { ou dependência }\end{array}$ & $\begin{array}{l}\text { Assume alguma correlação } \\
\text { com o sinal apropriado }\end{array}$ & $\begin{array}{lr}\text { A curva resultado } \\
\text { assume somente um } \\
\text { sinal de dependência e } \\
\text { assume } & \text { valores } \\
\text { diversos } & \\
\end{array}$ \\
\hline $\begin{array}{l}\text { Não se conhece a natureza } \\
\text { da dependência }\end{array}$ & $\begin{array}{l}\text { Assume independência } \\
\text { (usualmente) ou repete a } \\
\text { análise para diferentes } \\
\text { correlações }\end{array}$ & $\begin{array}{l}\text { As curvas resultantes } \\
\text { são aplicáveis para } \\
\text { todos os casos de } \\
\text { dependências }\end{array}$ \\
\hline Incerteza do modelo & $\begin{array}{l}\text { Usa uma mistura estocástica } \\
\text { de funções de distribuição }\end{array}$ & $\begin{array}{l}\text { Usa um envelope de } \\
\text { funções de distribuição }\end{array}$ \\
\hline
\end{tabular}

A análise por curvas probabilísticas, de forma análoga a de Montecarlo, é um método muito usado em análise de risco. Os métodos possuem muito em comum em relação a seus 
propósitos, teoria e interpretação. Eles diferem em termos de mecanismos computacionais. $O$ método de Monte Carlo é baseado em uma simulação pseudo-randômica de números e a análise por curvas probabilísticas é baseada em uma abordagem analítica, implementada por processo de discretização. Mas estas diferenças são meramente computacionais. Na verdade, Monte Carlo é um caminho efetivo para se aproximar da distribuição de interesse enquanto analise por curvas probabilísticas proporciona um envelope que torna possível ter uma idéia da amplitude de variação do resultado. O mais importante é que os métodos proporcionam perspectivas complementares de como quantificar a incerteza em análise de risco.

\subsection{Comparação metodológica}

Não existe, em princípio, um método, ou metodologia adequada para todas as hipóteses e situações que envolvam análise de risco e o conseqüente conhecimento do grau de incerteza envolvido no processo. Na verdade, o método mais adequado depende de uma série de fatores como: informações disponíveis, natureza da incerteza, variabilidade natural do modelo, conhecimento teórico do processo etc. São apresentados os prós e contras das diversas abordagens de forma resumida, porém, não conclusiva, já que uma análise mais profunda foge ao escopo deste trabalho. A análise, a seguir, não leva em consideração a impossibilidade de se aplicar o método a um dado modelo. Assim, partindo do princípio que um método é adequado para um modelo ou processo, pode-se criticar a aplicação e a adequabilidade do método.

\section{Análise determinística}

Tem a seu favor que o resultado representa a melhor estimativa do risco, além de produzir resultados mais realísticos; tem contra si o fato de representar um caso muito específico envolvendo o modelo; necessita de dados bem determinados e um bom conhecimento do modelo, além de ser pouco abrangente e não proporcionar uma visão mais ampla das condições gerais de operação. Esta metodologia é muito interessante quando se quer analisar um caso específico e bem definido que exija especial atenção do analista.

\section{Análise do pior caso}

É um método conservativo muito útil para estipular o coeficiente de segurança no dimensionamento de projetos; de certa forma, possui a mesma desvantagem do método determinístico e é, ate certo ponto, uma derivação dele. Este método dificulta a comparação de diversas hipóteses existentes e pode gerar um modelo excessivamente conservativo. $O$ analista deve ter uma grande certeza de que está realmente examinando o pior caso ou o caso mais significativo. 


\section{Análise intervalar}

Trata-se de uma evolução da análise do pior caso, já que possui, em um dos extremos, o pior caso possível. Tem como principal vantagem um estudo amplo das diversas condições, sendo simples e fácil de usar. No caso de serem usadas muitas variáveis de entrada, pode se tornar computacionalmente mais difícil o processamento dos dados. Especial atenção deve ser dada no caso de uma mesma variável ser usada diversas vezes no modelo, o que poderia acarretar algumas distorções no resultado.

\section{Aritmética ớuzzyòou nebulosa}

O que se observa, de forma geral, é certa resistência na aplicação de lógica ớuzzyôe dos conceitos matemáticos da aritmética ófuzzyô em estudo de risco, sendo considerado por muitos uma generalização da matemática intervalar. Teoricamente, a metodologia ớuzzyô é uma representação robusta da indeterminação quando a informação empírica é muito esparsa, vaga ou ambígua. Tem como vantagem a sua enorme difusão no meio acadêmico, em geral, e a existência de muitos programas computacionais que facilitam a obtenção do resultado. Dependência e correlação entre as variáveis não precisam ser definidas, porém, para muitos os conceitos ớuzzyônão são definidos com exatidão matemática.

\section{Análise probabilística}

A análise probabilística, apesar de não ter sido expressamente estudada neste trabalho, é uma metodologia muito comum em diversos campos do conhecimento humano, quando as variáveis envolvidas são definidas em termos probabilísticos. Trata-se, na verdade, de uma generalização do modelo determinístico onde as variáveis são representadas em curvas probabilísticas bem definidas. Este método exige um conhecimento profundo do modelo e uma especificação precisa das variáveis em termos probabilísticos, com o conhecimento de parâmetros bem definidos como média e variância. Para problemas simples onde a incerteza é pequena, métodos de aproximação Gaussiana têm se mostrado úteis. A abordagem é simples e tem a grande credibilidade matemática. Em muitos problemas se possui apenas a média e variância sem uma definição mais específica da distribuição, para isto outros métodos podem ser usados.

\section{Montecarlo (incluindo hipercubo latino e outros métodos similares)}

É um método relativamente simples de ser implementado e academicamente aceito em diversas áreas do conhecimento; é extremamente amigável computacionalmente e facilmente explicável. Quando usado corretamente, a distribuição total das saídas do modelo é facilmente obtida, representa de forma clara a incerteza total e permite o uso de informações de dependência e correlação entre as variáveis. Necessita de uma gama enorme de informações empíricas e informações explícitas das distribuições das variáveis e suas correlações e 
dependências. Na prática, freqüentemente força o analista a adotar uma série de hipóteses, por exemplo, independência das variáveis, forma das curvas de distribuição das variáveis de saída.

Análise por curvas probabilísticas (ñpprobability bounds analysiso)

É um método bastante usado para analise de incerteza em estudos de risco. Método preferencialmente empregado em estudos ambientais de contaminação e análise hidrológica. Grande parte do seu desenvolvimento se deve a estudos na área de risco e incertezas. Possui a enorme vantagem de poder ser usado em conjunto com diversos tipos de informações, como intervalares ou determinísticas. Permite uma visão ampla do problema e, de certa forma, consegue abranger diversos métodos propostos anteriormente. É extremamente consistente e matematicamente fundamentado. Necessita de, pelo menos, algumas informações referentes às curvas envolvidas, e pode utilizar resultados empíricos e esparsos. Necessita de uma grande capacidade computacional para sua execução e aplicação, sendo indispensável o uso de computador e algoritmos apropriados. Por apresentar resultados amplos, exige um exame criterioso do analista em relação aos seus resultados, não dispensando uma descrição minuciosa já que as curvas respostas são amplas e ilustram uma gama de situações a que são submetidos os modelos.

\section{$\underline{\text { Requisitos computacionais exigidos }}$}

Torna-se importante à análise dos requisitos computacionais exigidos pelos diversos métodos, já que no mundo atual é extremamente difícil um analista dispensar o uso de um computador, não só em virtude da complexidade dos modelos como também pela facilidade da implementação dos algoritmos computacionais. A tabela 7.2 é uma adaptação de Ferson et al 1999 e Abrahamssom, 2004. Nesta tabela é apresentado o tempo relativo de execução das diversas metodologias propostas.

Tabela 7.2- Tempo relativo de execução das diversas metodologias propostas ( Adaptado de Ferson et al 1999 e Abhramssom, 2001)

\begin{tabular}{|c|c|}
\hline METODOLOGIA & TEMPO RELATIVO DE EXECUÇÃO \\
\hline ANÁLISE DETERMINÍSTICA & $\mathrm{T}$ \\
\hline ANÁLISE INTERVALAR & $4 \mathrm{~T}$ \\
\hline ARITMÉTICA ñFUZZYò & MT, Onde M [40, 200] \\
\hline MONTECARLO & NT, Onde N $[400,50000]$ \\
\hline CURVAS PROBABILISTTICAS & KT, Onde K $[20,100]$ \\
\hline MONTECARLO DE SEGUNDA ORDEM & $\mathrm{N}^{2} T$, Onde N $[400,50000]$ \\
\hline
\end{tabular}




\section{CAPÍTULO 8}

\section{MÉTODOS PARA MEDIR AS INCERTEZAS}

\subsection{Análise inicial}

Para se ter uma completa análise de Incerteza em um estudo de Risco uma série de etapas precisam ser seguidas; uma das mais importantes consiste na classificação ponderada dos parâmetros com respeito à contribuição de cada incerteza no Modelo (IAEA, 1989; Morgan \& Henrion, 1990). A partir do momento que se conhece a inexatidão das variáveis envolvidas no modelo, e se consegue descobrir as origens das incertezas, a fase seguinte é a da determinação de como as incertezas das variáveis de entrada influenciam a incerteza na saída (propagação das incertezas). Como etapa final deve-se estimar a contribuição relativa de cada uma das incertezas na incerteza global, que consiste na classificação ponderada de incertezas.

Obviamente que a escolha do método adequado para a classificação ponderada irá depender do tipo de método de propagação que foi usado, por exemplo, o método analítico é muito útil quando existe uma expressão matemática definida com uma formulação adequada; neste caso deve-se optar por um método de classificação ponderada que valorize esta disponibilidade de fórmula e a facilidade de possuir variáveis bem definidas. Optou-se por apresentar, de uma forma mais precisa, somente os métodos probabilísticos. Algumas sugestões de métodos são analisadas visando estabelecer um contraponto como, por exemplo, o método fuzzy ou nebuloso.

\subsection{Métodos analíticos}

Métodos Analíticos de Probabilidade para propagação de incerteza foram discutidos anteriormente..

\subsection{Métodos numéricos}

Alguns modelos numéricos são apresentados a seguir. Os modelos numéricos são muito úteis na classificação ponderada dos parâmetros de incerteza. Para a utilização de métodos numéricos necessita-se, pelo menos, conhecer os valores, empíricos ou não, que relacionem as variáveis de entrada com as variáveis de saída. A seguir será apresentado um pequeno arcabouço teórico que permitirá compreender melhor a importância do estudo das incertezas paramétricas envolvidas e como é possível estimá-las 


\subsubsection{Coeficientes de correlação}

a) Coeficiente de correlação linear.

Mede o grau e o tipo do relacionamento entre as variáveis estudadas. É também chamado de coeficiente de correlação de Pearson, em homenagem ao seu criador.

Simbologia: R (amostra) ou f (população).

O valor de R pode ser calculado por:

$$
R=\frac{n \Sigma X Y-\Sigma X \Sigma Y}{\sqrt{n\left(\Sigma X^{2}\right)-(\Sigma X)^{2}} \sqrt{n\left(\Sigma Y^{2}\right)-(\Sigma Y)^{2}}}
$$

onde $\mathrm{n}$ é o numero de pares de valores $(\mathrm{X}, \mathrm{Y})$ observados.

A partir dos valores de $\mathrm{R}$ ou $\mathrm{f}$, pode-se verificar o tipo da correlação existente entre as variáveis estudadas, conforme mostrado na Tabela 8

Tabela 8.1 Tabela de correlação

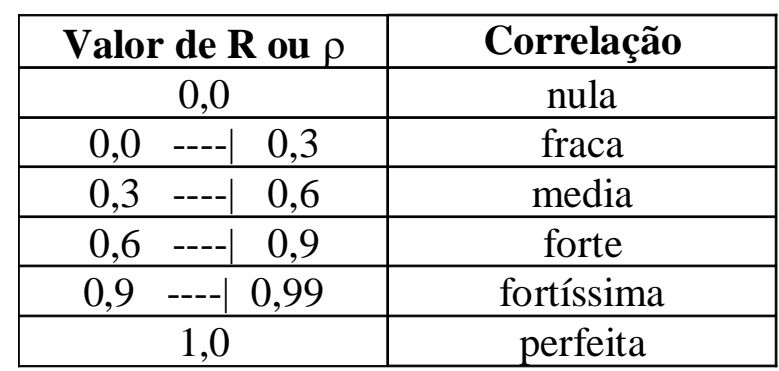

b) Coeficiente de determinação linear

O coeficiente de determinação linear mede a proporção de variações de $Y$ que são explicadas diretamente indiretamente pelas correspondentes variações de $\mathrm{X}$. Deve ser expresso em porcentagem.

Simbologia $R^{2}$ (amostra) ou f ${ }^{2}$ (população). 
c) Grau de significância do coeficiente de correlaçâo linear

Como regra geral, a hipótese nula de interesse é que o coeficiente de correlação populacional seja igual a zero, pois se essa hipótese for rejeitada ao nível de significância Ŭ estipulado, pode-se concluir que efetivamente existe uma relação entre as variáveis estudadas.

Na maioria das vezes utiliza-se a distribuição de Student, com g (grau de liberdade) $=n$ - 2, para testar a significância do coeficiente de correlação linear populacional, sendo que a estatística de teste será calculada por:

$$
t_{t}=\frac{R}{\sqrt{\frac{1-R^{2}}{n-2}}}
$$

Este método simples e muito seguro, que é o de classificação ponderada dos parâmetros de incerteza, pode ser calculado com o coeficiente de correlação. Como já descrito, o coeficiente de correlação deve ser calculado a partir de uma relação de variáveis de saída e suas as respectivas variáveis de entrada, considerando, por exemplo, $\mathrm{n}$ conjuntos de pares ordenados entrada- saída para um sistema simples de uma entrada e uma saída.

$$
r_{X Y}=\frac{\sum_{j=1}^{n}\left(x_{j}-\bar{x}\right) \cdot\left(y_{j}-\bar{y}\right)}{\sqrt{\sum_{j=1}^{n}\left(x_{j}-\bar{x}\right)^{2} \cdot \sum_{j=1}^{n}\left(y_{j}-\bar{y}\right)^{2}}}
$$

O coeficiente de correlação proporciona uma estimativa do grau de relação linear entre duas variáveis do modelo, em geral variável de entrada e de saída. Se isto for feito para cada variável de entrada, pode-se ter uma idéia de como cada variável de entrada contribui para a incerteza da saída.

$O$ sinal do coeficiente indica o sentido da relação, enquanto que o valor absoluto do coeficiente indica a força da relação ( -1 significa correlação negativa e +1 uma completa correlação positiva). Em estudo de análise de risco existem diversas variáveis que podem estar, ou não, relacionadas. Logo, pelo comportamento do coeficiente de correlação das variáveis, muitas informações relevantes do sistema podem ser descobertas. Por exemplo, pode-se estimar se a contribuição de um parâmetro de incerteza para a incerteza total em uma saída é significante ou não. Em outras situações a utilização de coeficientes de correlação não é a forma mais adequada de tratar a classificação ponderada. Em situações freqüentemente encontradas em Análises de Risco, onde há significativa correlação entre os parâmetros de 
entrada, o coeficiente de correlação pode falhar em medir e reconhecer as correlações. Por exemplo, se tivermos um sistema com várias entradas, e se deseja avaliar a contribuição na incerteza de saída causada por duas de suas variáveis. Considere-se ainda que a contribuição da incerteza paramétrica de uma das entradas seja extremamente alta e esta entrada seja fortemente correlacionada com outra variável de entrada. Neste caso o coeficiente de correlação computado para os dois parâmetros de entrada deveria ser o mesmo em termos absolutos (IAEA,1989) porém, nem sempre isto acontece. Entretanto, Iman e Helton (1988) mostraram como a utilização de coeficientes correlação parcial pode eliminar os efeitos de uma entrada correlacionada.

\subsubsection{Coeficientes parciais de correlação}

Coeficientes parciais de correlação são medidas da contribuição de cada variável de entrada sobre a incerteza total da saída, que é obtida depois que os efeitos atribuídos a outros parâmetros de entrada são removidos (Morgan e Henrion, 1990). Veja o report da IAEA, The International Atomic Energy Agency, Agência Atômica Internacional (1989) para informação de como calcular o CPC (Coeficiente Parcial de Correlação).

Entretanto, a própria IAEA aponta uma série de limitações sobre a utilidade deste instrumento na classificação ponderada de incertezas. Por exemplo, em um modelo não linear, não é possível obter uma estimativa de como a variação final na saída do modelo pode ser explicada por uma relação linear entre os parâmetros incertos e a saída do modelo. Isto obriga a buscar outros meios tais como Regressão Linear e Normalização de coeficientes de regressão.

\subsubsection{Analise de regressão linear}

Análise de regressão consiste em um processo estatístico que permite a análise de relações associativas entre uma variável dependente e uma ou mais variáveis independentes. Este método pode ser utilizado para diversos propósitos como, por exemplo, determinar a dependência entre uma variável dependente e a(s) variável(is) independente(s); o valor desta relação permite verificar a contribuição da variável independente sobre a dependente. Assim, o objetivo da análise de regressão é identificar a natureza e também o grau de associação entre variáveis e isto não implica ou supõe qualquer causalidade. Diz-se ainda que uma regressão linear é múltipla quando envolve uma variável dependente e duas ou mais variáveis independentes. (Malhotra, 2004; Hair Et Al., 2005)

Em uma análise de regressão múltipla, a relação presumida é uma associação linear baseada em correlações entre as variáveis independentes e a variável dependente. Um possível objetivo da análise de regressão múltipla é utilizar as variáveis independentes, que possuem valores conhecidos, para descobrir os valores da variável dependente selecionada 
pelo pesquisador. Assim, uma variável independente é ponderada pelo procedimento da análise de regressão para obter a máxima previsão. O conjunto de variáveis independentes ponderadas forma a variável estatística de regressão, que representa a combinação linear dessas variáveis que melhor prevê a variável dependente (Hair et al., 2005). Maiores detalhes podem ser obtidos em Hair, J.F et al, 2005

Perigos e limitações associados com as análises de regressão e de correlação

1- $\mathrm{Na}$ análise de regressão, um valor de $\mathrm{Y}$ não poderá ser legitimamente estimado, se o valor de $X$ estiver fora do intervalo de valores que serviam de base para a equação de regressão.

2 ï Se a predição de $Y$ envolve um resultado que ainda não ocorreu, os dados históricos que serviram de base para a equação de regressão podem não ser relevantes para futuros eventos.

3 ï O uso de um intervalo de predição ou de confiança está baseado na hipótese de que as distribuições condicionais de $Y$ são normais e possuem variâncias iguais.

4 ï Um coeficiente de correlação significante não indica, necessariamente, uma relação de causalidade, mas pode indicar, isto sim, uma ligação comum a outros eventos.

5 ï Uma correlação significante não é necessariamente uma correlação importante. Dada uma grande amostra, uma correlação de, digamos, $R=+0,10$ pode ser significantemente diferente de 0 a $\breve{U}=0,05$.

8.3.4 Analise de regressão multilinear

A análise Multivariada explora a capacidade de determinação de uma variável dependente a partir de um conjunto de variáveis independentes, tornando possível predizer uma variável $(Y)$ a partir de um conjunto de variáveis $(X n)$.

A regressão múltipla observa a quantidade de mudança de uma variável (Y), dita dependente, ocasionada pelas alterações em variáveis independentes $(X n)$; esta quantidade de mudança é indicada pelos parâmetros da equação de regressão, indicada pela fórmula abaixo:

$\mathrm{Y} 12=\mathrm{A} 12+\mathrm{B} 12 \mathrm{X} 1+\mathrm{B} 21 \mathrm{X} 2+\mathrm{U}^{\circ}$

Onde $\mathrm{Y} 12$ é o valor estimado de $\mathrm{Y}$ a partir das variáveis independentes $\mathrm{X} 1$ e X2; $\mathrm{A} 12$ é o valor interceptor (ponto do plano de regressão que cruza o eixo dos $Y$ quando $X 1=X 2=0$ ); é o erro; B12 e B21 são os coeficientes de regressão parciais, indicando a inclinação das relações entre $\mathrm{Y}$ e $\mathrm{X} 1$ e $\mathrm{Y}$ e $\mathrm{X} 2$, respectivamente, enquanto as outras variáveis são mantidas constantes.

Um Modelo Regressão Linear, de $Y$ como função de $X$, assume que a relação linear do tipo $\mathrm{Y}=\mathrm{a}+\mathrm{bX}+\mathrm{E}$, onde $\mathrm{E}$ é o erro randômico (IEAE,1989). Essencialmente, um modelo tenta 
encontrar uma equação de primeiro grau que melhor representa a relação entre as variáveis de entrada $x 1, x 2, x 3, x 4, \ldots, x n$ e as variáveis de saída $y 1, y 2, y 3, \ldots, y n$, obtendo uma estimativa dos coeficientes a e b (veja IEAE, 1982). No caso de Regressão Linear Múltipla assume-se uma expressão linear para $Y$ e não é função de uma única variável $X$, mas várias variáveis $x 1, x 2, x 3 ., x 4 \ldots . . x m$. O resultado aproximado da expressão é freqüentemente chamado de Resposta Superficial. Para um exemplo do método superficial veja Frantzich,Harrada \& Magnussun (1995).

\section{Padronização dos coeficientes de Correlação Parcial}

Se um modelo de Regressão Múltipla apresentado na seção anterior $Y$ e $X$ i são padronizados de acordo com a formulação abaixo.

$$
\mathrm{V}=(\mathrm{Y}-\mathrm{E}(\mathrm{Y})) / \mathrm{D}(\mathrm{Y}), \quad \mathrm{U}_{\mathrm{i}}=\left(\mathrm{X}_{\mathrm{i}}-\mathrm{E}\left(\mathrm{X}_{\mathrm{i}}\right)\right) / \mathrm{D}\left(\mathrm{X}_{\mathrm{i}}\right)
$$

onde os coeficientes bi , i=1,2,3,...m de um modelo de regressão linear múltipla

$$
\mathrm{V}=\mathrm{b}_{1} \mathrm{U}_{1}+\mathrm{b}_{2} \mathrm{U}_{2}+\ldots+\mathrm{b}_{\mathrm{m}} \mathrm{U}_{\mathrm{m}}+\epsilon
$$

são chamados de coeficientes parciais de regressão padronizados. O significado prático destes coeficientes bi indica como o desvio padrão no modelo de saída $Y$ com as mudanças em Xi relativas a um valor determinado do seu próprio desvio padrão para todo Xk onde k é diferente de $\mathrm{i}$.

\subsubsection{Uso de coeficientes de correlação}

Coeficiente de correlação ró de spearman

Uma ferramenta interessante para classificação ponderada é o chamado coeficiente de correlação de Spearman, que mede a intensidade da relação entre variáveis. Não utiliza o valor observado, usa somente a ordem das observações. Assim, este coeficiente não é sensível a assimetrias na distribuição, nem à presença de pontos muito fora do padrão predominante; não se exige, assim, que os dados provenham de duas populações normais. O coeficiente $f$ de Spearman é a ferramenta mais apropriada para o caso em que os dados não apresentam uma distribuição îbem concentradaò com pontos bem afastados dos restantes, ou ainda em que parece existir uma relação crescente ou decrescente em formato de curva.

A forma fácil para calcular o coeficiente $f$ de Spearman é dada por:

$$
r_{\text {rank }}=1-\frac{6 \sum_{i=1}^{n} D_{i}^{2}}{n\left(n^{2}-1\right)}
$$


em que Di é a diferença nos números de ordem (ranks) entre o $n^{\text {ésimo }}$ par de dados. Se houver rempatesò isto é, se um valor particular aparece mais que uma vez, todos os valores que forem designados naquela ordem receberão a média de seus números de ordem (rank) antes de computar Di. Por exemplo, se existirem 8 dados e os dois últimos dados mais altos forem idênticos, então os dois (o dado que receberia o número de ordem 7 e número de ordem 8) receberão $(7+8) / 2=7,5$. No caso em que os 3 últimos dados são iguais, eles recebem $(6+7+8) / 3=7$.

A variação do coeficiente f de Spearman vai de -1 e 1 . Quanto mais próximo estiver de um destes extremos, maior será a associação entre as variáveis. O sinal negativo da correlação significa que as variáveis variam em sentidos opostos, assim, as categorias mais elevadas de uma variável são associadas às categorias mais baixas da outra variável. 


\section{CAPÍTULO 9}

\section{PROPOSTA METODOLÓGICA}

Neste capítulo será apresentada uma proposta metodológica que permita, de uma forma racional e estruturada, não só identificar as incertezas envolvidas como também dimensioná-las e, em seguida, reduzi-las.

Como já visto anteriormente, as incertezas estão presentes em diversas etapas de um estudo tais como: na escolha do modelo estrutural como simplificação da realidade; no uso de aproximações numéricas na solução de equações definidas no modelo estrutura; na definição de condições de fronteiras, incluindo dados de entradas; e na escolha de valores paramétricos.

Poder-se-ia assim, de forma simples, enumerar todas as etapas de um processo de análise de risco e, em seguida, seriam estabelecidas recomendações para minimizar os erros e incertezas, porém isto corresponderia a simplesmente elaborar um manual de análise de risco.

Uma idéia que foi analisada e que é adotada nesta tese, consiste em pensar no processo criador do estudo como um processo tripartite, ou seja, existem 3 grandes grupos de processos que são utilizados em um estudo de risco. Eles são classificados quanto a sua natureza em processos matemáticos ou racionais, qualitativos ou por especialistas e estatísticos ou banco de dados.

Processos matemáticos racionais são processos relacionados aos cálculos numéricos, sejam eles analíticos, determinísticos, probabilísticos. Estudando as incertezas relacionadas a estes processos, determinam-se as incertezas numéricas, como foram abordadas nos capítulos 7 e 8 . As incertezas numéricas estão presentes nas atividades que demandam algum cálculo matemático ou avaliação numérica.

Processos qualitativos são processos que derivam do conhecimento de especialistas. A análise de risco, como qualquer produto da mente humana, incorpora todos os defeitos e virtudes que o ser humano pode gerar. Por isso, atualmente crescem em importância os estudos dos mecanismos psicológicos utilizados pelo homem no processo de tomada de decisão. Muitos métodos estruturais podem ser usados para compreender melhor a informação baseada na opinião de vários especialistas, Morgan \& Henrion (1990). Segundo os estudos de Amos Tversky e Daniel Kahnemann (1974), como já vistos, heurísticas são atalhos mentais que tornam mais leve a carga cognitiva de tomar decisões, mas que podem conduzir a vieses no processo de decisão. As heurísticas são os caminhos pelos quais os agentes encontram soluções ótimas, levando em consideração os custos para tomar decisões plenamente 
racionais, uma vez que é da natureza humana a existência de restrições ao exercício da plena e ilimitada racionalidade. Os vieses cognitivos são erros sistemáticos de julgamento, ou melhor, são erros mentais causados pela simplificação da estratégia de processamento da informação, que ocasionam muitas vezes uma distorção na maneira como os indivíduos percebem a realidade.

Processos estatísticos ou por banco de dados são todos os processos em análise de risco que, de algum modo, utilizam informações contidas em Bancos de Dados. Estas informações são muito úteis para o cálculo de freqüência de falhas ou ainda para se obter dados de equipamentos. Foi visto no capítulo 6 que, em estudos de risco e confiabilidade, o uso de banco de dados é essencial, porém, sem o devido cuidado, inúmeros erros são introduzidos nestes estudos. Por isso uma série de cuidados deve ser tomada para, pelo menos, evitar erros grosseiros.

\subsection{Proposta de classificação das incertezas}

Procurou-se por uma divisão tripartite das incertezas que são: QUANTO À NATUREZA, QUANTO À FUNCIONALIDADE E QUANTO À ETAPA DA ANÁLISE DE RISCO. A classificação quanto à natureza considera as incertezas quanto a seu aspecto intrínseco, aborda o problema de forma macro. A classificação quanto à funcionalidade aborda a incerteza no contexto da utilidade da variável incerta; trata-se mais de um problema de aplicabilidade. Por último, na classificação quanto ao processo, busca localizar a incerteza dentro da etapa de análise de risco em que ela está presente. Uma dada classificação não exclui as demais, assim pode-se classificar uma incerteza quanto à natureza, sem excluir a classificação quanto à funcionalidade ou quanto à etapa da análise de risco.

\subsubsection{Classificação das incertezas quanto à natureza}

Esta divisão com relação à natureza explica uma grande parte das incertezas, porém não engloba todos os casos possíveis. Ela está calcada em aspectos intrínsecos da incerteza e independe do processo de análise de risco e do próprio estudo de risco; elas estão presentes, independentemente do estudo, em diversas áreas do conhecimento humano.

Quanto à natureza, as incertezas podem ser divididas em dois grupos: incertezas naturais (ou aleatórias) e incertezas epistêmicas. As incertezas naturais (ou aleatórias) são inerentes ao processo e não podem ser diminuídas com a utilização de modelo mais sofisticado ou com a coleta de dados adicionais. As incertezas epistêmicas advêm da falta de conhecimento, da lacuna, ou de um entendimento errôneo do processo. 
Incerteza Natural

Como já visto, as incertezas naturais (ou aleatórias) são inerentes aos processos e não podem ser diminuídas com a utilização de modelo mais sofisticado ou com a coleta de dados adicionais. De uma forma geral, os fenômenos naturais apresentam comportamento tão complexo que os modelos matemáticos detalhados não conseguem reproduzir, com exatidão, os processos naturais. As incertezas naturais são, portanto, aquelas inerentes aos processos naturais, e não podem ser reduzidas pelo uso de um modelo mais sofisticado ou pela coleta de mais informações. Elas não podem mudar e, assim, deve-se conhecê-las e incorporá-las ao planejamento. A chamada incerteza aleatória possui diversos nomes na literatura: variabilidade, vagueza (ou vaguidade), estocástica e incerteza irredutível. Esta incerteza representa de uma forma simples, a aleatoriedade da natureza. Deve-se atentar que somente a incerteza baseada no conhecimento pode ser reduzida. A incerteza estocástica é por definição irredutível. Outra importante diferença é que as incertezas de natureza estocástica podem cancelar-se entre si, por exemplo, pode-se ter uma variável de entrada que possui uma correlação positiva com a saída, enquanto outra variável de entrada apresenta uma correlação negativa, logo elas podem eventualmente se anular. Mas para a falta de conhecimento isto não é possível.

\section{Incerteza epistêmica}

A incerteza epistêmica advém da falta de conhecimento subjetivo, da ignorância ou da ambigüidade. Para lidar com ela é necessário melhorar ou aumentar o conhecimento. Por isso torna-se importante descobrir qual a origem da incerteza e identificar e separar os diversos tipos possíveis de incertezas ${ }^{32}$

A incerteza epistêmica tem nomes tais como ambigüidade, ignorância, falta de conhecimento base, incerteza redutível ou subjetiva.

\subsubsection{Classificação quanto à funcionalidade}

Quanto à funcionalidade, pode-se ter: incerteza na base de dados -relacionada aos métodos de amostragem, erros de medição ou nos métodos de análise dos dados; incerteza no modelo - relacionada a modelos matemáticos inadequados ou erro na estimativa dos

\footnotetext{
32 Somente a incerteza baseada no conhecimento pode ser reduzida. A incerteza natural ou estocástica é por definição irredutível, como já visto. Outra importante diferença é que as incertezas de natureza estocástica podem cancelar-se entre si, por exemplo, pode-se ter uma variável de entrada que possui uma correlação positiva com a saída, enquanto outra variável de entrada apresenta uma correlação negativa, logo elas podem eventualmente se anular. Mas para a falta de conhecimento isto não é possível.
} 
parâmetros; e ainda incertezas operacionais - relacionadas à construção, operação e manutenção de obras de engenharia.

As incertezas no modelo podem ser divididas em duas categorias: incertezas no modelo matemático e incertezas nas estimativas dos parâmetros. As estruturas matemáticas, utilizadas para representar os fenômenos e cenários, são uma das principais fontes de incertezas. Os modelos são apenas uma representação simplificada do fenômeno, os modelos são limitados. Com relação às incertezas na estimativa dos parâmetros, adota-se a metodologia proposta por Morgan \& Henrion (1993), que as separam em incertezas nas quantidades medidas empiricamente (por exemplo, medidas de concentração de poluentes), nas constantes utilizadas por convenções (constante de Plank, velocidade da luz, etc), nas variáveis de decisão, nos valores dos parâmetros e ainda nos parâmetros associados ao modelo utilizado.

\subsubsection{Classificação quanto às fases da ar}

Classificar as incertezas conforme a fase da Análise de Risco é extremamente fácil, basta verificar em que ponto do processo de análise de risco está inserida a incerteza. Assim, no caso de uma incerteza em um parâmetro utilizado na análise das conseqüências, tem-se uma incerteza na análise de conseqüência. Esta divisão é interessante, pois propicia ao estudioso identificar em que etapa está presente a incerteza. Permite ainda identificar em quais etapas estão presentes as maiores quantidade de incertezas, e os seus tipos.

\subsection{Aspectos gerais da metodologia proposta}

Após a classificação das incertezas e a proposta da classificação dos processos que fazem parte metodologia, a etapa posterior consiste em identificar as incertezas e tratá-las. Uma série de considerações deve ser feita quando se pretende minimizar as incertezas em estudos que envolvam Análise de Risco, independentemente da natureza do processo, seja ele qualitativo, matemático ou estatístico. Estas considerações são de caráter geral e devem ser aplicadas em qualquer faze do estudo. Estes cuidados estão relacionados ao estudo como um todo e sua relação com o fenômeno a ser tratado, como descrito a seguir.

\section{Avaliação da variabilidade do fenômeno (identificação das incertezas)}

Os fenômenos naturais aparentam muitas vezes serem bem definidos; isto ocorre porque eles são definidos por meio de fórmulas determinísticas que os tornam aparentemente exatos e bem preditivos. Mas, na verdade, eles possuem uma variabilidade natural que pode comprometer, ou não, a sua modelagem. Este comportamento variável depende da complexidade do fenômeno e do grau de exatidão requerido para representar o processo. 
Estudar e conhecer o fenômeno que se quer modelar, e adequá-lo ao fim prático do estudo, minimiza as incertezas envolvidas e possibilita que sejam otimizados os recursos de material e pessoal envolvidos na condução da análise de risco e, em contrapartida, possibilita um estudo mais célere e prático.

Entendimento das incertezas envolvidas (identificação das incertezas)

Como já mencionado, é necessária a conscientização das incertezas envolvidas por parte do analista do processo. Os estudiosos ou pesquisadores devem ter uma visão crítica do seu próprio trabalho e o entendimento das incertezas envolvidas é um bom começo. Para isto é fundamental a localização das fontes de incertezas e a classificação delas.

\section{Conhecimento do modelo (identificação das incertezas)}

O modelo estrutural consiste, na verdade, uma simplificação da realidade. Deve estar claro para o especialista que ele nunca terá um modelo completo e que uma análise crítica, no sentido de obter um modelo suficientemente próximo da realidade, mas que otimize os recursos existentes, deve ser uma meta a ser alcançada. Deve-se considerar ainda, que, em muitos modelos, existem aproximações numéricas na solução de equações definidas no modelo estrutural e estas aproximações irão gerar erros ou incertezas. Por último, deve-se ter cuidado especial na definição de condições de contorno, e este cuidado inclui a seleção dos dados de entradas e a escolha de valores paramétricos.

\section{Especificação do problema}

A especificação do problema é a fase inicial de qualquer estudo e é de suma importância. Para uma correta especificação do problema deve-se contar primeiro com um profundo conhecimento das características do problema: quais os fenômenos relacionados ao problema, quais os fatores mais importantes, suas causas e consequências. Deve-se buscar, nesta fase inicial, elementos que possibilitem, no futuro, uma formulação determinística ou probabilística que represente o problema. Para isto, é necessária uma boa observação da realidade que irá proporcionar uma correta especificação do problema. Outro fator importante é que o estudioso esteja o mais bem familiarizado possível sobre o problema; só assim ele poderá resolver alguns problemas inicialmente pouco previsíveis.

\section{Formulação conceitual e computacional do problema}

O modelo conceitual é muito útil e necessita ser bem construído já que é a expressão do problema em uma linguagem humana. Os processos, trajetórias, variáveis e as interações 
entre as variáveis precisam ser bem definidos. Nem todos os processos e mecanismos precisam ser considerados para análise do fenômeno e a seleção de quais são os processos representativos deve ser feita com cuidado. Obviamente, para situações práticas, geralmente relacionadas à baixa qualidade de dados, torna-se virtualmente impossível incluir todos os processos e mecanismos imaginados no modelo conceitual.

O modelo computacional é constituído por equações e parâmetros, que são utilizados em simulações, ou ainda por meio de dados bibliográficos ou históricos, que são utilizados para alimentar o modelo computacional. Os modelos computacionais são usados para obter resultados quantitativos já que não dependem de laboratório ou de simulações que utilizem modelos físicos. Os seus resultados quantitativos precisam ser validados. Para isto, critérios de validação, de comparação e verificação devem ser definidos; estes critérios são necessários e úteis para testar e confirmar o modelo. Basicamente, testar um modelo computacional consiste em comparar o resultado do modelo com algum resultado que se conhece previamente.

\section{Especificação dos parâmetros (identificação das incertezas)}

A especificação dos parâmetros ocorre como conseqüência da realização de experimentos que permitem, assim, o conhecimento dos valores relacionados a um fenômeno. Muitas vezes os parâmetros relacionados a um modelo específico não podem ser usados em um modelo fisicamente semelhante, porém não idêntico. Por exemplo, se um modelo de dispersão de poluentes na atmosfera é usado de forma eficiente para a velocidade do vento entre 2 e 5 nós, este modelo de dispersão pode não ser útil em um fenômeno semelhante, mas com velocidade do vento entre 4 e 10 nós $\mathrm{Na}$ determinação dos parâmetros dos modelos muitas incertezas podem estar associadas, originadas pelo julgamento subjetivo do estudioso, ou ainda pelo caráter determinístico ou probabilístico do modelo.

\section{Cálculo, apresentação e documentação do resultado}

Algumas das principais fontes de incertezas estão associadas à documentação e apresentação dos resultados (IAEA 1989). Para diminuir as incertezas, os resultados devem ser expressos de forma clara, com a indicação das condições em que foram obtidos, permitindo assim, que os resultados possam ser comprovados e validados por outros especialistas.

\section{Determinação da confiabilidade do binômio modelo/fenômeno}

Uma boa forma de inserir a incerteza da concepção do modelo consiste em atribuir um valor ou curva à incerteza do modelo em si. Por exemplo, para cálculo da descarga de um 
líquido contaminante (de volume específico vf, submetido a uma pressão interna Po) através de um orifício de área $A$, o modelo é representado por uma equação determinística e exata:

$$
Q=C_{d} A \sqrt{\frac{2\left(P_{0}-P_{a}\right)}{v_{f}}}
$$

onde:

Q é a taxa da massa de descarga $[\mathrm{kg} / \mathrm{s}]$;

Cd é o coeficiente adimensional de descarga;

A é a área do furo $\left[\mathrm{m}^{2}\right]$;

Pó é a pressão no tanque no nível do buraco $\left[\mathrm{N} / \mathrm{m}^{2}\right]$;

3 é o volume específico do líquido $\left[\mathrm{m}^{3} / \mathrm{kg}\right]$.

Pode-se introduzir a incerteza total deste modelo de descarga, multiplicando o resultado da equação anterior por uma distribuição do tipo Uniforme $(0,5 ; 1,5)$. Como pode ser visto em Hanna et al (1991), esta fórmula apresenta um certo grau de incerteza, que pode ser representado por esta distribuição uniforme. Outro exemplo ocorre no modelo de dispersão atmosférica de contaminante que, a princípio, é dado por:

$$
C(x, y, z)=\frac{Q}{2 \pi \sigma_{y}(x) \sigma_{z}(x) U} e^{-\frac{y^{2}}{2 \sigma_{y}^{2}}}\left[e^{-\frac{\left(z-H_{e f f}\right)^{2}}{2 \sigma_{z}^{2}}}+e^{\frac{\left(z+H_{e f f}\right)^{2}}{2 \sigma_{z}^{2}}}\right]
$$

Pode-se introduzir, novamente, uma incerteza em todo o modelo, multiplicando-se o $2^{\circ}$ membro de (9.2) por uma distribuição uniforme do tipo uniforme $(0,5 ; 1,5)$ onde:

$C(x, y, z)$ é concentração média na posição $x, y, z$;

$Q$ é a taxa de vazamento;

$\sigma_{\mathrm{v}}, \sigma_{\mathrm{z}}$ são coeficientes de dispersão nas posições geográficas;

$U$ é a velocidade do vento em $\mathrm{m} / \mathrm{s}$;

Heff é a altura do nível do solo onde ocorre o vazamento.

\section{Avaliação qualitativa do modelo}

O método qualitativo, já abordado no Capítulo 4, pode ser usado com esta finalidade. Este método procura classificar o modelo de acordo com características pré-concebidas. Para um melhor esclarecimento pode ser consultado COWI, (1996a). 
Propõe-se que a tabela 4.1, reproduzida abaixo (Tabela 9.1), extraída de COWI, seja utilizada para qualificar o modelo e identificar o seu grau de INCERTEZA. Este procedimento facilita uma revisão crítica do modelo, permitindo que o analista perceba desde o início os pontos fracos na determinação do modelo.

Tabela 9.1 Sub-Classes da Incerteza do Modelo UF3 (Adaptado de COWI, 1996a)

\begin{tabular}{|l|l|l|l|}
\hline PARÂMETROS & \multicolumn{3}{|c|}{ NÍVEL DE INCERTEZA } \\
\hline & $\begin{array}{l}\text { Pequena Incerteza } \\
1<U F i<2\end{array}$ & $\begin{array}{l}\text { Média Incerteza } \\
2<U F i<10\end{array}$ & $\begin{array}{l}\text { Grande Incerteza } \\
10<U F i\end{array}$ \\
\hline Relevância-UF1 & Alta & Média & Baixa \\
\hline Validade-UF2 & Alta & Média & Baixa \\
\hline Variabilidade-UF3 & Baixa & Média & Alta \\
\hline
\end{tabular}

Como a classificação é subjetiva, ela irá obviamente depender do analista ou especialista no modelo

A incerteza total do modelo pode ser calculada por:

$$
U F=\exp \left(\sum_{i=1}^{n}\left(\ln U F_{i}\right)^{2}\right)^{\frac{1}{2}}
$$

onde UF é definido como o nível de incerteza do modelo e UF $\mathrm{U}_{\mathrm{i}}$ são os valores atribuídos às diferentes características, no caso relevância, validade e variabilidade.

Uma forma mais completa de definir a confiabilidade dos modelos foi proposta no ano seguinte na publicação dinamarquesa COWI que, ao invés das características básicas relevância, variabilidade e validade, adota outras características com maiores detalhes, que facilitam o seu uso pelo analista.

A tabela abaixo simplifica a determinação da INCERTEZA do modelo, para isto, basta que $o$ analista classifique o seu modelo conforme a característica representada nas linhas da tabela, por exemplo no caso do analista se julga com uma experiência ( linha 1 da tabela 9.2) razoável, deve utilizar a coluna 3 da tabela 9.2 e avaliar o UF1 de 3 a 9 , a critério do analista. 
Tabela 9.2 Sub-Classes da Incerteza do Modelo UF, análise completa (Adaptado de COWI, 1996a)

\begin{tabular}{|c|c|c|c|}
\hline & $\begin{array}{c}\text { Pequena incerteza } \\
1<U F i<2\end{array}$ & $\begin{array}{c}\text { Incerteza Média } \\
2<U F i<10\end{array}$ & $\begin{array}{c}\text { Grande Incerteza } \\
10<\mathrm{UFi}\end{array}$ \\
\hline $\begin{array}{l}\text { Experiência do } \\
\text { analista e } \\
\text { Competência } \\
\text { UF1 }\end{array}$ & $\begin{array}{l}\text { Vasta. O analista e } \\
\text { qualificado e possui } \\
\text { experiência }\end{array}$ & $\begin{array}{l}\text { Razoável. O analista } \\
\text { é capaz de estimar a } \\
\text { grande maioria das } \\
\text { incertezas envolvidas }\end{array}$ & $\begin{array}{l}\text { Pequeno. O analista pode } \\
\text { apenas especificar a } \\
\text { incerteza envolvida em } \\
\text { alqumas variáveis }\end{array}$ \\
\hline $\begin{array}{c}\text { Conhecimento } \\
\text { anterior e } \\
\text { condições do } \\
\text { projeto UF2 } \\
\end{array}$ & Vasto & Razoável & Pequeno \\
\hline $\begin{array}{c}\text { Tempo disponível } \\
\text { e recursos UF3 }\end{array}$ & Suficiente & Razoável & Não suficiente \\
\hline $\begin{array}{l}\text { Conhecimento } \\
\text { Geral na área } \\
\text { específica UF4 }\end{array}$ & $\begin{array}{c}\text { Vasto. A área } \\
\text { específica do } \\
\text { conhecimento é bem } \\
\text { conhecida. Há um } \\
\text { consenso dos } \\
\text { especialistas }\end{array}$ & $\begin{array}{l}\text { Há alguma falta de } \\
\text { conhecimento ou não } \\
\text { concordância dos } \\
\text { analistas }\end{array}$ & $\begin{array}{c}\text { Há uma substancial falta } \\
\text { de conhecimento }\end{array}$ \\
\hline
\end{tabular}

\subsection{Minimização das incertezas em processos qualitativos (especialistas)}

Um primeiro conceito que deve ser compreendido é que não há uma estrutura simples que garanta o sucesso de um estudo, mesmo que ele seja conduzido por um grupo de especialistas de alto renome. A primeira preocupação que surge, na composição de uma equipe é sobre a composição do grupo que vai analisar um dado processo ou um dado fenômeno. Para uma dada situação, diferentes metodologias podem ser usadas para selecionar e compor o grupo de especialistas que irá estudar o problema. Um método simplificado que permite a seleção de especialista é apresentado, por exemplo, por Clemen (1996). Estas e outras questões são tratadas em seguida. Abaixo são reproduzidos os passos propostos para minimização das incertezas de natureza subjetivas ou provenientes de processos qualitativos.

a) Criação de um protocolo para a avaliação dos especialistas 
Deve ser criado um protocolo mínimo que especifique as características pessoais dos participantes, tais como graduação, formação acadêmica ou profissional, áreas de atuação, teses realizadas, trabalhos correlatos, tempo de estudo, bem como tempo de trabalho na área. Este protocolo deve servir de baliza para uma avaliação contínua da equipe de trabalho; isto ajuda a manter a equipe focada evitando que, de alguma forma, o estudo tome uma direção irreversível ou ainda se torne confuso e pouco prático.

Como já ressaltado diversas vezes, ñTodo o processo de formulação do estudo de risco precisa e deve ser auditado para que o estudo ocorra da forma mais precisa possível, para um resultado satisfatórioò $O$ mesmo ocorre com o processo de seleção dos especialistas. O processo de seleção dos especialistas deve ser feito de forma criteriosa, escolhendo os profissionais que efetivamente possam agregar conhecimento ao estudo, pela natureza do conhecimento que possuem. A escolha deve ser despida de denominação ou de títulos já que, nem sempre, o ocupante de um cargo de natureza política é o possuidor do conhecimento

Sugere-se a leitura de Clemen (1996) na publicação ñAttributes of a Good Assessment Protocolòou ainda Morgan \& Henrion (1990).

b) Definição da terminologia e metodologia

Uma importante medida a ser tomada, visando diminuição das incertezas e, consequentemente, a melhoria no estudo de risco, consiste em padronizar os procedimentos, que começa pela definição da linguagem utilizada e a metodologia empregada. Em geral, um estudo de tamanha complexidade, como analise de risco, exige uma diversidade muito grande de especialistas que, com origem em áreas diversas, possuem diferentes metodologias, além de diferentes linguagens. O líder, ou chefe da equipe, deve estabelecer a forma comum de linguagem, com a definição clara dos termos técnicos principais. Além disto, a escolha da terminologia deve ser encarada nesta hora, buscando algo que atenda não só os objetivos do estudo como também se encaixe nas diversas origens filosóficas dos estudiosos.

c) Avaliação inicial (identificação das incertezas)

Deve-se proceder à identificação e descrição das variáveis que eventualmente podem necessitar de um especialista para sua especificação ou mensuração. Isto pode ser feito usando conhecimentos dos eventos anteriores, obtido a partir da literatura científica ou ainda poderia vir do conhecimento de especialistas, o qual é definido como aquele conhecimento que tem como fonte primária a experiência de algum dos participantes do estudo e que, de certa forma, não poderia ser obtido de forma fácil por outra fonte. Todo o conhecimento precisa de uma ñmente humanaò para que possa ser elaborado e utilizado. O conhecimento que deriva exclusivamente da ação de um especialista é mais caro e difícil de ser auditado. Por isso, é importante que numa fase prévia do estudo haja uma correta definição qual parte do estudo ou 
processo demandará a ação de um especialista ou de um grupo de especialistas. Porém, a necessidade de um especialista pode ainda ocorrer em uma etapa não prevista inicialmente, fruto de dificuldades encontradas e difíceis de serem superadas pelas formas tradicionais de conhecimento.

d) Identificação e recrutamento de especialistas

Para esta tarefa, pode-se solicitar, eventualmente, a ajuda de associações profissionais para o recrutamento dos especialistas. Deve-se notar, porém, que nem todas as etapas necessitam a elaboração de um conhecimento genuinamente originado pela opinião de especialistas porque, como já mencionado antes, grande parte do conhecimento humano se encontra de alguma forma descrito, publicado ou ainda deriva de um determinado banco de dados ou da aplicação de fórmulas ou cálculos pré-existente. Define-se como conhecimento oriundo de um especialista aquele que, utilizado em uma etapa do processo, passa pela reflexão subjetiva e decisiva de um participante do estudo. Assim, pode-se por meio de entrevista, questionário ou qualquer outro meio de produção de conhecimento indagar a um ou mais especialistas sobre um assunto que na literatura (seja fruto de conhecimento já sedimentado) geraria algum tipo de contradição ou alguma espécie de lacuna no conhecimento. A correta escolha dos especialistas e o dimensionamento do grupo devem ter como objetivo harmonizar as diversas origens dos especialistas. A criação de um grupo homogêneo e criativo deve ser o objetivo a ser alcançado.

e) Conscientização da existência de incertezas e da possibilidade de sua determinação.

É natural que o especialista, muitas vezes, se julgue grande conhecedor do assunto que é estudado. Mas, o primeiro passo para um estudo com erros consiste na prepotência de achar que o mundo é perfeito e determinístico e que todo o conhecimento necessário já foi de alguma forma determinado. Uma visão crítica e serena sobre o processo, visando identificar os pontos fracos do estudo é extremamente saudável. É muito melhor uma reflexão objetiva sobre as fraquezas do que produzir um estudo anacrônico que só convence aos participantes do mesmo.

f) Entendimento das incertezas envolvidas nos fenômenos (identificação das incertezas). 
A partir da conscientização de que existem incertezas, a etapa seguinte é a determinação da natureza das incertezas envolvidas. Para isto uma espécie de ñorainstormò pode ser empregada pela equipe na tentativa de listar as fontes de incertezas, a natureza delas ou ainda as etapas do processo em que elas ocorrem. Para isto, o líder ou chefe da equipe pode dividir o grupo maior em pequenos grupos, que ficariam com a tarefa de avaliar as incertezas em etapas bem definidas do estudo como: análise dos dados, árvore de falhas, estudo das conseqüências etc. Com a definição das incertezas, ou pelo menos a sua identificação, o estudo passa a trilhar um caminho mais confiável.

g) Motivação dos especialistas

O líder ou organizador do estudo deve manter os componentes da equipe focados e motivados nas metas a serem alcançadas. Alguns pesquisadores são relutantes em participar de estudos comparativos, porque temem que suas opiniões não estejam cientificamente corretas e sejam criticamente discutidas. Cabe ao líder mostrar aos demais participantes da equipe que as discussões e divergências são bem vindas, pois elas permitem uma maior reflexão sobre os aspectos envolvidos no estudo. O líder deve demonstrar que a contribuição de todos é importante e que a produção do conhecimento se faz necessário, para isto deve manter o nível de motivação que desperte a criatividade dos participantes.

h) Estrutura e decomposição

Os especialistas devem saber exatamente o que cabe a da um deles estudar e avaliar. O líder deve explorar os especialistas para um melhor entendimento das relações causais e estatísticas entre as diferentes variáveis. Por exemplo, uma determinada distribuição de probabilidade de uma variável pode ser condicionada à distribuição de outra variável. Assim, se necessário, deve-se dividir um dado grupo em subgrupos que, necessariamente, deverão possuir especialistas mais focados neste novo objetivo.

i) Treinamento para avaliação de probabilidades

Em geral, os especialistas em determinadas áreas do conhecimento humano carecem de um conhecimento mais profundo dos mecanismos psicológicos que produzem tendências ou vieses errados no mecanismo de elaboração do conhecimento. Assim, é importante que haja uma explanação do funcionamento destes mecanismos tendenciosos pautados em heurísticas comuns. Nesta apresentação deve-se mostrar que, no processo de produção do conhecimento, o T̃omemòse baseia em fundamentos pré-concebidos de forma consciente ou 
inconsciente. Estes fundamentos podem de forma tendenciosa produzir um conhecimento aparentemente lógico, mas que em uma análise mais detalhada se mostra ser imperfeito.

j) Elicitação e verificação de probabilidades

O Termo em português r̃elicitaçãoòderiva do termo inglês ñelicitationò Em textos científicos da Teoria da decisão, é comum encontrar rêlicitarò ou r̃elicitaçãoò de preferências ou probabilidades ${ }^{20}$.

As previsões são classificadas em dois grupos principais:

i) As previsões nas quais se acredita (o que é subjetivo), que a estrutura de comportamento dos eventos no passado se repetirá no futuro. Nestas circunstâncias faz-se uso de técnicas de estatística e as previsões são chamadas de projeções. Assim mesmo, há incerteza, pois nas projeções obtêm-se ñalores centraisòe intervalos de previsão com um nível de confiança. A incerteza é modelada por uma distribuição normal. As previsões com incerteza podem ser utilizadas em simulações.

ii) As previsões para as quais não se pode apoiar em dados do passado, tanto por serem inexistentes como por não serem representativos da percepção que se tem em relação ao futuro.

A obtenção de estimativas de um painel de especialistas enfrenta problemas de duas ordens: divergências de percepções entre os especialistas e pressões psicológicas no comportamento do grupo ï uma boa percepção de um especialista tímido pode ficar prejudicada pela ação de um indivíduo mais extrovertido e com características de líder.

Existe um grande número de relatos de problemas desta ordem. A solução encontrada foi resumida no chamado processo Delphi que tem muitas variantes. Ele se baseia no anonimato para evitar a pressão de grupo e perda de riqueza de informação. O organizador do processo se esforça para manter ao máximo o anonimato dos participantes do grupo.

k) Evitar vieses ou tendências baseadas em heurísticas erradas

Grande número de psicólogos se debruçou sobre a questão dos vieses. Até o presente, somente foi possível constatar que eles existem e que o melhor que se pode fazer é tentar

\footnotetext{
${ }^{2}$ Mas para o Professor Carlos Bana e Costa da Universidade de Lisboa "Elicitar" e "elicitação" são simples adaptações de palavras inglesas: o verbo (to) elecit, «extrair, fazer sair; obter; desencadear, provocar; deduzir; descobrir; esclarecer»; e o substantivo elicitation, «obtenção gradual; dedução» (ver Dicionário Inglês-Português da Porto Editora). Estas formas inglesas provêm do latim elicitus, particípio passado de elicere, «tirar para fora», de ex, «fora» e -licere, forma de lacere, «atrair com engano, enredar» (Online Etymology Dictionary e Novo Dicionário Lello Latino-Português)Acontece, porém, que, em português, com a mesma etimologia latina, já temos eliciar, «fazer sair; expulsar, expelir» e «desviar com conjuro; esconjurar; exorcizar, afugentar» (Dicionário Houaiss), que tem o derivado nominal eliciação (cf. idem, verbete de laç-). Com o mesmo radical -lic-, existe também aliciar, «atrair a si, seduzir, envolver» (idem). Eliciação e eliciar são, portanto, formas mais corretas que "elicitação" e "elicitar", porque estão mais de acordo com a formação tradicional de latinismos em português.
} 
evitar as armadilhas que estes vieses colocam. Trabalhos para identificar as origens dos vieses estão em fase incipiente. Possivelmente o pior deles é a ancoragem. As pessoas podem ancorar em percepções (em geral numéricas) dos modos mais diversos e absurdos. Ancora-se numa referência e todo esforço mental reduz-se a pequenas variações em torno da âncora.

O estabelecimento inicial de âncoras pode ter alto valor estratégico em negociações. $O$ primeiro a estabelecer a âncora força os outros a somente negociarem em torno dos pontos que ele estabeleceu. Numa negociação, deve-se contestar e tentar evitar as âncoras postas pelos outros. Se alguém conseguir impor uma âncora da sua conveniência, a negociação tenderá a lhe ser bem mais favorável.

A partir do conhecimento já oferecido aos especialistas no autoconhecimento e na determinação de vieses ou heurísticas erradas, agora cabe aos mesmos, em um processo de auto-reflexão ou em grupo, estruturar o conhecimento. Eles devem procurar identificar se o processo de elaboração do mesmo ocorreu de forma clara e lógica.

\section{l) Supervisão dos processos}

Nesta etapa da elaboração do conhecimento especialista, cabe ao líder, ou aos líderes de grupo, fazer uma supervisão do processo e acompanhamento. Muitas vezes, torna-se útil provocar uma discussão mais ampla com toda a equipe, permitindo que todos tenham conhecimento de como o estudo está sendo feito e assim buscar eliminar possíveis arestas existentes entre subgrupos ou indivíduos.

m) Emprego de diferentes abordagens para agregar a opinião de especialistas

Como visto anteriormente, diversas abordagens podem ser usadas para agregar a opinião de diversos especialistas. Para que isto ocorra de forma satisfatória, torna-se necessário que os mesmos estejam com um espírito colaborador e sejam capazes de aceitar críticas ou opiniões diversas. Cabe ao líder ou organizador do grupo discutir e encontrar a melhor forma de agregar as diversas opiniões dos especialistas, lançando mão de uma das técnicas já apresentadas.

n) Agregação de opiniões de especialistas

Para sito pode-se utilizar os três clássicos caminhos para agregar a opinião de especialistas descritos por Patê-Cornell (1996) são:

ABORDAGEM ANALÍTICA ï quando cada especialista fornece a sua distribuição de probabilidades; quando alguém (o tomador de decisão) cria uma função distribuição combinada, por exemplo, distribuindo pesos nas avaliações dos especialistas. 
ABORDAGEM ITERATIVA (teoria Delphi) - quando diferentes avaliações provenientes de diversos especialistas são analisadas e, posteriormente, reenviadas aos especialistas, dando possibilidade para eles revisarem a sua opinião, com base no que os ; isto geralmente avança rápido se, juntamente com a opinião for informada, a forma como os resultados foram obtidos.

ABORDAGEM INTERATIVA - quando especialistas são questionados e debatem e explicam como avaliaram. Os especialistas têm a chance de mudar de opinião sobre o problema.

\subsection{Minimização das incertezas em processos estatísticos (banco de dados)}

Os processos estatísticos são os processos que derivam de tarefas relacionadas à aquisição, pesquisa, manipulação em banco de dados. Será visto agora como devem ser trabalhadas as incertezas relacionadas ao processo de aquisição de conhecimento com o uso de banco de dados.

a) Analise preliminar da variabilidade do modelo (identificação das incertezas)

Estudar e conhecer o fenômeno que se quer modelar, e adequá-lo ao fim prático do estudo, minimiza as incertezas envolvidas e possibilita que se otimize os recursos de material e pessoal no estudo de análise de risco e em contrapartida possibilita um estudo mais célere e prático se possível. Como citado anteriormente, os fenômenos naturais, apesar de aparentarem ser bem definidos (isto ocorre porque nestes casos são definidos por meio de fórmulas determinísticas que os tornam aparentemente exatos e bem preditivos) possuem uma variabilidade natural.

As incertezas são de avaliação difícil, uma vez que todo modelo é, por si mesmo, uma simplificação da realidade. De forma geral, os fenômenos naturais apresentam comportamento tão complexo que os modelos matemáticos detalhados podem não conseguir reproduzir, com exatidão, os processos naturais. De acordo com Morgan \& Henrion (1993), ñodo modelo é, definitivamente, falsoà já que mesmo quando o modelo é o resultado de boas aproximações de um dado sistema natural, ele nunca será completamente exato. Eles afirmam ainda que mesmo que se possa determinar que um modelo é melhor que outro - na precisão de suas previsões, não se pode afirmar que ele é o mais provável. Conclui que, desta forma, não se pode atribuir probabilidades a modelos.

b) Conhecimento do modelo ( identificação das incertezas)

Como o especialista nunca terá um modelo completo, uma análise crítica no sentido de obter um modelo próximo o possível da realidade, mas que otimize os recursos existentes deve ser uma meta ser alcançada. Outra consideração é que em muitos modelos existem 
aproximações numéricas na solução de equações definidas no modelo estrutural e estas aproximações irão gerar erros ou incertezas.

Mesmo que a complexidade dos fenômenos possa ser fielmente reproduzida por um modelo, ainda se coloca uma questão: Será que os parâmetros da população, tais como média e variância, obtidos a partir de amostras relativamente pequenas em uma única série histórica disponível representam, com fidelidade, os parâmetros da população? Ou eles vão conter uma grande dose de incerteza? Costuma-se admitir, em estudos, que séries de 30 anos de dados, por exemplo, permitem a obtenção de resultados com a precisão aceitável. Campos (1997) adverte que a validade desta assertiva depende da variabilidade do fenômeno em análise.

c) Determinação da compatibilidade do modelo

Uma questão importante na coleta de dados (seja via bibliográfica ou pesquisa de campo) diz respeito à compatibilidade entre modelo e as premissas estabelecidas na avaliação inicial do fenômeno. Um banco de dados pode ser extremamente útil, se for obtido de uma fonte séria, através de um processo científico. Mas ao mesmo tempo pode ser inútil se não é compatível com o modelo apresentado, seja por padrões metodológicos, seja por utilizar parâmetros diversos do ideal, ou ainda por representar situações distintas da apresentada no modelo.

d) Definição da metodologia usada na coleta de dados

A metodologia de coleta de dados, usada em uma ou mais fases do estudo, precisa ser bem definida, pois, além de homogeneizar a interpretação dos dados, facilita a compreensão e verificação de potenciais erros. Como mencionado anteriormente, a transparência deve ser buscada em todas as atividades do estudo de risco. A discussão sobre a melhor metodologia a ser usada deve ser incentivada já que se trata de uma parte essencial do estudo e que não pode ser tratada como de menor importância.

e) Definição da terminologia

A uniformização da nomenclatura e da terminologia é um passo importante para evitar erros relacionados aos bancos de dados já que, em geral, estes bancos possuem nomenclaturas diversas dependendo da instituição que foi responsável pela sua catalogação, bem como da diferença de épocas ou países. Os dados obtidos em campo também devem ser uniformizados, pois eventuais diferenças entre pesquisadores e métodos de coleta geram erros no trabalho. De uma forma geral, a uniformização da terminologia empregada possibilita uma melhor comunicação entre os membros do estudo independentemente de suas origens e formação profissional. 


\section{f) Coletar de dados}

Antes de efetuar a coleta de dados para a pesquisa, é necessário saber que técnica é mais adequada para a questão em foco. $O$ termo dados refere-se às informações que os pesquisadores coletam. Os dados consistem no conjunto de informações que os próprios pesquisadores produzem bem como aqueles que se encontram disponíveis no campo de pesquisa. No primeiro caso, estão transcrições de entrevistas e notas de campo que se referem a observações como exemplos típicos da produção de dados. No segundo caso, os dados foram criados por outros; são registros de diferentes naturezas, tais como: diários, fotografias, documentos oficiais, artigos de jornal. Os dados estabelecem a ligação com o mundo empírico e quando sistemática e cuidadosamente coletados fornecem esteio para a produção intelectual $^{33}$.

g) Filtragem de dados

Após a aquisição dos dados é interessante uma reunião entre os estudiosos desta fase, com o objetivo de discutir e eventualmente eliminar os dados considerados inadequados ou que, de alguma forma, não são representativos do fenômeno. Isto facilita o trabalho das fases seguintes e, desde já, permite uma análise crítica desta parte do estudo.

h) Estimação dos intervalos ( identificação das incertezas)

Muitos métodos usados para propagação e classificação ponderada de incertezas utilizam intervalos de variação das variáveis para determinação da incerteza final. A determinação dos intervalos de variação deve ser realizada pela equipe, analisando o modelo e as condições ambientais em que o mesmo está inserido; além disto, torna-se importante aferir os instrumentos de medidas e especificar qual a grau de confiabilidade de cada medida.

i) Uso de distribuições probabilísticas

Com a determinação dos intervalos de variação, outro passo importante a ser dado consiste na determinação das curvas probabilísticas que melhor se amoldam às características das variáveis apresentadas. Por exemplo, distribuição de característica populacional se amolda geralmente em curvas do tipo normal. Se possível, deve-se verificar se os dados obtidos são compatíveis com a curva escolhida, utilizando-se para isto algum tipo de teste estatístico.

j) Diversificação dos bancos de dados

33 Para chegar até o ponto de coleta de dados as definições mais importantes já devem estar pensadas e registradas. A partir do estudo a que se quer realizar, discute-se as diferentes fontes e os instrumentos de investigação a serem utilizados. (Bibliografia: VASCONCELOS, Eduardo Mourão. Complexidade e Pesquisa Interdisciplinar: Epistemologia e Metodologia Operativa. 2a. ed. Petrópolis: Editora Vozes, 2002.) 
Diversificar os bancos de dados significa que o grupo de pesquisa não deve se limitar a uma única fonte de informações; a diversificação possibilita não só a comparação entre dados similares, como também permitir a determinação de intervalos de incerteza entre as variáveis.

k) Analise da adequabilidade do banco de dados

Um estudo de análise de risco deve ser dinâmico e ao mesmo tempo necessita ser preciso. Assim, à medida que algumas etapas são realizadas deve-se sempre que possível buscar revisá-las e adequá-las às etapas anteriores, bem como às etapas seguintes. Um procedimento que ameniza possíveis incertezas em banco de dados, consiste em verificar de forma prática a adequabilidade do Banco de Dados à situação fática. Por exemplo, se alguns dados sobre freqüência de acidentes em plataformas de petróleo na Região do Mar do Norte foram extraídos de uma publicação Européia (com características próprias de vento, temperatura, correntes e umidade do ar) estes dados, podem eventualmente, ser úteis para um estudo de risco envolvendo uma plataforma no Golfo do México. Para isto, devem ser analisadas de forma criteriosa as condições do problema e a natureza dos dados. Outro exemplo, um dado sobre a freqüência de objeto caídos em uma plataforma pode ser útil se as diferenças climáticas entre as duas situações, já que esta freqüência, a princípio não está correlacionada a alterações climáticas.

I) Utilização se de um protocolo de avaliação crítica

O organizador do estudo deve agora pensar na criação de um protocolo de avaliação crítica, que permita aos participantes do processo de coleta de dados, classificar e conhecer melhor das informações obtidas. No capítulo referente à Banco de Dados é apresentada uma série de características importantes que devem possuir os Bancos de dados. Estas características podem ser usadas na criação de um protocolo de avaliação. Os requisitos para que um banco de dados possa ser usado em AR (Análise de Risco) podem variar consideravelmente, dependendo de uma série de fatores, como o objetivo da AR ou o estágio da análise. Em alguns estágios em que a análise de risco é muito específica, informações detalhadas são muito úteis, mas em outros estágios é mais importante dispor de informações gerais e abrangentes. É extremamente difícil conseguir dados que representem todas as situações possíveis e possam cobrir todas as hipóteses de forma simultânea. Entretanto, alguns requisitos básicos e comuns para o uso em todas as fases foram propostos por Davidson et al (1999) e devem ser usados ${ }^{34}$.

34 Na formulação do protocolo de avaliação crítica do banco de dados, pode-se utilizar os requisitos propostos por Davidson et al (1999), que são: acessibilidade, facilidade de uso, confiabilidade, relevância, cobertura e atualização regular.

ACESSIBILIDADE

FACILIDADE DE USO

CONFIABILIDADE (RASTREABILIDADE DAS INFORMAÇÕES) 


\subsection{Minimização das incertezas em processos racionais (matemáticos)}

Como visto anteriormente, os processos racionais ou matemáticos são os processos relacionados aos cálculos numéricos e às incertezas relacionadas a estes processos foram abordadas nos capítulos 7 e 8 . São explicitados, em seguida, como eles devem ser empregados na análise de risco.

a) Listagem de todos os parâmetros (identificação das incertezas)

A primeira tarefa a ser realizada, visando minimizar as incertezas, consiste em determinar todos os parâmetros existentes nas diversas equações que serão usadas no estudo. Para isto é necessário que o executor desta tarefa conheça com profundidade o estudo que está sendo realizado e assim elabore a lista mais completa possível dos parâmetros.

b) Identificação dos tipos e origens de incertezas (identificação das incertezas)

Identificar e diferenciar os tipos e fontes de incertezas é, por razões obvias, importante, uma vez que os mesmos necessitam ser tratados de diferentes formas. Já foi visto, no capítulo 3, que vários autores na literatura têm analisado diversos tipos de incertezas e estabelecido várias distinções, tais como subjetivas e objetivas, secundárias e primárias, tecnológicas e naturais. No início deste capítulo foi apresentada a definição de incerteza adotada nesta tese. Diversas classificações de tipos de incertezas podem ser encontradas. em Morgan \& Henrion (1993) ou ainda em Bernier (1987), que faz distinção entre as incertezas naturais, devidas à aleatoriedade dos processos naturais e as incertezas tecnológicas, as quais envolvem erros de amostragem e de adequabilidade do modelo adotado ou ainda em Beck (1987), que examinou detalhadamente as incertezas na estrutura do modelo, na estimativa dos parâmetros e a propagação dos erros nas estimativas. O importante é que, uma vez escolhida a classificação julgada mais adequada, esta deve servir como instrumento para determinar, classificar, medir, estudar a sua propagação e em seguida mitigar as mesmas.

c) Identificação das variáveis que possam incluir algum grau de incerteza

A modelagem de eventos físicos através de técnicas computacionais possui uma grande limitação em termos da contabilidade dos parâmetros utilizados. Os dados utilizados na realização da modelagem de qualquer evento físico são obtidos, via de regra, por medições. Estes dados apresentam intrinsecamente um erro, quer seja por falha humana (erro de leitura), quer seja por deficiência mecânica nos próprios instrumentos (erro do instrumento). Por outro lado, a representação numérica utilizada nos computadores digitais nem sempre permite que os números sejam armazenados com exatidão, U. Kulisch, (1999). Isto pode gerar erros de

\section{RELEVÂNCIA (COM RESPEITO A ANÁLISE OBJETIVA) COBERTURA}

ATUALIZAÇÃO REGULAR. 
arredondamento e/ou truncamento, tanto na modelagem quanto na execução dos cálculos numéricos.

Devido principalmente a estes fatores, modelar eventos físicos é uma tarefa que permite apenas a obtenção de resultados aproximados. Em alguns casos, ocorrem aproximações bastante pobres, o que torna necessária a execução de tarefas auxiliares que permitam analisar os erros associados ao problema. Este tipo de análise, além de exigir um considerável esforço computacional, não é uma tarefa simples de ser operacionalizada.

d) Especificação com o máximo de conservadorismo dos intervalos de variação das variáveis e valores médios

A maior parte dos problemas científicos envolve incerteza em parâmetros ou dados inexatos. Uma maneira simples de representar e executar operações em informações inexatas é utilizar a aritmética intervalar, também chamada de análise intervalar. Neste contexto, uma incerteza em um dado real pode ser representada por um intervalo de números reais, que presumivelmente, contém o valor desconhecido exato da variável em questão. Desta maneira, a incerteza é envolvida pelo tamanho do intervalo e não há necessidade de nenhuma distribuição de probabilidade para representá-la, simplificando assim o trabalho de operações e análises.

e) Especificação, se possível, da função distribuição de probabilidades para valores incluídos nos intervalos

O mundo real não é representado apenas por funções determinísticas. Muitas propriedades, como, por exemplo, a resistência mecânica de um material, a vida de uma lâmpada, a soma de dois dados honestos jogados ao acaso ou a temperatura máxima em Curitiba no mês de janeiro, variam de amostra para amostra. Um valor médio é obtido, porém é impossível prever exatamente qual o valor a ser encontrado na própria amostra a ser testada.

Funções que apresentam imprevisibilidade são denominadas de aleatórias. Como são imprevisíveis, não podem ser equacionadas através dos recursos usuais da matemática determinística. Ferramentas estatísticas são necessárias para tal ${ }^{35}$. .

f) Verificação da dependência ou correlação das variáveis

Modelos envolvendo duas ou mais variáveis são recorrentes na agricultura, biologia, matemática, física e em diversas outras áreas do conhecimento. Algumas vezes, o interesse do pesquisador é verificar se existe relação linear entre estas variáveis. A correlação estuda a re-

35 Por exemplo, ao se analisar estatisticamente o comportamento de uma máquina ensacadeira que, idealmente, deveria empacotar $1,00 \mathrm{~kg}$ do produto por saco, verifica-se, na prática, que isto não ocorre sempre. Por imperfeições no seu mecanismo, sacos com massas, por exemplo, entre 0,98 kg e 1,02 kg podem resultar. Embora seja muito difícil calcular teoricamente a função densidade de probabilidade do processo, é possível determiná-la aproximadamente através de um grande número de observações experimentais 
lação e o grau de associação entre duas ou mais variáveis. Como exemplos de correlação entre duas variáveis, podem ser citados: a relação entre peso e altura, demanda e preço de venda, aplicação de adubo e produtividade na lavoura, etc.

Os testes estatísticos utilizados para medir esta relação, em geral, têm como base o coeficiente de correlação de Pearson e o coeficiente de correlação de Spearman. Porém, devese verificar se os pressupostos são satisfeitos. Um pressuposto bastante comum nos métodos convencionais de estatística é a aleatoriedade da amostra, que nem sempre ocorre na prática. Existem métodos que prescindem de tais exigências, um exemplo é o teste de aleatoriedade, que revela se existe ou não algum padrão entre duas variáveis, ou seja, se as variáveis estão correlacionadas.

g) Execução de análise de sensibilidade

A análise de sensibilidade permite identificar a importância das variáveis no modelo, isto é, quais as variáveis que possuem maior impacto na resposta do modelo. A análise de sensibilidade é freqüentemente utilizada numa espécie de ñwhat ifò ou seja, muda-se o valor de uma variável enquanto as outras são mantidas constantes, em seu valor nominal, avaliando, assim, o impacto relativo de cada mudança na resposta do modelo. Neste sentido, a análise de sensibilidade pode ser usada como um método simples de avaliar a importância das variáveis, e conseqüentemente o efeito de suas incertezas. Entretanto, um sério problema está associado ao uso da análise de sensibilidade, que é a dificuldade de se trabalhar com variáveis que possuem diferentes unidades de medida; isto se torna ainda mais difícil quando as variáveis de saída possuem unidades diferentes; neste caso, é necessário efetuar algumas manipulações, como já visto anteriormente.

$\mathrm{Na}$ verdade, análise de sensibilidade é utilizada geralmente para saber que variáveis devem ser incluídas no estudo das incertezas, ou seja, se uma variável é ou não importante ou ainda se é necessário incluí-la em um estudo de análise de incertezas.

h) Uso de procedimentos analíticos ou numéricos para propagação das incertezas numéricas das variáveis de entrada

A partir do momento em que se conhece a incerteza das variáveis envolvidas no modelo e se consegue descobrir as origens das incertezas, a fase seguinte consiste em determinar como as incertezas das variáveis de entrada influenciam a incerteza na saída (propagação das incertezas). Como etapa final, deve-se estimar a contribuição relativa de cada uma das incertezas na incerteza global, que consiste na propagação de incertezas como já mostrado no capítulo 7 .

i) Avaliação e tratamento das incertezas envolvidas

Após a determinação das incertezas envolvidas e seus efeitos nos resultados finais (propagação das incertezas), pode-se estabelecer uma série de medidas que visem diminuir 
estas incertezas. Estas medidas podem ser, por exemplo, melhorar o processo de aquisição de dados das variáveis que mais contribuem com a incerteza, propor alterações ou modificações no modelo estrutural ou ainda avaliar pontualmente uma ou outra situação que mereça uma maior definição. No exemplo numérico do capítulo 10 será mostrado como pode ser minimizada a incerteza a partir do seu conhecimento.

j) Classificação ponderada das incertezas

Obviamente que a escolha do método adequado para o classificação ponderada irá depender do tipo de método de propagação que foi usado, por exemplo, o método analítico é muito útil quando existe uma expressão matemática definida com uma formulação adequada, neste caso deve-se optar por um método de classificação ponderada que valorize esta disponibilidade de fórmula e a facilidade de possuir variáveis bem definidas. Optou-se por apresentar de uma forma mais clara somente os métodos probabilísticos. Algumas sugestões de métodos são analisadas visando estabelecer um contraponto como, por exemplo, o método fuzzy ou nebuloso.

k) Identificação das maiores contribuidores para as incertezas numéricas

Analisando os resultados obtidos nos diversos métodos de classificação ponderada, pode-se determinar qual o maior contribuinte individual para a incerteza total. Com a determinação das maiores fontes das incertezas, passa-se em seguida por um processo que busque minimizar as incertezas envolvidas

I) Limitação do escopo da abordagem visando minimizar as incertezas

A Agência de Proteção Ambiental Americana (U.S. Environmental Protection Agency) enfatizou a importância de caracterizar os riscos e incertezas. Por exemplo, em 1992 foi editado o ñEPA RISK ASSESSMENT COURIAL (RAC) GUINDANCEò e em 1995 o ñEPA POLICY FOR RISK CHARACTERIZATIONò Nestes estudos a principal diretriz estabelecida pela EPA é que ño propósito do escopo deve ser bem claro na seção referente à formulação do problema.òPor escopo entende-se a correta determinação do objeto de estudo, este não pode ser amplo ou vago.

Um processo de reavaliação dos dados sempre é importante. Assim, à medida que o estudo for avançando, é desejável que casos específicos de condições de operação, ou ainda situações que envolvam maior freqüência ou maior risc, sejam mais bem depuradas e analisadas. Isto tem a finalidade de, pelo menos, minimizar as incertezas nestas situações mais frequentes e também nas situações que possuam algum efeito catastrófico, com consequências mais danosas. 
m) Utilização de Monte Carlo

Uma das recomendações mais importantes encontradas em praticamente todos os estudos de incertezas em análise de risco é o emprego de Monte Carlo. Esta recomendação também está presente em praticamente todas as Normas Internacionais e Estudos relacionados. Monte Carlo (MC) é uma ferramenta muito útil em análise de risco. Quando se diz que se deve utilizar sempre que possível MC, está se dizendo, que mesmo que existam outros métodos apropriados ou mesmo que a equipe tenha as suas preferências pessoais, a utilização de MC propicia, no mínimo, a possibilidade de comparação de resultado com outros métodos como será mostrado no capítulo seguinte. Esta é uma recomendação muito comum em diversos estudos, por exemplo, Yoe ( 2001) e Hoffman (1997).

\section{n) Explicitação das incertezas existentes no estudo}

As incertezas devem ser claramente definidas, de modo a proporcionar maior objetividade ao estudo, possibilitar a sua revisão pelo próprio analista, facilitar a sua compreensão pelos leitores, tornar o trabalho reproduzível e auditável.

\section{7-Aplicação da metodologia proposta}

Foi apresentada neste capítulo uma proposta metodológica para tratamento de incertezas em uma Análise de Risco. Esta metodologia será aplicada parcialmente a um exemplo no próximo capítulo. Não será possível aplicar os aspectos da metodologia referentes aos processos estatísticos e processos qualitativos, pois isto exigiria um exemplo completo, com a composição de uma equipe multidisciplinar que estivesse realizando um estudo de risco real em um sistema complexo.

\section{6-Fluxograma resumido}

A seguir é apresentado um fluxograma resumido do processo 


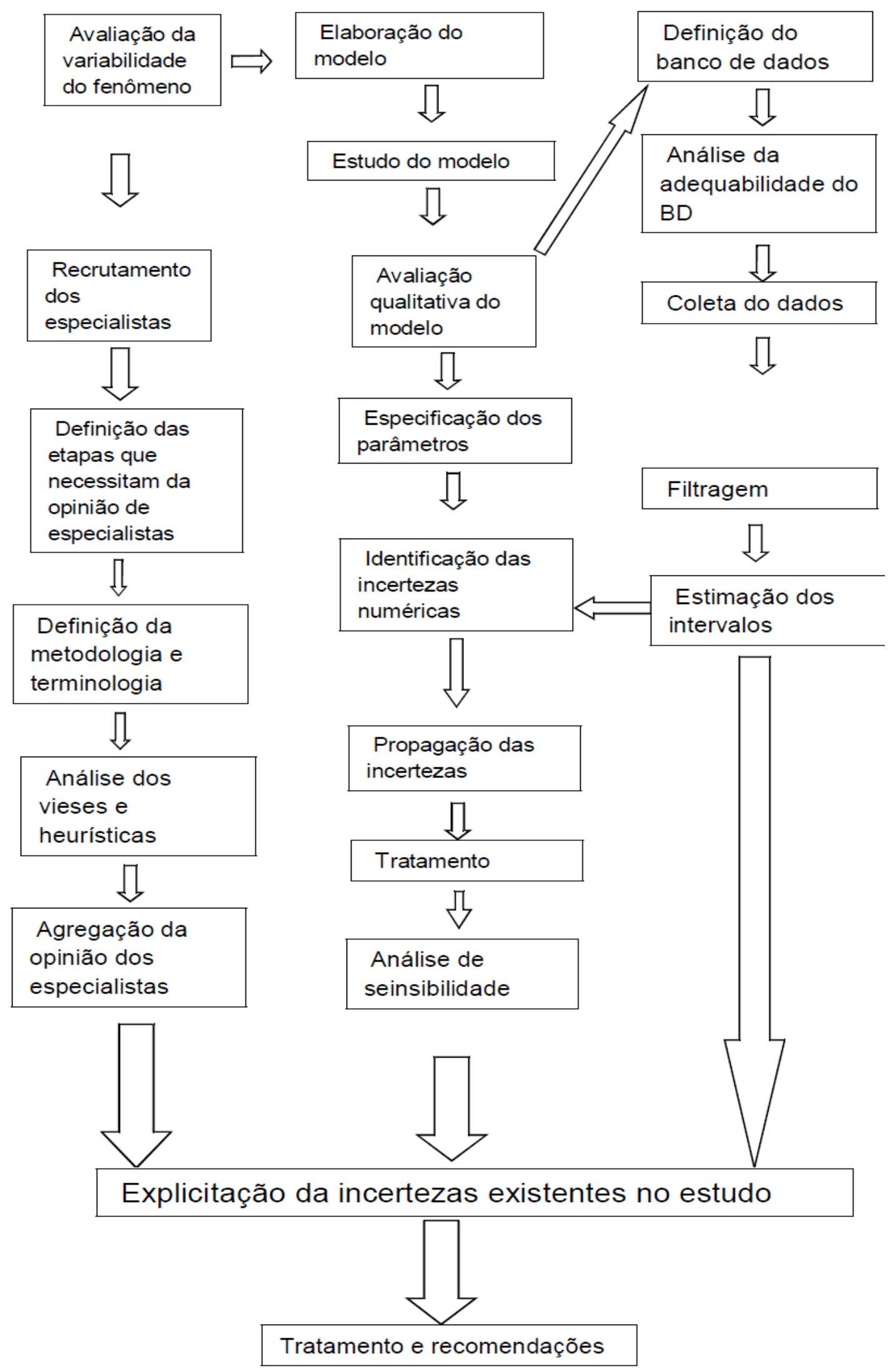




\section{CAPÍTULO 10}

\section{EXEMPLO DE APLICAÇÃO}

\subsection{Considerações iniciais}

Tudo o que foi apresentado nos capítulos anteriores serve de base para uma análise mais crítica dos estudos de risco e oferece ferramentas que permitem uma determinação mais precisa das incertezas nas diversas fases do estudo. Apresenta-se neste capítulo um exemplo prático que permite observar com mais clareza tudo o que foi abordado, além de oferecer as bases para uma metodologia que avalie de uma forma mais crítica o estudo.

A apresentação de um exemplo prático, adaptado do projeto ASSURANCE, permite visualizar como os diferentes métodos trabalham na determinação da propagação da incerteza. O exemplo prático considerado está ilustrado na Figura 10.1, e representa um processo simplificado de amônia, consistindo em um tanque pressurizado e $3 \mathrm{~m}$ de linha de $50 \mathrm{~mm}$ de diâmetro. Para a exemplificação será admitido um vazamento de amônia pressurizada . A avaliação pretende chegar a 3 pontos:

* Concentração de amônia em uma determinada posição geográfica $(x, y)$;

* Cálculo do risco Individual (conforme definido em CCPS 2000) em uma determinada localização geográfica $(x, y)$;

* Cálculo do Risco Social (conforme definido em CCPS 2000) em uma determinada localização geográfica $(\mathrm{x}, \mathrm{y})$. 


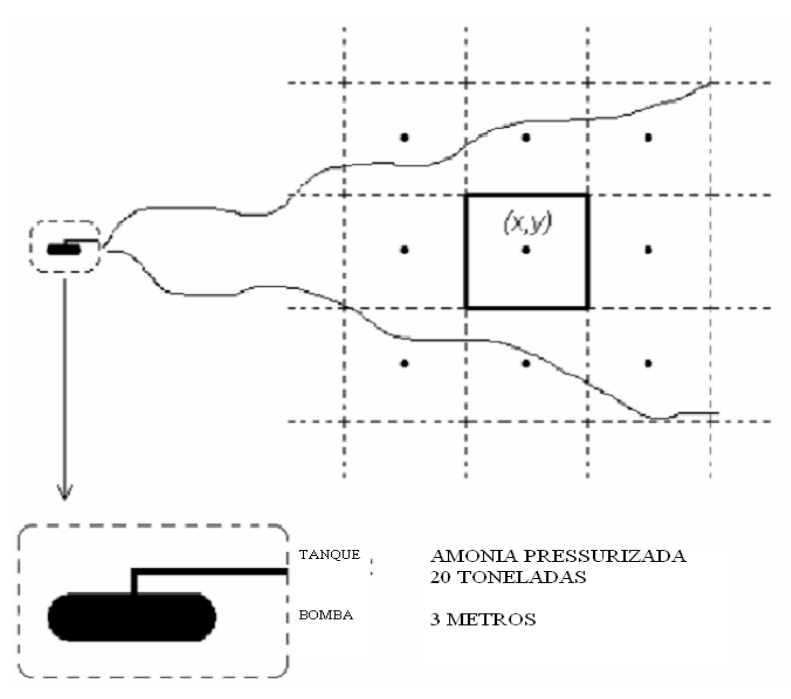

Figura 10.1 Representação gráfica do exemplo.

Os diferentes métodos de propagação de incerteza descritos anteriormente podem ser usados para cada um dos objetivos. Para efeito de comparação, a instalação será analisada usando abordagem Holandesa (Dutch approach) descrita pelo Comitê de Prevenção de Desastre no Report CPR 18 E (1999).

Três diferentes modelos físicos são usados: um Modelo de Descarga, para estimar a Vazão; um Modelo de Dispersão para estimar a concentração de Amônia em um ponto geográfico específico; e a Função PROBIT, vide apêndice A, para a representação da resposta da dose da substância tóxica no organismo humano. Os modelos usados no exemplo estão colocados na forma analítica, que é pré-requisito para o emprego de muitos métodos de propagação de incertezas.

Deve-se observar que, quando se usam modelos físicos mais elaborados, utiliza-se, em contrapartida, modelos computacionais complexos. Nestes casos Métodos de Resposta Superficial são viáveis para a produção de expressões analíticas, baseadas em poucas variáveis para representar modelos computacionais.

\subsection{Cenários e incidentes}

Em qualquer Análise de Risco é importante identificar quais os possíveis cenários. Um bom começo, é utilizar a metodologia Holandesa como linha mestra, que utiliza uma abordagem determinística, com fórmulas claras para resolver o problema, COMMITEE FOR THE PREVENTION OF DISASTERS (1999). Para o modelo de perda de líquido contaminante, denominado usualmente r̂Perda de Contaminanteò usa-se a sigla em inglês LOC. Apresentase abaixo os parâmetros de LOC para os equipamentos:

T1: perda instantânea de todo o conteúdo no tanque; 
T2: vazamento contínuo de todo o inventário em 10 minutos, com uma taxa de vazamento constante;

T3: vazamento contínuo através de um furo de diâmetro efetivo de $10 \mathrm{~mm}$;

P1: ruptura total de uma bomba;

P2: vazamento através de um furo de diâmetro efetivo, variando de $10 \%$ do diâmetro nominal da bomba até o máximo de $50 \mathrm{~mm}$.

Alguns dos parâmetros dos cenários acima descritos, como o tempo requerido para esvaziar um tanque em um vazamento, LOC, do tipo T2, podem ser tratados como variáveis que possuem alguma incerteza. Os diversos métodos de propagação de incerteza podem ser usados para a determinação da Incerteza Geral. Deve-se atentar que no Brasil ainda não há uma metodologia institucionalizada para o cálculo de incertezas em riscos industriais que possa ser usada como padrão. Existem métodos para o cálculo ou tratamento de incertezas numéricas em estudos ambientais que envolvam poluição em rios, mas nestes casos só são tratados os chamados processos racionais, sendo deixado de lado os processos relacionados a banco de dados e os de natureza subjetiva. Os estudos de incertezas em análise de risco estão ainda em uma fase embrionária

\subsection{Concentração de contaminante em um ponto determinado}

Pode-se calcular a concentração média de amônia, resultante de uma descarga, em um ponto $(\mathrm{x}, \mathrm{y})$, onde $\mathrm{x}$ é a distância no sentido do vento a partir do ponto de descarga e y é a distância de um ponto geográfico ao centro de nuvem de gás.

De acordo com a abordagem Holandesa, cada LOC tem que ser avaliado sob 6 perspectivas diferentes de condições meteorológicas, como apresentado na tabela 10.1. Isto obviamente é para atender as variações estocásticas das condições atmosféricas. As condições meteorológicas apresentadas, a seguir, são na verdade um conjunto de características de pressão, umidade e temperatura que estão agrupadas em Classes ou Condições Meteorológicas para, assim, facilitar o estudo.

Tabela 10.1 Condições meteorológicas contempladas (retirado de óCommitee for Prevention of Disastersô, 1999);

\begin{tabular}{|c|c|}
\hline Condições meteorológicas & Velocidade do Vento \\
\hline B & $(3-5 \mathrm{~m} / \mathrm{s})$ \\
\hline D Baixa & $(1-2 \mathrm{~m} / \mathrm{s})$ \\
\hline D média & $(3-5 \mathrm{~m} / \mathrm{s})$ \\
\hline D Alta & $(8-9 \mathrm{~m} / \mathrm{s})$ \\
\hline E & $(3-5 \mathrm{~m} / \mathrm{s})$ \\
\hline F & $(1-2 \mathrm{~m} / \mathrm{s})$ \\
\hline
\end{tabular}




\section{A) CÁLCULO DA TAXA DE DESCARGA DO CONTAMINANTE}

Para o cálculo da taxa de descarga do contaminante emprega-se:

$$
Q=C_{d} A \sqrt{\frac{2\left(P_{0}-P_{a}\right)}{v_{f}}}
$$

onde:

$Q$ é a taxa da massa de descarga $[\mathrm{kg} / \mathrm{s}]$;

Cd é o coeficiente adimensional de descarga;

A é a área do furo $\left[\mathrm{m}^{2}\right]$;

Pó é a pressão no tanque no nível do orifício [N/ $\left./ \mathrm{m}^{2}\right]$;

3 é o volume específico do líquido $\left[\mathrm{m}^{3} / \mathrm{kg}\right]$.

\section{B) DISPERSÃO DA NUVEM DE VAPOR}

Para determinação da dispersão do vapor da substância contaminante é empregado o modelo Gaussian Plume Model, descrito em Fisher et all 1997. Este modelo é previsto para o contínuo vazamento de material, e a resposta é dependente da taxa de descarga, das condições atmosféricas, da altura do vazamento do solo, e da distância do vazamento (CCPS 2000, Center for Chemical Process Safety), conforme expresso por:

$$
C(x, y, z)=\frac{Q}{2 \pi \sigma_{y}(x) \sigma_{z}(x) U} e^{-\frac{y^{2}}{2 \sigma_{y}^{2}}}\left[e^{-\frac{\left(z-H_{e f}\right)^{2}}{2 \sigma_{z}^{2}}}+e^{\frac{\left(z+H_{e f f}\right)^{2}}{2 \sigma_{z}^{2}}}\right]
$$

onde:

$C(x, y, z)$ é concentração média na posição $x, y, z$;

$Q$ é a taxa de vazamento;

$\sigma_{\mathrm{v}}, \sigma_{\mathrm{z}}$ são coeficientes de dispersão nas posições geográficas;

$U$ é a velocidade do vento em $\mathrm{m} / \mathrm{s}$;

Heff é a altura do nível do solo onde ocorre o vazamento.

Esta equação pode ser simplificada quando se deseja obter a concentração no nível do solo $z=0$ e no centro da nuvem $y=0$. Por outro lado, se a descarga ocorre no nível do solo Heff $=0$, pode ser simplificado para:

$$
C(x, y, z)=\frac{Q}{\pi \sigma_{y}(x) \sigma_{z}(x) U}
$$


Os coeficientes de dispersão podem ser extraídos de CCPS, Center for Chemical

Process Safety, e se referem às condições rurais conforme tabela 10.3

Tabela 10.3 Coeficientes de dispersão extraídos de CCPS (2000)

\begin{tabular}{|c|c|c|}
\hline Pasquill-Gifford stability class & $\sigma_{y}[\mathrm{~m}]$ & $\sigma_{z}[\mathrm{~m}]$ \\
\hline $\mathrm{B}$ & $0.16 x(1+0.0001 x)^{-1 / 2}$ & $0.12 x$ \\
\hline $\mathrm{D}$ & $0.08 x(1+0.0001 x)^{-1 / 2}$ & $0.06 x(1+0.0015 x)^{-1 / 2}$ \\
\hline $\mathrm{E}$ & $0.06 x(1+0.0001 x)^{-1 / 2}$ & $0.03 x(1+0.0003 x)^{-1}$ \\
\hline $\mathrm{F}$ & $0.04 x(1+0.0001 x)^{-1 / 2}$ & $0.016 x(1+0.0003 x)^{-1}$ \\
\hline
\end{tabular}

As classes de estabilidade Pasquill-Gifford são classes meteorológicas definidas em função das condições ambientais.

\subsection{Equações probit}

A função PROBIT, muito útil no cálculo de conseqüências, pode ser extraída de CCPS (2000):

$$
Y=k_{1}+k_{2} \ln \left(C^{n} t_{e}\right)
$$

onde $Y$ é a função PROBIT;

$k_{1}, k_{2}$ são constantes dependentes da substância que escapa;

$C$ é a concentração média da substância $\left[\mathrm{mg} / \mathrm{m}^{3}\right.$ ou $\left.\mathrm{ppm}\right]$;

n é constante dependendo da substância usada;

te é o tempo de exposição.

Para a substância usada, no caso amônia, pode-se retirar os valores das constantes de duas publicações diferentes, conforme a Tabela 10.4 .

Tabela 10.4 Valores da constante na fórmula PROBIT

\begin{tabular}{|l|l|l|l|}
\hline Referência & K1 & K2 & $n$ \\
\hline $\begin{array}{l}\text { CCPS-Center for Chemical Process } \\
\text { Safety }\end{array}$ & $-9,82$ & 0,71 & 2 \\
\hline $\begin{array}{l}\text { Committee for Prevention of } \\
\text { Disasters }\end{array}$ & $-15,6$ & 1 & 2 \\
\hline
\end{tabular}

Para conversão do valor PROBIT em percentual da população morta, emprega-se a expressão extraída de CCPS 2000.

$$
P=50\left[1+\frac{Y-5}{|Y-5|} \operatorname{erf}\left(\frac{|Y-5|}{\sqrt{2}}\right)\right]
$$

Para melhor definição da fórmula da equação 10.5 
A Tabela 10.5 mostra os diversos valores usados nas equações e as respectivas distribuições para cada um dos diferentes métodos usados. Na primeira coluna aparecem os parâmetros que possuem alguma incerteza, na segunda coluna estão os valores para a abordagem holandesa, que é uma abordagem determinista; os seus valores foram obtidos do projeto ASSURANCE já detalhado anteriormente. Na terceira coluna tem-se a análise intervalar, na quarta a analise de Monte Carlo e na última coluna tem-se a análise por curvas probabilísticas. Os cenários possíveis são P1, P2, T1, T2 e T3 e as diversas condições meteorológicas $\mathrm{B}, \mathrm{D}, \mathrm{E}$ e F; Cd é o coeficiente de descarga, A (P1-T3) é a área do orifício para cada um dos cenários, $U(B-F)$ é a velocidade do vento para cada uma das condições meteorológicas, $T(P 1-T 3)$ é o tempo de exposição para cada um dos cenários, f(P1-T3) é a freqüência para cada um dos cenários, $N$ é o número de pessoas numa grade hipotética $(x, y)$, fcc é fator de correção para as pessoas dentro desta grade. Ainda com relação à tabela 10.5 adotou-se como abreviação ñTr ròara distribuição triangular e ñunifòpara distribuição uniforme.

Tabela 10.5 Especificação dos parâmetros incertos

\begin{tabular}{|c|c|c|c|c|}
\hline Par. & $\begin{array}{l}\text { Abordagem } \\
\text { Holandesa }\end{array}$ & $\begin{array}{l}\text { Analise } \\
\text { intervalar }\end{array}$ & MonteCarlo & $\begin{array}{c}\text { Curvas } \\
\text { probabilísticas }\end{array}$ \\
\hline $\mathrm{Cd}$ & 1 & {$[0,7 ; 0,9]$} & Unif $(0,7 ; 0,9)$ & Unif $(0,7 ; 0,9)$ \\
\hline $\mathrm{A}(\mathrm{P} 1)$ & 0,004 & {$[0,0025 ; 0,0056]$} & $\begin{array}{c}\text { Tri }(0,0025 ; 0,004 ; 0,005 \\
5)\end{array}$ & $\begin{array}{c}\text { Tri }(0,025 ; \\
{[0,0035 ; 0,0045] ; 0,00} \\
56) \\
\end{array}$ \\
\hline $\mathrm{A}(\mathrm{P} 2)$ & $2 \times 10-5$ & $\begin{array}{l}{\left[1,25 \times 10^{5}\right.} \\
\left.2,83 \times 10^{-5}\right]\end{array}$ & Tri(0,018;0,019;0,02) & $\begin{array}{c}\text { Tri }(1,25 ; \\
\left.[1,8 ; 2,2] ; 2,83 \times 10^{-5}\right) \\
\end{array}$ \\
\hline $\mathrm{A}(\mathrm{T} 1)$ & NA & {$[0,018 ; 0,02]$} & $\begin{array}{c}\text { Tri }(0,0012 ; 0,00185 ; 0,0 \\
025)\end{array}$ & $\begin{array}{c}\text { Tri }(0,018 ; \\
{[0,0185,0,0195] ; 0,02} \\
)\end{array}$ \\
\hline $\mathrm{A}(\mathrm{T} 2)$ & NA & {$[0,0012 ; 0,0025]$} & $\begin{array}{c}\operatorname{Tri}(0,00003 ; 0,00009 ; 0 \\
00015)\end{array}$ & $\begin{array}{c}\text { Tri }(0,0012 ; \\
{[0,0016 ; 0.0021] ; 0,02} \\
5)\end{array}$ \\
\hline $\mathrm{A}(\mathrm{T} 3)$ & 0,00009 & $\begin{array}{c}2,8 \times 10- \\
\left.5 ; 1,5 \times 10^{-4}\right]\end{array}$ & $\operatorname{Normal}(4 ; 0,4)$ & $\begin{array}{c}\operatorname{Tri}\left(2,8 \times 10^{-5} ;\right. \\
\left.[7 ; 11] \times 10-5 ; 1,5 \times 10^{-4}\right)\end{array}$ \\
\hline $\mathrm{U}(\mathrm{B})$ & 3 & {$[3,5]$} & $\operatorname{Normal}(5 ; 1,5)$ & $\begin{array}{c}\text { Normal }([3,9 ; 4,1], \\
[0,3,0,4])\end{array}$ \\
\hline $\mathrm{U}(\mathrm{D})$ & 1,$5 ; 5,9$ & {$[1 ; 9]$} & Normal $(4 ; 0,4))$ & $\begin{array}{c}\text { Normall([4,5;5,5], } \\
[1,0 ; 1.3])\end{array}$ \\
\hline $\mathrm{U}(\mathrm{E})$ & 5 & {$[3 ; 5]$} & Unif(3;5) & Unif(3;5) \\
\hline$U(F)$ & 15 & {$[1 ; 2]$} & Unif $(1 ; 2)$ & Unif(1;2) \\
\hline $\mathrm{T}(\mathrm{P} 1)$ & 5,5 & {$[3 ; 8]$} & Unif(3;8) & Unif(3;8) \\
\hline
\end{tabular}


TABELA 10.5 CONTINUAÇÃO

\begin{tabular}{|c|c|c|c|c|}
\hline $\mathrm{T}(\mathrm{P} 2)$ & 30 & [20;40] & Unif(20;40) & Unif(20;40) \\
\hline $\mathrm{T}(\mathrm{T} 1)$ & 2 & {$[1 ; 2]$} & Unif(1;2) & Unif(1;2) \\
\hline $\mathrm{T}(\mathrm{T} 2)$ & 10 & {$[5 ; 15]$} & Unif(5;15) & Unif(5;15) \\
\hline $\mathrm{T}$ (T3) & 30 & [20;40] & Unif(20;40) & Unif(20;40) \\
\hline fP1 & $3 \times 10-6$ & {$\left[8 \times 10^{-7} ; 8 \times 10^{-6}\right]$} & Unif $\left(6.5 \times 10^{-6} ; 6.5 \times 10^{-5}\right)$ & $\begin{array}{c}\text { Unif }\left([5,8] \times 10^{-7} ;\right. \\
\left.[5,8] \times 10^{-6}\right)\end{array}$ \\
\hline fP2 & $1.5 \times 10-5$ & $\begin{array}{c}{\left[6.5 \times 10^{-6}, 6.5 \times 10^{-}\right.} \\
7] \\
\end{array}$ & Unif(5;15) & $\begin{array}{c}\text { Unif }\left([3,5 ; 6,5] \times 10^{-6} ;\right. \\
\left.[3,5 ; 6,5] \times 10^{-5}\right)\end{array}$ \\
\hline $\mathrm{fT1}$ & $5 \times 10-7$ & {$\left[1 \times 10^{-7} ; 1 \times 10^{-6}\right]$} & Unif(20;40) & $\begin{array}{l}\text { Unif }\left([1,3] \times 10^{-7} ;\right. \\
\left.[3,5,6,5] \times 10^{-6}\right)\end{array}$ \\
\hline fT2 & $5 \times 10-7$ & {$\left[1 \times 10^{-7} ; 5 \times 10^{-6}\right]$} & Unif $\left(8 \times 10^{-7} ; 1 \times 10^{-6}\right.$ & 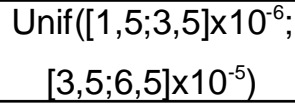 \\
\hline fT3 & $1 \times 10-5$ & {$\left[5 \times 10^{-6} ; 5 \times 10^{-5}\right]$} & Unif $\left(6,5 \times 10^{-6} ; 6,5 \times 10^{-5}\right)$ & $\begin{array}{c}\text { Unif }\left([8,9] \times 10^{-7} ;\right. \\
\quad[1,3 \times] 10^{-6} \\
\end{array}$ \\
\hline $\begin{array}{c}\text { Númer } \\
\text { o }\end{array}$ & 100 & {$[80 ; 120]$} & $\begin{array}{l}\text { Normal } \\
(100 ; 10)\end{array}$ & $\begin{array}{c}\text { Normal } \\
([95 ; 105],[3,10])\end{array}$ \\
\hline FCC & 0,8 & {$[0,6 ; 0,9]$} & Normal $(0,8 ; 0,05)$ & $\begin{array}{c}\text { Normal }([0,7 ; 0,8] \text {, } \\
[0,03,0,05])\end{array}$ \\
\hline
\end{tabular}

Deve-se ainda estimar a probabilidade de ocorrência de cada uma das condições meteorológicas e direção do vento. A Tabela 10.6 apresenta os valores adotados para as condições meteorológicas enquanto a Tabela 10.7 as de direção de vento.

Tabela 10.6 Probabilidades Adotadas para as Condições Meteorológicas

\begin{tabular}{|c|c|}
\hline Condições Meteorológicas & Probabilidade \\
\hline B & 0,15 \\
\hline D & 0,65 \\
\hline E & 0,15 \\
\hline F & 0,05 \\
\hline
\end{tabular}


Tabela 10.7 Probabilidades Adotadas para cada uma das Condições de Vento

\begin{tabular}{|c|c|}
\hline Direção do Vento & Probabilidade \\
\hline N & 0,15 \\
\hline NE & 0,15 \\
\hline E & 0,1 \\
\hline SE & 0,1 \\
\hline S & 0,15 \\
\hline SW & 0,1 \\
\hline W & 0,15 \\
\hline NW & 0,1 \\
\hline
\end{tabular}

Apresenta-se, a seguir, a aplicação das diferentes metodologias vistas no Capítulo 8 para a determinação da propagação da incerteza. Inicia-se pelo cálculo da concentração usando a abordagem Holandesa, ñDutch Approachò abordagem determinista, usando a velocidade média do vento. Na tabela 10.8 têm-se os valores da concentração da substância vazada, em função da velocidade média do vento, para cada condição meteorológica no cenário T2.

Tabela 10.8 Concentração para abordagem Holandesa

\begin{tabular}{|c|c|c|}
\hline Classes de LOC & $\begin{array}{l}\text { Velocidade do } \\
\text { Vento }\end{array}$ & Concentração $\left.\mathbf{( m g} / \mathbf{m}^{3}\right)$ \\
\hline T2B & 4 & 1.556 \\
\hline T2D & 1,5 & 19.990 \\
\hline T2D & 4 & 7.496 \\
\hline T2D & 8,5 & 3.538 \\
\hline T2E & 4 & 18.095 \\
\hline T2F & 1,5 & 185.394 \\
\hline
\end{tabular}

A taxa de massa descarregada $Q$ é gerada a partir da definição do LOC; por exemplo, para um vazamento contínuo de $20.000 \mathrm{~g} \mathrm{em} 600 \mathrm{~s}$, resulta em $Q=33,3 \mathrm{~kg} / \mathrm{s}$. 
Abordagem por matemática intervalar

Como já explicado no capítulo 7 , a abordagem por matemática intervalar necessita do conhecimento do intervalo das variáveis usadas nos modelos, conhecidas como variáveis incertas, conforme Tabela 10.9

Tabela 10.9 Os intervalos adotados para as variáveis incertas

\begin{tabular}{|c|c|}
\hline VARIÁVEL INCERTA & INTERVALO USADO NA ANÁLISE \\
\hline Velocidade do vento , U classe B & {$[3 ; 5][\mathrm{m} / \mathrm{s}]$} \\
\hline Velocidade do vento , U classe D & {$[1 ; 9][\mathrm{m} / \mathrm{s}]$} \\
\hline Velocidade do vento , U classe $\mathrm{E}$ & {$[3 ; 5][\mathrm{m} / \mathrm{s}]$} \\
\hline Velocidade do vento , U classe F & {$[1 ; 2][\mathrm{m} / \mathrm{s}]$} \\
\hline Área do furo , A & {$[0,0012 ; 0,0025]\left[\mathrm{m}^{2}\right]$} \\
\hline Coeficiente de descarga, Cd & {$[0,7 ; 0,9]$} \\
\hline
\end{tabular}

Os resultados de concentração média da substância obtidos com o emprego da abordagem intervalar estão apresentados na Tabela 10.10 .

Tabela 10.10 Concentração resultante na abordagem intervalar

\begin{tabular}{|c|c|}
\hline LOC Classes & Concentração $\left(\mathbf{m g} / \mathbf{m}^{3}\right)$ \\
\hline T2B & {$[698,3116]$} \\
\hline T2D & {$[1878,45273]$} \\
\hline T2E & {$[8091,36121]$} \\
\hline T2F & {$[57326,306632]$} \\
\hline
\end{tabular}

Abordagem por aritmética nebulosa (fuzzy)

Inicialmente devem ser constituídos os conjuntos fuzzy que representam as diversas variáveis envolvidas. Por exemplo, para o coeficiente de descarga e para a área do orifício 
pode-se representar por funções triangulares, na forma da figura 10.2, usando os intervalos já definidos. A Tabela 10.11 mostra os valores das variáveis fuzzy empregadas.

Tabela 10.11 Variáveis Fuzzy

\begin{tabular}{|c|c|}
\hline Variável & NÚMERO FUZZY \\
\hline $\begin{array}{c}\text { Velocidade do vento, } \\
\text { condição B }\end{array}$ & {$[3 ; 4 ; 5][\mathrm{m} / \mathrm{s}]$} \\
\hline $\begin{array}{c}\text { Velocidade do vento, } \\
\text { condição D }\end{array}$ & {$[1 ; 5 ; 9][\mathrm{m} / \mathrm{s}]$} \\
\hline $\begin{array}{c}\text { Velocidade do vento, } \\
\text { condição E }\end{array}$ & {$[3 ; 4 ; 5][\mathrm{m} / \mathrm{s}]$} \\
\hline $\begin{array}{c}\text { Velocidade do vento, } \\
\text { condição F }\end{array}$ & {$[1 ; 1,5 ; 2][\mathrm{m} / \mathrm{s}]$} \\
\hline Área do buraco & {$[0,0012 ; 0,00185 ; 0,0025]\left[\mathrm{m}^{2}\right]$} \\
\hline Coeficiente de descarga & {$[0,7 ; 0,8 ; 0.9][-]$} \\
\hline
\end{tabular}

A Figura 10.2 mostra uma exemplificação simples para duas variáveis, o coeficiente de descarga, à esquerda, e a área do buraco, à direita.
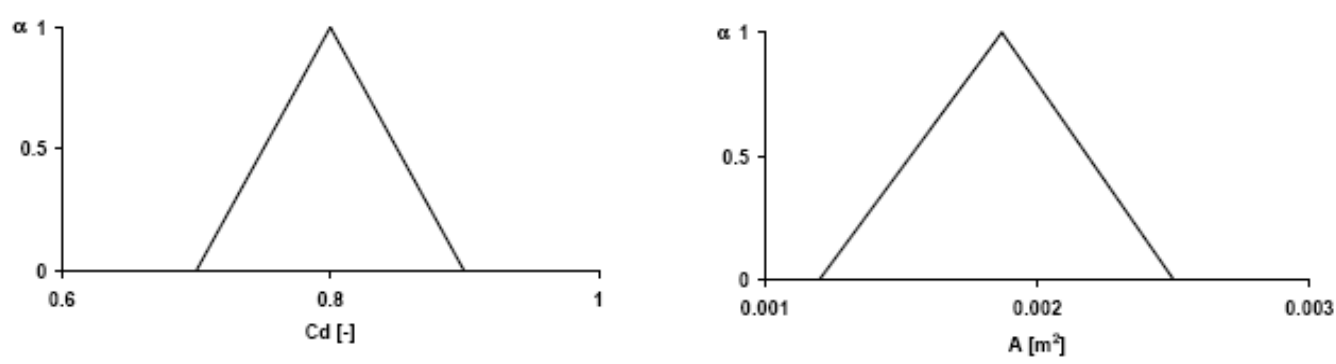

Figura 10.2 Representação das variáveis: coeficiente de descarga (Cd) e área (m2)

Os resultados obtidos, podem ser vistos utilizando uma ferramenta computacional que trabalhe com lógica fuzzy. 


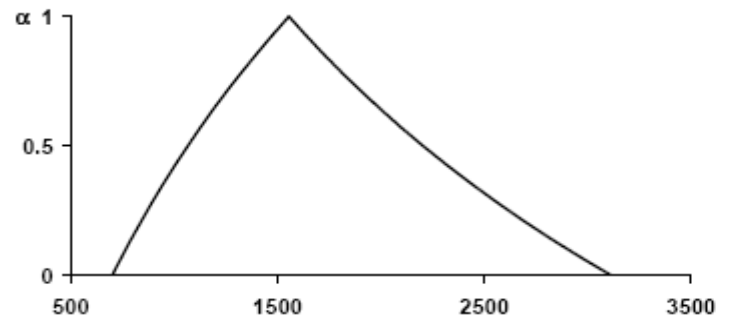

Concentração-condição meteorológica B

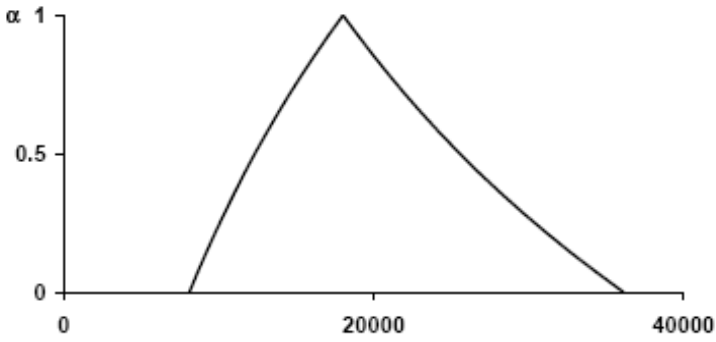

Concentração, condição meteorológica $E$

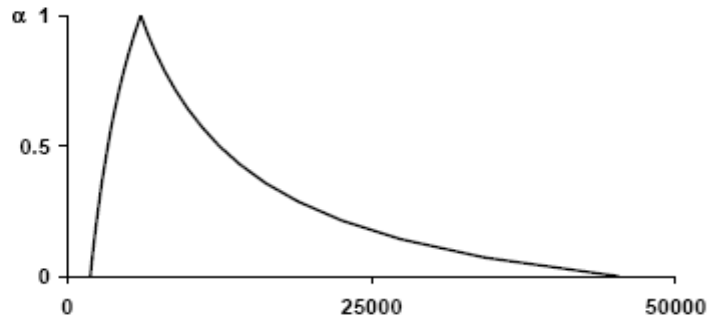

Concentração-condição meteorológica D

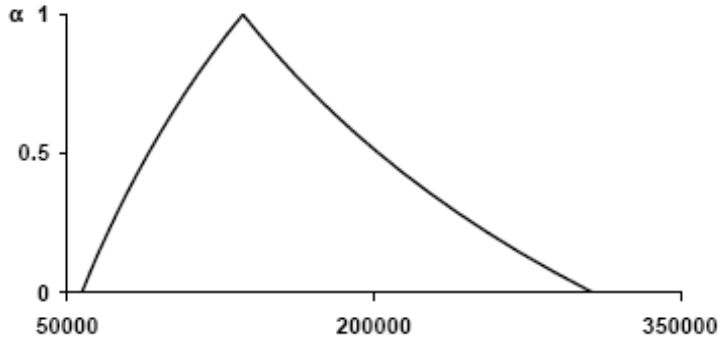

Concentração, condição meteorológica. F

Figura 10.3 Concentração média para diferentes condições meteorológicas. Concentração $\left(\mathrm{mg} / \mathrm{m}^{3}\right)$

\section{Abordagem por montecarlo}

Para se utilizar a metodologia de Monte Carlo, as variáveis de Incerteza precisam ser definidas como distribuição de probabilidades. A Tabela 10.12 contém um exemplo ilustrativo da representação das variáveis de incerteza como distribuição de probabilidade .

Tabela 10.12 Representação das variáveis de incerteza como distribuição de probabilidades

\begin{tabular}{|l|l|}
\hline Variável de Incerteza & Distribuição \\
\hline Velocidade do vento, condição B & Normal $(4 ; 0,4)[\mathrm{m} / \mathrm{s}]$ \\
\hline Velocidade do vento, condição B & Normal $(5 ; 1,5)[\mathrm{m} / \mathrm{s}]$ \\
\hline Velocidade do vento, condição B & Normal $(4 ; 0,4)[\mathrm{m} / \mathrm{s}]$ \\
\hline Velocidade do vento, condição B & Uniforme $(1 ; 2)[\mathrm{m} / \mathrm{s}]$ \\
\hline Área do furo & $\begin{array}{l}\text { Triangular }(0,0012 ; 0,00187 ; 0,0025) \\
{[\mathrm{m} / \mathrm{s}]}\end{array}$ \\
\hline Coeficiente de descarga & Uniforme $(0,7,0,9)[-]$ \\
\hline
\end{tabular}


No caso em tela, utiliza-se o método Hipercubo latino com 10.000 interações, com emprego do software Palisade 2001. Obtêm-se as curvas indicadas na Figura 10.4 para as 4 condições meteorológicas consideradas.

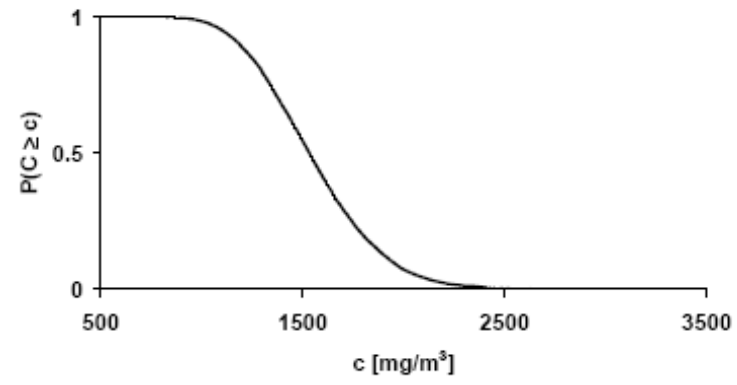

Concentração na Condição B

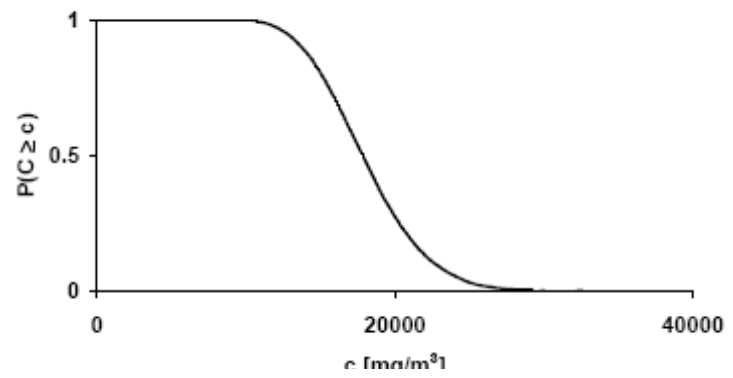

Concentração na Condição E

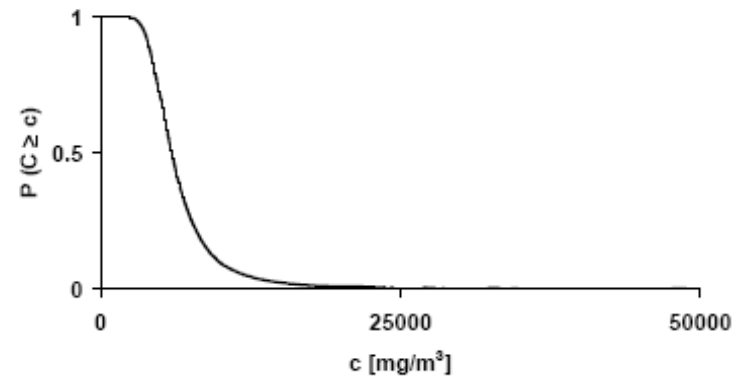

Concentração na Condição D

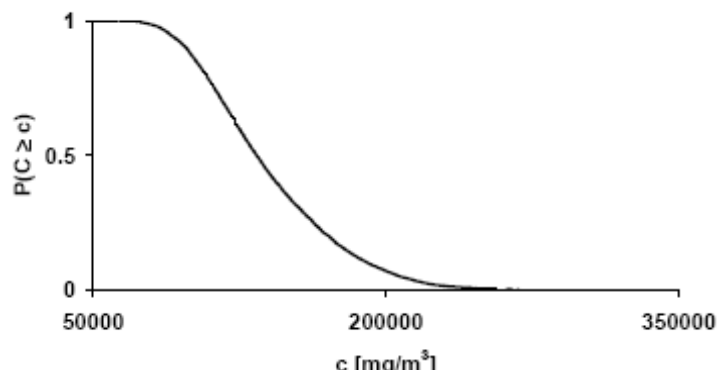

Concentração na Condição F

Figura 10.4 Resultados obtidos para diferentes condições meteorológicas. Concentração $\left(\mathrm{mg} / \mathrm{m}^{3}\right)$

Análise de curvas probabilísticas

$\mathrm{Na}$ abordagem por curvas probabilísticas, cada variável de incerteza deve ser posta em forma de curvas probabilísticas que possuam parâmetros que variem em um certo intervalo. Como exemplo, apresenta-se na Figura 10.5 a velocidade do vento na condição meteorológica $B$, em que a média varia entre 4,5 e $5,5 \mathrm{~m} / \mathrm{s}$ e o desvio padrão varia de 1,0 a 1,3 m/s. 


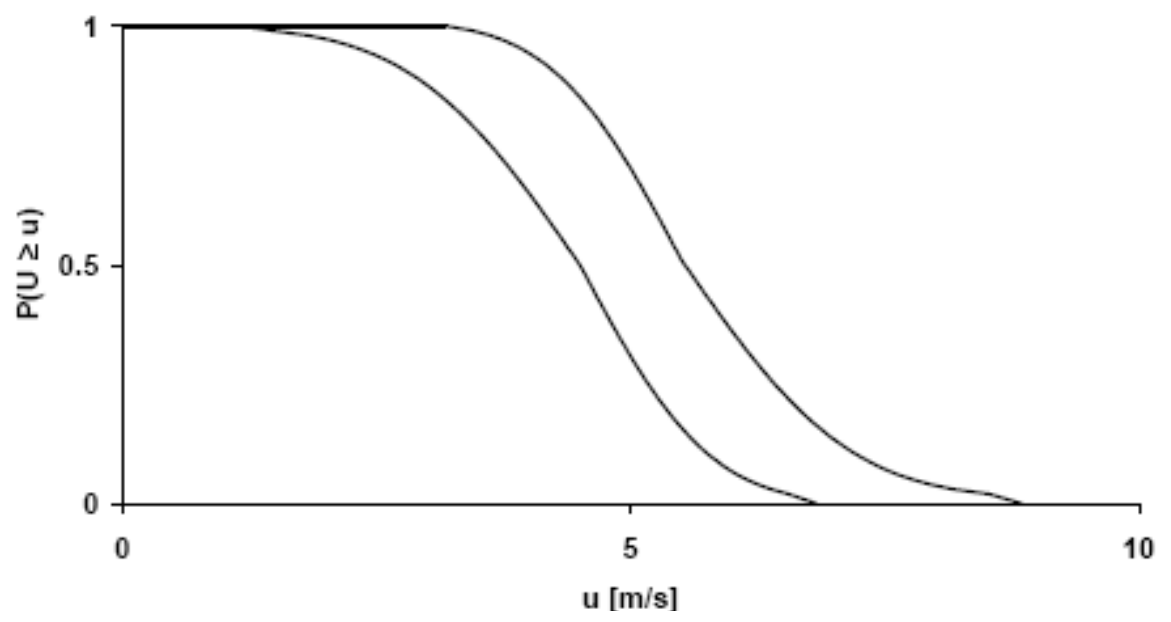

Figura 10.5 Curvas probabilísticas para a velocidade do vento na condição D

A representação das curvas probabilísticas é apresentada na Tabela 10.12 com a indicação dos intervalos de variação.

Tabela 10.12 Variáveis de incertezas e suas distribuições

\begin{tabular}{|c|c|}
\hline Variável de Incerteza & Curvas Probabilísticas \\
\hline Velocidade do vento, condição B & Normal $(4 ; 0,4)[\mathrm{m} / \mathrm{s}]$ \\
\hline Velocidade do vento, condição B & Normal $(5 ; 1,5)[\mathrm{m} / \mathrm{s}]$ \\
\hline Velocidade do vento, condição B & Normal $(4 ; 0,4)[\mathrm{m} / \mathrm{s}]$ \\
\hline Velocidade do vento, condição B & Uniforme $(1 ; 2)[\mathrm{m} / \mathrm{s}]$ \\
\hline Área do furo & Triangular $(0,0012 ; 0,00187 ; 0,0025)[\mathrm{m} / \mathrm{s}]$ \\
\hline Coeficiente de descarga & Uniforme $(0,7 ; 0,9)[-]$ \\
\hline
\end{tabular}

Os resultados de concentração média da substância obtida com o emprego de Análise por curvas probabilísticas estão apresentados na Figura 10.6 


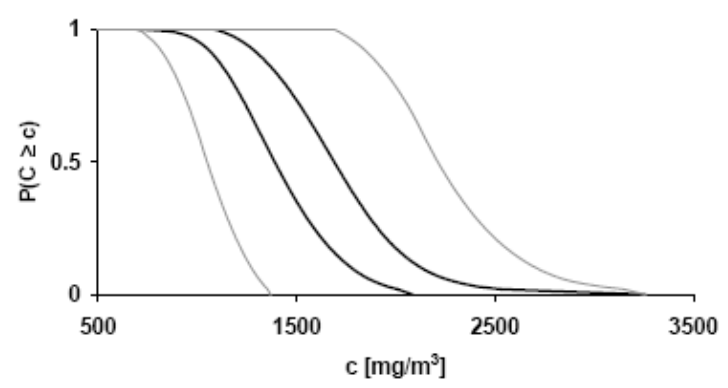

Concentração na condição B

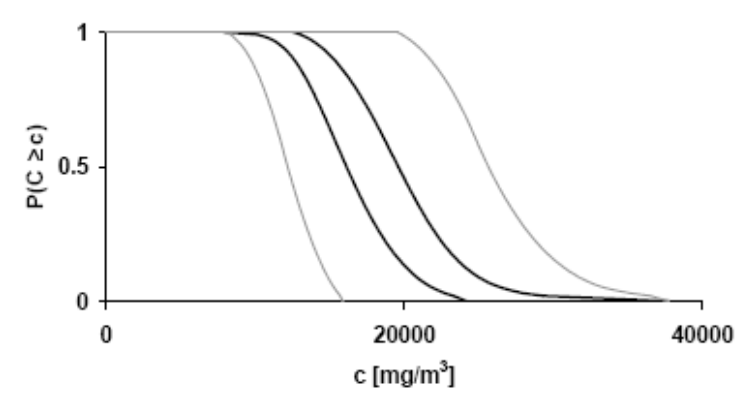

Concentração na condição $E$

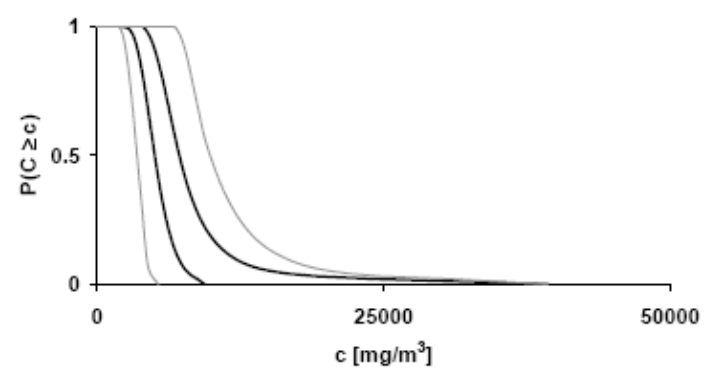

Concentração na condição D

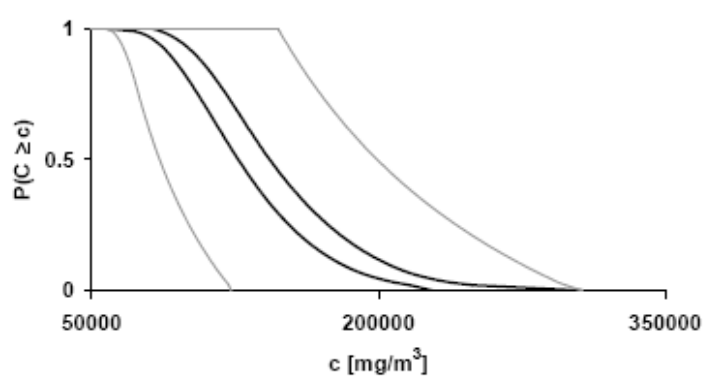

Concentração na condição $F$

Figura 10.6 Concentração para as diversas condições meteorológicas. Concentração $\left(\mathrm{mg} / \mathrm{m}^{3}\right)$

\subsection{Comparação de resultados}

São apresentados e discutidos, a seguir, os valores obtidos para a concentração média usando os diversos métodos de estudo de propagação de incertezas para a condição meteorológica D. Estes resultados estão agrupados na Figura 10.7.

A abordagem holandesa é representada por três retas verticais, a primeira considerando a velocidade do vento de $8,5 \mathrm{~m} / \mathrm{s}$, a segunda para uma velocidade de $4 \mathrm{~m} / \mathrm{s}$ e a terceira para $1,5 \mathrm{~m} / \mathrm{s}$. Já, a análise intervalar é representada por duas retas verticais. A analise de Monte Carlo gera uma curva tracejada, enquanto que a análise usando curvas probabilísticas pode usar a dependência ou a independência das variáveis. 


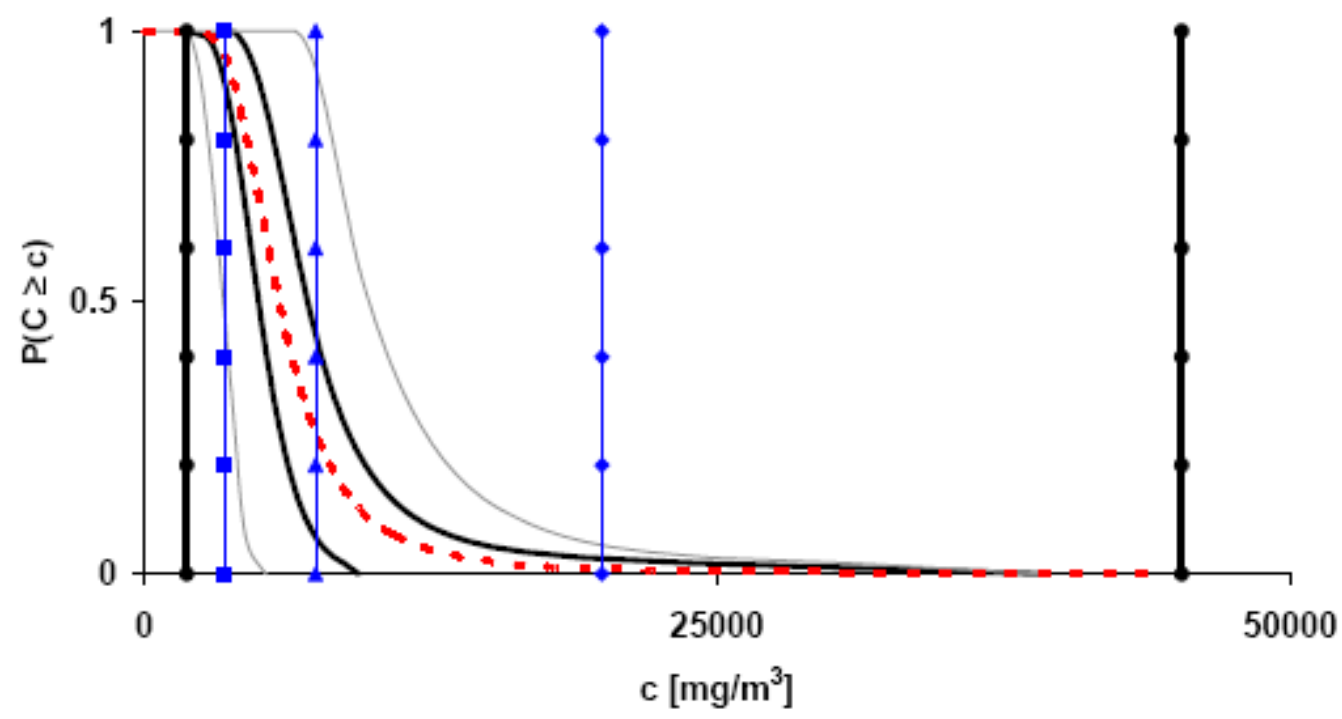

$\longrightarrow$ Análise intervalar

Análise por curvas probabilísticas, dependência das variáveis (Max-min)

Análise por curvas probabilísticas, dependência das variáveis (Max-min)

- - - Análise com Monte Carlo

Abordagem Holandesa $(8,5 \mathrm{~m} / \mathrm{s})$

$\longrightarrow$ Abordagem Holandesa $(4 \mathrm{~m} / \mathrm{s})$

$\longrightarrow$ Abordagem Holandesa $(1,5 \mathrm{~m} / \mathrm{s})$

Figura 10.7 Concentração média para a condição meteorológica D (comparação de resultados)

Poder-se- ia ainda fazer um segundo ñoopòde interação com Monte Carlo (Monte Carlo de 2 fases). Para isto, dever-se-ia considerar a incerteza dos modelos em si. Por exemplo, para cálculo da descarga, o modelo é representado por uma equação determinista exata, (10.1).

Pode-se introduzir a incerteza total deste modelo de descarga multiplicando o resultado da equação anterior por uma distribuição uniforme do tipo Uniforme $(0,5 ; 1.5)$. Como pode ser visto em Hanna et al (1991), esta fórmula apresenta um certo grau de incerteza que pode ser representado por esta distribuição uniforme. Outra incerteza que pode ser introduzida é a incerteza no modelo de dispersão que, a princípio, é dado por:

$$
C(x, y, z)=\frac{Q}{2 \pi \sigma_{y}(x) \sigma_{z}(x) U} e^{-\frac{y^{2}}{2 \sigma_{y}^{2}}}\left[e^{-\frac{\left(z-H_{e f f}\right)^{2}}{2 \sigma_{z}^{2}}}+e^{\frac{\left(z+H_{e f f}\right)^{2}}{2 \sigma_{z}^{2}}}\right]
$$


Para se introduzir a incerteza em todo o modelo multiplica-se o resultado da equação (10.1) por uma distribuição do tipo uniforme $(0.5,1.5)$.

\subsection{Risco individual no ponto $(300,0)$}

Para o cálculo do risco individual no ponto $(300,0)$, emprega-se o procedimento descrito no CCPS. O cálculo do risco individual é realizado na forma já exposta em capítulo anterior, expressa por:

Risco Individual $=($ Freqüência do cenário T2) $\times$ (Probabilidade de ocorrência da condição meteorológica) $x$ (Probablidade de morte (usando o CCPS e o método holandês)) $\mathrm{x}$ (Probabilidade de que a nuvem de vapor irá viajar até o ponto), em que a probabilidade de morte é o resultado da função PROBIT usando os parâmetros das tabelas e a concentração já calculada. O resultado está apresentado na figura 10.8

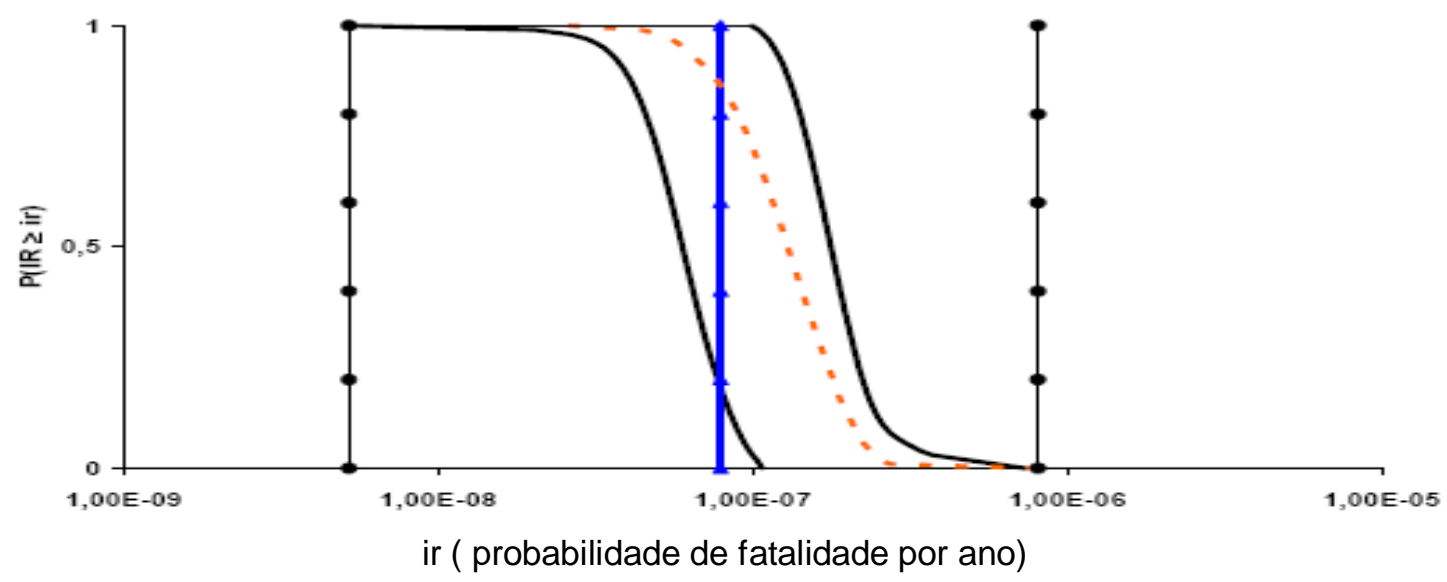

Figura 10.8 Risco Individual

$\longrightarrow$ Análise intervalar

Análise por curvas probabilísticas Max e Min

- - - Monte Carlo

$\longrightarrow$ Abordagem holandesa

\subsection{Classificação ponderada das incertezas}

O processo de classificação ponderada das incertezas pode ser efetuado conforme apresentado no capítulo anterior. Por exemplo, para o risco individual, no evento T2 na condição meteorológica $E$, as diversas variáveis incertas como freqüência do evento T2, tempo de exposição, área do furo, velocidade do vento e coeficiente de descarga pode-se obter os valores abaixo usando os diversos métodos de classificação ponderada

As Figuras 10.9 e 10.10 apresentam os resultados obtidos com os diferentes procedimentos. Analisando os resultados obtidos nos diversos métodos de classificação de 
forma ponderada, percebe-se que a maior contribuinte individual para a incerteza total é a frequência de T2, e que a velocidade do vento contribui de forma contrária a das outras variáveis. Assim, como uma medida para reduzir a incerteza, poder-se ï ia estimar com maior precisão a variável freqüência de T2.Obviamente que se trata de uma aplicação do exemplo para um cenário específico e em determinadas condições meteorológicas,poder-se-ia explorar diversos outros cenários nas mais deferentes condições, o intuito final deste exemplo é exemplificar como a incertezas no modelo e paramétricas podem ser trabalhadas matematicamente.

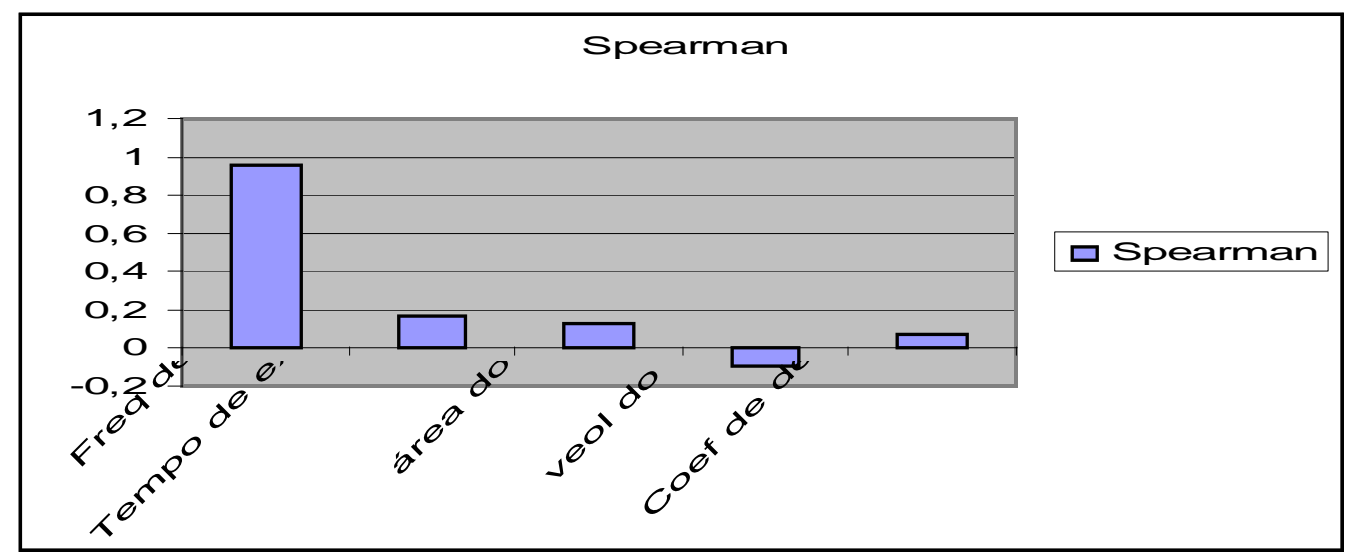

Figura 10.9 classificação ponderada usando Sperman

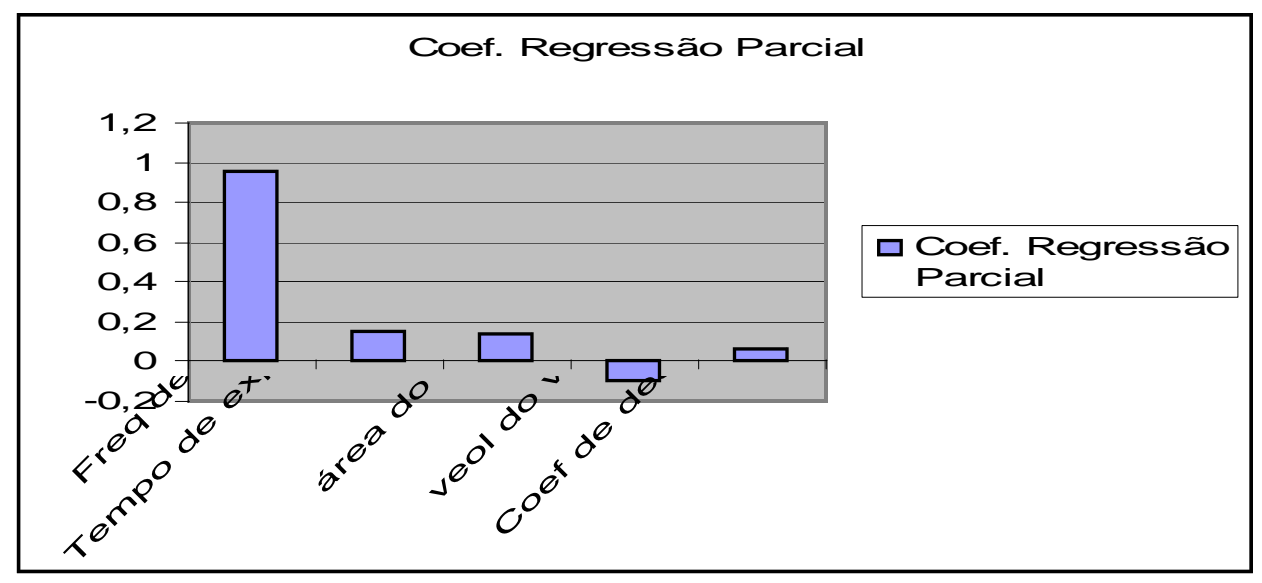

Figura 10.10 classificação ponderada usando Coeficiente de Regressão Parcial 
Coef Correlação

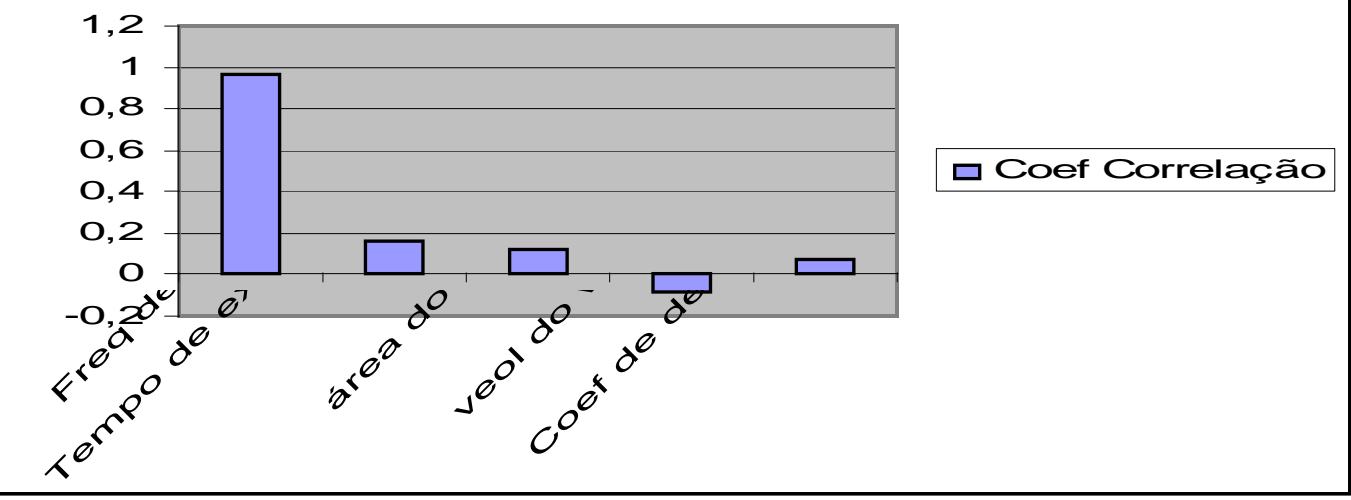

Figura 10.11 classificação ponderada usando Coeficiente de correlação

\subsection{Considerações finais}

Neste capítulo é apresentado um problema prático, que é utilizado como exemplo para a avaliação, classificação e possível tratamento das incertezas numéricas. Para o tratamento das incertezas relacionadas a processos estatísticos e a processos subjetivos seria necessário não só um exercício real com uma equipe atuando em um problema de forma que fosse possível ñust in timeòavaliar e aplicar os conceitos observados no capítulo 9. 


\section{CAPÍTULO 11}

\section{NORMATIZAÇÃO}

\subsection{Considerações iniciais}

Como já dito anteriormente, o objetivo da Análise de Risco é estabelecer a fundação para o processo de tomada de decisão. O ponto principal desta tese é apresentar um sumário dos tipos de incertezas que podem ser introduzidas em uma AR (Análise de Risco), apresentar formas de identificação e tratamento para as mesmas, e formular uma proposta de metodologia para condução do estudo.

Vários aspectos de incertezas foram discutidos. Qual o papel das incertezas no processo de tomada de decisão? Quais as partes do processo de análise de risco que podem produzir incertezas? Quais os tipos de incertezas existentes? Qual a importância de se separar as diferentes tipos de incertezas quando realizamos a análise de risco? etc.

Sabe-se que a AR produz uma variedade de incertezas e.g. Morgan et al (1990), Amendola et al (1998), Van Asset (1999) e Patê Cornell (1996). Não se discute que a AR é uma ferramenta racional para o processo de tomada de decisão, como se pode observar em muitas áreas como a indústrias aerospacial, nuclear, e de estruturas marítimas ( Berg \& Kafka 1997).

No capítulo 1 foi visto que no estudo r̃Benchmark exercise on major hazard analysis for a chemical plantô gerenciado pela Joint Research Center (JRC) durante o período de 1988 e 1990, 11 grupos de diferentes países realizaram a análise pré determinada de um sistema de armazenamento de amônia (Amendola et al 1992). Os objetivos deste estudo era avaliar o estado da arte e obter estimativas dos graus de incertezas em estudos de riscos. O resultado deste estudo demonstrou uma grande variedade nas estimativas de riscos. Este tem sido reconhecido em outras áreas, por exemplo, no risco de transporte de produtos químicos perigosos, Saccomanno et al (1990) mostra que diferentes estimativas de taxas de acidentes e probabilidades de vazamentos e áreas perigosas que por conseguinte gerará uma variedade de estimativas de riscos .

Com a classificação e caracterização das incertezas em estudos de riscos, e a criação de uma metodologia que possibilite a determinação das incertezas e a mitigação, uma próxima etapa que deve ser alcançada em nosso país é a Normatização dos estudos de riscos. A normatização em análise de risco é uma tendência mundial, como será visto a seguir e já é realizada em algumas áreas, variando de país para país.

Os holandeses, por exemplo, apresentam diversos valores iniciais para muitos parâmetros e prescrevem modelos que podem ser usados, trata-se na verdade de uma 
abordagem quase puramente determinista. Esta abordagem tem a enorme vantagem de permitir uma uniformização não só nos modelos e varáveis, mas também permite a comparação mais fácil entre diversos estudos que utilizam a mesma abordagem. Por outro lado, esta abordagem produz uma limitação nos resultados, já que pode inibir o desenvolvimento científico de novos modelos que poderiam ser utilizados em avaliação de risco. Pode-se assim desmotivar a busca de diferentes parâmetros. A Agência de Proteção ambiental Americana tem, por exemplo, uma abordagem distinta dos holandeses, na medida em que incentiva a utilização de modelos probabilísticos, mas em muitas situações um estudo completo probabilístico é inviável. Por outro lado, o guia holandês permite que o estudioso avalie previamente a viabilidade ou não de uma APR (Análise Probabilística de Risco).

A seguir serão apresentadas as diversas formas como setorialmente alguns países tem lidado com este assunto

\section{Política dos Estados Unidos}

A) Comissão de Regulação Nuclear NRC

US NRC Regulatory Guide 1174, contida em óApproach for using probabilistic risk assessment in risk $\tilde{n}$ informed decisions on Plant- Specific Changes to the licences Basisô $O$ backgroud deste regulamento foi uma adaptação da NRC (Nuclear Regulatory Commission) em agosto de 1995, que estabelece que a APR e análises associadas (estudo de sensibilidades, análise de incertezas etc) devem ser realizadas de forma a permitir uma avaliação futura por outros estudiosos. Algumas decisões estabelecidas pela NRC são apresentadas abaixo:

1- O uso de Análise Probabilística de Risco precisa ser incrementado;

2- Análise Probabilística de Risco e análises associadas (Estudo de sensibilidade, análise de incertezas etc) precisam ser melhor reguladas e realizadas com rigor e transparência;

3- Análise Probabilística de Risco precisa ser realista e prática de forma a permitir futuras revisões;

4- O objetivo do Guia da NRC é ser usado de forma voluntária já que este oferece uma abordagem genérica.

B) Agência de Proteção Ambiental - EPA (Environmental Protection Agency)

A Agência de Proteção Ambiental Americana enfatizou a importância de caracterizar os riscos e incertezas (U.S. Environmental Protection Agency). Por exemplo, em 1992 foi editado - ñEPA RISK ASSESSMENT COURIAL (RAC) GUINDANCEòe em 1995 o ñEPA POLICY FOR RISK CHARACTERIZATIONò Pode-se extrair deste documento a seguinte afirmação: ñtt is the 
policy of the U.S Environmental Protection Agency that such probabilistic analysis techiniques as monte Carlo analysis, given adequate supporting data and credible assumptions, can be a viable statistical tool for analysing variability and uncertainty in risk assessmentsà ou seja é a política da agência a utilização de técnicas de probabilidade como Monte Carlo para dar o suporte adequado e credibilidade, tornando viável o estudo da variabilidade e das incertezas em análise de Risco.

É importante ressaltar que em nenhum momento afirmou-se que a análise de Monte Carlo é a única técnica adequada, mas ao contrário, demonstra-se que outras formas são viáveis

Algumas diretrizes são estabelecidas pela EPA, tais como:

- O propósito do escopo deve ser bem claro na seção referente à formulação do problema;

- Os métodos usados na análise (incluindo todos os modelos usados, os dados e todas as hipóteses que têm significativo impacto na análise, devem ser documentados e facilmente localizáveis;

- Os resultados das análises de sensibilidade devem ser discutidos. Devem ser especificadas as técnicas de probabilidades utilizadas e os caminhos e outros fatores importantes para a análise;

- presença, ou ausência, de moderada para forte correlação ou dependência entre variáveis de entrada deve ser discutida e abordada bem como seus efeitos nas variáveis de saída;

- informação sobre as curvas de distribuição devem ser explicadas e justificadas;

- estabilidade da tendência central (numerical stability of central tendency) e os picos das distribuições das variáveis de saída devem ser apresentados e discutidos;

- cálculos de riscos com o uso de métodos determinísticos devem ser incentivados. E servem de comparação com análises passadas e nas determinísticas.

A proposta fundamental da EPA é estabelece política para definir métodos para caracterizar quantitativamente, a variabilidade e incerteza e sua contribuição relativa no processo como todo.

Consideração importante a interação entre analistas algumas questões são levantadas. 1-A análise quantidativa das incertezas e variabilidades poderá influenciar na avaliação de risco?

2-Quais são as maiores fontes de variabilidade ou incerteza? Como as variabilidades e incertezas poderiam ser separadas na análise?

3-Há tempo e recurso para uma análise completa e complexa?

4-Como a estimativa da incerteza afeta a decisão? Como os regulamentos e normas podem ser afetados pela análise de variabilidade e incerteza?

5-Quais as fraquezas e fortalezas dos métodos usados? 
6-Como as variabilidades e incertezas dos métodos são comunicados ao público e aos tomadores de decisão?

Outro aspecto importante consiste na comunicação dos dados e resultados, que deve ser feita de forma clara, com o máximo de informações possíveis. O guia da Agência Americana fornece alguns pontos que mereceriam um detalhamento maior no estudo, tais como:

1- Uma apreciação de todos os graus de variabilidade e incerteza e grau de confiança que são determinados na análise;

2- A determinação das principais origens das incertezas e seus impactos para a análise;

3- A determinação das condições críticas e sua importância para a análise;

4- Descrição das hipóteses que foram descartadas e uma explicação do porque do descarte;

5-Descrição de hipótese alternativas e considerações sobre os modelos usados;

6-Explicitar possíveis controvérsias científicas.

\section{Política na Holanda}

Baseado no artigo de Uijt de haag et al (1999). O guia holandês para a avaliação quantitativa de risco tem como origem os regulamentos holandeses e estudos de experientes analistas. Pode-se extrair, por exemplo, que, se os resultados da Análise de Risco serão usados no processo de tomada de decisão, então eles precisam ser precisos, reproduzíveis e comparáveis. Estes requisitos são importantes e a análise comparativa necessita que seja feita com base em considerações iniciais, modelos e dados básicos similares, e eventuais diferenças devem derivar de peculiaridades dos processos ou informações específicas - ñlf the results of QRA are to be used in the decision making process, they must be unificable, reprocible and comparable. There requirements necessitate that $Q R A$ are made on the basis of similar starting points, models and basic data. Ideally, differences in QRA results should only arise from differences in process- and site specific informationò

$\mathrm{Na}$ Holanda muitos documentos guias foram publicados e chamam a atenção para a comparabilidade entre estudos (Red Book, Green Book, Yellow Book ref 1.2,1.3,1.4). O guia holandês mostra a importância da escolha do local que contribui com o risco (baseado na quantidade de substância perigosa e condições de armazenamento ou processamento).

A descrição do LOC (Loss of containment events- eventos com perda de contaminante) é importante para estabelecer uma uniformização na estrutura dos dados de entrada já que determinam os parâmetros das variáveis.

A importância deste Guia está também na possibilidade de se obter alguns valores iniciais para os cálculos. Porém, o analista pode até adotar valores diversos se o caso em tela exigir. No entanto, quaisquer desvios precisam ser aprovados pelas autoridades competentes e eles precisam ser claramente motivados no estudo. 
O guia fornece diversos processos que podem gerar perda de contaminante ou na sigla em inglês LOC. A descrição da origem do LOC permite a segura conclusão para o cálculo das conseqüências da dispersão de contaminantes etc.

Estes valores que são fornecidos pelo guia facilitam o cálculo. As diferenças entre os LOCs incluem não só os casos genéricos de LOC ( corrosão, erros de construção), LOC causado por impacto externo, carga e descarga e outros casos específicos de LOC. Os LOCs incluídos no guia e que são relatados em tanques e vasos, bombas, tubulações, transferidores de calor, caminhões tanque em carga e descarga, vagões tanque e navios. Um exemplo é apresentado na figura 11.1 abaixo:

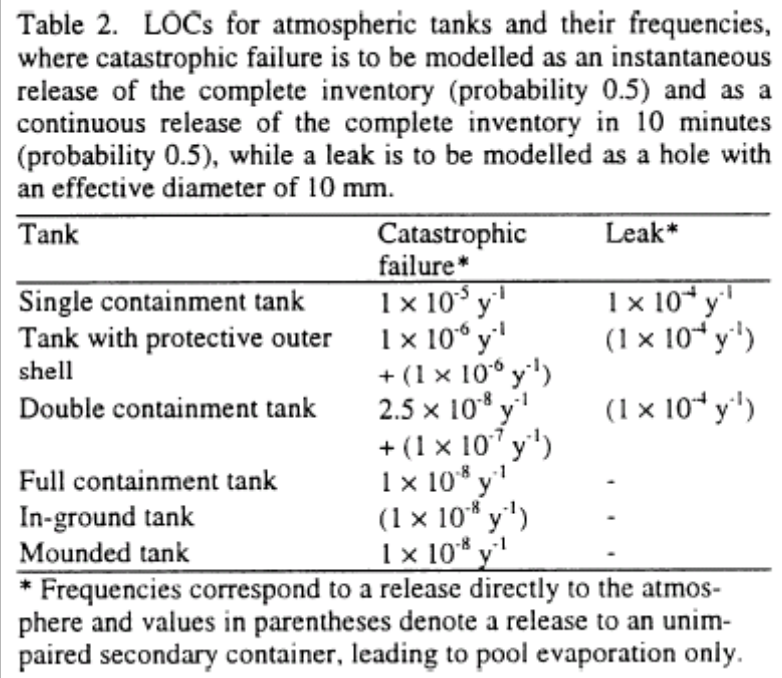

Figura 11.1 LOCs sugeridos in DUTCH GUIDELINES, Ujit de Haag et al (1999)

Este tipo de informação está disponível para diversos tipos de vazamentos e são fruto de consenso entre diversos representantes da indústria, autoridades competentes e o governo holandês. Uma preocupação importante do guia é a transparência nos dados que são alterados conforme eventuais congressos ou reuniões.

\section{EUROPA}

\section{COMISSÃO EUROPÉIA DE PROTEÇÃO AMBIENTAL}

A comissão européia de proteção ambiental elaborou um documento denominado ñGuindance on the preparation of safety report to meet the requeriments of Council Directive 96/82/ECô (SEVESO II). Teve como intenção prevenir os acidentes mais perigosos que poderiam ocorrer, envolvendo substâncias nocivas. Uma das principais medidas nesta diretiva para atingir o objetivo, está no conceito de ósafetyâ Não se trata de uma legislação e não é mandatória. O guia provê informação não explicita de como tratar a incerteza quando trabalhando em análise de risco. 
Os maiores acidentes são identificados e os riscos associados com os mesmos são monitorados. Este guia inclui resultados e análise de perigos e avaliação de risco em termos de identificação de fontes de perigos, freqüência relativa dos maiores acidentes e suas conseqüências.

Um possível procedimento para conduzir análise de perigos, avaliação de risco, é apresentado no guia este procedimento é realizado em 3 etapas. A primeira consiste na identificação das seções relevantes; para isto usa-se a experiência anterior, em conjunto com métodos para identificar perigos, ou outros métodos úteis. A segunda etapa permite identificar quais destas fontes de perigos são provenientes de erro humano, técnico, etc e, assim, interligá-los com os eventos externos, segurança ou outras causas definidas no projeto, construção e gerenciamento da segurança, que podem causar os maiores incidentes nas instalações. A terceira, finalmente, é focada na prevenção, controle e medidas mitigadoras, usando princípios como a ñALARAò(As Low as Reasonably Achievable).

\subsection{Normas internacionais}

O estudo de normas já publicadas sobre análise de risco facilita a percepção do atual estágio de preocupação sobre os aspectos relacionados às incertezas em estudos de risco. já que a normatização de procedimentos na área científico ocorre em situações pontuais sendo uma atitude enérgica apenas utilizada apenas em casos bem específicos. A importância da normatização está associada a áreas da engenharia notoriamente conhecidas como potenciais fontes de eventos catastróficos ou com perigos, tais como: energia nuclear, medicina, proteção contra incêndio.

\section{NORMA DINAMARQUESA DS/INF 85}

A primeira edição da DS-Information DS/INF 85 ï Análise de Risco, requisitos e terminologia) foi publicada em 1993 e revisada diversas vezes . O propósito principal pode ser encontrado no sumário em inglês que diz: ñto assure a high quality of risk analyses as they are carried out in a wide range of applications, while more detailed, descriptive guidelines might be obtained in the various areas separatelyò. Ou seja, o objetivo principal é garantir uma alta qualidade das análises de risco já que elas são realizadas em uma ampla faixa de aplicações; reconhece, porém, que guias descritivos, mais detalhados, podem ser obtidos nas várias areas separadamente.

NORMA INTERNACIONAL IEC 60300-3-9 
A Norma Internacional IEC é uma norma genérica que é utilizada por diversos países, sendo inclusive literalmente copiada na Inglaterra (Norma BS 8444) e na Austrália / Nova Zelândia (Norma AS/NZS 3931). Estas três normas estão intimamente ligadas entre si. $\mathrm{Na}$ verdade, as normas BS 8444 e AS/NZS 3931 reproduzem diretamente o que está escrito na IEC. Outras normas, como a NS 5814, de alguma forma fazem referência a esta IEC.

O objetivo da norma é trazer qualidade e consistência ao planejamento e execução de análise de risco. A norma IEC estabelece linhas mestras para o planejamento, execução e documentação em análise de risco; ela estabelece também bases para a especificação de requisitos de qualidade em análise de risco, bases para a própria avaliação da análise de risco após a sua conclusão.

\section{NORMA CANADENSE CAN/CSA-Q 850}

A Norma Canadense ñRisk Management Guideline for decision Makersôfoi preparada pela CSA Techinichal committee on Risk management publicada em 1997.

Este guia foca nos motivos e propósitos que levam diferentes ñstakeholdersô no gerenciamento de risco. A definição de ñstakeholdersô nesta norma é : Indivíduos, grupos ou organismos que são capacitados para efetar ou que são afetados ou acreditam que podem afetar a tomada de decisão ou a atividade de outras pessoas. Esse documento remete ainda a uma importante discussão sobre a percepção de risco, já que de acordo com a norma , o risco e a percepção do risco dependeriam de uma série de fatores que são exaustivamente abordados na norma canadense.

NORMA INGLESA BS 8444

Trata-se como já visto anteriormente de uma cópia da IEC 60300-3-9

NORMA AUSTRALIANA/NEOZELANDESA AS/NZS 3931

Como a norma BS 8444, trata-se de uma cópia da IEC 60300-3-9

\section{NORMA EUROPÉIA EN 1050}

A NORMA EUROPÉIA 1050:1996/2.3 r̃́Segurança de mecanismosò foi preparada pelo Comitê Técnico CEN/TC 14. O escopo desta norma é estabelecer princípios gerais para a análise de riscos relacionados ao projeto e uso de máquinas durante as fases da vida dos seus mecanismos.

\section{NORMA NORUEGUESA NS 5814}

A norma NS 5814, que estabelece requisitos para Análise de Risco, foi preparada pela NORWEGIAN SATANDARDISATION ASSOCIATION e inicialmente publicada em 1991. O campo de aplicação da norma é vasto, tendo como objetivos os mesmos da IEC, que são: 
estabelecer as linhas mestras para o planejamento, execução e documentação em análise de risco; estabelecer bases para a especificação de requisitos de qualidade em análise de risco; e estabelecer bases para a própria avaliação da análise de risco após a sua conclusão.

Com diversos exemplos em seu bojo, a norma é muito utilizada na Noruega e países vizinhos, principalmente em áreas relacionadas à exploração de petróleo.

\section{NORMA AUSTRALIA/NEOZELANDESA AS/NZS 4360}

Esta norma foca especificamente o gerenciamento de risco, mostrando pouca preocupação com a execução da Análise de Risco; ela proporciona ferramentas genéricas para identificação, análise, tratamento e monitoramento de risco.

No apendice B é apresentada uma tabela extraída de Abrahamsson, 2000, que sintetiza a aplicabilidade destas normas.

\subsection{Normatização e padronização no Brasil}

Conforme se pode perceber pela exposição acima, existe uma crescente preocupação com normatização e procedimentos de padronização em estudos de riscos em diversas partes do mundo. No Brasil, no entendimento do autor estas ações ainda são embrionárias. Por exemplo, há uma carência de normas que permitam a um estudioso balizar as suas ações; esta carência se observa também na falta de publicações oficiais ou extra-oficiais, que estabeleçam requisitos mínimos, ou critérios mensuráveis, para emprego em análise de risco. Não há tampouco publicações que questionem as incertezas existentes em estudos de Risco ou até mesmo que possibilitem uma validação segura do estudo. Para orientar futuros estudos, que estejam comprometidos com a boa prática, e que estabeleçam uma doutrina com transparência ou que permita uma auditoria séria, este esforço de normatização merece ser incentivado.

As normas brasileiras são ainda incipientes neste campo. Há, por exemplo, a norma ABNT NBR/IEL 27005, de 2008, GESTÃO DE RISCOS DE SEGURANÇA DA INFORMAÇÃO, específico para a segurança física e de software relacionados a tecnológica da informação,

Trata-se da versão brasileira da norma internacional publicada recentemente, e que foi elaborada para apoiar o entendimento das especificações e conceitos estabelecidos pela norma ISO/IEC 27001:2006, definindo as melhores práticas em gestão de riscos de segurança da informação. A norma ABNT NBR ISO/IEC 27005:2008 pode ser aplicada a organizações de todos os portes e segmentos. Fornece diretrizes para o processo de gestão de riscos, atendendo particularmente aos requisitos de um Sistema de Gestão de Segurança da Informação (SGSI), de acordo com a norma ABNT NBR ISO/IEC 27001 - Tecnologia da informação - Técnicas de segurança - Sistemas de gestão de segurança da informação ï 
Requisitos. As ameaças podem ser intencionais ou acidentais e podem se relacionar tanto ao uso e aplicação de sistemas de $\mathrm{TI}$ como aos seus aspectos físicos e ambientais. Essas ameaças podem assumir diversas formas, desde furto de mídia, documentos e equipamentos, forjamento de direitos, espionagem a distância, escuta não-autorizada, até fenômenos climáticos e sísmicos, incêndio, inundação e radiação eletromagnética. As conseqüências dessas ameaças podem ser traduzidas por vários impactos aos negócios das organizações como, por exemplo, perdas financeiras, interrupção de serviços essenciais, perda de confiança dos clientes, pane no fornecimento de energia e falhas de telecomunicações. Um risco, no contexto da nova ISO 27005:2008, é a combinação das conseqüências que se seguirão à ocorrência de um evento indesejado e da probabilidade de ocorrência desse evento. A avaliação de riscos quantifica ou descreve qualitativamente um risco e permite aos gestores priorizar os riscos de acordo com a sua severidade ou com outros critérios estabelecidos pela organização. A ISO 27005 fornece as diretrizes para o gerenciamento dos riscos de segurança da informação (SI) e dá sustentação aos conceitos especificados na ISO 27001:2005, que é a norma de requisitos de sistemas de gestão da SI, além de auxiliar sobremaneira na implementação e certificação de tais sistemas de gestão. A norma ABNT NBR ISO/IEC-27001, TECNOLOGIA DA INFORMAÇÃO - TÉCNICAS DE SEGURANÇA DE SISTEMAS DE GESTÃO DE SEGURANÇA DA INFORMAÇÃO segue a mesma linha da ISO 27001. A exemplo de outras normas de sistemas de gestão, ela também adota o modelo PDCA (Plan, Do, Check, Act), o qual é aplicado para estruturar todos os processos do SGSI. Agora cabe a pergunta: como tais processos do SGSI se alinham ao processo de gestão de riscos recomendado pela ISO 27005 ?

Não existe uma norma para a avaliação de risco em processo industriais, processos relacionados a indústria de petróleo, para acompanhamento de acidentes relacionados a indústria de petróleo, ou ainda na área nuclear. Não existem ainda normas que busquem o tratamento da incertezas nestes diversos processos.

Portanto, o autor entende que deve ser introduzida uma norma que trate destes temas. Entende também que esta norma deverá conter as seguintes recomendações:

1. A Análise Probabilística de Risco precisa ser auditável, de forma a permitir futuras revisões; 2- A Análise Probabilística de Risco e análises associadas (Estudo de sensibilidade, análise de incertezas, etc) precisam ser realizadas com rigor e transparência, e as hipóteses referentes ao pior caso devem ser expressas de forma clara;

3- As hipóteses adotadas no trabalho precisam ser descritas de forma clara; adicionalmente, quando alguma hipótese não for utilizada, deve haver uma explicação consistente; hipóteses adotadas alternativamente devem ser descritas; hipóteses adotadas alternativamente devem ser descritas;

4- Devem ser apresentadas considerações sobre os modelos empregados na Análise de Risco; também devem ser discutidos os valores adotados para os parâmetros; 
5- Deve ser feita a determinação das condições críticas e explicitada a sua importância para a análise; devem ser explicitadas possíveis controvérsias científicas;

6-O propósito do escopo deve ser bem definido na seção referente à formulação do problema;

7- Os métodos usados na análise (incluindo todos os modelos adotados, os dados e todas as hipóteses que tem significativo impacto na análise) devem ser documentados e facilmente localizáveis;

8-Os resultados das análises de sensibilidade devem ser discutidos; devem ser especificadas as técnicas de probabilidades utilizadas bem como outros fatores importantes para a análise;

9- As informações utilizadas para construção das curvas de distribuição devem ser explicadas e justificadas;

10- A estabilidade da tendência central (numerical stability of central tendency) e os picos das distribuições das variáveis de saída devem ser apresentados e discutidos;

11- A presença ou ausência de moderada para forte correlação ou dependência entre variáveis de entrada deve ser discutida e os seus efeitos sobre as variáveis de saída devem ser discutidos;

12- Cálculos de riscos com o uso de métodos determinísticos devem ser incentivados;

13- Deve ser feita uma avaliação crítica de todos os graus de variabilidade e incerteza e do grau de confiança que são determinados na análise;

14- Devem ser determinadas as principais origens das incertezas bem como seus impactos para a análise.

Além da introdução de uma norma para condução de Análise de Risco, o autor entende que para que o Brasil possa avançar nos estudos de risco, devem ser tomadas, entre outras, as seguintes medidas:

1- Criação de uma entidade normatizadora/padronizadora que fomente a pesquisa e que seja específica para a área de Risco;

2- Estabelecimento de um número mínimo de normas para o desencadeamento de estudos na área de Risco;

3- Padronização na medida do possível de procedimentos em Análise de Risco;

4- Estabelecimento de critérios para medir e quantificar as incertezas em estudos de Risco;

5- Avaliação dos bancos de dados usados nos estudos de Risco no país. 


\section{CAPÍTULO 12}

\section{CONCLUSÕES}

\subsection{Considerações finais}

No decorrer desta tese mostrou-se a importância dos Estudos de Risco em diversas áreas do conhecimento humano e em especial nos diversos ramos da Engenharia. A análise de risco é uma ferramenta importante no projeto e na análise de viabilidade de processos industriais e tecnológicos.

Sabe-se que ao longo das últimas décadas, estudos na área de risco têm sido sistematicamente usados na engenharia e em áreas afins como suporte para análise de potenciais eventos danosos e suas consequências. A análise de risco é um instrumento muito útil já que funciona como um primeiro termômetro da viabilidade de um projeto e permite, dentre outras coisas, dimensionar os perigos e minimizar as consequências.

Por outro lado, percebeu-se ao longo dos últimos anos, que a comunidade internacional ou países isolados, têm-se mostrado preocupados com a enorme diversidade de estudos nesta área. Questionamentos passaram a surgir sobre a precisão, metodologia e possibilidade de reprodução destes estudos. Qual a garantia de que os resultados podem ser auditáveis?

Tentativas de normatização e padronização passaram a existir. Com isto, passou-se a estudar com mais intensidade processos que determinem o grau de incerteza numérica associada ao Estudo e como estas incertezas podem ser interpretadas e apresentadas.

No Brasil esta preocupação está relativamente embrionária. Algumas áreas como Risco Ambiental e Hidrologia, têm-se observado uma maior preocupação com as incertezas numéricas, denominadas nesta teses como incertezas provenientes de processo racionais. Este tipo de incerteza pode ser facilmente calculável usando diversos métodos como mostrado no exemplo numérico do capítulo 10. Porém, torna-se cada vez mais importante a preocupação do analista de Risco com as incertezas envolvidas no seu estudo, sejam elas numéricas ou não, e assim deve-se saber que apesar de possuir uma fórmula matemática que modele 0 processo em estudo e ter como resultado com um número de 4 ou 5 algarismos significativos não significa, por exemplo, que seu estudo é isento de erro.

Outros processos que incorrem em erros, que foram observados nesta tese, estão relacionados ao uso de Banco de dados (Processos Estatísticos ou relacionados a Banco de Dados) e incertezas associadas aos processos de natureza subjetiva, denominados de processos qualitativos ou que derivam do conhecimento de especialistas . 
A Análise de Risco é aqui descrita como um processo estruturado para identificar e analisar as contribuições mais importantes no risco total em uma atividade da vida humana, do meio ambiente ou alguma outra parte vulnerável da sociedade.

Foi criado um conceito de classificação de incertezas e estudos de riscos dividos quanto a natureza, a funcionalidade e a etapa da analise de risco, desta forma o pesquisador poderá saber, não só aspectos intrínsecos da incerteza como também a sua aplicabilidade e a sua localização na análise de risco.

Por outro lado foi necessário dividir os processos que envolvem a Análise de Risco em três grupos distintos, processos racionais, subjetivos e estatísticos. Esta divisão facilita metodologia de identificação, propagação e tratamento das incertezas envolvidas.

Partiu-se assim, nesta tese, para uma tentativa de dimensionar, classificar às incertezas e ainda propor alternativas para minimizar e caracterizá-las. Não só as incertezas dos processos racionais como também as incertezas probabilísticas e subjetivas. Uma proposta de classificação das incertezas é apresentada no Capítulo 9

Ainda no capítulo 9 é apresentada uma proposta metodológica, nela são abordados diversos procedimentos que ora surgem como sugestões ora como imposições necessárias que, de alguma forma, facilitam o tratamento das incertezas e minimizam os seus efeitos. Esta Metodologia é parcialmente testada em um exemplo numérico no capítulo seguinte. As incertezas são assim tratadas no capítulo 10, sendo analisada a sua propagação e sua minimização.

Aborda-se ainda a questão e a padronização e normatização em estudos de Riscos. Algumas normas internacionais são apresentadas tendo como objetivo mostrar a importância da padronização ou normatização. Objetivando que estudos relacionados ao risco fiquem mais transparentes e reproduzíveis.

No capítulo 11 propõe um embrião de Normatização e Padronização a ser aplicado no Brasil

Os questionamentos que foram introduzidos nos capítulos 1 e 2 foram respondidos no decorrer dos demais capítulos, percebe-se assim que é possível criar uma metodologia para tratar as incertezas existentes nos estudos de riscos.

Espera-se ter sido alcançado o objetivo que foi apresentar uma proposta metodológica que diminua e caracterize as incertezas envolvidas em estudos de risco. Esta preocupação será crescente na medida da que os estudos relacionados a Risco, produzidos em nosso país, passem a ser apresentados na comunidade Científica Internacional com maior frequência.

Em trabalhos futuros pode-se partir da proposta metodológica para a criação prática de protocolo de análise do trabalho dos especialistas, normatização e padronização. 


\section{BIBLIOGRAFIA}

Abrahamsson, M., Treatment of Uncertainty in Risk Based Regulations and Standards for Risk Analysis. Report 3116, Department of Fire Safety Engineering, Lund University, Lund, 2000.

Abrahamsson, M., Behandling av osäkerheter i riskanalyser $\tilde{n}$ Studie av befintliga analyser. Department of Fire Safety Engineering, Lund University, Lund, to be published. (In Swedish),2002.

Abrahamsson, M., Johansson, H., \& Magnusson, S.E., Methods for treatment of uncertainty in quantitative risk analysis. Safety, Risk and Reliability ï Trends in Engineering, Conference report, IABSE, Zürich, 2001.

Abrahamsson, M., \& Magnusson, S.E., Treatment of uncertainties in quantitative risk analysis. Foresight and Precaution, Cottham, Harvey, Pape \& Tait (eds.), Balkema, Rotterdam, 2000.

Adams, E. and U. Kulisch (eds.)., Scientific Computing with Automatic Result Verification., Mathematics in Science and Engineering, Volume 189, Academic Press, San Diego,1993.

Addiscott, T.M.; Thomas, V.H.; Janjua, M.A. Measurement and simulation of anion diffusion in natural soil aggregates and clods. Journal of Soil Science, Reading, v.34, p.709-721, 1983.

Apostolakis, G.E. , A commentary on model uncertainty. Proceedings of Workshop on Model Uncertainty, A. Mosleh, N. Siu, C. Smidts, and C. Lui (eds.), Center for Reliability Engineering, University of Maryland, College Park, Maryland,1995.

Alefeld, G., \& Herzberger, J., Introduction to Interval Computations. Academic Press, New York, 1983.

Amendola, A., Contini, S., \& Ziomas, I., Uncertainties in chemical risk assessment: Results of a European benchmark exercise. Journal of Hazardous Materials, vol. 29, Elsevier Science Publishers, Amsterdam, 1992 Ang, A.H-S., \& Tang, W.H., Probability concepts in Engineering Planning and Design, Volume 1 ñ Basic Principles. John Wiley \& Sons, New York, 1975.

Arrow, K. J., I Know a Hawk from a Handsaw. In: M. SZENBERG (Ed.), Eminent Economists: Their Life and Philosophies. Cambridge University Press, Cambridge,1992.

Beck, M.B.. Water Quality Modeling: A Review of the Analysis of Uncertainty. In: Water Resouces Research, vol. 23 No 8, august, 1987. 
Bar-Hillel, M., The base-rate fallacy in probability judgments. Acta Psychologia, 44, 211 233,1980 .

Bernier, J.M.. Elements of Bayesian Analysis of Uncertainty in Hydrological Reliability and Risk Models. In: Duckstein, L. \& Plate, E.J. (Eds), Engineering Reliability and Risk in Water Resources, NATO ASI Series, Serie E: Applied Sci., No. 124, Nijhoff, Dordrecht, Netherlands, 1987.

Bernstein, P.L., Desafios aos Deuses ñ A Fascinante História do Risco. Rio de Janeiro, Editora Campus. 1997.

Birnbaum, M. H. \& Mellors, B. A. . Bayesian inference: Combining base rates with opinions of sources who vary in credibility. Journal of Personality and Social Psychology, 45, $792-804,1983$

Brown, J. D. and Heuvelink, G. B. M. Assessing uncertainty propagation through physically based models of soil water flow and solute transport. Encyclopedia of Hydrological Sciences, pp. 1181-1196. Wiley, Chichester, UK ,2005

Canter, L.W., Scientific Uncertainty and Water Resources Management .In: LEMONS, J. (Ed.), Scientific Uncertainty and Environmental Problem Solving, Blackwell Science Inc., Cambridge, 1996.

Campos, J.N.B., A Procedure for Reservoir Sizing on Intermittent Rivers Under High Evaporation Rate. Fort Collins, Colorado State University. PhD thesis,1987.

CCPS, Guidelines for Chemical Process Quantitative Risk Analysis. Center for Chemical Process Safety, American Institute of Chemical Engineers, New York, 2000.

Clemen R.T., Making Hard Decisions ñ An Introduction to Decision Analysis. Wadsworth Publishing Company, Belmont, 1996.

Committee for the Prevention of Disasters, Guidelines for Quantitative Risk Assessment. CPR18E óPurple bookô Sdu Uitgevers, Den Haag, 1999.

Cohen, L. J., Can human irrationality be experimentally demonstrated? Behavioral and Brain Sciences, 4, 317-331,1981.

Cohen, L. J., The dialogue of reason: An analysis of analytical philosophy. Oxford: Clarendon Press, 1986.

Cosmides, L. ., The logic of social exchange: Has natural selection shaped how humans reason? Studies with wason selection task. Cognition, 31, 187-276,1989.

Cosmides, L. \& Tooby, J., Evolutionary psychology and the generation of culture, part II. Case study: A computational theory of social exchange. Ethology and Sociobiology, 10, 5197,1989 .

Cosmides, L. \& Tooby, J., Are humans good intuitive statisticians after all? Rethinking 
some conclusions from the literature on judgment under uncertainty. Cognition, 58, 1-73,1996

Cooke R.M., Experts in Uncertainty ñ Opinion and Subjective Probability in Science. Oxford University Press, New York, 1991.

COWI, Usikkerhedsbeskrivelse $i$ kvantitative risikoanalyser $\tilde{n}$ vejledning. COWI, Denmark, 1996a. (em dinamarques).

COWI, Usikkerhedsbeskrivelse i kvantitative risikoanalyser ñ projektrapport. COWI, Denmark, 1996b. (em dinamarques).

COWI, Usikkerhedsbeskrivelse i kvantitative risikoanalyser $\tilde{n}$ gasspredningsmodeller. COWI, Denmark, 1996c. (em dinamarques).

COWI, Usikkerhedsbeskrivelse i kvantitative risikoanalyser ñ litteraturgennemgang. COWI, Denmark, 1996d. (em dinamarques).

Dwyer, P., Linear Computations. John Wiley \& Sons, New York, 1951.

Davidsson, G., Haeffler, L., Hannah, J., \& Akersten, P.A., Databaser om olyckor och olycksrisker. Räddningsverket, Karlstad, 1999. (em sueco).

Davidsson, G., Lindgren, M., \& Mett, L., Värdering av risk. Räddningsverket, Karlstad, 1997. (em sueco).

Ermoliev,Y.M., Uncertainties and Decision Making. International Institute for Applied Systems Analysis, Laxenburg, Austria, 1993.

Ferson, S., \& Kuhn, R., Propagating uncertainty in ecological risk analysis using interval and fuzzy arithmetic. Computer Techniques in Environmental Studies IV, Elsevier Applied Science, London, 1992.

Ferson, S., \& Ginzburg, L.R., Different methods are needed to propagate ignorance and variability. Reliability Engineering and System Safety 54, Elsevier Science limited, Northern Ireland, 1996.

Ferson, S., \& Sunil, D., Probability Bounds Analysis. Proceedings of the $4^{\text {th }}$ International Conference on Probabilistic Safety Assessment and Management, PSAM 4, Edited by Mosleh, A. \& Bari, R.A., New York, 1998.

Ferson, S., Root, W., \& Kuhn, R., Ramas Risk Calc ñ Risk Assessment with Uncertain Numbers. Applied Biomathematics, Setauket, New York, 1999.

Ferson, S. 2002. RAMAS Risk Calc 4.0 Software: Risk Assessment with Uncertain Numbers. Lewis Publishers, Boca Raton, Florida.

Ferson, S. and M. Burgman. , Correlations, dependency bounds and extinction risks. Biological Conservation 73:101-105,1995.

Ferson, S. and L.R. Ginzburg., Different methods are needed to propagate ignorance and variability. Reliability Engineering and Systems Safety 54: 133ï 144,1996.

Ferson, S. and T.F. Long., Conservative uncertainty propagation in environmental risk assessments. Environmental Toxicology and Risk Assessment, Third Volume, ASTM STP 
1218, J.S. Hughes, G.R. Biddinger, and E. Mones (eds.), ASTM, Philadelphia, pp. 97i 110,1995.

Ferson et al. , Bounding uncertainty analyses. Proceedings from a Workshop on the Application of Uncertainty Analysis to Ecological Risks of Pesticides. A. Hart (ed.), Society for Environmental Toxicology and Chemistry, Pensacola, Florida, 2003

Ferson, S., V. Kreinovich, L. Ginzburg, D.S. Myers, and K. Sentz. , Constructing Probability Boxes and Dempster-Shafer Structures. SAND2002-4015. Sandia National Laboratories, Albuquerque, NM,2003.

Finkel, A.M. , A second opinion on an environmental misdiagnosis: the risky prescription of Breaking the Vicious Circle. New York University, 1995

Environmental Law Journal 3: 295-381.

Finley, B., D. Proctor, P. Scott, N. Harrington, D. Paustenbach, and P. Price., Recommended distributions for exposure factors frequently used in health risk assessment. Risk Analysis 14: 533-553, 1994.

Fischhoff, B; Beyth, R. ól knew it would happenô Remembered probabilities of once future things. Organizational Behavior and Human Performance, volume 13, 1ї 16, 1975.

Fischer, H.-C., Automatic differentiation and applications. Scientific Computing with Automatic Result Verification. E. Adams and U. Kulisch (eds.), Mathematics in Science and Engineering, Volume 189, Academic Press, San Diego,1993.

Fisher, R.A., The underworld of probability. $18201-210,1957$

Fisher, S., Forsén, R., Hertzberg, O., Jacobsson, A., Koch, B., Runn, P., Thaning, L., \& Winter, S., Vådautsläpp av brandfarliga och giftiga gaser och vätskor ñ metoder för bedömning av risker. Försvarets Forskningsanstalt, Grindsjön, 1997. (In Swedish).

Frank, M.J., R.B. Nelsen, and B. Schweizer., Best-possible bounds for the distribution of a sumò a problem of Kolmogorov. Probability Theory and Related Fields 74: 199$211,1987$.

Frantzich, H., Uncertainty and Risk Analysis in Fire Safety Engineering. Doctoral dissertation, Department of Fire Safety Engineering, Lund University, Lund, 1998.

Frantzich,H.,Nystedt,F.,Lundin,J., Risk Concepts in Safety Design 2003,

Frantzich, H., Harrada, K., \& Magnusson S.E., Fire Safety Design Based on Calculations ñ Uncertainty Analysis and Safety Verification. Report 3078, Department of Fire Safety Engineering, Lund University, Lund, 1995.

Fréchet, M., Généralisations du théorème des probabilités totales. Fundamenta Mathematica 25: 379ї 387,1935.

Fréchet, M., Sur les tableaux de corrélation dont les marges sont données. Annales de IڤJniversité de Lyon. Section A: Sciences mathematiques et astronomie 9: 53-77, 1951

Furuta, H., \& Shiraishi, N., Fuzzy importance in fault tree analysis. Fuzzy Sets and Systems 12, Elsevier Science, 1984. 
Ganoulis, J.G. , Engineering Risk Analysis of Water Pollution. VCH Publishers Inc., New York, NY,1994.

Goovaerts P., Geostatistical modeling of uncertainty in soil science. Geoderma 103: 3.26, 2001.

Hair, J.F et al. Análise multivariada de dados. 5. ed., Porto Alegre: Bookman, 2005.

Hale, A.R., \& Hovden, J. Management and Culture: the third age of safety. Occupational Injury: Risk, Prevention and Intervention, Edited by Feyer, A.M., and Williamson A. Taylor \& Francis, United Kingdom, 1998.

Hale, A.R., Oh, J.I.H., Brouwer, W.G.J., Bellamy, L.J., Ale, B.J.M., \& Papazoglou, I.A. The IRISK project: Development of an integrated technical and management risk control and monitoring methodology for managing and quantifying on-site and of-site risks. Proceedings of the $4^{\text {th }}$ International Conference on Probabilistic Safety Assessment and Management, PSAM 4, Edited by Mosleh, A., \& Bari R.A., New York, 1998a.

Hammerton, M., A case of radical probability estimation. Journal of Experimental Psychology, 101, 242-254,1973.

Hanna, S.R., Strimaitis, D.G., \& Chang, J.C., Evaluation of fourteen hazardous gas models with ammonia and hydrogen fluoride field data. Elsevier Science Publishers, Amsterdam, 1991.

Hendershot, D.C., Risk Guidelines as a Risk Management Tool. Prepared for presentation at the 1996 Process Plant Safety Symposium. Rohm and Haas Company, Bristol, 1995.

Helton, J.C., \& Davis, F.J. Sampling-Based Methods for Uncertainty and Sensitivity Analysis. Sandia Report SAND99-2240, Sandia National Laboratories, Albuquerque, 2000.

Helton, J.C., Treatment of uncertainty in performance assessments for complex systems. Risk Analysis 14: 483-511,1994.

Helton, J.C. and F.J. Davis., Latin Hypercube Sampling and the Propagation of Uncertainty in Analyses of Complex Systems. SAND2001-0417, Sandia National Laboratories, Albuquerque, New Mexico,2002.

Hofer, E., When to Separate Uncertainties and When Not to Separate. Reliability Engineering and System Safety 54, Elsevier Science limited, Northern Ireland, 1996.

Hromkovic, J. Algorithms for hard problems:introduction to combinatorial optimization, randomization, approximation, and heuristics. [S.I.]: Springer-Verlag London Berlin Heidelberg New York, $\underline{2001}$

IAEA, Evaluating the reliability of predictions made using environmental transfer models. International Atomic Energy Agency, Vienna, 1989.

IEC, International standard nr 60300-3-9: Dependability management ñ part 3: Application guide $\tilde{n}$ Section 9: Risk analysis of technological systems. International Electrotechnical Commision, Geneva, 1995. 
Iman, R.L., Davenport, J.M., \& Ziegler, D.K., Latin Hypercube sampling (a program userës guide). Technical Report SAND79-1473, Sandia National Laboratories, Albuquerque, 1980.

Iman, R.L. \& Helton, J.C., An Investigation of Uncertainty and Sensitivity Analysis Techniques for Computer Models. Risk Analysis 8, no. 1, Kluwer Academic/Plenum Publishers, New York, 1988.

Isukapalli, S.S., Uncertainty analysis of transport-transformation models. PhD dissertation, The State University of New Jersey, New Brunswick, 1999.

Johnson, N.L., Kotz, K., \& Kemp, A.D., Univariate Discrete distributions. John Wiley \& Sons, New York, 1993.

Johnson, N.L., Kotz, K., \& Balakrishnan, N., Continuous Univariate distributions (Vol. 1). John Wiley \& Sons, New York, 1994.

Johnson, N.L., Kotz, K., \& Balakrishnan, N., Continuous Univariate distributions (Vol. 2). John Wiley \& Sons, New York, 1995.

Kahneman, D., Slovic, P., \& Tversky, A., (eds.) Judgement under Uncertainty, Heuristics and Biases. Cambridge University Press, Cambridge, 1982.

Kaufmann, A., \& Gupta, M.M., Introduction to Fuzzy Arithmetic ñ Theory and Applications. Van Nostrand Reinhold, New York, 1985.

Klir, G. J. , Methodological Principles of Uncertainty in Indutive Modelling: a New Perspective. In: ERICKSON, G. J. \& SMITH, C.R. (Eds), Maximum-Entropy and Bayesian Methods in Science and Engineering Vol. I, 1989.

Koriat, A; Lichtenstein, S; Fischhoff, B. Reasons for confidence. Journal of Experimental Psychology: Human Learning and Memory, volume 6, p. 107-I 18, 1980.

Kundzewicz, Z.W., Hydrological Uncertainty in Perspective. In: Kundzewicz, Z.W.(Ed.), New Uncertainty Concepts in Hydrology and Water Resources. International Hydrology Series, Cambridge University Press, Cambridge, 1995.

Kumamoto, H. \& Henley, E.J Probabilistic Risk Assessment, IEEE, New York , 1991.

Larsson, D., Developing the Structure of a Fire Index Method for Timber-frame Multistorey Apartment Buildings, Department of Fire Safety Engineering, Lund University, Sweden, Report 5062, Lund 2000,

Laskey, K., Model confidence (Lecture notes) Summer Institute on Probability in Al, George Mason University, 1994.

Lauridsen, K., Christou, M., Amendola, A., Markert, F., Kozine, I., \& Fiori, M., Assessing the Uncertainties in the Process of Risk Analysis of Chemical Establishments: Part 1. Proceedings ESREL conference Towards a Safer World, Torino, 2001a.Available from: http://www.aidic.it/italiano/congressi/esrel2001/webpapersesrel2001/pro.html (2002-02-05)

Lauridsen, K., Christou, M., Amendola, A., Markert, F., Kozine, I., \& Fiori, M., Assessing the Uncertainties in the Process of Risk Analysis of Chemical Establishments: Part 2. 
Proceedings ESREL conference Towards a Safer World, Torino, 2001b.Available from: http://www.aidic.it/italiano/congressi/esrel2001/webpapersesrel2001/pro.html (2002-02-05).

Lundin, J. Uncertainty in Smoke Transport Models. Dept. of Fire Safety Engineering, Lund University, 1997.

Lees, F.P., Loss Prevention in the Process Industries. 2:nd edition, Vol. 1-3, Butterworth-Heinemann, Oxford, 1996.

Lopes, L. L. \& Oden, G. D. , The rationality of intelligence. Em E. Eels \& T. Maruszewki (Orgs.), Poznan studies in the philosophy of the sciences and the humanities. (Vol. 21, pp. 225249). Amsterdam: Rodopi, 1991

Lyon, D. \& Slovic, P. ,. Dominance of accuracy information and neglect of base rates in probability estimation. Acta Psychologia, 40, 287-298,1975.

Macedo, M. A. S., Alyrio, R. D E Andrade, R. O. B. Julgamento Intuitivo e Aspectos Cognitivos no Processo Decisório. Anais do XVI Congresso Latino-Americano de Estratégia (SLADE 2003). Lima/Peru: SLADE, 2003.

Macedo, M. Fontes P. Impacto da Racionalidade Limitada no Processo Decisório: uma análise do comportamento de analistas contábil-financeiros Universidade Federal Rural Do Rio De Janeiro., 2008.

Malleta B. V,Modelos baseados em Simulação de Monte Carlo, UFRJ ,2005

Meacham, B. J., The SFPE Handbook, Fire Protection Engineering, section five, chapter 12, 3rd edition, 2002.

Model Evaluation Group, Model Evaluation Protocol. Can be requested from the European Communities, DG XII/D1, Rue de la Loi 200, B-1049 Brussels, Belgium, 1994.

Moore, R.E. Methods and Applications of Interval Analysis. SIAM Studies on Applied Mathematics, Vol. 2, Philadelphia, 1979.

Moore, R.E., Interval analysis. Prentice-Hall, Englewood Cliffs, New Jersey, 1966.

Morgan, G.M., \& Henrion, M., Uncertainty $\tilde{n}$ A guide to Dealing with Uncertainty in Quantitative Risk and Policy Analysis. Cambridge University Press, New York, 1990.

Morgan, G.M., \& Henrion, M.. Uncertainty $\tilde{n}$ A guide to Dealing with Uncertainty in Quantitative Risk and Policy Analysis. Cambridge University Press, New York,1993.

Murphy, D.M., \& Paté-Cornell, E., The SAM Framework: Modelling the Efects of Management Factors on Human Behaviour in Risk Analysis. Risk Analysis, Vol. 16, No 4, Plenum Press, New York, 1996.

Olesen, H.R., Ten years of Harmonisation activities: Past, present and future. Introductory address to the $7^{\text {th }}$ International conference on Harmonisation within Atmospheric Dispersion Modelling for Regulatory Purposes, Belgirate, Italy, May 2001.Proceedings available from:http://www.dmu.dk/atmosphericenvironment/Harmoni/Proclntr.htm (2002-02-05)

Palisade Corporation, Guide to using @RISK. Palisade Corporation, Newfield, 2001. 
Parry, G.W., Uncertainty in PRA and its Implications for use in Risk-Informed Decision Making. Proceedings of the $4^{\text {th }}$ International Conference on Probabilistic Safety Assessment and Management, PSAM 4, Edited by Mosleh, A. \& Bari, R.A., New York, 1998.

Paté-Cornell, M.E., Uncertainty in risk analysis: Six levels of treatment. Reliability Engineering and System Safety 54, Elsevier Science limited, Northern Ireland, 1996.

Paté-Cornell, M.E., Priorities in Risk Management: Human and Organisational Factors as External Events and a Maritime Illustration. Proceedings of the $4^{\text {th }}$ International Conference on Probabilistic Safety Assessment and Management, PSAM 4, Edited by Mosleh, A. \& Bari, R.A., New York, 1998.

Plate, E.J. \& Duckstein, L., Reliability in Hydraulics Design. In: Plate, E.J. \& Duckstein, L. (Eds), Engineering Reliability and Risk in Water Resources, NATO ASI Series, Serie E: Applied Sci., No. 124, Nijhoff, Dordrecht, Netherlands,1987.

Rasmussen, J., Risk Management, Adaptation, and Design for Safety. In Sahlin, N.E., and Brehmer, B., (Eds.) Future Risks and Risk Management, Kluwer, Dordrecht, 1994.

Rasmussen, J., Risk Management in a Dynamic Society: A Modelling Problem. In Safety Science 27/2-3, pp 183-213, Elsevier Science, 1997.

Robinson, D.G., A Survey of Probabilistic Methods Used in Reliability, Risk and Uncertainty Analysis: Analytical Techniques 1. Sandia Report SAND98-1189, Sandia National Laboratories, Albuquerque, 1998.

Saccomanno, F.F., \& Bakir, O., Analysis of Risk Uncertainty for the Transport of Hazardous Materials. In Transportation of Dangerous Goods: Assessing the Risks. Institute for Risk Research, University of Waterloo, Ontario, Canada, 1991.

Saltelli, A., \& Sobol, I.M., About the Use of Rank Transformation in Sensitivity Analysis of Model Output. In Reliability Engineering and System Safety, Vol. 50, no. 3. Elsevier Science limited, Northern Ireland 1995.

Schemel, S.D., Schemel, C.F., \& Van Brunt, V., Methodology for determining reliability of a foam suppression system using fuzzy set theory and fault tree analysis. Appendix $A$ in óAircraft Hangar Fire Suppression System Design Study ô Scheffey et al., Naval Research Laboratory, Washington DC, 2000.

Sedlmeier, P., Hertwig, R. \& Gigerenzer, G. . Are judgments of the positional frequencies of letters systematically biased due to availability? Journal of Experimental Psychology: Learning, Memory, and Cognition, 24, 754-770, 1998.

Sklet, S., \& Øien, K., Bruk av risikoanalyser i driftsfasen, etablering av sikkerhetsindikatorer og modellering av organisatoriske faktorers efekt på risikonivået $\tilde{n}$ en ôstate of the art ô beskrivelse. SINTEF rapportnr. STF38 A99416, SINTEF, Trondheim, 1999. (In Norwegian).

Simon, H. A. . Models of man: Social and rational. New York: Wiley,1957.

Simon, H. A. . Models of bounded rationality. Cambridge, MA.: MIT Press, 1982. 
Slovic, P., Fischoff, B., \& Lichtenstein, S., Facts versus Fears: Understanding Perceived Risk. In Kahneman, D., Slovic, P., and Tversky, A., (eds.) Judgement under Uncertainty, Heuristics and Biases. Cambridge University Press, Cambridge, 1982.

S.S. Wilks, On the independence of $k$ sets of normally distributed statistical variables. Econometrica, 3, 309-326).cap 3,1935.

Stirling, A., Renn, O., Klinke, A., Rip, A., \& Salo, A., On Science and Precaution in the Management of Technological Risk. EUR 19056 EN, ECSC-EEC-EAEC, Luxembourg, 1999.

Suresh, P.V., Babar, A.K., \& Venkat Raj, V., óUncertainty in fault tree analysis: A fuzzy approach. Fuzzy Sets and Systems 83, Elsevier Science, 1996.

Tucker, W. Troy \& Scott Ferson, Probability bounds analysis in environmental risk assessments,2003

Tversky, A., \& Kahneman, D., Availability: A Heuristic for Judging Frequency and Probability. In Kahneman, D., Slovic, P., and Tversky, A., (eds.) Judgement under Uncertainty, Heuristics and Biases, Cambridge University Press, Cambridge, 1982a.

Tversky, A., \& Kahneman, D., Causal Schemas in Judgements Under Uncertainty. In Kahneman, D., Slovic, P., and Tversky, A., (eds.) Judgement under Uncertainty, Heuristics and Biases, Cambridge University Press, Cambridge, 1982b.

Tversky, A., \& Kahneman, D., Judgement under Uncertainty: Heuristics and Biases. In Kahneman, D., Slovic, P., and Tversky, A., (eds.) Judgement under Uncertainty, Heuristics and Biases, Cambridge University Press, Cambridge, 1982c.

U.S. Environmental Protection Agency, Policy for use of Probabilistic Analysis in Risk Assessment and Guiding Principles for Monte Carlo Analysis. EPA/630/R-97/001, EPA, 1997.

Viera, V.P.P.B. Análise de Risco Aplicada a Recursos Hídricos. Notas de Aula. Curso de Doutorado em Recursos Hídricos, Departamento de Engenharia Hidráulica e Ambiental, Universidade Federal do Ceará, 1997.

Vincens,G.J., I. Rodrigues-iturbe e J.C. Shaake (1975). A Bayesian Framework for the use of Regional Information in Hydrology._Res.,11(3). p.405-4114, 1975.

Vose, D., Risk Analysis ñ A Quantitative Guide. 2:nd edition. John Wiley \& Sons Ltd., Chichester, 2000.

Winkler, R.L., Uncertainty in Probabilistic Risk Assessment. Reliability Engineering and System Safety 54, Elsevier Science limited, Northern Ireland, 1996.

Zadeh, L.A., Fuzzy sets. Information and Control Theory 8:338-353, 1965.

Zindel, Márcia T, O Viés Cognitivo De Excesso De Confiança No Julgamento De Investidores, Programa De Pós-Graduação Em Engenharia De Produção.

\section{Publicações de organismos internacionais}


Amendola A. \& Papadakis G.A. (Editors) Guidance on the preparation of a safety report to meet the requirements of Council Directive 96/82/EC (SEVESO II), JRC European Commission, 1997

CPR, Committee for the Prevention of Disasters, Methods for the calculation of damage, óGreen bookô. Voorburg: Ministry of social affairs and employment, 1990

CPR, Committee for the Prevention of Disasters, Methods for determining and processing probabilities, óRed bookô. The Hague: SDU, 1997a.

CPR, Committee for the Prevention of Disasters, Methods for the calculation of physical effects, ơ ellow bookô. The Hague: SDU, 1997b.

USNRC: An Approach for Using Probabilistic Risk Assessment in Risk-Informed Decisions on Plant-Specific Changes to the Licensing Basis, Regulatory Guide 1.174, U.S. Nuclear Regulatory Commission, 1998

USNRC: Use of Probabilistic Risk Assessment Methods in Nuclear Activities: Final Policy Statement, Federal Register, Vol. 60, p. 42622 (60 FR 42622), August 16, 1995.

U.S. Environmental Protection Agency: Policy for use of Probabilistic Analysis in Risk Assessment and Guiding Principles for Monte Carlo Analysis, EPA/630/R-97/001, EPA 1997

\section{Normas internacionais}

Australian/New Zealand Standard AS/NZS 3931: Risk analysis of technological systems - application guide, Standards Australia, Standards New Zealand, 1998.

Australian/New Zealand Standard AS/NZS 4360: Risk Management, Standards Australia, Standards New Zealand, 1995.

Canadian Standard CAN/CSA-Q850-97: Risk management: Guideline for DecisionMakers, Canadian Standards Association, 1997.

DS-Information DS/INF 85: Risk Analyses, requirements and terminology, Danish Standards Association, 1993.

European Standard EN 1050:1996: Safety of machinery - Principles for risk assessment, European Committee for Standardisation, 1996.

IEC International standard $\mathrm{nr}$ 60300-3-9: Dependability management- Part 3: Application guide- Section 9: Risk analysis of technological systems, International

Norwegian Standard NS 5814: Requirements for risk analyses, Norwegian Standardisation Association, 1991. 